\title{
A Low Cost and High Quality Solid Fuel From Biomass and Coal Fines
}

\author{
Final Report \\ DOE Contract No. DE-AC26-99FT40157 \\ March 1, 1999 to May 31, 2000 \\ by \\ John T. Kelly, George Miller and Mehdi Namazian
}

July 2001

Altex Technologies Corporation

650 Nuttman Road, Suite 114

Santa Clara, Ca. 95054 


\section{Disclaimer}

This report was prepared as an account of work sponsored by the United States Government. Neither the United States, any agency thereof, nor any of their employees, makes any warranty, express or implied, or assumes any legal liabilities or responsibility for the accuracy, completeness or usefulness of any information, apparatus, product, or process disclosed, or represents that its use would not infringe privately owned rights. Reference herein to any specific commercial product, process, or service, by trade name, mark, manufacturer, or otherwise, does not necessarily constitute or imply its endorsement, recommendation, or favoring by the United States or any agency thereof. The views and opinions of authors expressed herein do not necessarily state or reflect those of the United States Government or any agency thereof. 


\begin{abstract}
Use of biomass wastes as fuels in existing boilers would reduce greenhouse gas emissions, $\mathrm{SO} 2$ and NOx emissions, while beneficially utilizing wastes. However, the use of biomass has been limited by its low energy content and density, high moisture content, inconsistent configuration and decay characteristics. If biomass is upgraded by conventional methods, the cost of the fuel becomes prohibitive. Altex has identified a process, called the Altex Fuel Pellet (AFP) process, that utilizes a mixture of biomass wastes, including municipal biosolids, and some coal fines, to produce a strong, high energy content, good burning and weather resistant fuel pellet, that is lower in cost than coal. This cost benefit is primarily derived from fees that are collected for accepting municipal biosolids. Besides low cost, the process is also flexible and can incorporate several biomass materials of interest
\end{abstract}

The work reported on herein showed the technical and economic feasibility of the AFP process. Low-cost sawdust wood waste and light fractions of municipal wastes were selected as key biomass wastes to be combined with biosolids and coal fines to produce AFP pellets. The process combines steps of dewatering, pellet extrusion, drying and weatherizing. Prior to pilotscale tests, bench-scale test equipment was used to produce limited quantities of pellets for characterization. These tests showed which pellet formulations had a high potential. Pilot-scale tests then showed that extremely robust pellets could be produced that have high energy content, good density and adequate weatherability. It was concluded that these pellets could be handled, stored and transported using equipment similar to that used for coal.

Tests showed that AFP pellets have a high combustion rate when burned in a stoker type systems. While NOx emissions under stoker type firing conditions was high, a simple air staging approach reduced emissions to below that for coal. In pulverized-fuel-fired tests it was found that the ground pellets could be used as an effective NOx control agent for pulverized-coal-fired systems. NOx emissions reductions up to $63 \%$ were recorded, when using AFP as a NOx control agent. In addition to performance benefits, economic analyses showed the good economic benefits of AFP fuel. Using equipment manufacturer inputs, and reasonable values for biomass, biosolids and coal fines costs, it was determined that an AFP plant would have good profitability. For cases where biosolids contents were in the range of $50 \%$, the after tax Internal Rates of Return were in the range of $40 \%$ to $50 \%$. These are very attractive returns. Besides the baseline analysis for the various AFP formulations tested at pilot scale, sensitivity analysis showed the impact of important parameters on return. From results, it was clear that returns are excellent for a range of parameters that could be expected in practice. Importantly, these good returns are achieved even without incentives related to the emissions control benefits of biomass. 


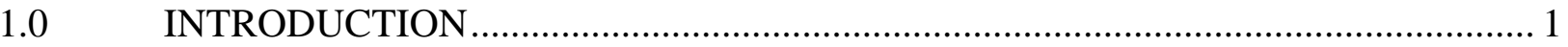

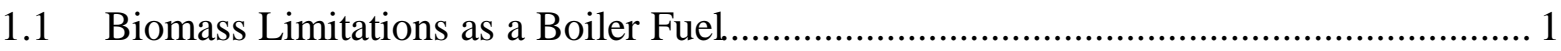

1.2 Altex Fuel Pellet (AFP) Process Concept.............................................................. 2

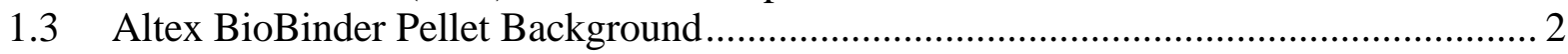

1.4 Biomass Materials Background ……………..................................................... 4

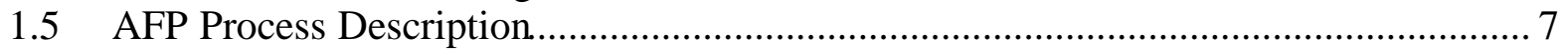

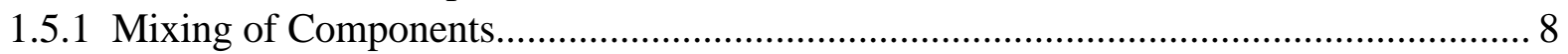

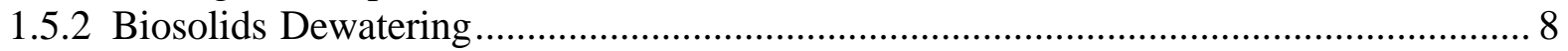

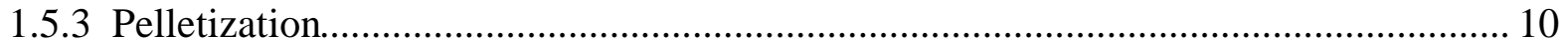

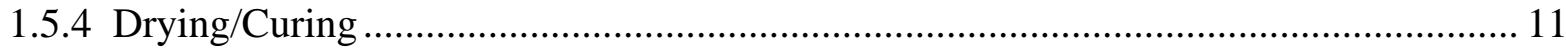

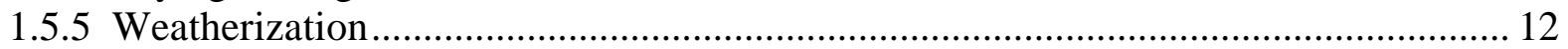

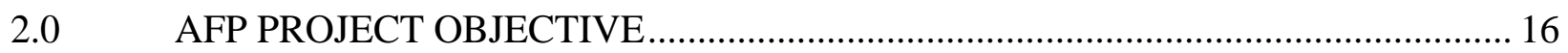

3.0 RAW MATERIALS DEFINITION AND EVALUATION .................................... 16

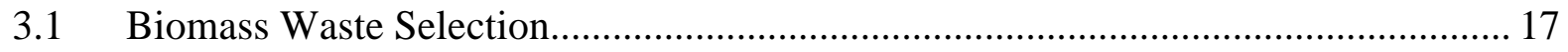

3.2 Biomass Waste Environmental/Emissions Issues...................................................... 20

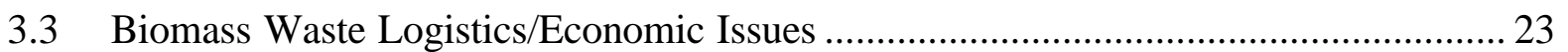

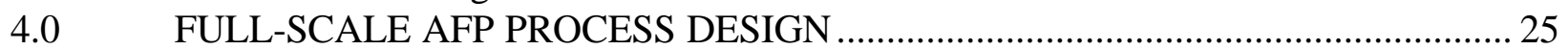

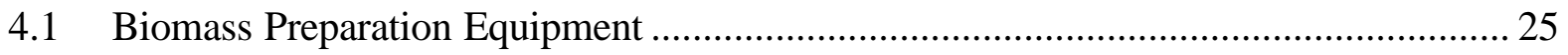

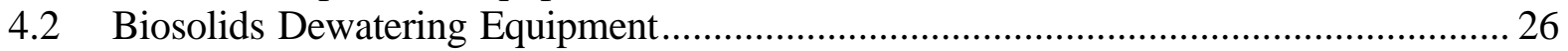

4.2.1 Small Scale Dewatering Tests................................................................................ 27

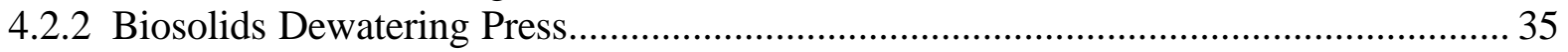

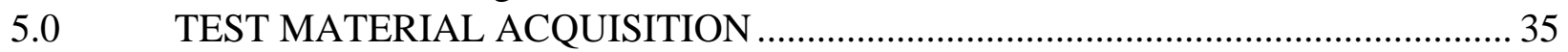

6.0 PELLET PRODUCTION TEST EQUIPMENT SETUP ……................................. 38

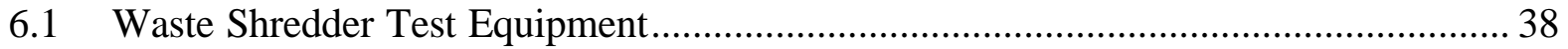

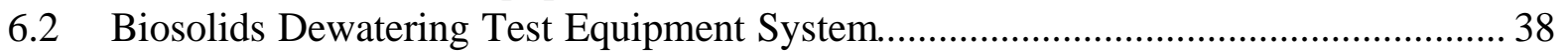

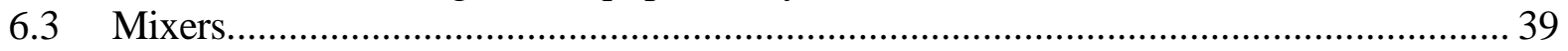

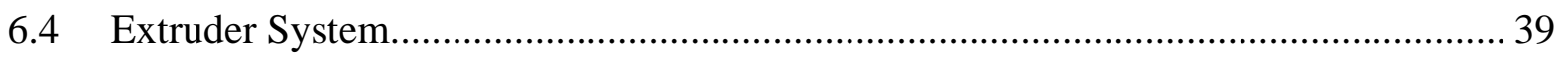

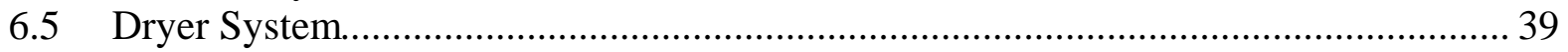

6.6 Weatherizer Application System................................................................................. 39

7.0 PELLET PRODUCTION PROPOSED TEST PLAN ............................................... 40

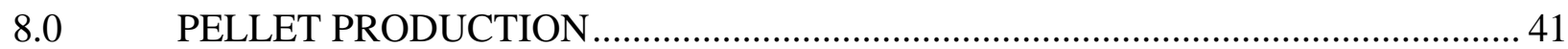

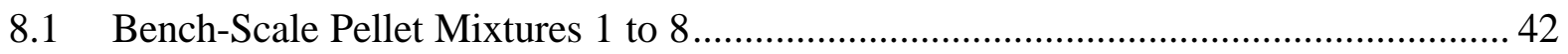

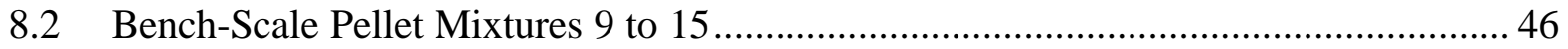

8.3 Bench-Scale Pellet Mixtures 16 to 20....................................................................... 47

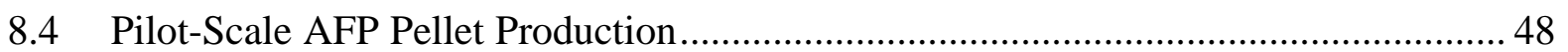

8.5 Pilot-Scale Pellet Production Summary .................................................................... 57

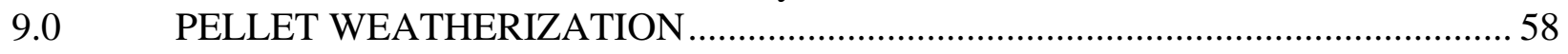

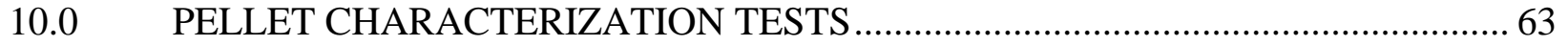

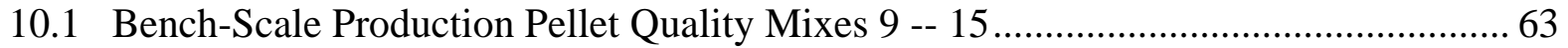

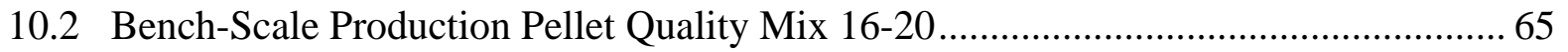

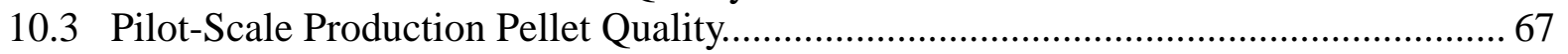

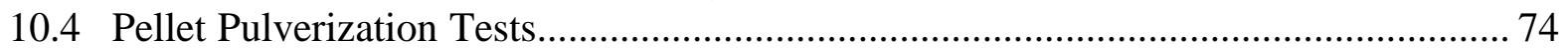

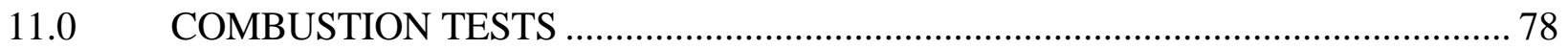

11.1 Fixed-Bed Combustion Tests.................................................................................. 78 


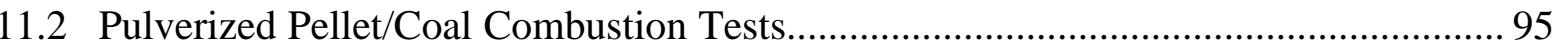

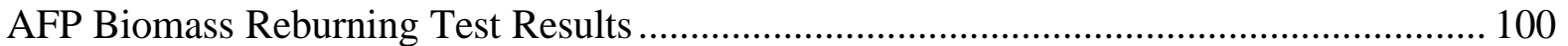

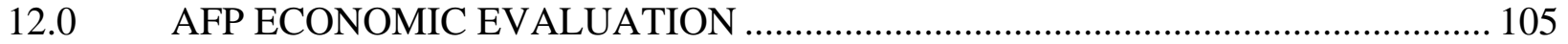

12.1 Baseline Formulation Economic Analysis Results ...................................................... 106

12.2 AFP Cost Sensitivity Analysis Results ................................................................ 110

13.0 PROJECT SUMMARY CONCLUSIONS AND FUTURE PLANS.......................... 115

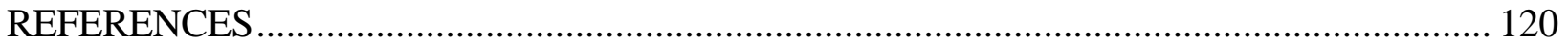

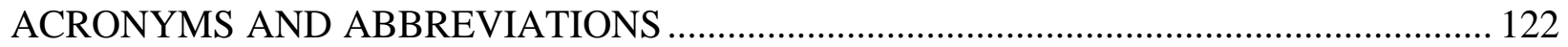




\section{List of Figures}

Figure 1 -- Layout of Altex Pilot-Scale Pelletization Test Facility...................................... 3

Figure 2 -- The Altex Fuel Pellet (AFP) Process …………........................................... 8

Figure 3 -- Illustration of Sludge Water Distribution.................................................... 9

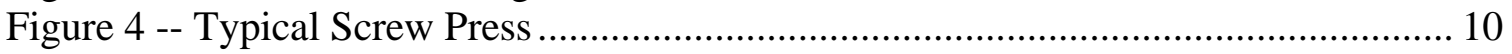

Figure 5 -- Altex PR9 Screw Extruder...………………...................................... 11

Figure 6 -- Proctor-Schwartz Conveyor Dryer............................................................. 12

Figure 7 -- Sludge/Biomass /Coal Fines Segment Cross Section..................................... 13

Figure 8 -- Wet and Dry Strength of Sisal Fiber Epoxy Composite with (a) Mercerized

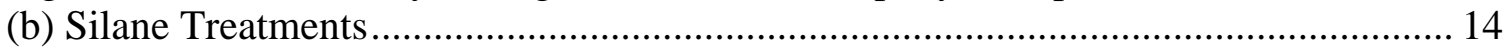

Figure 9 - Pellet Immersion Bath Step for Weatherization Sealing ............................... 16

Figure 10 -- Water Drop Out Rates at Elevated Temperatures: 365 kN/m² (53 psi). ...... 29

Figure 11 -- Water Drop Out Rates at Elevated Temperatures: 70psi............................. 30

Figure 12 -- Biosolids Primary Belt Press Followed by High Pressure Secondary Belt

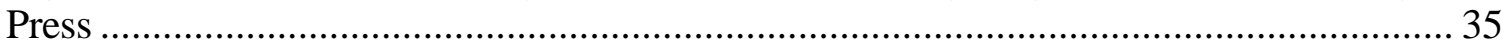

Figure 13 -- Weatherizer: Tall Oil Soap. 12-Hour Submersion Test............................... 59

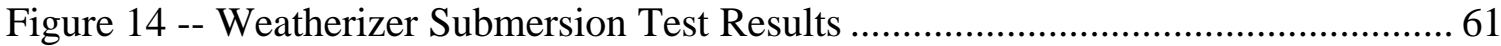

Figure 15 -- Commercial Sealant Tests of AFP Wood Pellets............................................ 62

Figure 16 -- Commercial Sealant Tests of AFP Paper Pellets ...........................................63

Figure 17 -- Lab-Scale Production Crush Test Results............................................................ 65

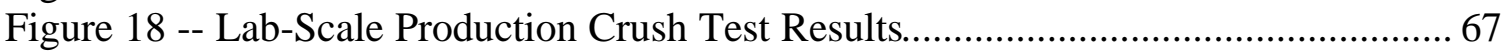

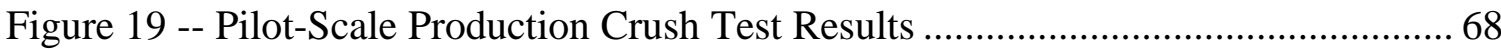

Figure 20 -- Pilot Scale AFP Wood Pellet Crush Test Results .......................................... 69

Figure 21 -- Crush Test Results of Wood Pellets and Paper Pellets................................. 70

Figure 22 -- Pilot-Scale AFP Paper Pellet Crush Test Results .......................................... 71

Figure 23 -- Pilot-Scale AFP Paper and Plastic Pellet Crush Test Result ......................... 72

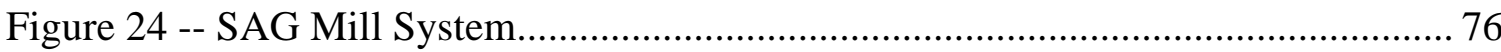

Figure 25 -- Fixed-Bed Test Combustor Schematic........................................................... 79

Figure 26 -- Fixed Bed Utah Coal CO Emissions Versus Excess Oxygen........................ 80

Figure 28 -- Comparison of Utah Coal NOx Test Results to Full-Scale Stoker Results .. 82

Figure 29 -- Fixed-Bed NOx Emissions for 55\% Biosolids/45\% Wood AFP .................. 84

Figure 30 -- Fixed-Bed CO Emissions for 55\% Biosolids/45\% Wood AFP ...................... 85

Figure 31 -- Fixed-Bed NOx Emissions for 50\% Biosolids/50\% Paper AFP.................... 86

Figure 32 -- Fixed-Bed CO Emissions for 50\% Biosolids/50\% Paper AFP...................... 87

Figure 33 -- Fixed-Bed NOx Emissions for 40\% Biosolids/55\% Paper/5\% Plastic AFP 88

Figure 34 -- Fixed-Bed CO Emissions for 40\% Biosolids/55\% Paper/5\% Plastic AFP... 88

Figure 35 -- Fixed-Bed NOx Emissions for 38\% Bisolids/32\% Wood/30\% Coal AFP... 89

Figure 36 -- Fixed-Bed NOx Emissions for 27\% Biosolids/23\% Wood/50\% Coal AFP. 90

Figure 37 -- Fixed-Bed CO Emissions for 38\% Biosolids/ 32\% Wood/30\% Coal AFP .. 91

Figure 38 -- Fixed-Bed CO Emissions for $27 \%$ Biosolids $/ 23 \%$ Wood/50\% Coal AFP ... 91

Figure 39 -- Fixed-Bed NOx Emissions for 24\% Biosolids/24\% Paper/2\% Plastic/50\%

Coal AFP 92

Figure 40 -- Fixed-Bed CO Emissions for 24\% Biosolids/24\% Paper/2\% Plastic/50\%

Coal AFP. 92

Figure 41 -- Air-Staged AFP NOx Emissions. 38\% Biosolids,32\% Wood, 30\% Coal... 94

Figure 42 -- Air-Staged AFP CO Emissions ................................................................. 94 
Figure 43 -- Pulverized Fuel Test Facility............................................................ 96

Figure 44 -- Typical Pulverized Coal Burner Configuration........................................... 96

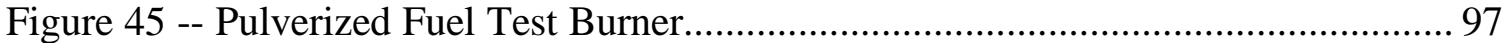

Figure 46 -- Biomass Reburning Test Injector........................................................... 99

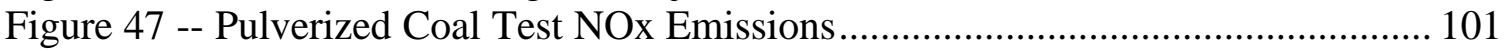

Figure 48 -- Pulverized Coal Test CO Emissions ...................................................... 102

Figure 49 -- Biomass Reburn Test NOx Emission Results........................................... 103

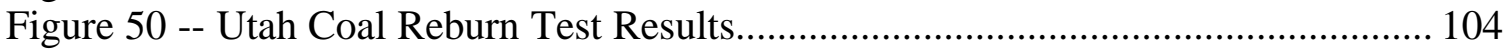

Figure 51 -- Biomass Reburn CO Emissions ............................................................... 105

Figure 52 -- Impact of Biosolids Fraction on Internal Rate of Return.......................... 111

Figure 53 -- Impact of Biomass Fraction on Internal Rate of Return........................... 112

Figure 54 -- Impact of Biomass Cost on Internal Rate of Return................................ 113

Figure 55 -- Impact of Natural Gas Fuel Cost on Internal Rate of Return.................... 114

Figure 56 -- Impact of Biosolids Fee on Internal Rate of Return................................ 115 


\section{List of Tables}

Table 1 -- Typical Municipal Sludge Composition........................................................... 3

Table 2 -- Biomass Waste and Fuels Analyses ............................................................ 6

Table 3 -- Comparison of Wet and Dry Pellet Strength With and Without Lime

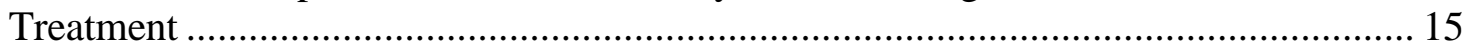

Table 4 -- Water Absorption for Coated and Uncoated Pellets....................................... 15

Table 5 -- Potential Biomass Feedstock Material Characteristics.................................. 17

Table 6 -- Costs Associated with Timer Cutting and Logging..................................... 18

Table 7 -- Costs Associated with Recovering Logging Waste Wood............................ 19

Table 8 -- Projected Emission Factors and Other Properties of Selected AFP.............. 22

Table 9 -- Allowable Co-fire to Limit NOx Emissions Increase to 10 Percent............ 23

Table 10 -- Sludge Cake Dewatering Water Dropout Rates @ $78^{\circ} \mathrm{F}$............................ 28

Table 11 -- Effect of Temperature on Water Drop Rates @ 365 kN/m² $(53$ psi).......... 29

Table 12 -- Effect of Temperature on Water Dropout Rates @ 483kN/m² (70 psi).... 30

Table 13 -- Sludge Cake Dewatering Gradual Pressure Application Test Results ........ 31

Table 14 -- Sludge Cake Dewatering Water Drop Out Rates With Paper Addition..... 33

Table 15 -- Sludge Cake Dewatering Water Drop Out Rates With Sawdust Addition 33

Table 16 -- Palo Alto, California Biosolids Analysis ...................................................... 37

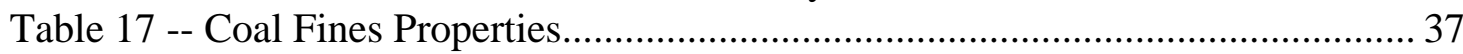

Table 18 -- Proposed Pellet Test Formulations .......................................................... 40

Table 19 -- Pelletization Baseline Test Conditions ………………………………....... 41

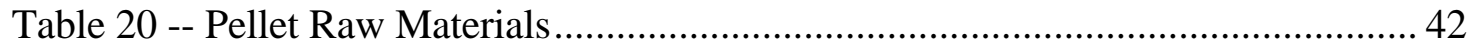

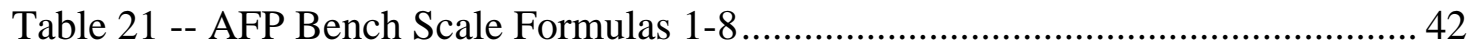

Table 22 -- Pellet Quality Test Results ...................................................................... 45

Table 23 -- Bench-Scale AFP Pellet Formulas 9-15 ..................................................... 46

Table 24 -- Bench Scale AFP Pellet Formulas 16-20 …............................................ 48

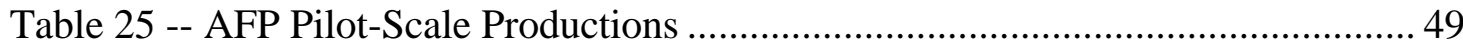

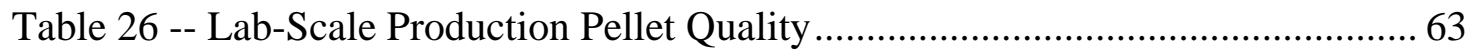

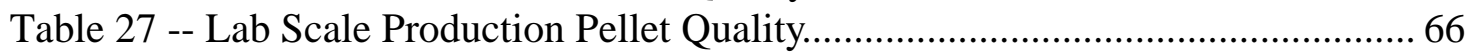

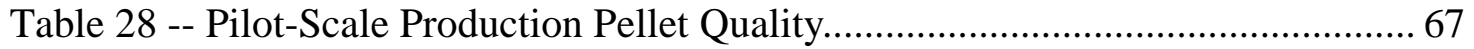

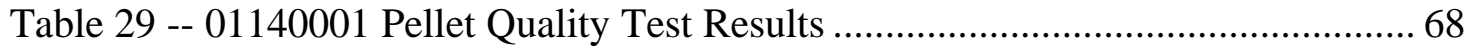

Table 30 -- 01210001 Pellet Quality Test Results ........................................................ 69

Table 31 -- 02220001 Pellet Quality Test Results ....................................................... 70

Table 32 -- 02230001 Pellet Quality Test Results .................................................... 71

Table 33 -- 03010001 Pellet Quality Test Results ....................................................... 73

Table 34 -- AFP Pilot-Scale Pellet Quality Summary..................................................... 73

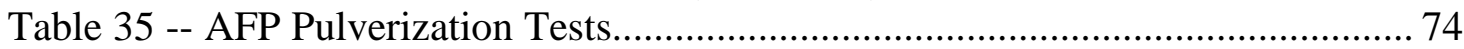

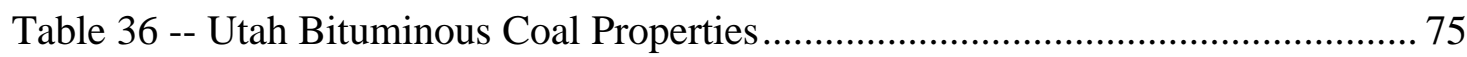

Table 37 -- Size Distribution of As-Received Coal................................................... 75

Table 38 -- Summary of AFP 01140001 and AFP 02220001 Tests ............................. 76

Table 39 -- PSD for 10\% AFP 01140001 Tests......................................................... 77

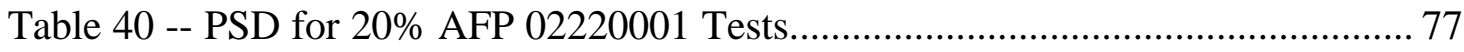

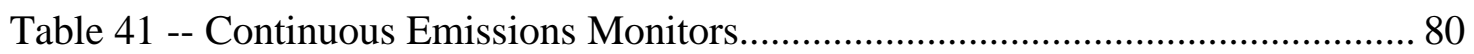

Table 44 -- Burner Firing Mode Options ................................................................... 98

Table 45 -- Comparison of Coal and Biomass Properties ............................................ 98

Table 46 -- Biomass-Based Reburn Fuel Properties .................................................... 103 
Table 47 -- Economic Analysis AFP Formulations and IRR Results........................ 106

Table 48 -- AFP Plant Capital Costs and Power, Maintenance and Labor Needs ...... 107

Table 49 -- AFP Plant Raw Material Data and Costs ........................................... 108

Table 50 -- AFP Plant Costs Per Ton Product for $48 \%$ biosolids/48\% Paper/4\% Plastic

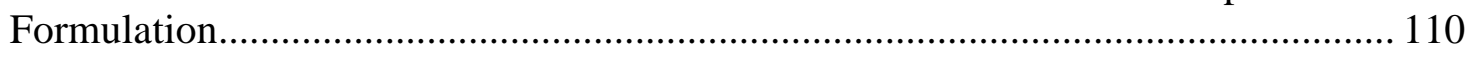




\section{Executive Summary}

Use of biomass wastes as fuels in existing boilers would reduce greenhouse gas emissions, $\mathrm{SO}_{2}$ and NOx emissions, while beneficially utilizing wastes. However, the use of biomass has been limited by its low energy content and density, high moisture content inconsistent configuration and poor decay characteristics. If biomass is upgraded by conventional methods to become more compatible with existing combustion equipment, the cost of the fuel becomes prohibitive. Altex has identified a process called the Altex Fuel Pellet (AFP) process, that utilizes a mixture of biomass wastes, including municipal biosolids, and some coal fines, to produce a strong, high energy content, good burning and weather resistant fuel pellet that is lower in cost than coal. This cost benefit is primarily derived from fees that are collected for accepting municipal biosolids. Besides low cost, the process is also flexible and can incorporate several biomass materials of interest.

Under the project, several biomass waste sources were evaluated and it was found that biomass materials are available in sufficient quantities for power production. However, these materials must be processed to increase energy content and density, and improve storage, handling and transport characteristics for use in existing combustion equipment. This increases fuel delivered cost, even if the biomass waste has zero initial cost. From analysis for biomass supplies and costs, it was concluded that only biomass wastes associated with a product that has borne the cost of collection and transport to the vicinity of the power plant would be economically viable. Specifically low-cost sawdust wood waste and light fractions (e.g. dirty paper) of municipal wastes were selected as key biomass wastes to be combined with biosolids and coal fines to produce AFP pellets.

The AFP process combines steps of dewatering, pellet extrusion, drying and weatherizing. The dewatering step introduces a secondary pressing of the material under higher temperature conditions to achieve moisture reductions of up to $39 \%$. This increases the energy content of the material and reduces the drying need. To prepare centimeter sized pellets, a screw extruder and conveyor dryer are utilized. The material mixtures and moisture contents are well suited to this equipment. After drying, pellets are coated with organic compounds (e.g. tall oil soap, waste plastic) to limit water infiltration and improve weatherability.

Prior to pilot-scale tests, bench-scale test equipment was used to produce limited quantities of pellets for characterization. These tests indicated the potential of various pellet formulations. Pilot-scale tests then showed that extremely robust pellets could be produced that have a high energy content, high density, consistent form and adequate weatherability. More specifically, AFP pellets, depending on formulation could resist crushing forces of $1034 \mathrm{kN} / \mathrm{m}^{2}$ (150 psi) up to $5516 \mathrm{kN} / \mathrm{m}^{2}$ (800 psi). Energy density was substantially increased to the range of $17668 \mathrm{~kJ} / \mathrm{kg}$ $(7597 \mathrm{Btu} / 1 \mathrm{bm})$ to $25902 \mathrm{~kJ} / \mathrm{kg}(11136 \mathrm{Btu} / \mathrm{lbm})$ and density was increased 641 to $801 \mathrm{~kg} / \mathrm{m}^{2}(40$ to $\left.50 \mathrm{lb} / \mathrm{ft}^{3}\right)$. This density is approximately one-half the density of coal. Besides showing higher crush strength than coal, tests showed that pellets could be dropped repeatedly from $4.6 \mathrm{~m}$ (15ft) onto a concrete pad. Lastly, pellets produced less than $3.4 \%$ dust loss during severe abrasion tests. It was concluded that these pellets could be handled, stored and transported, using equipment similar to that used for coal. 
The very robust pellets were well suited for stoker boiler use. However, the beneficial pellet strength for stoker firing represents a significant grinding challenge for pulverized coal fired applications. To assess how AFP pellets would respond in a coal pulverizing mill, initial grinding tests were carried out at Altex and complete pulverization tests were carried out at Hazen Research Inc. Altex initial grinding tests showed that inclusion of coal fines or plastic particles in AFP pellet formulas improved pellet response to crushing and grinding forces. Without these additions, the highly fibrous pellets were extremely resistant to crushing. Coal fines were added to AFP pellets formulated with wood. The higher the fraction of added coal fines, the easier it was to crush the pellets. At a coal fines fraction of 50\%, test results showed almost no difference between the response of the pellets and the response of a like sized sample of lump coal. With waste paper based AFP formulations the addition of plastic particles, in fractions of up to 5\%, improved the crush response for these pellets as well. Interestingly, coal additions did not substantially improve the response of pellets formulated with paper. These Altex test results were supported by those from Hazen Research. AFP pellets of wood and coal fines, and AFP pellets of paper and plastic were more readily pulverized that pellets without coal and plastic, respectively. However, grinding time for these materials was long, suggesting that special grinding equipment would be required for these materials. In contrast to pellet only results, pellets co-ground with lump coal at $10 \%$ or $20 \%$ weight fraction had grinding characteristics similar to that of coal. This suggests that pellets could be co-ground with coal at low fractions in existing pulverized fuel facilities. However, the lower energy density of pellets might limit peak load for pulverizer capacity limited systems.

To evaluate the combustion and emissions of AFP formulations, tests were carried out in instrumented facilities at Altex that simulated both full-scale stoker and pulverized fuel fired systems. In stoker firing tests, all AFP firing rates exceeded typical stoker firing rate intensities with coal. This was attributed to the high volatile content and the porous nature of AFP pellets relative to lump coal. Because of the high nitrogen content of the biosolids in the formulations, NOx emissions were high, exceeding $1000 \mathrm{ppm}$ in some cases. Both the high nitrogen content and high volatility were driving high NOx production under conventional combustion conditions. While NOx was high, $\mathrm{CO}$ was acceptable, at the correct excess oxygen level. While the baseline NOX emissions during stoker firing were high, air-staging tests showed that NOx could be reduced by $50 \%$. The very effective air-staging NOx reduction was likely related to the easily volatilized fuel bound nitrogen, that was reduced to molecular nitrogen in the fuel rich region of the combustor. These results show that AFP pellets can be efficiently burned in stokers, and with the implementation of air-staging, achieve NOx emissions lower than those for conventional coal firing.

Cofiring AFP with coal at low fractions (e.g. 10\% AFP) in a pulverized fuel facility is expected to change emissions by less than $10 \%$. It is of higher interest to assess how AFP pellets, when co-fired with coal, might influence fuel handling, processing and transport equipment performance. However, these are questions that would best be answered at full-scale facilities, rather than with the pilot-scale equipment at Altex. Therefore, the major thrust of the pulverized fuel tests at Altex was to determine the pollution control benefits of AFP fuel, when it is separately injected into a pulverized coal fired facility. 
To control NOx with pulverized AFP, a reburn fuel injector and a downstream air injection system were integrated into the Altex pilot-scale combustion test facility. Pulverized mixtures of biosolids/wood, and biosolids/paper, were then injected downstream of the coal burner. While more difficult to pulverize than coal, use of separate and special pulverizers for the reburn fuel will accomplish the needed pulverization. Tests were run with reburn fuel fractions of from $15 \%$ to 30\%. Test results showed that biosolids/wood and biosolids/paper AFP could reduce baseline coal NOx emissions by up to $63 \%$ and $58 \%$, respectively. These are very substantial NOx reductions that add to the economic value of biomass fuel. Of course, to this NOx control value has to be added the value of greenhouse gas (i.e. fossil $\mathrm{CO}_{2}$ ) emissions reductions. Depending on the setting of carbon tax levels, this AFP benefit can be very large.

While future greenhouse gas environmentally related economic benefits of AFP could be large, the present economic benefits of the AFP process can also be substantial. Using raw material costs, equipment cost estimates from manufacturers, and utilities and labor costs, the economic return for an AFP plant operating at 1000TPD was calculated. After tax Internal Rates of Return (IRR) were found to vary from an extraordinary $59 \%$ to an acceptable $21 \%$, depending on the AFP formulation. For those formulations with high biosolids content, IRR was high. Sensitivity analyses then indicated the importance of various parameters. When biosolids were displaced by coal, IRR decreased. The cost of moisture reduction was also important to return, and underscored the benefit of dewatering. In fact, eliminating the dewatering step reduced IRR by nearly one half. In addition, the impact of natural gas dryer fuel cost on IRR was determined. As the natural gas fuel cost in increased from \$1.50/MM Btu to \$8.00/MM Btu, IRR decreases from an attractive $45 \%$ to an inadequate $5 \%$. This suggests that low cost AFP should be used to fuel the dryer, rather than high cost natural gas. Another strong driver on AFP IRR is the cost of biomass. As biomass costs are increased from zero to \$30/WT, the IRR decreases from an attractive $50 \%$ to an inadequate $10 \%$. Lastly, the impact of the biosolids tip fee on IRR was determined. With a biosolids tipping fee of $\$ 40 / \mathrm{WT}$, the return is an extraordinary $90 \%$. Given that it costs wastewater treatment plants up to $\$ 62 / \mathrm{WT}$ to incinerate biosolids, a $\$ 40 / \mathrm{WT}$ tipping fee is not unreasonable. Only when the biosolids tipping fee drops to $\$ 10 / \mathrm{WT}$ does IRR approach zero. Therefore, with a conservative tipping fee of $\$ 20 / \mathrm{WT}$, or higher, AFP return is attractive. From these results, it is clear that returns are excellent for a range of parameters that could be expected in practice. Importantly, these good returns are achieved even without incentives related to the emissions control benefits of biomass. 


\subsection{INTRODUCTION}

Coal combustion for electric power production in the U.S. produces over 1.7 billion tons of $\mathrm{CO}_{2}$ greenhouse gas emissions per year. To prevent further global warming, governments worldwide are beginning to set limits on these emissions. To help address the global warming problem, available agricultural and municipal biomass wastes should be used to generate electricity in existing power plants. Furthermore, because of the lower sulfur content and lower combustion peak temperatures for biomass, acid rain precursors, such as $\mathrm{SO}_{2}$ and $\mathrm{NOx}$ are also reduced. While emissions benefits of biomass combustion are clear, the form of the material presents several obstacles to its use in existing boilers, including:

- High moisture content and low density reduces the energy value

- Variable and inconsistent fuel form requires special equipment to handle and burn the material, that is not typically available at utility boiler sites

- Inconsistent form and high moisture content makes the transportation of the material difficult and costly

- Inherent moisture levels, makes long-term storage problematic, due to spoilage and decay

- Susceptibility to moisture uptake once dried, and lack of weather resistance also put its longterm storage capability at a disadvantage with respect to conventional utility fuel

To increase the utilization of biomass wastes as a boiler fuel, it must be processed to reduce or eliminate these obstacles. By processing the biomass to a form that is more compatible with existing coal-fired boiler fuel handling, transport, and storage equipment, the need for power plant capital equipment investment is minimized. This substantially reduces the negative economic impact of biomass fuel conversion on the power industry. However, while processing biomass to a more acceptable form is possible, it has also been prohibitively expensive. This is the primary challenge preventing the widespread use of biomass fuels in existing boilers.

\subsection{BIOMASS LIMITATIONS AS A BOILER FUEL}

Although biomass materials have previously been densified into more compatible fuel forms, none of the methods used to date have been able to create a form with the necessary features of durability, weatherability, and storability, at a competitive cost. "Cubing", or briquetting of sawdust materials has been accomplished for stoker-type boilers. While this produces a convenient form for handling and transportation, it is expensive \$33/tonne ( $\$ 30 /$ ton), utilizes a feedstock of limited availability, and the produce cannot withstand exposure to the elements [1]. This lack of weather resistance is also a problem for non-densified biomass materials, such as rice hulls, which have been burned in pulverized coal-fired boilers [2]. The only use option has been to acquire the biomass material, and utilize it immediately, with no inventory stockpile. This is impractical for utility boiler operations. Chipped woody-type materials have been utilized in grate-type boilers. But chipped wood is not compatible with fuel pulverization and feed equipment at utility boilers. In addition, attempts to utilize green woody materials in pulverized coal-fired boilers have been unsuccessful [3]. Light weight components (e.g. paper and cardboard) in municipal solid wastes (MSW) have also been tested as a boiler fuel. Experience has been less than desirable, with substantial fuel handling problems (e.g. plugging, bridging, holdup in bins), wetting of material, decay, odors and degradation of equipment. 


\subsection{Altex Fuel Pellet (AFP) Process Concept}

To advance the use of biomass waste resources for power generation, a low-cost and effective moisture reduction, densification, and weatherization method is needed. Also the approach should increase energy content and reduce shipping weight. Altex has identified and tested an approach for forming robust biomass-based fuel pellets. The Altex Fuel Pellet (AFP) process consists of dewatering, densification, and drying steps, that use low, or negative cost, chemical agents, and heat treatment, to produce a fuel pellet that maintains its integrity even under severe weather conditions. Typically, the extensive processing utilized in the AFP would increase the fuel cost to an unacceptable level. However, the AFP fuel is low in cost, because the processing costs are offset by the use of a negative cost waste binder in the pellets.

The binder is formed from biosolids, or municipal sewage sludge, which currently costs well over \$176/per dry tonne (\$160/per dry ton) to incinerate. Therefore, Waste Water Treatment Plant (WWTP) operators will pay an AFP plant owner to accept sludge. These substantial fees are what drives the good economics of AFP fuel. Through the special AFP process, the sludge becomes a strong, sterile, low odor and effective binder, that also adds fuel value to the pellet. In addition, a portion of the municipal wastewater sludge by-products can be processed to form an effective, and negative cost, weatherization agent. Therefore, through the use of the AFP process, biomass limitations as a fuel for existing boilers can be overcome, at an attractive cost. Furthermore, by utilizing sludge as a binder, a waste that is typically incinerated in large cities, it becomes a useful product. Lastly, sludge is a biomass-type material, that has greenhouse gas emissions benefits. Therefore, its use in binding biomass materials into a quality fuel pellet is very attractive from an environmental perspective as well.

\subsection{Altex B ioBinder Pellet Background}

Altex's optimism in creating low cost and valuable AFP pellets is based on earlier successful efforts using the Altex BioBinder process [4]. In the process, municipal sludge is used as a binder of waste coal fines, and weatherizing additives are incorporated, to create fuel pellets that are "coal like" and lower in cost than the parent coal [4]. To form pellets, the pilotscale 5 TPD screw extruder and conveyor dryer system, illustrated in Figure 1, was utilized. 


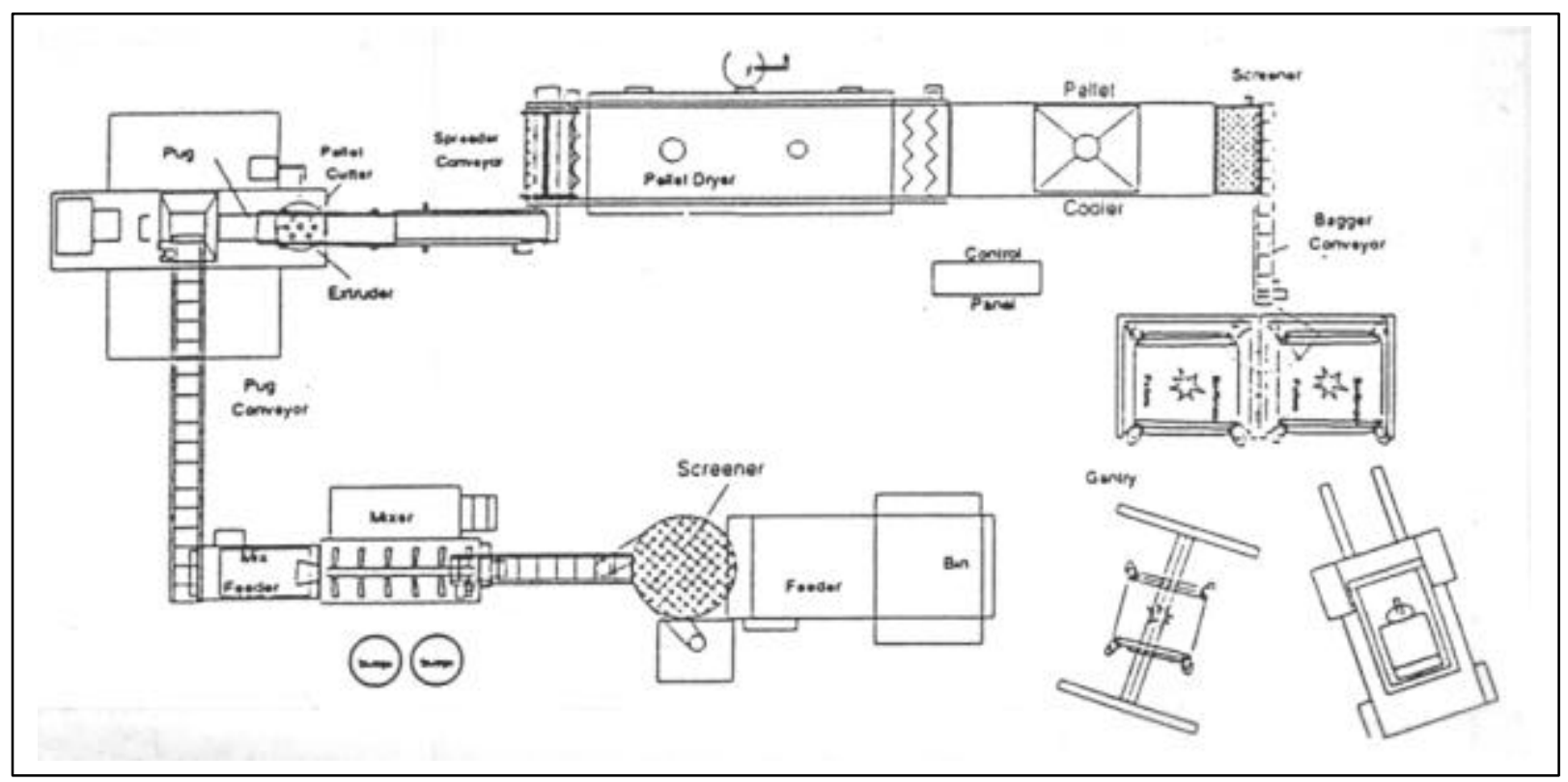

Figure 1 -- Layout of Altex Pilot-Scale Pelletization Test Facility

In the BioBinder process, a mixture of sludge and coal is extruded into pellets, which are dried and cured to a durable form. The key element in the process is municipal sludge, that is composed of fats and grease, protein, cellulose fiber and lignins, and inorganics, as listed in Table 1. These components give sludge special characteristics for binding materials.

Over 30 million wet tons of sewage sludge are produced every year [5]. The material is available wherever there are people. It is recognized that municipal and industrial wastewater sludge production rates are increasing, with production rates expected to substantially increase in the future due to storm water overflow management. At the same time, new or impending regulations concerning waste disposal, will impact current disposal options [6]. Through processing and ultimate landfilling, the cost to dispose of wet sludge is in the range of $\$ 44 /$ tonne (\$40/ton) [7]. Since the water content is typically 75 percent, the disposal cost per dry ton of sludge is over $\$ 176 /$ tonne $(\$ 160 /$ ton). Thus, there is a significant incentive to utilize this material.

Table 1 -- Typical Municipal Sludge Composition

\begin{tabular}{|l|c|}
\hline \multicolumn{1}{|c|}{ Sludge Composition } & Dry (\%) \\
\hline Fats and grease & $6-30$ \\
\hline Protein & $23-30$ \\
\hline Cellulose and lignin & $8-15$ \\
\hline Inorganics & $17-28$ \\
\hline
\end{tabular}


Using Palo Alto, CA sludge as a binder, and Consol coal fines, the equipment illustrated in Figure 1, was used to produce 32 tonnes( 35 tons) of BioBinder fuel pellets at Altex. These pellets were characterized by a suite of tests which showed:

- Pellets were durable, requiring $2070 \mathrm{kN} / \mathrm{m}^{2}$ to $2760 \mathrm{kN} / \mathrm{m}^{2}$ (300 to $400 \mathrm{psi}$ ) to crush the pellets

- Abrasion tests produced less than 2 percent dust

- Pellets could be dropped from a height of $4.57 \mathrm{~m}(15 \mathrm{ft})$ and survive

- Pellets maintained integrity after 6 months of winter weather exposure on the east coast

- Pellets burn better than coal, with 30 percent less NOx emissions and over 80 percent less carbon in ash

Most importantly, a detailed economic analysis, using inputs from equipment suppliers, showed that even when priced 10 percent less than coal, internal rates of return could exceed 40 percent. These are very attractive economic parameters, that are far superior to the typical 10 to 20 percent return, required by industry. The good pellet performance and economic potential has stimulated the interest of coal companies and utilities. Furthermore, the success with BioBinder suggests a similar success, when some, or all, of the coal is replaced by biomass, and the equipment and process is adapted to the biomass material. This is the main thrust of the AFP concept.

The special BioBinder processing creates a durable and weather resistant fuel pellet, which is consistently sized to match conventional coal fuel in electric utility and industrial boilers. It is envisioned that municipal biosolids, municipal solid wastes, and/or agricultural biomass could be mixed together, with or without coal fines, and processed using similar equipment, to create a low cost and robust, odorless and weather resistant fuel pellet for electric power production. However, fibrous biomass presents a weatherization challenge.

Dry biomass more readily absorbs water than the coal in BioBinder pellets. This is problematic from a pellet strength and odor perspective. Therefore, Altex has incorporated an enhanced weatherization approach into the AFP process, to fully address biomass storage and transport challenges. Importantly, the weatherization agent is created from low-cost wastes. Therefore, the weatherization procedure has only a minimal impact on cost.

AFP biomass-based pellets will have the needed handling, storage, and transport characteristics required for a boiler fuel. For those applications that require a more coal-like fuel, coal fines can also be included in the pellet formulation. This shows the flexibility of the AFP process. AFP pellets can be blended with coal fuel, and easily utilized as a co-fired fuel supply in pulverized coal-fired boilers. Altex tests have shown that BioBinder pellets can be pulverized [6], and International Flame Research Foundation tests [7] have shown the viability of firing pulverized sludge and coal together. Tests conducted under this program have shown that AFP pellets can also be pulverized and effectively burned in utility boilers. By addressing pulverized coal-fired and stoker boiler needs, AFP pellets are positioned to supply a portion of the $\$ 27$ billion solid fuels market. In addition, AFP products could also serve as feedstocks for other biomass electricity generating options, such as biomass gasification technologies. Prior to describing the AFP process in more detail, some background on biomass is presented.

\subsection{BIOMASS MATERIALS BACKGROUND}

Coal is biomass that has been transformed by natural processes, over long periods of time, into a high-energy, low-moisture, dense, and slow decaying energy resource. In comparison, 
biomass has lower energy, higher moisture, lower density, and decays rapidly. This decay results in a loss of energy content, and the production of VOCs and odors. Also, biomass based fuel storability is limited. These characteristics limit the use of currently available biomass fuel options in direct combustion equipment. While biomass materials have several disadvantages as a fuel, they do have some benefits. Advantages of biomass-based materials include low sulfur content, and lower NOx production and greenhouse gas emissions. Also, these materials will not be depleted in the long term.

Solid biomass waste production in the U.S. approaches two billion tons/year, with 21 percent municipal, 57 percent agricultural, 7 percent forest, 7 percent industrial, and 8 percent miscellaneous wastes [10]. This is approximately two times the U.S. coal output of one billion tons/year [10]. Of the municipal waste amount, 10 percent is biosolids (i.e. dewatered municipal sludge), derived from wastewater treatment, and 90 percent is from collected municipal solid waste [10].

Movement of populations to cities has concentrated the production of municipal wastes. Over 200 million tons of MSW are produced in the U.S. every year. This material consists of large fractions of cardboard, paper, and yard wastes, combined with a smaller fraction of food, plastic, rubber, wood, and textile wastes. Given a typical $\$ 44 /$ tonne $(\$ 40 /$ ton) disposal cost of MSW, and its proximity to industrial and urban centers, the utilization of this material as a fuel is attractive.

Large concentrations of biomass wastes are a threat to the environment. MSW, when incinerated, produces concentrated air pollution. When landfilled, the material and leachates can contaminate the ground and water supplies. Disposal of biosolids from wastewater treatment plants can similarly pollute the air, ground and water supplies. In addition, only so much biosolids can be land applied, as a fertilizer and soil amendment, before the capacity of the soil to absorb the nutrients is saturated.

This is also a problem with animal agricultural wastes. Animal agricultural wastes include cattle, swine and poultry manure. Recently, large corporations have concentrated agricultural operations [11]. For example, feed lot operations now handle up to 50,000 head of cattle producing approximately 1600 TPD of manure wastes [11]. This exceeds by over a factor of five the municipal biosolids production of cities like Indianapolis. It has been estimated that animal waste Biological Oxygen Demand (BOD) is equivalent to the water pollution impact of a population of 1 billion people [12]. In addition, these wastes attract pests and disease. Legislation currently being considered, (Animal Agriculture Reform Act, S.1323) will make current animal manure disposal options more expensive.

Energy crops, and agricultural residues, include grain plants, or their residues, straws and corn stalk residues, rice hulls and nut shells. Sorghums, canes, and grasses, such as switchgrass or tall fescue, are also appropriate for use as a fuel. Since aged residue materials can be available in a low moisture state, they are preferred to green biomass, which can have a moisture content of more than 70 percent.

Paper plant sludges are composed of very fibrous material, consisting largely of very short fibers, unusable wood fragments, and microorganisms. Filler materials from the paper making process are found in the sludge. These are inert materials, such as clays and ash. These sludges have a fuel value of between $17408 \mathrm{~kJ} / \mathrm{kg}$ and $22050 \mathrm{~kJ} / \mathrm{kg}(7500$ and $9500 \mathrm{Btu} / \mathrm{lbm})$ dry basis, depending on the waste stream composition, and the fiber recovery systems employed at the plant. Only a small fraction of the paper sludge produced is utilized for energy recovery in the U.S... Landfilling is still the most common means of disposal. 
Table 2 lists analyses for biomass, coal, municipal solids and sludge, manure, and industrial wastes. As shown, wet biomass (manure, bagasse, and wood) has low energy content, and due to the moisture content, high shipping weight. This decreases the value of these materials as a fuel. After drying, energy content is increased and shipping costs are reduced. As shown, municipal refuse, dried manure, bagasse, and rice hulls have energy content similar to lignite. This is partly due to ash content, but it is also due to the higher chemical oxygen content of the material, which is again similar to the characteristics of lignite, or young coal. While these materials require larger quantities of fuel to achieve a given heat release, the higher oxygen content typically gives higher fuel volatility and better ignition characteristics. This is useful in some applications.

While coal is resistant to microbial decay, the biomass and wastes listed in Table 2 can be subject to significant microbial decay. If the process is anaerobic, VOCs and odorous compounds (e.g. $\mathrm{H}_{2} \mathrm{~S}$ ) are generated that add to atmospheric pollution. Under aerobic conditions, $\mathrm{CO}_{2}$ is created. In both cases, energy content is degraded. This makes biomass material less valuable as a fuel. Lastly, dried biomass fuels, like rice hulls or dried bagasse, have a very low density, as well as a low energy value per pound. Therefore, large volumes of material are needed to equal the heat input of a smaller volume of coal. Special transport, handling, and combustion equipment are then needed to handle this low-density material.

\section{Table 2 -- Biomass Waste and Fuels Analyses}

\begin{tabular}{|c|c|c|c|c|c|c|c|c|c|}
\hline & & Biomass & & & Coal & Municipal & Cattle manure & Paper mill & Municipal \\
\hline & Rice hulls & Bagasse & Wood & Lignite & Bituminous & & & & \\
\hline Low Moisture & 7.6 & 0 & 0 & 40 & 3.0 & 4.9 & 3.6 & 23.2 & 4.2 \\
\hline Btu/lbm & 6,610 & 8,869 & 9,120 & 7,040 & 13,130 & 8,890 & 7,110 & 5,350 & 7,080 \\
\hline $\mathrm{kJ} / \mathrm{kg}$ & 15,342 & 20,586 & 21,170 & 16,340 & 30,475 & 20,634 & 16,503 & 12,418 & 16,432 \\
\hline High Moisture & 28 & 50 & 50 & & & & 82 & 74 & 76 \\
\hline Btu/lbm & 5,155 & 4,435 & 4,560 & & & & 1,328 & 1,811 & 1,774 \\
\hline $\mathrm{kJ} / \mathrm{kg}$ & 11,965 & 10,294 & 10,584 & & & & 3,082 & 4,203 & 4,118 \\
\hline $\begin{array}{l}\text { Ultimate } \\
\text { analysis, } \\
\text { As-received, \%: }\end{array}$ & & & & & & & & & \\
\hline Hydrogen & 5.7 & 5.8 & 5.7 & & 4.5 & 7.2 & 5.7 & 7.0 & 6.8 \\
\hline Carbon & 38.5 & 48.8 & 53.9 & & 74.7 & 47.6 & 41.2 & 30.9 & 45.5 \\
\hline Nitrogen & 0.5 & & & & 1.2 & 2.0 & 2.3 & 0.5 & 2.4 \\
\hline Oxygen & 39.8 & & & & 5.4 & 35.7 & 33.3 & 51.2 & 25.8 \\
\hline Sulfur & 0.0 & Trace & Trace & 1.4 & 1.3 & 0.3 & 0.3 & 0.2 & 0.5 \\
\hline Ash & 15.5 & 3.5 & 2.0 & 9.0 & 6.8 & 7.2 & 17.2 & 10.2 & 19.0 \\
\hline
\end{tabular}


The AFP process can be used to upgrade many of the biomass materials referenced above. The process is flexible enough to adapt to the biomass material of interest. Through variations in processing conditions, and the ratio of sludge/coal/biomass, durable fuel pellets can be formed. Given the low cost of MSW, this can be a good AFP feedstock, to maximize profitability for early investors in the AFP process. An easier application might be a consistently-sized biomass, such as rice hulls. Rapid growing energy crops may also be of longer-term interest. In most cases, the biomass of interest for AFP is dictated by the logistics of biomass supply and user needs. Therefore, each application has to be examined, and all sitespecific factors must be factored into the choice of biomass materials. The flexibility and broad applicability of the AFP process fits this site specific nature of biomass very well.

\subsection{AFP PROCESS DESCRIPTION}

Altex has identified a means to create high value "green" fuel pellets from biomass, at a low cost, which addresses the shortcomings of unprocessed, or partially processed biomass and waste materials. To create a low-cost AFP fuel, that can be burned in existing coal-fired systems, several biomass components are optimally processed together.

These components include municipal sludge, municipal solid wastes and/or agricultural biomass, coal fines, and low or negative cost chemical/waste material additives. The materials are then processed to produce a durable, weather resistant, odorless fuel, with favorable combustion characteristics. An important advantage of the process is its ability to handle a range of raw materials. Therefore, the process is broadly applicable to several biomass based applications.

Given the costs to collect and process biomass, the economic production of fuel pellets is a challenge. However, Altex has found that, as in the BioBinder process [4], municipal sludge is a very effective binder. And, most importantly, the disposal fees for the sludge are high enough to substantially offset pellet production costs [4]. Furthermore, if negative cost municipal wastes are utilized in the AFP process, their additional disposal fees will further reduce processing costs, making the pellet costs much less than coal, on an equivalent Btu basis.

The goals of the AFP process are to:

- Reduce biomass moisture to increase Btu content and reduce shipping weight

- Increase density to make the fuel more compatible with existing coal handling, transport, storage and combustion equipment

- Weatherize and sterilize the material, to reduce decay and water uptake, and thereby improve storability

- Incorporate a flexible composition, which can take advantage of site specific resource and economic factors

- Reduce greenhouse gas (e.g. $\mathrm{CH}_{4}, \mathrm{CO}_{2}$ ), $\mathrm{SO} 2$ and NOx emissions

- Reduce fuel cost below that of coal

The AFP process is based on the successful BioBinder process that has produced quality fuel pellets from coal fines [4]. The AFP process steps are schematically represented in Figure 2.

As shown, the AFP process consists of an initial mixing step, where municipal sludge, sized biomass and coal are mixed together. The reduced moisture mixture is then extruded into pellets and transported into a dryer, which cures and dries pellets. As needed, coal, or low moisture biomass, can also be added prior to the extruder step, to trim mixture moisture. In the last step, pellets are coated with a low-cost weatherization agent, which is derived from wastes. These process steps can be implemented by essentially commercially available equipment. The 
process innovation comes from the mixture of components, and processing them in such a way, that takes full advantage of their complementary characteristics. Also, the addition of special weatherizing and sterilizing agents, and simple but important modifications to equipment, further enhances AFP processing and product. Details of the steps and the special conditions created are described below.

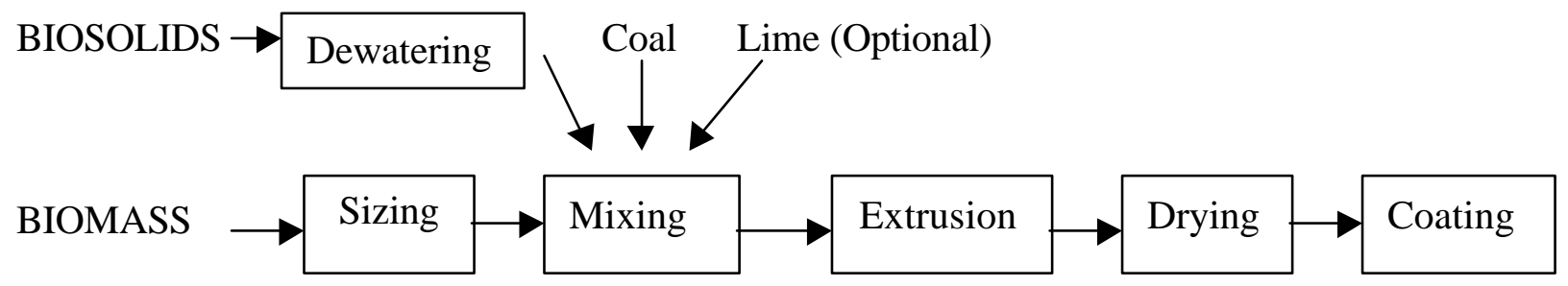

Figure 2 The Altex Fuel Pellet (AFP) Process

\subsubsection{MIXING OF COMPONENTS}

At the initiation of the formation process, one to five percent hydrated or unhydrated lime can be introduced into the dewatered sludge, of approximately 25 percent solids content. The lime reacts with the sludge components and creates a simple weatherproofing agent. Lime addition also has odor and microbial control benefits. As shown in Table 1, municipal sludge contains fats, greases, protein, cellulose fiber, and inorganic components. The weatherproofing effect is caused when the lime selectively reacts with these fats and grease, producing calcium stearate, an insoluble white powder that has waterproofing properties [13]. Alternative reactions with protein are not favored. However, by making the sludge overall alkaline, some of the organic metal compounds could precipitate. These may also help block pores and add weather resistance. However, calcium stearate is the most likely reaction product that has the needed waterproofing capability. In addition, it should be noted that each percent lime could theoretically generate eight times as much calcium stearate on a mass basis. Therefore, there is a substantial leveraging of the small amount of lime in creating a large amount of weatherproofing agent. In fact, the calcium stearate product could be limited by fat availability in some cases. It should be noted that, besides weatherization benefits, adding lime has been found to significantly reduce sludge and biomass odor and biological activity. The lime changes the $\mathrm{pH}$, and also reacts with the volatile fatty acids created by decay of greases/fats, and reduces their volatility and odor impact. This synergistic biosolids/biomass stabilization effect is an important one for the biomass based fuel pellet, which would be subjected to various levels of moisture exposure. Also, calcium from the lime can help capture $\mathrm{SO}_{2}$ during combustion of the pellets in stokers. These additional benefits have already been demonstrated in tests at Altex and elsewhere [13].

While the use of lime is beneficial for applications requiring long term storage and weatherization, the addition of lime increases fuel ash content and decreases energy density. Therefore, for applications where the fuel will be used immediately after preparation, lime is excluded. In the next step of the AFP process, the MSW, or biomass material, is shredded or ground, as appropriate, to sized particles. This material, and the limed sludge, are then thoroughly mixed with a pug mixer.

\subsubsection{BIOSOLIDS DEWATERING}

To increase fuel value, moisture must be removed from the material, preferably by means other than expensive thermal drying. Fuel pellet drying costs can be up to 50 percent of the cost of processing the material. 
Figure 3 presents a schematic of a sludge material, where free, capillary, colloidal and cellular water are displayed. Free water, which includes both interstitial and surface moisture, is the easiest water to remove. Capillary water, trapped in small areas within the material, is much more difficult to remove, due to surface tension effects. Colloidal water removal usually requires chemical conditioning to remove as a liquid, while cellular water is trapped within cell walls.

By raising the temperature of this material to $82^{\circ} \mathrm{C}\left(180^{\circ} \mathrm{F}\right)$ temperature, viscosity and surface tension are reduced by 71 and 20 percent, respectively [14]. These reductions make it easier to squeeze interstitial, and capillary moisture out of the material. Since the material is ultimately to be dried, heating at this step does not incur an energy penalty.

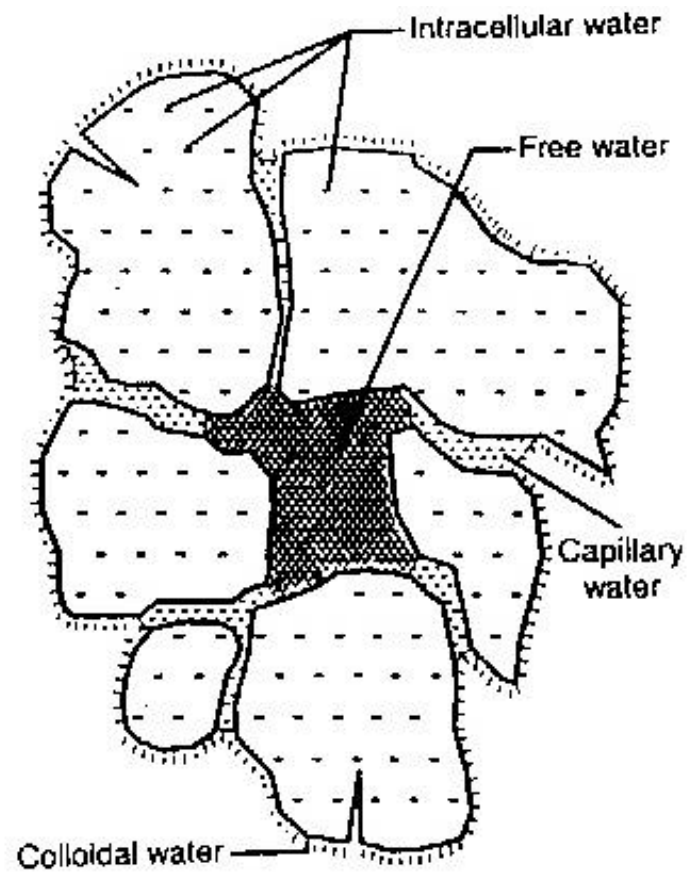

Figure 3 -- Illustration of Sludge Water Distribution

Altex has conducted tests of the impact of heat on the mechanical dewatering of high moisture biosolids. The tests have showed that by raising the material temperature to $82^{\circ} \mathrm{C}$ (180 F), while simultaneously pressing the material, the solids content can be increased from 25 to 37 percent. This substantially reduces the need for expensive thermal drying.

Vincent Corporation, a major screw press manufacturer, which supported the AFP development program, has extensive experience in developing screw press dewatering technology, and has recently developed a low-cost, high-throughput dewatering press for cattle and swine manures. Their experience was helpful in optimizing the dewatering step in the AFP process. Furthermore, with the application of low grade $82^{\circ} \mathrm{C}(180 \mathrm{~F})$ heat to the mixture, through steam injection into the auger body, the viscosity and surface tension of the water in a sludge can be reduced, and dewatering facilitated. Figure 4 illustrates a typical press. 


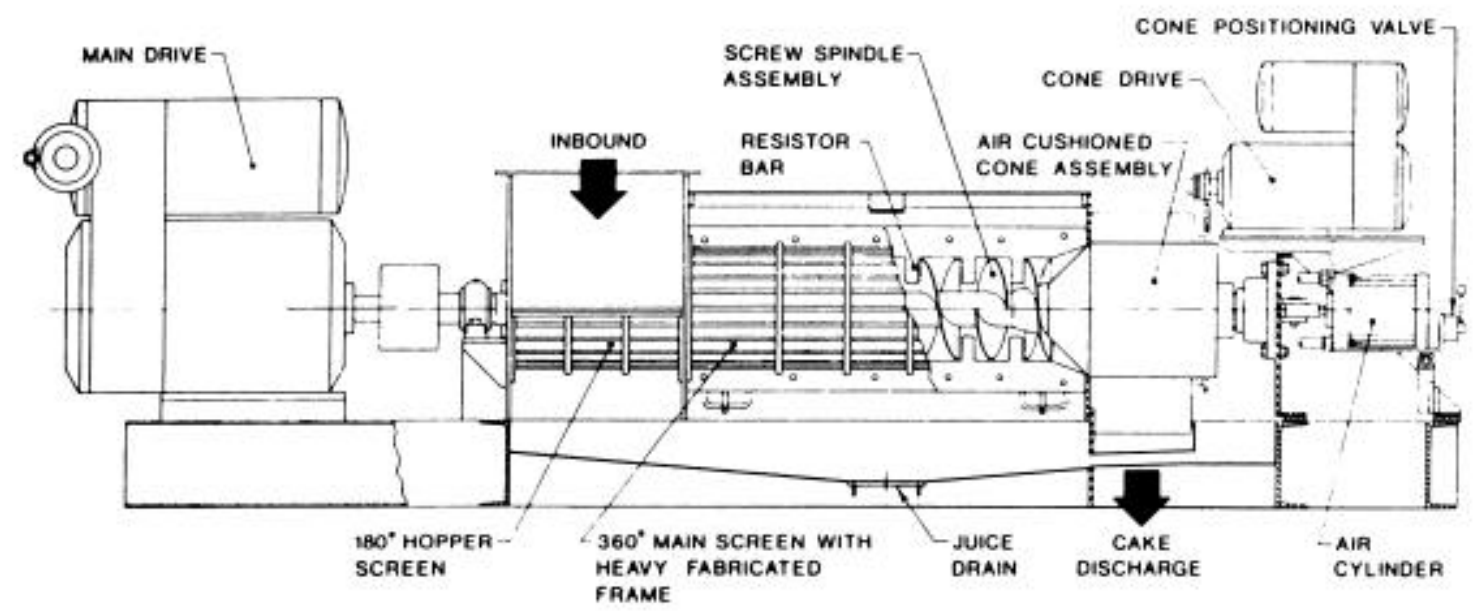

Figure 4 -- Typical Screw Press

\subsubsection{Pelletization}

The dewatered mixture of sludge, biomass and coal needs to be compacted into pellets of the proper size for optimal handling in existing coal equipment. From the BioBinder experience, Altex found that screw extrusion is the best approach for the wet materials of interest, and is therefore well suited to the AFP process. Figure 5 presents an illustration of the Altex PR9 extruder. It is a conventional clay extrusion system, consisting of a pugmill mixer, and a barrel and auger, that forces material mixtures through a die plate, with holes of the needed pellet diameter. Based on our experience, extrusion has the best characteristics for forming pellets, at reasonable cost. Briquetters and pellet mills are more expensive to own, maintain, operate and are less flexible. With a screw extruder, depending on the die design, temperature, and system set up, the operating conditions can be changed to alter pellet characteristics. This gives considerable flexibility in forming pellets.

It also may be possible to combine dewatering and extrusion steps. By combining these steps into one machine, a major equipment component cost is avoided, and processing costs reduced. In screw presses, an extrusion-like process normally occurs in the annular region beyond the auger, where the material exits the press. This is shown in Figure 4. It is feasible that the end plate, or cone, could be replaced by die plate, to produce a sized extruded pellet with a screw press. By making this slight modification, two process steps, dewatering and extruding/pelletizing, could be combined, with significant savings of both capital and operating costs. 


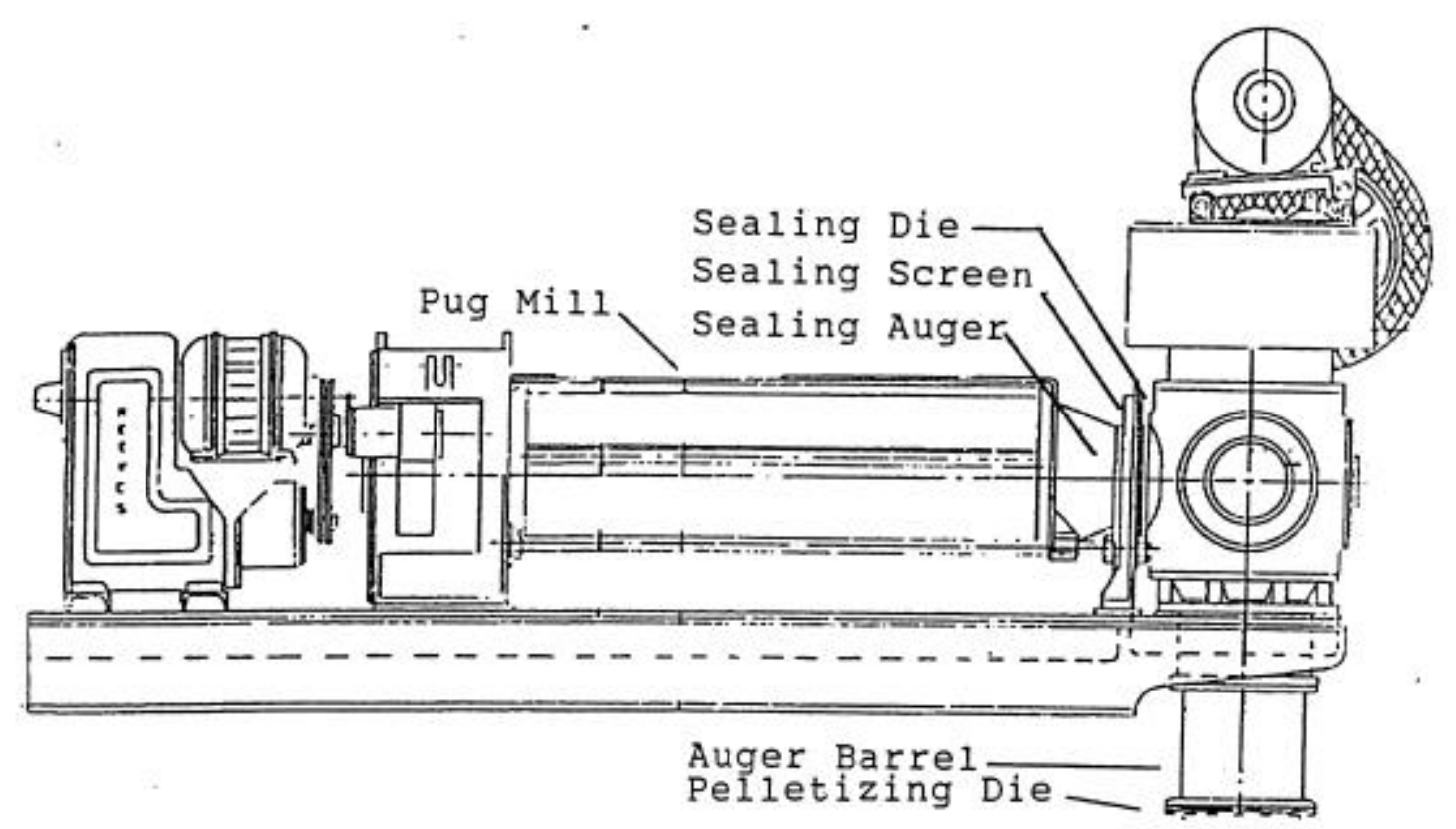

Figure 5 -- Altex PR9 Screw Extruder

The drying cost is affected by the size of the pellet, so it is advantageous to keep the pellet diameter to a minimum, all other factors being considered equal. As the AFP pellets were extruded, an integrated cutter cut the pellets to approximately a L/D of 2 . From Altex experience, this is a good configuration to limit bending stresses on the pellet, and resulting breakage during handling. The pellets produced during this program ranged from $.95 \mathrm{~cm}$ to 2.5 cm (3/8" to 1 ")in diameter.

\subsubsection{DRYING/CURING}

The pellets, although compacted, are not robust in their extruded green state. Following extrusion, the pellets are heated and dried. Commercial conveyor dryer equipment, similar to the Altex Proctor-Schwartz dryer, illustrated in Figure 6, is used to dry the AFP pellets to less than 10 percent moisture. Besides drying, heating the pellets performs an important function, that adds pellet strength.

During heating, the substantial protein content of the sludge (See Table 1) becomes denatured and converts irreversibly to a semi-solid that has substantial toughness. In this step, the protein becomes the "glue" binding cellulosic fibers. An illustration of this protein denaturing is the frying of egg whites. Once the egg white is heated, it becomes opaque and "rubbery". It can stick to bare surfaces and must be scrapped off with a kitchen implement. While the raw egg is watery, when cooked it must be cut with a knife. Furthermore, submerging the denatured material in water doesn't change its strength or solubilize the material. Therefore, through the heating and denaturing step, the protein in the sludge becomes a strong and weatherresistant glue that holds fibers and coal fines together.

Besides providing pellet strength, heating the pellets also destroys all pathogens in the sludge and biomass, and reduces odorous compounds in the final product. 


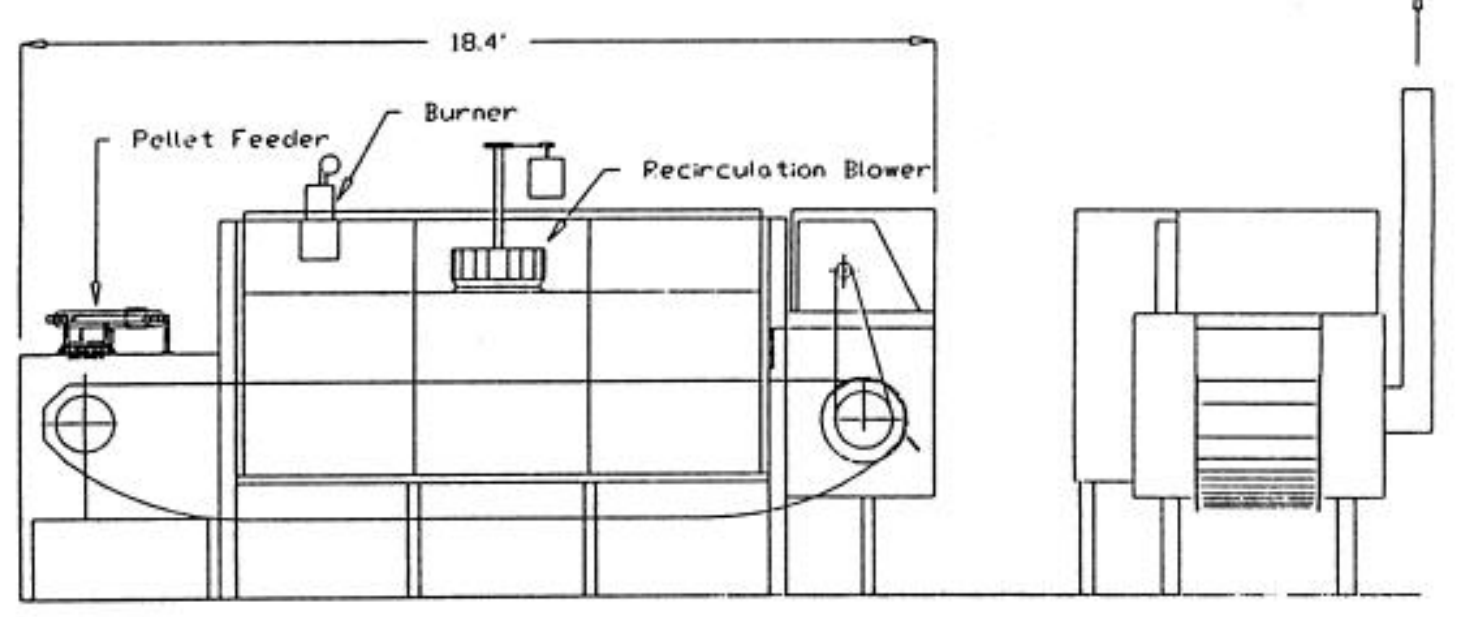

Figure 6 -- Proctor-Schwartz Conveyor Dryer

Heated and dried pellets exit the dryer and can then be cooled prior to storage and/or transport. At this point, the AFP process has created a calcium stearate weatherproofing agent, converted proteins to a tough binding agent and, through reduced viscosity at elevated temperature, distributed the remaining fats and greases throughout the pellet matrix to further weatherproof pellets.

\subsubsection{WEATHERIZATION}

The AFP pellets have considerable strength when dry. However, in typical transport, storage and handling situations, they will be exposed to weather and may become wet. Special processing and agents are utilized in the AFP process to ensure that pellet strength and integrity are not compromised by weather. This is a significant departure from many other biomass pelletization processes, where material quality degrades significantly upon exposure to normal weather conditions.

As with any biomass based material, when the biomass-based pellets are substantially dry, the cellulose fibers in the material are very strong and tightly bonded, and pellet strength is substantial. Essentially, the cellulosic fiber composite material holds the material together in a strong matrix. Even with only 10 percent sludge binder, pellet crush strength can exceed 500 psi, in some cases. However, if they become water logged, strength degrades. In some cases, the pellet becomes soft, and the entire value of the densification process is lost. In addition, the wet material is subject to microbial decay, that can lead to energy degradation, VOCs formation, and odorous gas production. The degradation in strength can be related to cellulosic material, moisture absorption and the softening/swelling process.

To highlight the challenge of weather, Figure 7 illustrates a small segment of a sludge /biomass/coal fines pellet. As shown, cellulosic fibers are separated by coal fines, with fibers and coal particles bound by the protein component in sludge. As shown, fibers and coal fines are held together in a "fiber-composite" like system, that provides substantial dry pellet strength. 


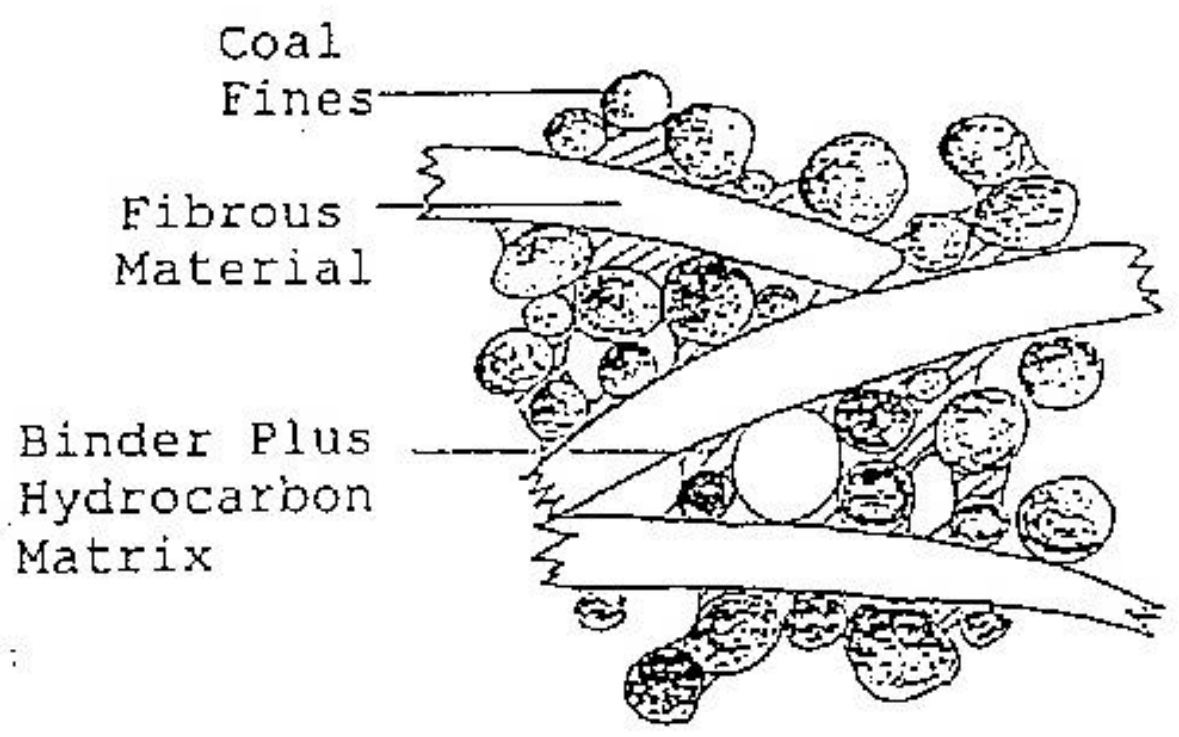

Figure 7 -- Sludge/Biomass /Coal Fines Segment Cross Section

Under typical transport and storage conditions for utility boilers, biomass-based pellets may become wet. Only in limited circumstances will pellets be completely sheltered from weather during transport and storage. As with any relatively porous and cellulosic material, water can infiltrate into exposed, unprotected pellets. The tight hydrogen bonds which give strength to the cellulose fibers and the material, will be degraded by water molecules, resulting in the swelling and weakening of pellets. This loss in strength is illustrated by strength tests on cellulose fiber-based composite materials described below.

Cellulose in biomass materials is bonded together by hydrogen bonds. When water is added, it migrates to the areas between the microfibrils, and causes the structure to swell and degrade. In this state, the once robust composite-like structure becomes weak, and the material is susceptible to crushing or decrepitation. A common example of this phenomena is when cardboard becomes wet. A relatively stiff piece of cardboard, upon wetting, will swell and become soft to the point where it cannot even support its own weight. Another illustration is with a sisal fiber (69-75\% cellulose) - epoxy composite material. The cellulosic sisal fibers are embedded in an epoxy matrix. Figure 8a illustrates how water uptake seriously degrades the flexural strength of the composite with mercerized fibers [16]. This process reduces water uptake compared with untreated fibers. Nevertheless, water uptake in the treated fibers, and strength degradation, is still very substantial. As shown in Figure 8a, when dry, increasing fiber content substantially increases the strength of the material. This is in line with Altex pellet test experience, where fiber content enhances pellet strength. In the presence of water, the composite moisture content increases as the amount of fiber increases. For the material in Figure 8a, moisture increases from 10 to 25 percent, as fiber volume fractions increase from 30 to 60 percent, respectively [16]. This is expected. Most significantly, as shown in Figure 8a, absorption of 10 to 25 percent water has caused a strength reduction of one third. 

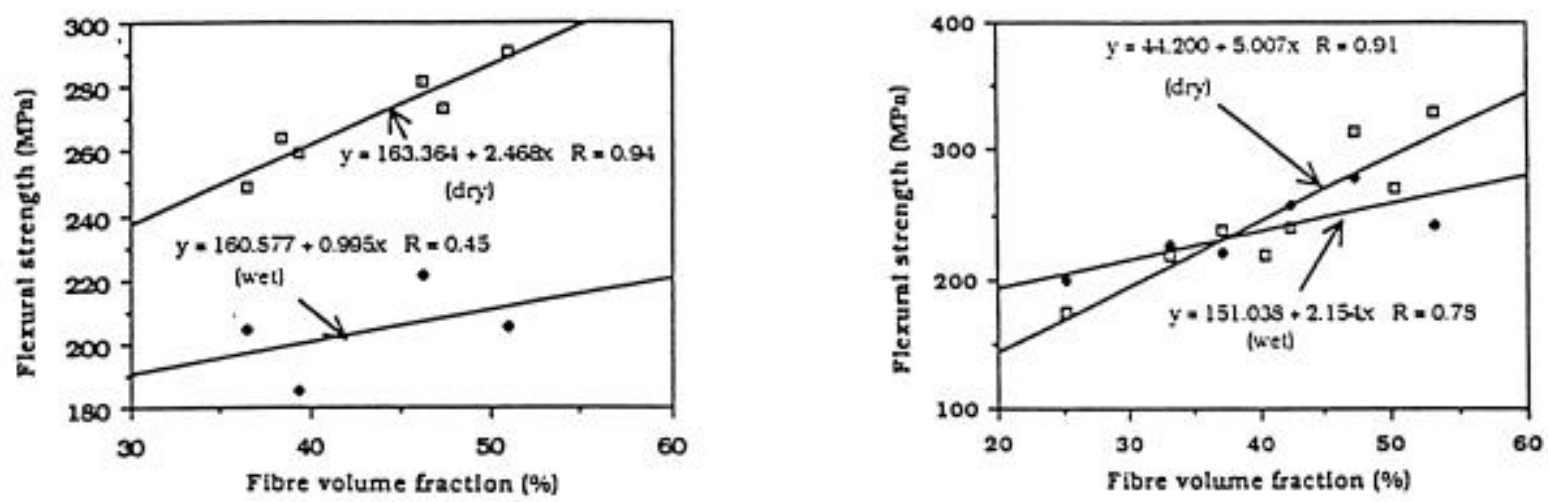

Figure 8 -- Wet and Dry Strength of Sisal Fiber Epoxy Composite with (a) Mercerized (b) Silane Treatments

When silane fiber treatment is utilized, water uptake is reduced to below 10 percent, even for fiber contents of up to 60 percent. In this case, flexural strength reductions, as a result of water content, are significantly reduced. This is illustrated in Figure 8b. Essentially, by reducing water uptake to below 10 percent, substantial strength is retained. This was the experience with BioBinder pellets, where moisture contents of less than 10 percent had little impact on pellet strength, while water uptake of 29 percent led to substantial degradation [4]. It should be noted that the effect of water uptake on strength is nearly reversible. Experiments with untreated BioBinder pellets showed that pellets submerged in water for 24 hours absorbed over 25 percent moisture, and became soft. However, when dried, pellets recovered over 90 percent of their strength [4]. Again, this is consistent with cellulose fiber behavior, where moisture degrades strong hydrogen bonding, but drying reestablishes these bonds.

The above comments highlight the dry strength benefits, and the wet strength problem of pellets containing cellulosic fiber biomass. Through recent BioBinder related efforts, Altex has developed a process that maintains the wet strength of sludge/coal pellets. Since the processing helps shield the cellulosic portion of the BioBinder sludge/coal pellets, it should be very effective in mitigating moisture uptake, and attendant strength degradation in biomass based AFP pellets.

As mentioned above, the weatherizing process steps to this point, will yield good wet and dry pellet strength. Altex tests support this suggestion. Following the above process, sludge/coal pellets were made with and without lime to confirm the benefits of this weatherization process. In these tests, approximately 7 percent lime was added to the mix. This amount of lime, that far exceeds the theoretical requirement, was used to ensure that all fats and greases were contacted with lime. Test results are listed in Table 3. As expected, extruded pellets without the heat curing step were soft. Upon drying and heat curing, pellets with and without lime addition were strong, requiring approximately $2068 \mathrm{kN} / \mathrm{m}^{2}$ (300 psi) to crush the pellets. 
Table 3 -- Comparison of Wet and Dry Pellet Strength With and Without Lime Treatment

\begin{tabular}{|l|c|c|c|}
\hline & \multicolumn{2}{|c|}{$\begin{array}{c}\text { Axial Compression Strength } \\
\mathbf{k N} / \mathbf{m}^{\mathbf{2}} \text { (psi) }\end{array}$} & $\mathbf{H}_{\mathbf{2}} \mathbf{O}$ Absorption \% \\
\hline & Dry & Wet & \\
\hline No lime & 298 & $352(51)$ & 29 \\
\hline With lime & 302 & $848(123)$ & 11 \\
\hline
\end{tabular}

When pellets without this AFP weatherizing process were submerged for 24 hours, water absorption was 29 percent, and pellet crush strength was reduced to $352 \mathrm{kN} / \mathrm{m}^{2}$ (51 psi). In contrast, when submerged for 24 hours, pellets with the AFP weatherizing process absorbed only 11 percent moisture and pellet strength was $848 \mathrm{kN} / \mathrm{m}^{2}(123 \mathrm{psi})$. This is a substantial 240 percent improvement in wet strength over untreated pellets. The full immersion test can be considered an extreme test of weatherizing.

As impressive as these results are, even greater moisture protection was achieved, even without lime addition, by the application of a unique low cost grease and wax coating, as a final AFP process weatherization step. The grease coating was derived from the "floatable" sludge fraction (i.e. scum) that is collected separately from the wastewater solids. The floatables contain a high percentage of grease, which is released from the raw material by heating and straining. This sterilized grease is then used to coat the pellets, by quick immersion, to seal pellet porosity from water uptake. The pellet can then be sealed again, with a similar quick immersion in a petroleum based "slack" wax bath, to further seal the pellet from any water uptake and control any microbial-based decay. Also, all wet condition odors are completely eliminated in these final two steps.

Table 4 presents the results of the 24 hour moisture absorption tests for coated and uncoated pellets. This data represents multiple trials for the coated pellets. As expected, the uncoated pellets absorbed 29 percent moisture. With a waste derived grease coating, the water uptake was 9.8 percent. With wax application over the waste grease, water uptake was 8.3 percent. The amount of wax needed in this case was under $2 \%$. These results are very favorable. By controlling moisture to below 10 percent, strength is maintained as noted above, and microbial decay produced by molds and bacteria, is minimized. In addition, pellets are sealed from microbes that can be reintroduced into the material and cause future decay.

Table 4 -- Water Absorption for Coated and Uncoated Pellets

\begin{tabular}{|l|c|}
\hline & Water Absorption (\%) \\
\hline No Coating & 29 \\
\hline Waste Plus Wax Coating & 8.3 \\
\hline Waste Coating & 9.8 \\
\hline
\end{tabular}

This quick weatherizing immersion bath step in the AFP process is illustrated in Figure 9. As shown, a volume of the melted grease or wax is contained in a shallow vat, into which the pellets drop after leaving the dryer. The material is brought out of the bath by a screw type conveyor system, as shown in the figure. The system is designed to keep the average immersion time sufficient to achieve a coating of a few weight percent. 


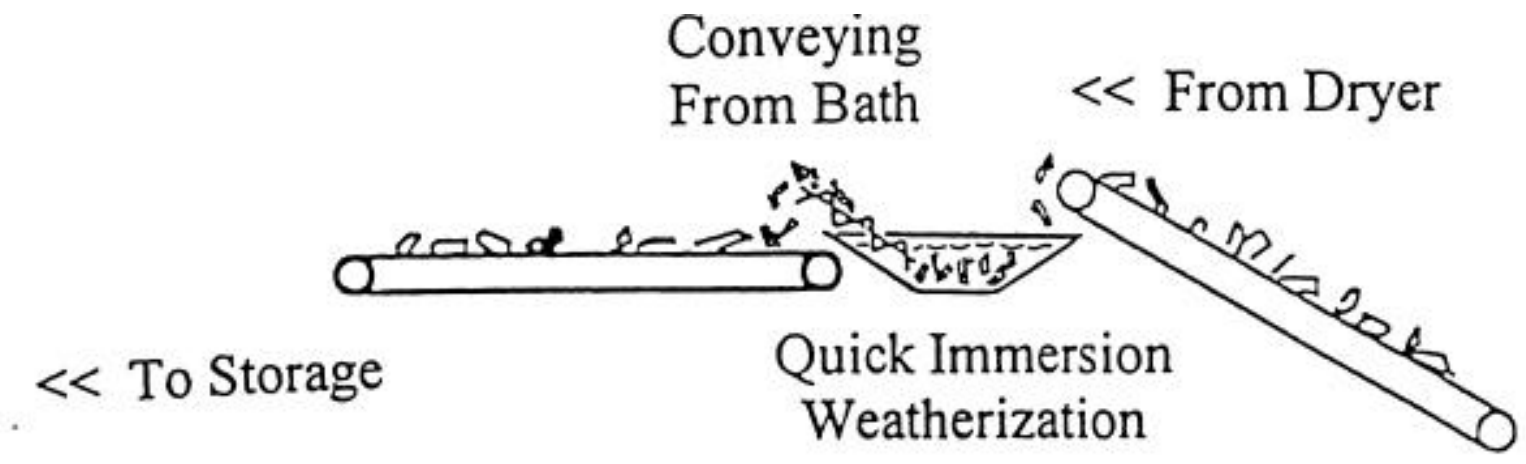

Figure 9 - Pellet Immersion Bath Step for Weatherization Sealing

AFP pellets have resistance to the most severe weather conditions, and have the necessary long-term storage capability, required for a utility fuel. Full pellet strength and Btu value are maintained, and handling and shipping costs are not compromised. These are all important benefits, which will allow AFP pellets to become a widely used utility fuel option for cofiring with coal. If shorter storage requirements are applicable, or weather/storage conditions are less severe, one or both of the coatings could be eliminated.

\subsection{AFP PROJECT OBJECTIVE}

The preliminary AFP tests, described above, showed that the AFP process has the potential to create a quality fuel pellet from biomass, municipal biosolid waste, and coal fines. More work was needed to develop the process with representative biomass materials. The objective of the project described herein was to show the feasibility of the Altex Fuel Pellet (AFP) process to create low-cost and high-quality fuel pellets from biosolids, biomass, and coal that have the needed handling, storage, transport and combustion characteristics for boiler applications. To achieve the objective, test and evaluation activities were carried out at Altex using bench-scale and pilot-scale equipment. Prior to describing tests and evaluation results, information is provided on biomass waste characteristics and selection.

\subsection{RAW MATERIALS DEFINITION AND EVALUATION}

The type of biomass governs AFP pellet quality, cost, and emissions characteristics. Therefore, biomass selection is very important. Given the initial focus of the effort on Detroit, feedstock availability and logistics for the Detroit area were primary factors in selecting biomass feedstocks. However, the criteria is broadly applicable to any large city.

To help define feedstocks, Detroit Edison (DTE) and several biomass resource organizations and companies in the Detroit/Wayne County area were contacted to get an assessment of biomass availability, quality and cost. The sources contacted included agricultural waste (e.g. degraded corn seed), forest waste (e.g. residue from pulp operations), paper waste (e.g. municipal refuse light fractions, low-grade paper recycling residues) and wood waste (e.g. wood residues from wood processing). Some sources were selected for contacting over others because of: 
Non-seasonality

- Good decay resistance

- Limited initial moisture

- Consistent configuration

- Reasonable energy content

- Reasonable cost

- Reasonable emissions when burned

Focusing on waste biomass was important, in that it was speculated that, for a waste, all or most of the cost of collecting/harvesting, processing and transporting to the Detroit area would be borne by the higher value product associated with the waste. Fresh agricultural residues or animal wastes were avoided, due to their high moisture, low energy value, high decay potential and high costs associated with collection and transport. Preliminary contacts indicated that agricultural wastes, such as corn seed wastes, were not viable near term, due to limited quantities and high delivered costs. Light fractions of municipal refuse appeared to be viable, with quantities and costs reasonable, relative to needs.

However, contaminants and environmental issues needed to be examined. Wood wastes appeared to be very attractive. However, adequate supplies must be available in Detroit/Wayne County for this to be a viable source.

\subsection{BIOMASS WASTE SELECTION}

There are many sources of biomass waste, and a broad range of energy content, moisture level, decay potential, configuration and consistency. Table 5 presents a list of potential biomass feedstocks for the AFP process and their characteristics.

Table 5 -- Potential Biomass Feedstock Material Characteristics

\begin{tabular}{|c|c|c|c|c|c|c|c|c|c|}
\hline & $\begin{array}{c}\text { Energy } \\
\text { Crops }\end{array}$ & $\begin{array}{l}\text { Poultry } \\
\text { Manure }\end{array}$ & $\begin{array}{c}\text { Agric } \\
\text { Residue } \\
\text { S }\end{array}$ & $\begin{array}{c}\text { Forest } \\
\text { Residues }\end{array}$ & $\begin{array}{c}\text { Lumber } \\
\text { Mill } \\
\text { Waste }\end{array}$ & $\begin{array}{c}\text { Mfr } \\
\text { Wood } \\
\text { Wastes }\end{array}$ & $\begin{array}{c}\text { Recycled } \\
\text { Paper } \\
\text { Waste }\end{array}$ & $\begin{array}{c}\text { MSW } \\
\text { (light } \\
\text { fractions) }\end{array}$ & Biosolids \\
\hline $\begin{array}{l}\text { Moisture } \\
\text { Level }\end{array}$ & $\begin{array}{l}10- \\
60 \% \\
\end{array}$ & $15-25 \%$ & $40-10 \%$ & $45 \%$ & $45 \%$ & Negl & $5 \%$ & $15 \%$ & $75 \%$ \\
\hline $\begin{array}{l}\text { Density, } \\
\text { dry } 1 \mathrm{bm} / \mathrm{ft}^{3} \\
\mathrm{~kg} / \mathrm{m}^{3}\end{array}$ & $\begin{array}{c}\text { (baled) } \\
13 \\
209\end{array}$ & $\begin{array}{c}17 \\
272\end{array}$ & $\begin{array}{r}7.5 \\
121\end{array}$ & $\begin{array}{l}10.5 \\
168\end{array}$ & $\begin{array}{c}9 \\
145\end{array}$ & $\begin{array}{c}12 \\
193\end{array}$ & $\begin{array}{c}7 \\
113\end{array}$ & $\begin{array}{c}7 \\
113\end{array}$ & $\begin{array}{r}6.5 \\
105\end{array}$ \\
\hline $\begin{array}{l}\text { Energy } \\
\text { Density } \\
\text { dry } \\
\text { Btu/lbm } \\
\mathrm{kJ} / \mathrm{kg}\end{array}$ & $\begin{array}{c}7950 \\
18453\end{array}$ & $\begin{array}{l}6700 \\
1552\end{array}$ & $\begin{array}{c}8030 \\
18639\end{array}$ & $\begin{array}{c}9020 \\
20937\end{array}$ & $\begin{array}{c}9120 \\
21169\end{array}$ & $\begin{array}{c}9030 \\
20960\end{array}$ & $\begin{array}{c}6750 \\
15668\end{array}$ & $\begin{array}{c}7975 \\
18511\end{array}$ & $\begin{array}{c}8390 \\
19474\end{array}$ \\
\hline $\begin{array}{l}\text { Decay } \\
\text { Potential }\end{array}$ & $\begin{array}{l}\text { Med- } \\
\text { High }\end{array}$ & $\begin{array}{l}\text { Med- } \\
\text { High } \\
\end{array}$ & $\begin{array}{l}\text { Med- } \\
\text { High } \\
\end{array}$ & Low & Low & Low & Low & $\begin{array}{l}\text { Med- } \\
\text { High } \\
\end{array}$ & High \\
\hline Odor & Some & Yes & Some & Low & Low & Low & No & Yes & Yes \\
\hline $\begin{array}{l}\text { Vector } \\
\text { Attraction }\end{array}$ & Some & Yes & Some & No & No & No & No & Yes & Yes \\
\hline
\end{tabular}

Biosolids represent an important binder component in the AFP process, and were included for that purpose in all formulations. Furthermore, given the high disposal cost $\$ 176 /$ tonne ( $\$ 160 /$ ton dry); biosolids were also included for economic reasons. While biosolids has these benefits, it also has high moisture content, decay potential, odor and insect and/or pest 
attraction. Therefore, it was beneficial to combine biosolids with biomass materials that offset these negative characteristics.

Energy crops have a high initial moisture content and a medium decay potential. Also according to current estimates, they are costly to harvest, dry and transport, resulting in a delivered cost of over $\$ 55 /$ tonne ( $\$ 50 /$ ton). Therefore, in the present economy, energy crops are not a good biomass option. Poultry litter, as well as other manures, has energy content, decay, odor and vector attraction characteristics that are similar to those for biosolids. Therefore, this material has little synergy with biosolids. Agricultural and forest residues should have a greater potential for use with biosolids than energy crops, given that they are a low value byproduct of agricultural and forest operations. This should make them lower in cost than energy crops. Also, upper Michigan forest operations and agricultural operations throughout the state produce large quantities of these wastes, according to the Michigan Biomass Energy Program. However, while supplies were found to be adequate, and raw costs acceptable, delivered costs are excessive. This is highlighted below for forest wastes.

An estimated 108 million tonnes/year (121 million tons/year) of wood are abandoned on the forest floor as a result of current timber cutting and logging practice. In Michigan the figure is over 2.7 million tonnes/year (3 million tons/year). The waste consists of treetops and limbs, that are removed immediately after the trees are felled and cut to length, in an operation known as "bucking". Trees are then hooked to a tractor with cable or chain, and skidded (dragged) to a staging area, or "deck", where they are sorted, and loaded onto trucks. Costs for these basic timber logging activities per completely dry, or per bone dry tonne (bdt) are listed below in Table 6. Collecting the waste from logging operations incurs additional costs.

Table 6 -- Costs Associated with Timer Cutting and Logging

\begin{tabular}{|l|c|}
\hline \multicolumn{1}{|c|}{ Activity } & \$/bdt (tn) \\
\hline Fell, Buck and Limb & $9.47(10.4)$ \\
\hline Skid & $13.06(14.37)$ \\
\hline Overhead & $8.06(8.90)$ \\
\hline TOTAL & $30.59(33.65)$ \\
\hline
\end{tabular}

In order to recover logging waste, the operation would break down into three main activities. The first activity would be collection of the material. This would be difficult, because the material lies scattered on the forest floor. A wood waste collection crew would have to work a large area, and it is likely that access to the terrain would be limited to the same crawler or wheeled tractor equipment used by the loggers. However, there would be no costs for felling and bucking the timber. Instead, the crew would have to selectively gather large limbs and tree tops to a centralized location, either with small tractor equipment, or by wench to the skid. It is difficult to estimate the cost of this activity. For the purpose of this analysis, an optimistic assessment of half the cost of felling and bucking timber is used for this activity.

The next activity would be dragging the material to a staging area accessible to a different mode of transportation, almost certainly trucks. It is improbable that this would be accomplished for any less than the cost of removing whole trees. At the staging area, the next activity would be to reduce material bulk for transport, by chipping or grinding. The bulk density of chipped green wood is about $676 \mathrm{~kg} / \mathrm{m}^{3}\left(42 \mathrm{lb} / \mathrm{ft}^{3}\right)$, which limits the capacity of standard truck equipment to $13.5-15.5$ tonnes per load(15-17 tons per load). Therefore, the average cost 
for truck transport will be $\$ 0.18 / \mathrm{tn} / \mathrm{mile}(\$ 0.17 / \mathrm{ton} / \mathrm{mile})$. A $32 \mathrm{~km}(20-\mathrm{mile})$ haul by truck will add $\$ 3.90 /$ tonne $(\$ 3.55 /$ ton) to the cost of recovered logging wood waste.

The distance to a metropolitan area will typically exceed several hundred miles. In this case, truck haul distances must be limited to a transfer point with a less expensive form of transportation from that location, such as barge or rail. For this analysis, a hypothetical distance of 400 kilometers (250 miles) is used to compare the costs of rail and barge transportation. Again, a premium will be paid for volume, because of the low bulk density of the material.

Rail rates are a mystery, even to experts. In addition to weight and distance, many site specific factors enter into a negotiated rate, such as routing due to track ownership, rail equipment costs, loading and unloading logistics, and more. For the purpose of this analysis we are using an overly optimistic rate of $\$ 0.06 /$ tonne $/ \mathrm{mile}(\$ 0.05 / \mathrm{ton} / \mathrm{mile}$ ) based on our study of coal transport. The $400 \mathrm{~km}$ (250-mile) rail haul will add at least another $\$ 13.75 /$ tonne (\$12.50/ton) to the cost of the recovered logging waste wood.

The availability of barge transport is limited; however, it is an option in certain areas and is included in this analysis. It is a real possibility in Michigan. Again, borrowing from our study of coal transport, a representative rate of $\$ 0.02 /$ tonne $/ \mathrm{mile}(\$ 0.01 /$ ton $/ \mathrm{mile})$ is used. A $400 \mathrm{~km}$ haul by barge will add $\$ 2.75 /$ tonne $(\$ 2.50 /$ ton) to the cost of recovered logging waste wood. The costs for activities associated with recovering logging waste wood are summarized below in Table 7.

Table 7 -- Costs Associated with Recovering Logging Waste Wood

\begin{tabular}{|l|c|c|}
\hline Activity & $\begin{array}{c}\text { Rail Case } \\
\text { \$/ton (tn) }\end{array}$ & $\begin{array}{c}\text { Barge Case } \\
\text { \$/ton (tn) }\end{array}$ \\
\hline Collection & $4.74(5.21)$ & $4.74(5.21)$ \\
\hline Skid & $13.06(14.37)$ & $13.06(14.37)$ \\
\hline Chipping & $5.67(6.24)$ & $5.67(6.24)$ \\
\hline Overhead & $8.06(8.90)$ & $8.06(8.90)$ \\
\hline Intermediate Truck Transfer & $3.55(3.91)$ & $3.55(3.91)$ \\
\hline Long Distance Transport: Rail & $12.50(13.75)$ & - \\
\hline Long Distance Transport: Barge & - & 2.50 \\
\hline TOTALS & $47.58(52.34)$ & $37.58(41.34)$ \\
\hline
\end{tabular}

This is an extremely optimistic bare bones analysis, and excludes many more detailed expenses. Terminal charges, temporary storage, loading and unloading costs, and transport to the final destination site, are just a few of the items that will significantly add to the costs itemized in the Table 7. Even ignoring these factors, it can be seen from Table 7 that "cheap" forest wastes become very expensive, when delivered in the proper form to an AFP plant. Given an energy content of approximately $11,606 \mathrm{~kJ} / \mathrm{kg}(5,000 \mathrm{Btu} / \mathrm{lbm})$ delivered, the cost per Btu would be \$4.53/ MM kJ (\$4.76/ MM Btu) and \$3.60/ MM kJ (\$3.78/ MM Btu), for the cases presented in Table 7 . These energy costs greatly exceed that of delivered coal in the Detroit area, which is $\$ 1.07 / \mathrm{MM} \mathrm{kJ}(\$ 1.13 / \mathrm{MM} \mathrm{Btu})$ for a mixture of eastern and western coals. Therefore, forest wastes do not look promising, even if the raw material cost is zero. This may also be the conclusion for remote agricultural wastes as well. Preparation and transport costs for these materials are so high that the economics will only make sense if a large disposal fee of $\$ 39.6 /$ tonne (\$36/ton) to $\$ 28.6$ (\$26/ton), depending on rail or barge transport, respectively, was 
received for hauling away the waste. Without this fee, these materials are not a viable biomass source for the AFP process applied in Detroit.

It is clear from the above that preparation and transport costs can increase delivered biomass costs to the point where they are not competitive with coal. A better approach is to identify by-product wastes, where costs for the preparation and transport to the vicinity of the AFP plant are borne by the primary product. Given this approach, the focus of biomass supply options was shifted to waste materials available in the vicinity of Detroit, including wood processing wastes, low-grade recycled paper waste and light fractions of municipal solid wastes. These materials are also listed in Table 5. As shown in the table, these biomass materials typically have higher energy contents then energy crops, manures and biosolids, due to their lower moisture content. Also, wood and paper wastes have a lower decay potential. This is beneficial. Importantly, in contrast to crop wastes, these biomass materials are non-seasonal. This simplifies operations and makes production more consistent.

While transport costs are limited with these waste materials, availability of large quantities of these materials, at an acceptable cost is sometimes a challenge. For example, it was found that low-grade paper waste, which initially looked promising, is in demand as a recycled paper pulp feedstock in the Detroit area, at $\$ 38.5 /$ tonne $(\$ 35 /$ ton $)$, or more. It is, therefore, too costly as a fuel feedstock.

Wood wastes are a clean, high fuel value material that are expected to mix well with biosolids to form quality fuel pellets. However, given their good characteristics, demand for these materials is high, limiting availability, and costs can also be substantial. Nevertheless, initial surveys uncovered some good wood waste opportunities in the Detroit area.

In investigating wood crate biomass sources, as well as other material sources, it was found that as the potential feedstock material becomes cleaner and has a more easily handled form, availability is reduced and costs increase. Therefore, for economically viable biomass applications, a balance must be struck between the cost of the material versus the processing required to make it a viable feedstock for the AFP. This cleanness versus cost relationship was also found for Municipal Solid Waste (MSW) light fractions. While large quantities of base MSW materials are readily available in the Detroit area at low cost, material separation processes must be applied to achieve the material configuration and quality that is needed for the AFP process. This adds costs to the process, which must be considered in evaluating MSW light fractions for use as a biomass feedstock. Furthermore, some metal components of MSW, when burned, could contribute to emissions. If concentrations of these emissions are sufficiently small, and the fuel is co-fired with coal at a small fraction (e.g. less than 10\%), then emissions will be acceptable. However, if fractions are burned where emissions are excessive, then additional boiler air pollution control equipment might be required. This would be very expensive, and make the combustion of this special fuel too costly. Therefore, besides evaluating energy content and the transport, handling and storage characteristics of the fuel, potential emissions characteristics must also be considered. This is highlighted below.

\subsection{BIOMASS WASTE ENVIRONMENTAL/EMISSIONS ISSUES}

AFP fuels consist of mixtures of biosolids and MSW light fractions or wood waste, both with and without some coal fines. Each of these materials has a unique emissions potential. To assess the impact of burning AFP in Detroit Edison powerplants, the potential AFP emissions must be compared to those from the currently used coal fuel. It should be noted that, in most cases, emissions will depend on the combustion and pollution control equipment. Furthermore, mixes of materials have different emissions characteristics than when components are burned 
individually. This is particularly the case for NOx emission. However, given that the AFP will be co-fired with baseline coal at fractions potentially under $10 \%$, power plant emissions may be driven by coal properties, rather than biomass properties. This will particularly be the case for NOx and SOx emissions. Lastly, although emission impacts can be estimated, only tests with the actual mixtures can truly define AFP emissions.

Biomass combustion can impact boiler NOx, SOx, and particulate emissions, depending on the type and quantity of biomass and the type of combustion equipment. Biomass will typically have higher nitrogen content and lower sulfur content than coal. Sulfur oxide emissions are relatively independent of the combustion equipment. Therefore, the impact of biomass sulfur on sulfur dioxide emissions can be simply projected from the biomass sulfur content, assuming $100 \%$ conversion to sulfur dioxide. For NOx emissions, fuel bound nitrogen conversions will be less than $100 \%$, and a complex function of fuel, burner and boiler factors. However, a 100\% conversion will indicate the relative NOx emissions potential of different fuels in the same combustion equipment. As in NOx emissions, particulate emissions will be a complex function of the fuel, burner and boiler factors. A $100 \%$ conversion rate will help indicate the relative potential of the various fuel components, with tests required to give absolute potentials.

Table 8 presents sulfur, and nitrogen projected emission factors for the four AFP fuel components, based on pollutant content, and the fuel component dry energy content. The sulfur and nitrogen emission factors assume 100 percent conversion to the oxide form.

As noted above, using this $\mathrm{SO}_{2}$ emissions assumption should be reasonable. Coal parameters were provided by DTE for their River Rouge powerplant. Biosolids data was provided by the Detroit Department of Water and Sewerage. For MSW light fractions, an estimate of pollutants was made based on information provided by the Michigan Department of Environmental Quality, Waste Management Division.

Referring to Table 8, it can be seen that the sulfur/MM Btu content of the biomass materials is much less than that for coal and biosolids. As shown, the wood and MSW SOx emissions would be superior to coal, and much better than biosolids. Biosolids have over twice the sulfur output per Btu as coal. Given the need to reduce sulfur dioxide emissions from coal firing under the recent CAAA, the high sulfur/MM Btu of biosolids could be a problem. However, mixing the low sulfur content biomass (e.g. wood waste) and biosolids together, in the right propositions, could yield an overall lower sulfur emissions from coal. Using component sulfur emissions factors in Table 8, an energy ratio of wood waste to biosolids plus wood waste of .65 or greater, would give sulfur emissions equal to or less than that of coal. With MSW light fractions, an energy ratio of MSW light fractions to biosolids plus MSW of .59 or greater, would give sulfur emissions equal to or less that that of coal. Since biomass fractions of this order match the AFP pellet formula, the sulfur emissions should be acceptable. 
Table 8 -- Projected Emission Factors and Other Properties of Selected AFP Raw Material Components

\begin{tabular}{|l|c|c|c|c|}
\hline & Coal & MSW (It frac) & Wood & Biosolids \\
\hline Energy Density, dry Btu/lbm & 10540 & 7975 & 9030 & 7167 \\
& 24464 & 18510 & 20959 & 16635 \\
\hline Cost/MM Bt/kg & $\$ 1.08$ & $\$ 3.26$ & $\$ 3.01$ & $-\$ 9.17$ \\
$\mathrm{Cost} / \mathrm{MM} \mathrm{kJ}$ & $\$ 1.03$ & $\$ 3.10$ & $\$ 2.87$ & $-\$ 8.73$ \\
\hline $\mathrm{lbm} \mathrm{SO} / \mathrm{MMBtu}$ & 0.79 & 0.05 & 0.22 & 1.86 \\
$\mathrm{lbm} \mathrm{SO} / \mathrm{MM} \mathrm{kJ}$ & 0.75 & 0.04 & 0.21 & 1.77 \\
\hline $\mathrm{lbm} \mathrm{NO} / \mathrm{MM} \mathrm{Btu}$ & 2.62 & 0.22 & 0.19 & 8.94 \\
$\mathrm{lbm} \mathrm{NOx/MM} \mathrm{kJ}$ & 2.50 & 0.21 & 0.18 & 8.51 \\
\hline
\end{tabular}

Fuel nitrogen conversion to NOx occurs by a complex process of nitrogenous species reactions that varies greatly with the type of combustion equipment and how it is operated. As indicated in Table 8. Biosolids nitrogen content per Btu exceeds that of coal. However, prior Altex tests have shown that fixed bed or stoker type combustion systems fired on biosolids produce NOx emissions 30\% lower than coal combustion NOx emissions in the same bed. This is a substantial reduction, particularly given the higher nitrogen content of the biosolids. Given the lower energy content of biosolids and expected lower combustion temperature, this result might be expected. Also, in a bed, the material burns such that the boundary layer surrounding the large pellets are deficient in oxygen, versus the oxygen content in the combustion air. This helps lower the conversion of fuel bound nitrogen to NOx. However, these beneficial characteristics of fixed bed burning may not apply when the AFP is pulverized and co-fired with coal in a suspension of air. In this case, temperatures will be driven by coal combustion and oxygen levels will be high and readily available to the fine AFP material. This condition will tend to drive higher NOx emissions production from biomass materials. However, a mitigating factor will be that the biomass fraction is limited to 10 percent in the cofiring case. Also, while biomass nitrogen tends to drive up NOx when oxygen is readily available, the more volatile nature of the biomass also tends to respond better to burner modifications for NOx control. In fact, biomass, because of its high volatile fraction, is being considered as a special boiler injectant for NOx control purposes. However, to maximize the NOx control benefit of biomass, a specially designed burner/injector is needed. This requires separate fuel prep and injector equipment that will require equipment investments to obtain the optimal NOx control effect. Without special equipment, NOx may modestly increase with $10 \%$ co-fire. Given the sensitivity of NOx to combustion conditions, the specific NOx increases or decreases need to be defined by tests. Nevertheless, the NOx factors listed in Table 8 can be used to calculate the required biomass fraction with the same NOx emission potential as coal. It is found that for both wood and MSW light fractions, a biomass to biosolids plus biomass fraction of .72 or greater is required to produce NOx emissions equal to or less than that of coal. This is consistent with the biomass fractions in AFP pellets.

The above analysis examined the case where SOx and NOx emissions are held constant while converting from coal to biomass plus biosolids. This is a more restrictive limit than that required for fuel changes in Michigan. The Michigan Department of Environmental Quality requires that any fuel change that would produce a significant increase in emissions would require a new permit application. To avoid the need to re-permit, only a $10 \%$ increase in 
emissions is allowed. The exact fraction of biomass and biosolids firing to meet the $10 \%$ limit would need to be determined by testing. However, some simple estimates of co-firing limits can be determined from the data in Table 8. As mentioned, the values in this table are worst case scenarios for NOx emissions. Recognizing the uncertainties in the Table 8 projections, the biomass fractions and co-fire requirements needed to control powerplant NOx emissions increases to $10 \%$ were determined. Table 9 presents the results of the analysis. As shown, for biomass fractions of 0.5 , a co-fire rate of $13 \%$ could be used without exceeding a $10 \%$ increase in NOx emissions. As the biomass fraction increases, the amount of possible co-fire increases until, at a biomass fraction of $0.7,100 \%$ AFP pellets could be fired in the system. Since fractions of biomass to biosolids plus biomass of 0.75 , are consistent with AFP formulations, these projection indicates that substantial levels of AFP fuel co-fire are possible, without significantly impacting NOx emissions. Also, these levels of co-firing will result in small impacts on SOx emissions

Table 9 -- Allowable Co-fire to Limit NOx Emissions Increase to 10 Percent

\begin{tabular}{|c|c|}
\hline AFP Biomass Fraction & Co-fire (\%) \\
\hline 0.50 & 13 \\
0.53 & 16 \\
0.57 & 19 \\
0.60 & 25 \\
0.63 & 30 \\
0.67 & 55 \\
0.70 & 100 \\
\hline
\end{tabular}

It can then be concluded that, at the right cofiring rate, the environmental impacts of AFP cofiring should be reasonable and within a range that will prevent the triggering of new operating permits. Therefore, AFP cofiring in Detroit should be environmentally acceptable on a powerplant source basis. Specific benefits would require combustion testing and more detailed analysis and assessment. Given these results, it can be concluded that biosolids, sawdust and MSW light fractions are viable biomass feedstocks for the AFP process.

\subsection{BIOMASS WASTE LOGISTICS/ECONOMIC ISSUES}

As noted earlier, the raw cost of AFP component materials is only the first cost. To this cost must be added preparation and transport costs that are incurred prior to introducing the materials into the AFP pelletization process. While the base cost could be low, or even negative, the preparation and transport charges can substantially increase AFP fuel component costs. These costs are highlighted below.

The second row in Table 8 shows the calculated "delivered" cost of the four AFP fuel components. To keep these costs more directly comparable, the values shown reflect the cost of delivering the material to the plant, in a form compatible with the pelletization process. As shown, biosolids have the highest negative cost, and coal the lowest positive cost. Both biomass materials are almost three times the cost of the coal on an energy basis, which highlights the basic dilemma for biomass fuels. Currently, biomass fuels cannot compete with coal delivered on a $\$ / M M ~ k J$ or $\$ / M M B t u$ basis. Even though the emission benefits can be substantial, especially fossil $\mathrm{CO}_{2}$ and $\mathrm{SOx}$, until there are substantial economic incentives in place, straight biomass fuels are generally too expensive. 
The benefit of the AFP process is that it incorporates negative cost biosolids with high cost biomass to create a fuel that has attractive characteristics as well as a cost that is competitive with that of coal. Therefore, the AFP represents an entry point for implementing biomass based fuels, prior to the time frame when economic incentives or fuels economics make biomass economically viable.

In Table 8, the wood fuel costs are for the delivery of a hogged wood fuel, from a paper mill located approximately $97 \mathrm{~km}(60 \mathrm{mi})$ from Detroit. This wood material contains about 40 percent moisture. Because it is initially large in size, it will require expensive grinding prior to use in AFP. This yields the high cost of wood waste, as noted in Table 8. As one alternative to the expensive wood waste size reduction step, sources of fine wood sawdust were also investigated. Large producers of adequate supplies of were not identified in the Detroit/Wayne County area. However, outside the Detroit area, a source of sawdust from a pressed wood operation was identified by the Michigan Department of Natural Resources. The company, Panel Processing, produces waste sawdust at two plants in the state. Although they only produce approximately 73 tonnes per week ( 80 tons per week) of the material, there are similar operations within the state. In aggregate, these operations may have the potential to supply a significant amount of this type of material. One company, for example, named Herman Miller, in Grand Rapids, produces 18 tonnes/day (20 tons/day) of sanding dust, which is currently burned in a Consumers Energy (a Michigan utility) power plant. Panel Processing presently gives their entire waste stream to local farmers, who use the material for animal bedding. Due to the fine size, this type of material is difficult to handle for most power plants, and unusable in stoker fired plants. Consumers energy said that they burn this material as a "community service", rather than for economic benefit. In the AFP process, however, this material is ideal for processing into a fuel pellet. The fine size makes it compatible with both the pelletizing and pulverizing equipment. This means that the cost of processing of the scrap wood, which can range to $\$ 11-\$ 13 /$ tonne $\$ 10-12 /$ ton for minus-5-cm material, to possibly twice as much for generating fine-sized material, is eliminated. Since there were no Detroit operations producing fine-sized wood wastes, greater transport costs had to be factored into the material delivered cost. These costs offset the reduction in processing costs to some extent. In the case of the Grand Rapids sawdust source, the cost of transporting the material $201 \mathrm{~km}(125 \mathrm{mi})$ to Detroit would offset the benefit of eliminating size reduction and using the lower moisture content sawdust (5\% moisture for the sawdust versus $40 \%$ for the wood waste). These results illustrate how preparation and logistics costs must be carefully considered, in selecting a biomass source.

For the AFP project, sawdust was chosen as the biomass material to test at small scale, and Panel Processing sent a sample of their waste wood to Altex for evaluation.

A similar sawdust material, acquired from sources local to Altex was used in the small scale processing tests to simulate the sawdust component to be used in a full-scale operation in Detroit. Also, a simulated MSW light fraction, composed of a mix of cardboard, newsprint, and film plastic, etc., was acquired to produce pellets. The composition of the MSW light fraction used in formulating AFP test mixtures, was extracted from national averages, as reported by the U.S. Environmental Protection Agency.

In summary, based on biomass feedstock supply screening criteria it was concluded that:

- Agricultural energy crops and residues and animal wastes have either quality or delivered cost problems. 
- Low-grade paper wastes are a good feedstock material, but could have availability and/or cost problems.

- Light municipal waste fractions (e.g. cardboard, paper materials and some plastics) are available in necessary quantities and at a reasonable cost to be a viable biomass source, with the provision that contaminants are limited and environmentally acceptable during combustion.

- Wastes from wood processing are attractive as a biomass source, especially sawdust, providing that sufficient quantities are found for a Detroit based operation.

\subsection{FULL-SCALE AFP PROCESS DESIGN}

Based on the biomass definition work highlighted above, it was concluded that high potential biomass wastes are characterized by low moisture, high density, low decay potential and high energy content, relative to typical biomasses. Also, in the case of wood waste, the material needs to be ground prior to incorporation in the mix. Given Altex's substantial experience in the preparation of fuel pellets from biosolids and coal fines, and from paper plant sludge, shredded paper, and plastic residues, it was concluded that the basic AFP design highlighted in Section 1 could be utilized for the planned mixtures without major modification. However, some component details have changed relative to the previous design. For example, recognizing that light fractions of municipal solid wastes would be utilized, a size reduction shredder was incorporated into the AFP system design, to ensure that the material was suitably sized for the pellet extrusion step. Also, a novel secondary dewatering press was conceived, that fully addresses the challenges of biosolids dewatering, in a reliable, low-maintenance and lowcost package. These changes to the full-scale design are discussed below.

\subsection{Biomass PREPARATION EQUiPMENT}

As noted above, light fractions of municipal solid waste were used as the biomass feedstock for some AFP formulations. In contrast to coal fines, this material has a broad range of sizes and a very large top size. If the optimal pellet size is in the range of $2.5 \mathrm{~cm}(1 \mathrm{inch})$, then the material must be reduced to a size that can be easily mixed with biosolids and then extruded into a pellet. While the cardboard and paper components of the material are flexible, and will form into pellets, the top size of this material cannot be larger than the pellet. Therefore, a machine that efficiently reduces the top size to about $2.5-\mathrm{cm}$ (1-inch) would be appropriate.

The machine selected to reduce the size of municipal solid waste was a hammermill-type shredder. A hammermill is a high-speed impact pulverizer, with several rows of hammer-like "beaters" revolving on a shaft within a chamber lined with wear resistant grinding plates. A cylindrical screen or grating encloses these mill components. The size of the product material is affected by rotor speed, feed rate, clearance between the hammers and the plates, and the size of the grate openings, through which the sized product is transported. Success with sizing similar materials made this type of equipment a good selection for use in the AFP process.

This type of sizing equipment has been used in many refuse derived fuel (RDF) or waste to energy (including wood) projects in Alaska, California, Idaho, and Wisconsin. Several manufacturers, or distributors, of this equipment were contacted to get detailed information, including Gruendler, Tollemache, and Arasmith. Based on an evaluation of the equipment, product literature, and user contacts, the Arasmith "Salvager" model was chosen as the most appropriate machine for the AFP process. It can handle both wood and paper materials, either separately or together. The Gruendler equipment is less expensive, but is limited to a nominal 
minimum product size of minus $5 \mathrm{~cm}$ (2-inch). The Tollemache machine can produce minus1.9-cm (.75-inch) material, but is significantly more expensive, and requires two to three times the horsepower of the Arasmith equipment. The Arasmith equipment produces a minus $-2.5 \mathrm{~cm}$ (1-inch) material, at reasonable cost and power requirement.

The minus-2.5-cm (1-inch) particle size was preliminarily chosen as an appropriate dimension, both from a standpoint of pellet extrusion requirements, and for feed size to the boiler's coal pulverizers. Coal pulverizer types vary, from high-speed hammermills, to mediumspeed ball-and-race types, to slow speed tube-and mill machines. A coal pulverizer manufacturer indicated that a minus-5-cm (2-inch) paper or wood based material should not be a problem in their equipment, and they have operated with a nominal five $\mathrm{cm}$ (2-inch) tree wood waste material, co-fired in a utility boiler in the Carolinas. This is good support for processing the material to a $2.5 \mathrm{~cm}$ ( 1-inch) top size.

It should be noted that, in general, within a range of particle sizes, size reduction costs vary with the inverse fourth power of particle size. This considers power needs, maintenance and equipment wear costs. Therefore, material that is already finely sized, such as sawdust, is an ideal material. However, first cost and availability of the material also needs to be considered. These costs can offset the advantage of not having to reduce the size of the biomass. Therefore, size reduction of the MSW light fractions is acceptable, given their availability and low cost.

\subsection{BIOSOLIDS DEWATERING EQUIPMENT}

Based on the high potential biomass sources identified above, biomass moisture is limited, relative to the moisture in biosolids. Therefore, the dewatering effort focused on biosolids, which have an initial moisture content of approximately 75 percent.

Water in municipal biosolids occurs in four major phases: free water, capillary water, colloidal water, and intracellular water. Free water can be separated by pressure with filtration. Capillary and colloidal water, which reside between solids and on surfaces, can generally be separated by mechanical means, with a polymer addition to chemically condition the sludge. Intracellular water exists within the cell walls of microorganisms in the sludge. This intracellular water accounts for 40 percent of the total moisture in sludge, and can only be separated by thermal processing. However, with the correct conditioning, temperature, pressure and time, successful separation of water from sludge, to a solids level as high as 45 percent can be achieved.

Primary dewatering of sludge, to cake solids levels of 20-25 percent, is routinely performed at wastewater treatment plants across the country, using belt filter presses that apply pressure up to $69 \mathrm{kN} / \mathrm{m}^{2}$ (10 psi). The overall efficiency of the belt filter press represents a compromise between dewatering capability, throughput, simplicity, and cost.

Another device used for primary biosolids dewatering is the centrifuge. It delivers only slightly higher performance, but at an increase in all associated costs. Therefore, the belt press is favored for primary dewatering.

To achieve higher dewatering performance than is achievable with a belt filter press requires equipment that becomes increasingly expensive and complex. The hydraulic filter press (also known as a membrane filter, diaphragm filter, or recess filter) is the most widely used example of this type of equipment. Hydraulic filter presses dewater biosolids by capturing sludge in an enclosed permeable cavity, then applying a high amount of pressure over an extended period of time. Cake solids levels up to 45 percent are produced. However this type of press only operates in a batch mode, and cycle times can exceed one hour. The inherently low- 
throughput capacity of the hydraulic filter press makes an industrial-scale unit a very large and expensive piece of equipment.

All of the dewatering machines described above are primary dewatering devices, which take in a low solids content slurry (e.g. 10\% solids) and then produce a higher solids cake. The concept of secondary dewatering is a strategy that combines the high overall efficiency of a primary dewatering device, like the belt filter press, with an equally efficient specialized secondary piece of equipment.

All primary sludge dewatering machinery described above is designed to accept a slurry feed, typically of less than 10 percent solids. Initial pressure on this slurry must be very slowly and gradually applied to prevent the material from migrating out from under the belt. As a consequence, a single mechanical press, designed to accept a slurry feed, is not optimal for the application of pressure levels required to produce a high solids filter cake. This is because the pressure applied by the machine needs to vary greatly over the length of the machine. A simple, compact, continuously operating secondary device, purposely built to accept a feed of dewatered filter cake (20-25 percent solids) from a conventional belt press, can apply the necessary higher levels of pressure. Another advantage of this separate secondary dewatering approach is that the existing belt press systems can be left in place, and the smaller secondary dewatering machine then added to the system. This would utilize the existing equipment at current facilities, thereby reducing costs.

\subsubsection{Small Scale DeWatering TeStS}

Removal of free and capillary water from sludge cake is facilitated by pressure and heat. Application of pressure pushes the solids closer together, reducing the available room for water, which then migrates out of the material. Surface tension forces and viscosity slow down water migration, reducing dewatering effectiveness for a given press time. Increasing the cake temperature reduces water surface tension force and viscosity, thereby speeding the dewatering process and maximizing water removal for a given press time. Also in this study, the use of biomass as a pressing aid was explored in small-scale tests. In addition, the effects of pressure and temperature on dewatering effectiveness were also quantified. Test results are described below.

To evaluate the potential of a secondary dewatering press, ahead of building or acquiring such a device for pilot-scale tests, small-scale laboratory tests were performed. To simulate a secondary dewater press, a simple piston press was used to apply pressure to dewatered sludge cake samples. The piston was a $10 \mathrm{~cm}$ (4 inch) on a side square that fit closely inside a cylinder. The cylinder was closed at one end by a fine screen that served as the water filter. Biosolids cake was loaded into the cylinder, and pressure was then applied by the piston.

The 12-mesh, stainless steel screen allowed water to drop out of the sludge, while retaining the sludge inside the cylinder. All tests were conducted on pre-weighed sludge samples of 170 grams to insure uniformity in cake thickness, operation of the press, and consistency between tests. For dewatering tests at elevated temperature, samples were heated in a microwave oven. To control evaporative loss from the sludge, the material was heated in plastic bags. Tests were timed, and water drop out rates, as well as total water removal, were recorded. Tested samples were also characterized for release from the screen and for filtrate clarity. Lastly, biomass was added to the sludge to evaluate its ability to improve dewatering.

Biosolids for the test were collected directly from a belt filter press at the City of Palo Alto Wastewater Treatment Plant. Palo Alto adds a polymer flocculent to condition the sludge 
before mechanical dewatering, and produces a filter cake with 27 percent solids. This is similar to the cake moisture at typical treatment plants.

The first test series evaluated water dropout from the biosolids as received, at ambient temperature under constant applied pressures of $365 \mathrm{kN} / \mathrm{m}^{2}$ (53 psi) and $483 \mathrm{kN} / \mathrm{m}^{2}$ (70 psi). This pressure level is more than five times the conventional belt press level. Water drop out was measured at 5 second intervals to determine the drop out rate. When water drop out rates fell below 1 gram, within a 5 second interval, a test was terminated. Test results are shown below in Table 10.

Table 10 -- Sludge Cake Dewatering Water Dropout Rates @ $78{ }^{\circ}$ F

\begin{tabular}{|c|c|c|}
\hline Press Time in Seconds & $\begin{array}{c}\text { Water Drop Out @ } \\
\text { (53psi) } \mathbf{3 6 5} \mathbf{k N} / \mathbf{m}^{\mathbf{2}}\end{array}$ & $\begin{array}{c}\text { Water Drop Out @ } \\
\left(\mathbf{7 0 p s i )} \mathbf{4 8 3 k} \mathbf{N} / \mathbf{m}^{\mathbf{2}}\right.\end{array}$ \\
\hline 5 & $19 \mathrm{~g}$ & $20 \mathrm{~g}$ \\
\hline 10 & $7 \mathrm{~g}$ & $10 \mathrm{~g}$ \\
\hline 15 & $2 \mathrm{~g}$ & $4 \mathrm{~g}$ \\
\hline 20 & $1 \mathrm{~g}$ & $1 \mathrm{~g}$ \\
\hline 25 & $1 \mathrm{~g}$ & $1 \mathrm{~g}$ \\
\hline 30 & $1 \mathrm{~g}$ & $1 \mathrm{~g}$ \\
\hline 35 & $1 \mathrm{~g}$ & $1 \mathrm{~g}$ \\
\hline 40 & $\mathrm{X}$ & $\mathbf{3 9 g}$ \\
\hline & $\mathbf{3 2 g}$ & Total \\
\hline Start Solids 27\% & Total & New Solids 35.1\% \\
\hline
\end{tabular}

In this first set of tests, the initial cake solids content of 27 percent was increased to 33 percent and 35 percent, at the two levels of applied pressure, respectively. This is a substantial increase in solids content and represents water reductions of $25 \%$ and $32 \%$, respectively. In both cases, release of the cake from the screen was good, and the filtrate was clear. These results show that secondary dewatering at increased pressure can remove a significant amount of water as a liquid, thereby directly decreasing the size and cost of a fuel pellet dryer. And, dryer fuel cost can be substantial (e.g. $\$ 11 /$ tonne $<\$ 10 /$ ton $>$ for dryer fuel for a $38 \%$ moisture content green pellet).

The next series of tests evaluated the impact of cake temperature on water drop out from sludge under pressure. Increasing temperature reduces water viscosity and surface tension, which makes it easier for water to migrate out of the material when it is pressed. To quantify the benefits of this technique, uniform samples were heated in a microwave oven to target temperatures of $65^{\circ} \mathrm{C}\left(150^{\circ} \mathrm{F}\right), 82^{\circ} \mathrm{C}\left(180^{\circ} \mathrm{F}\right)$, and $99^{\circ} \mathrm{C}\left(210^{\circ} \mathrm{F}\right)$.

Of course, the objective was to remove water as a liquid, rather than as a vapor. Therefore, heating under atmospheric pressure was limited to $99^{\circ} \mathrm{C}\left(210^{\circ} \mathrm{F}\right)$, to control evaporative loss. Also, samples were placed in plastic bags, before heating, to minimize vapor loss. In two series of pressings, one at a constant application of $365 \mathrm{kN} / \mathrm{m}^{2}$ (53 psi), and one at $483 \mathrm{kN} / \mathrm{m}^{2}$ (70 psi), total water drop out and drop out rate over time were measured. Again, sample solids content was 27 percent at the beginning of each test. The results of the tests are shown in Tables 11 and 12, and graphically illustrated in Figures 10 and 11. 
Table 11 -- Effect of Temperature on Water Drop Rates @ 365 kN/m² (53 psi)

\begin{tabular}{|c|c|c|c|}
\hline $\begin{array}{c}\text { Press Time } \\
\text { In Seconds }\end{array}$ & $\begin{array}{c}\text { Water Drop Out } \\
@ \mathbf{6 5}^{\mathbf{0}} \mathbf{C}\left(\mathbf{1 5 0}^{\mathbf{O}} \mathbf{F}\right)\end{array}$ & $\begin{array}{c}\text { Water Drop Out } \\
@ \mathbf{8 2}^{\mathbf{0}} \mathbf{C}\left(\mathbf{1 8 0}^{\mathbf{O}} \mathbf{F}\right)\end{array}$ & $\begin{array}{c}\text { Water Drop Out } \\
@ \mathbf{9 9} \mathbf{C}(\mathbf{2 1 0} \mathbf{~})\end{array}$ \\
\hline 5 & $22 \mathrm{~g}$ & $22 \mathrm{~g}$ & $22 \mathrm{~g}$ \\
\hline 10 & $8 \mathrm{~g}$ & $8 \mathrm{~g}$ & $10 \mathrm{~g}$ \\
\hline 15 & $2 \mathrm{~g}$ & $2 \mathrm{~g}$ & $1 \mathrm{~g}$ \\
\hline 20 & $1 \mathrm{~g}$ & $1 \mathrm{~g}$ & $2 \mathrm{~g}$ \\
\hline 25 & $1 \mathrm{~g}$ & $1 \mathrm{~g}$ & $2 \mathrm{~g}$ \\
\hline 30 & $1 \mathrm{~g}$ & $1 \mathrm{~g}$ & $1 \mathrm{~g}$ \\
\hline 35 & $1 \mathrm{~g}$ & $1 \mathrm{~g}$ & $1 \mathrm{~g}$ \\
\hline 40 & $\mathrm{X}$ & $\mathrm{X}$ & $1 \mathrm{~g}$ \\
\hline 45 & $\mathrm{X}$ & $\mathrm{X}$ & $1 \mathrm{~g}$ \\
\hline 50 & $\mathrm{X}$ & $\mathrm{X}$ & $42 \mathrm{~g}$ \\
\hline Totals & $36 \mathrm{~g}$ & $36 \mathrm{~g}$ & $\mathbf{3 6 \%}$ \\
\hline New Solids & $\mathbf{3 4 \%}$ & $\mathbf{3 4 \%}$ & \\
\hline
\end{tabular}

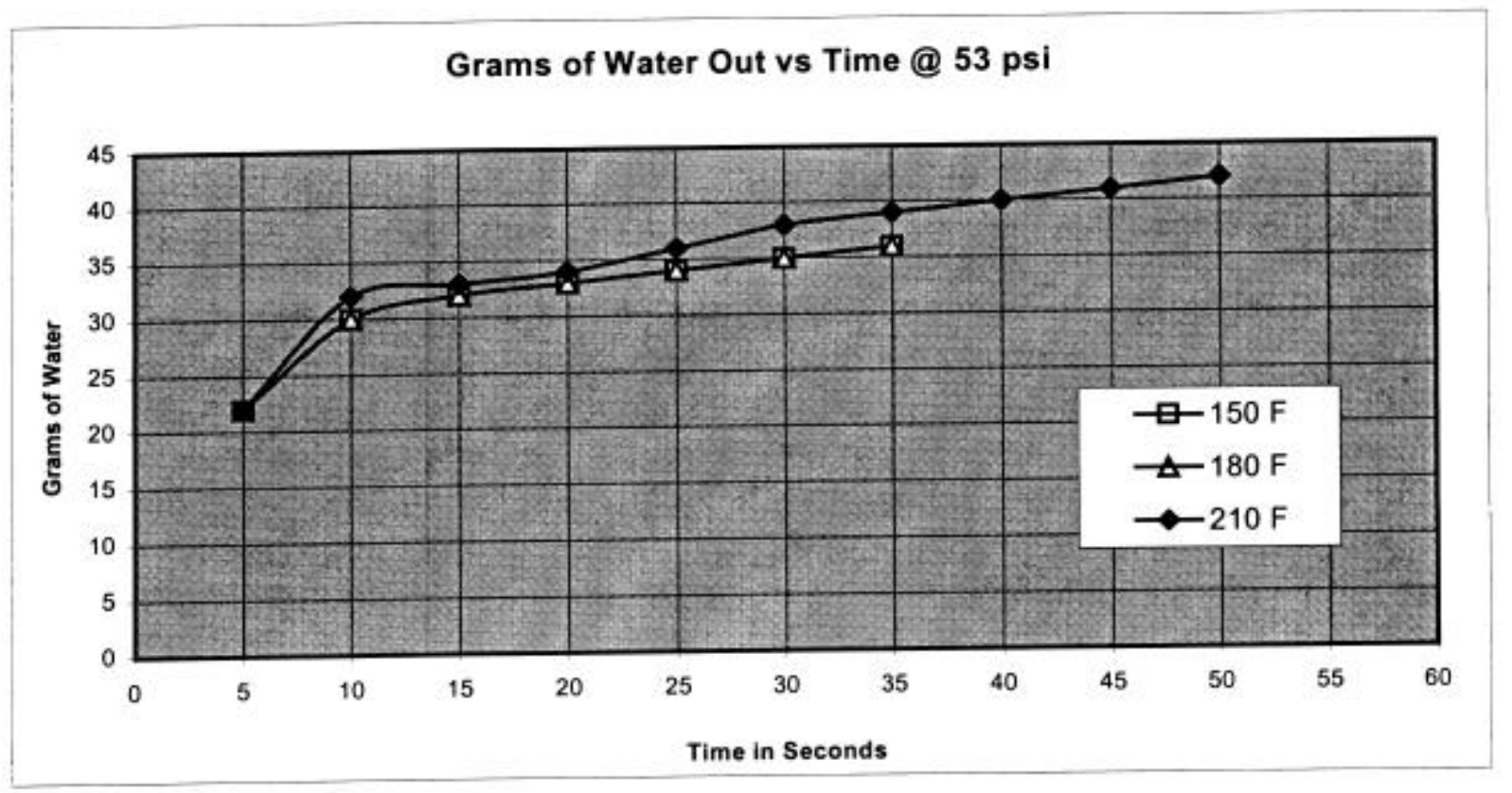

Figure 10 -- Water Drop Out Rates at Elevated Temperatures: 365 kN/m $\mathbf{m}^{2}(53 \mathrm{psi})$. 
Table 12 -- Effect of Temperature on Water Dropout Rates @ 483kN/m² (70 psi)

\begin{tabular}{|c|c|c|c|}
\hline $\begin{array}{l}\text { Press Time } \\
\text { In Seconds }\end{array}$ & $\begin{array}{c}\text { Water Drop Out } \\
@ 65^{\circ} \mathrm{C}\left(150^{\circ} \mathrm{F}\right)\end{array}$ & $\begin{array}{c}\text { Water Drop Out } \\
\text { @ } 82^{\circ} \mathrm{C}\left(180^{\circ} \mathrm{F}\right) \\
\end{array}$ & $\begin{array}{c}\text { Water Drop Out } \\
@ 99^{\circ} \mathrm{C}\left(210^{\circ} \mathrm{F}\right)\end{array}$ \\
\hline 5 & $28 \mathrm{~g}$ & $30 \mathrm{~g}$ & $32 \mathrm{~g}$ \\
\hline 10 & $8 g$ & $8 \mathrm{~g}$ & $8 g$ \\
\hline 15 & $3 g$ & $3 g$ & $4 \mathrm{~g}$ \\
\hline 20 & $1 \mathrm{~g}$ & $2 g$ & $2 g$ \\
\hline 25 & $1 \mathrm{~g}$ & $1 \mathrm{~g}$ & $1 \mathrm{~g}$ \\
\hline 30 & $1 \mathrm{~g}$ & $1 \mathrm{~g}$ & $1 \mathrm{~g}$ \\
\hline 35 & $X$ & $X$ & $1 \mathrm{~g}$ \\
\hline 45 & $\mathrm{X}$ & $\mathrm{X}$ & $X$ \\
\hline Totals & $42 \mathrm{~g}$ & $45 \mathrm{~g}$ & $49 g$ \\
\hline New Solids & $35.8 \%$ & $36.7 \%$ & $37.9 \%$ \\
\hline
\end{tabular}

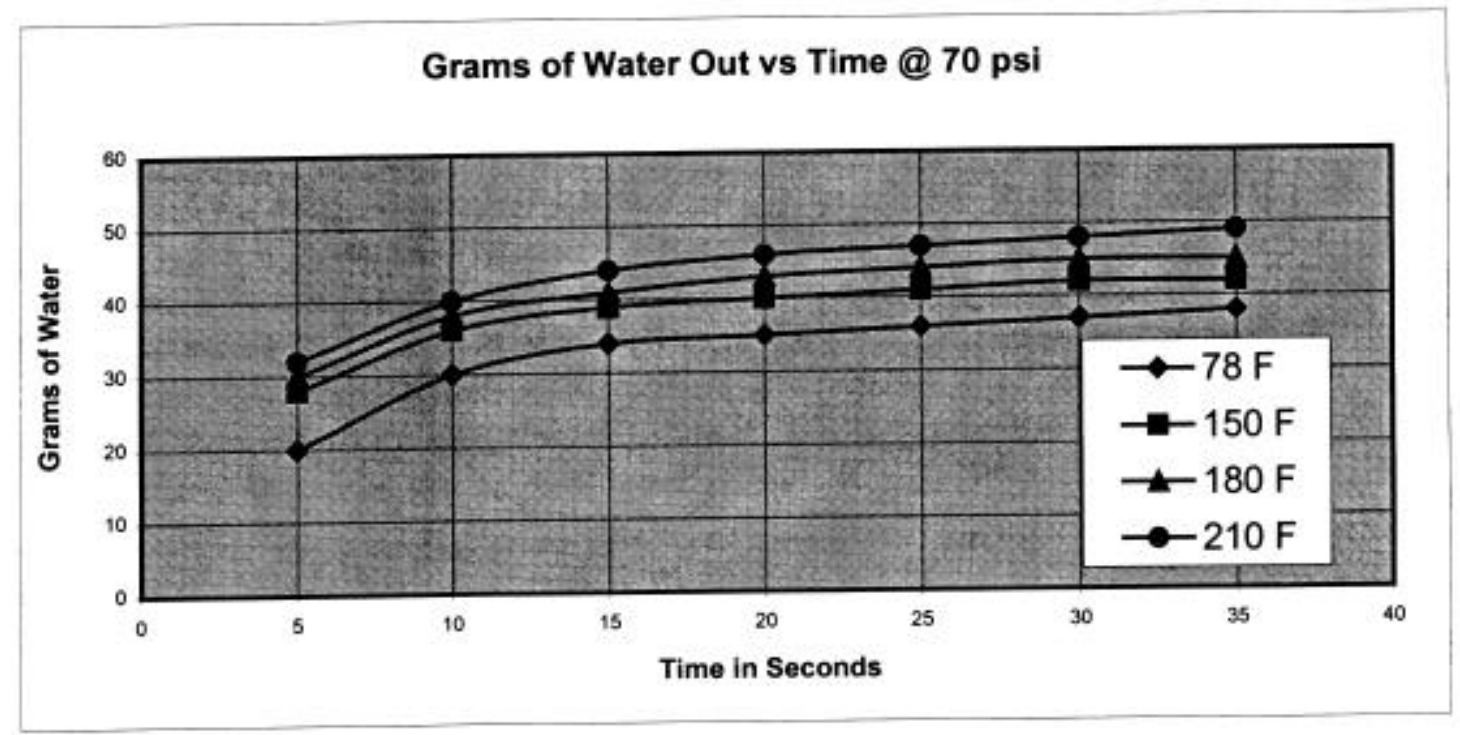

Figure 11 -- Water Drop Out Rates at Elevated Temperatures: 70psi

This second series of tests demonstrated the benefit of raising sludge temperature, to improve water drop out under pressure. Under $365 \mathrm{kN} / \mathrm{m}^{2}(53 \mathrm{psi})$, and $65^{\circ} \mathrm{C}\left(150^{\circ} \mathrm{F}\right), 82^{\circ} \mathrm{C}$ $\left(180^{\circ} \mathrm{F}\right)$, and $99^{\circ} \mathrm{C}\left(210^{\circ} \mathrm{F}\right)$, pressed cake solids were increased from 33 percent at $78 \mathrm{~F}$, to $36 \%$ at $99^{\circ} \mathrm{C}\left(210^{\circ} \mathrm{F}\right)$, or an increase of approximately 10 percent. The water content reduction increased from 19 percent to 25 percent, as temperature increased from $78^{\circ} \mathrm{F}$ to $210^{\circ} \mathrm{F}$ or a dewatering increase of dewatering of approximately 24 percent. It should be noted that the water removal was determined by measuring the weight of the liquid water expelled. For the higher temperature cases, some water was probably lost by evaporation. However, given the use of plastic bags during heating, the evaporative loss was estimated to be less than $2 \%$. Under $483 \mathrm{kN} / \mathrm{m}^{2}$ (70 psi), pressed cake solids were increased to $36 \%, 37 \%$ and $38 \%$ at $65^{\circ} \mathrm{C}\left(150^{\circ} \mathrm{F}\right)$, $82^{\circ} \mathrm{C}\left(180^{\circ} \mathrm{F}\right)$, and $99^{\circ} \mathrm{C}\left(210^{\circ} \mathrm{F}\right)$, respectively, as shown in Table 12 . This represents solids 
content increases of 1,2 and $3 \%$, relative to the room temperature press case at $483 \mathrm{kN} / \mathrm{m}^{2}(70$ psi).

At $483 \mathrm{kN} / \mathrm{m}^{2}(70 \mathrm{psi})$, water reduction increased by 32 percent and 40 percent, as temperature increased from $26^{\circ} \mathrm{C}\left(78^{\circ} \mathrm{F}\right)$ to $99^{\circ} \mathrm{C}\left(210^{\circ} \mathrm{F}\right)$. This is a substantial increase. While increasing temperature improved dewatering, raising temperature also created some less desirable consequences. Cake release from the screen became very poor, a tendency that increased with temperature and pressure. Also, filtrate clarity decreased.

An additional dewatering test series was performed to refine the definition of the operating profile for a secondary dewatering device. As noted above, typical belt presses apply increasing levels of pressure to the sludge, so that the initial press prepares the sludge to accept higher pressure. It was of interest to explore the impact of applying increasing levels of pressure over time, versus the simple constant pressure test described above. In this test series, pressure was gradually applied, and the impacts on water drop out rate, and total water drop out were measured. Each test was started at an applied pressure of $48 \mathrm{kN} / \mathrm{m}^{2}(7 \mathrm{psi})$, and every 5 seconds pressure was increased by $48 \mathrm{kN} / \mathrm{m}^{2}(7 \mathrm{psi})$ to a total of $483 \mathrm{kN} / \mathrm{m}^{2}$ (70 psi) over a 50 second period. Again, biosolids were tested at ambient and elevated temperatures, and the initial solids content was 27 percent. Results of this test series are listed below in Table 13.

Table 13 -- Sludge Cake Dewatering Gradual Pressure Application Test Results

\begin{tabular}{|c|c|c|c|c|c|}
\hline $\begin{array}{l}\text { Press Time } \\
\text { In Seconds }\end{array}$ & $\begin{array}{l}\text { Applied } \\
\text { Pressure } \\
\text { kN/m² (psi) }\end{array}$ & $\begin{array}{l}\text { Water } \\
\text { Drop } \\
\text { Out @ } \\
24^{\circ} \mathrm{C} \\
(75 \mathrm{~F})\end{array}$ & $\begin{array}{c}\text { Water Drop } \\
\text { Out } \\
@ 65^{\circ} \mathrm{C} \\
\left(150^{\circ} \mathrm{F}\right)\end{array}$ & $\begin{array}{c}\text { Water } \\
\text { Drop Out } \\
@ 82^{\circ} \mathrm{C} \\
\left(180^{\circ} \mathrm{F}\right)\end{array}$ & $\begin{array}{c}\text { Water Drop } \\
\text { Out } \\
@ 99^{\circ} \mathrm{C} \\
\left(210^{\circ} \mathrm{F}\right)\end{array}$ \\
\hline 5 & 48 (7psi) & $10 \mathrm{~g}$ & $20 \mathrm{~g}$ & $24 g$ & $22 g$ \\
\hline 10 & 96 (14psi) & $6 g$ & $10 \mathrm{~g}$ & $10 \mathrm{~g}$ & $10 \mathrm{~g}$ \\
\hline 15 & 144 (21psi) & $4 g$ & $4 \mathrm{~g}$ & $7 \mathrm{~g}$ & $4 g$ \\
\hline 20 & 193 (28psi) & $2 g$ & $2 g$ & $4 \mathrm{~g}$ & $2 g$ \\
\hline 25 & 241 (35psi) & $2 g$ & $2 g$ & $1 \mathrm{~g}$ & $2 g$ \\
\hline 30 & 289 (42psi) & $1 \mathrm{~g}$ & $1 \mathrm{~g}$ & $1 \mathrm{~g}$ & $1 \mathrm{~g}$ \\
\hline 35 & 338 (49psi) & $1 g$ & $1 g$ & $1 \mathrm{~g}$ & $1 g$ \\
\hline 40 & $386(56 \mathrm{psi})$ & $1 \mathrm{~g}$ & $1 g$ & $1 \mathrm{~g}$ & $1 g$ \\
\hline 45 & 434 (63psi) & $1 \mathrm{~g}$ & $1 \mathrm{~g}$ & $1 \mathrm{~g}$ & $1 \mathrm{~g}$ \\
\hline \multirow[t]{2}{*}{50} & 483 (70 psi) & $X$ & $X$ & $\mathrm{X}$ & $\mathrm{X}$ \\
\hline & Totals & $30 \mathrm{~g}$ & $42 \mathrm{~g}$ & $49 \mathrm{~g}$ & $44 \mathrm{~g}$ \\
\hline New & Solids & $32.7 \%$ & $35.8 \%$ & $37.9 \%$ & $36.4 \%$ \\
\hline
\end{tabular}

The gradual application of pressure produced several notable changes in the dewatering performance of the press. Although water drop out totals were nearly equal to those achieved under constantly applied pressures, the initial water drop out rate was reduced considerably, resulting in an average 10 -second increase in the amount of time necessary to achieve the same total water drop out. However, at all sludge temperatures, release of the cake from the screen and filtrate clarity were good. This was in contrast to the elevated temperature test results, in the previous test series, where pressures were constantly applied. 
The above tests focused on the removal of free and capillary water by pressure and thermal conditioning. To remove significantly more water, the intercellular water must be addressed. This requires the bursting of cell membranes that trap the water inside cells. This can be accomplished chemically, at substantially increased cost, or by heating the sludge beyond $149^{\circ} \mathrm{C}\left(300^{\circ} \mathrm{F}\right)$, under elevated pressure. By heating the sludge under elevated pressure, water is prevented from turning into steam. To burst the cells, pressure is quickly released, and a portion of intercellular water converts to steam, which expands and bursts cell walls. The released water can then be expelled by a follow up pressing. This multi-step approach should substantially increase sludge dewatering. However, the process also requires heating to a high temperature under pressure, a release of pressure to burst the cells and then a second application of increased pressure to expel the released water. This complicates the machinery substantially. The specific costs have not been identified for this approach, but an increase is expected for the more complicated machinery and special conditions. As an alternative to steam bursting, freezing the sludge, and then thawing prior to pressing, could be used to release more water from the sludge. By freezing the sludge, water is converted into ice crystals that separate from the organic solids. Ice can also degrade a cell, and even burst the membrane. Once thawed, this should release intra-cellular water, as well as the more easily expelled free and capillary water. As in the case where sludge is heated to improve dewatering, the use of freezing and thawing to improve dewatering has an additional cost. However, if dewatering is greatly increased, the energy expense and management of freezing and thawing may be acceptable.

To evaluate the impact of freezing and thawing on sludge dewatering, the baseline 27 percent solids cake samples were frozen in a standard freezer section of a refrigerator, thawed at room temperature and then pressed as in the $26^{\circ} \mathrm{C}\left(78^{\circ} \mathrm{F}\right)$ test case noted above. Pressing the material at $483 \mathrm{kN} / \mathrm{m}^{2}$ (70 psi)over a 45 -second timeframe produced $45 \mathrm{gms}$ of water. This was less water removal than $49 \mathrm{gms}$ of water in 35 -seconds at $99^{\circ} \mathrm{C}\left(210^{\circ} \mathrm{F}\right)$, and greater water removal than the $39 \mathrm{gms}$ of water in 35 -seconds at $26^{\circ} \mathrm{C}\left(78^{\circ} \mathrm{F}\right)$. This places the freeze-thaw dewatering enhancement midway between the room temperature and $99^{\circ} \mathrm{C}\left(210^{\circ} \mathrm{F}\right)$ cases, particularly when the freeze-thaw results are extrapolated back to 35-seconds of press time like the other cases. While the increased dewatering with freezing and thawing is significant, this increase does not justify the increased complexity and cost of the process. Lastly, the freezing and thawing changes the gelatinous character of the sludge which may impact its binding qualities.

The final test series focused on mixtures of sludge and biomass that were intended to improve dewatering performance. The series included the addition of selected materials to biosolids as "filter aids" to improve porosity and pressure response. The materials chosen were also candidates for inclusion in the AFP fuel pellet formulas being evaluated under this program, and so would serve a dual purpose as both a dewatering aid and ultimately a fuel source.

The materials selected for evaluation as filter aids were dry sawdust, dry paper, and dry coal fines. Sawdust was selected as a representative biomass wood waste, generated by secondary wood product manufacturers. Paper was selected as representative of a portion of municipal solid waste (MSW). The light fraction of MSW consists of paper and paperboard, corrugated cardboard, and plastics.

Additions of 10 and 25 percent biomass were mixed with dewatered sludge cake. Mixing was performed in a commercial Hobart mixer. The sawdust and coal fines both combined easily with the biosolids, producing a smooth, homogeneous mix. The paper proved more difficult to mix, and tended to wrap around the blades of the mixer. Heavier grades of paper required longer 
mixing times, and the heaviest grades persisted as unreduced lumps in the mix. Also problematic was the contrast in volume between the dense biosolids cake and the paper. A gradual addition of paper into the mixer helped to minimize this condition.

All tests were conducted at room temperature, and initial the biosolids moisture was 27 percent, as in prior tests. Pressure up to 70 psi was gradually applied in the press, as in the previous test series. Results of these tests are shown in Tables 14 and 15 below.

Table 14 -- Sludge Cake Dewatering Water Drop Out Rates With Paper Addition

\begin{tabular}{|c|c|c|c|}
\hline $\begin{array}{c}\text { Press Time } \\
\text { In Seconds }\end{array}$ & $\begin{array}{c}\text { Applied } \\
\text { Pressure } \\
\mathbf{k N} / \mathbf{m}^{2}(\mathbf{p s i})\end{array}$ & $\begin{array}{c}\text { Water Drop Out } \\
\text { With 10\% Paper }\end{array}$ & $\begin{array}{c}\text { Water Drop Out } \\
\text { With 25\% Paper }\end{array}$ \\
\hline 5 & $193(28 \mathrm{psi})$ & $0 \mathrm{~g}$ & $2 \mathrm{~g}$ \\
\hline 10 & $241(35 \mathrm{psi})$ & $1 \mathrm{~g}$ & $2 \mathrm{~g}$ \\
\hline 15 & $289(42 \mathrm{psi})$ & $2 \mathrm{~g}$ & $\mathrm{~g}$ \\
\hline 20 & $338(49 \mathrm{psi})$ & $1 \mathrm{~g}$ & $1 \mathrm{~g}$ \\
\hline 25 & $386(56 \mathrm{psi})$ & $1 \mathrm{~g}$ & $1 \mathrm{~g}$ \\
\hline 30 & $434(63 \mathrm{psi})$ & $1 \mathrm{~g}$ & $1 \mathrm{~g}$ \\
\hline 35 & $483(70 \mathrm{psi})$ & $1 \mathrm{~g}$ & $1 \mathrm{~g}$ \\
\hline 40 & $483(70 \mathrm{psi})$ & $1 \mathrm{~g}$ & $1 \mathrm{~g}$ \\
\hline 45 & $483(70 \mathrm{psi})$ & $1 \mathrm{~g}$ & $\mathrm{X}$ \\
\hline 50 & $483(70 \mathrm{psi})$ & $1 \mathrm{~g}$ & $\mathrm{X}$ \\
\hline 55 & $483(70 \mathrm{psi})$ & $0 \mathrm{~g}$ & $\mathbf{1 5 g}$ \\
\hline 60 & $483(70 \mathrm{psi})$ & $1 \mathrm{~g}$ & $\mathbf{2 9 . 6 \%}$ \\
\hline & Totals & $\mathbf{1 1 g}$ & \\
\hline & New Solids & $\mathbf{2 8 . 8 \%}$ & \\
\hline & & & \\
\hline & & &
\end{tabular}

Table 15 -- Sludge Cake Dewatering Water Drop Out Rates With Sawdust Addition

\begin{tabular}{|c|c|c|c|}
\hline $\begin{array}{l}\text { Press Time } \\
\text { In Seconds }\end{array}$ & $\begin{array}{l}\text { Applied } \\
\text { Pressure }\end{array}$ & $\begin{array}{c}\text { Water Drop Out } \\
\text { With } 10 \% \text { Sawdust }\end{array}$ & $\begin{array}{c}\text { Water Drop Out } \\
\text { With } 25 \% \text { Sawdust }\end{array}$ \\
\hline 5 & 193 (28psi) & $0 \mathrm{~g}$ & $0 \mathrm{~g}$ \\
\hline 10 & 241 (35psi) & $1 \mathrm{~g}$ & $2 g$ \\
\hline 15 & 289 (42psi) & $1 g$ & $4 g$ \\
\hline 20 & 338 (49psi) & $1 \mathrm{~g}$ & $2 g$ \\
\hline 25 & 386 (56psi) & $1 g$ & $1 g$ \\
\hline 30 & 434 (63psi) & $1 \mathrm{~g}$ & $1 \mathrm{~g}$ \\
\hline 35 & 483 (70 psi) & $1 \mathrm{~g}$ & $2 \mathrm{~g}$ \\
\hline 40 & $483(70 \mathrm{psi})$ & $1 \mathrm{~g}$ & $0 \mathrm{~g}$ \\
\hline 45 & 483 (70 psi) & $1 \mathrm{~g}$ & $1 \mathrm{~g}$ \\
\hline 50 & 483 (70 psi) & $0 \mathrm{~g}$ & $0 \mathrm{~g}$ \\
\hline 55 & $483(70 \mathrm{psi})$ & $1 \mathrm{~g}$ & $1 g$ \\
\hline 60 & 483 (70 psi) & $1 g$ & $\mathrm{X}$ \\
\hline 65 & $483(70 \mathrm{psi})$ & $1 \mathrm{~g}$ & $X$ \\
\hline 70 & 483 (70 psi) & $1 \mathrm{~g}$ & $\mathrm{X}$ \\
\hline & Totals & $12 \mathrm{~g}$ & $14 g$ \\
\hline & New Solids & $29.0 \%$ & $29.8 \%$ \\
\hline
\end{tabular}


As shown in these tables, the water dropout was $15 \mathrm{gm}$ or less for both the paper and sawdust additions. This is a much lower water dropout than the 30 gms of water measured in the previous test noted in Table 13. Therefore, instead of aiding dewatering, the addition of biomass actually decreased dewatering effectiveness. This was an unexpected result. While the biomass was expected to absorb some moisture and thereby decrease the dewatering effectiveness of that fraction of water, the biomass was expected to improve dewatering effectiveness overall. This was clearly not the case. Although the reason for this reduction in dewatering effectiveness was not immediately clear, it was noted that mixing of sludge and biomass changed the nature of the sludge. This change in character reduced dewatering effectiveness. Besides biomass addition and mixing, the addition of coal and mixing also changed the character of the sludge material. In fact, the mixing of small amounts of coal fines and sludge produced a consistency that was so thin and paste-like in consistency that the mixture simply extruded through the screen when pressed, even at low levels of applied pressure. Dewatering was impossible in this case, and the sludge solids flowed out with the water.

In conclusion, the addition of biomass materials and coal did not improve dewatering. Increases in cake solids were minimal, water drop out rates were greatly reduced, and pressing times increased to a minute or more. Although release of the cake from the screen was very good, with sawdust and paper additions, the inclusion of coal fines prevented any release. And, in all cases, filtrate clarity was poor. Given the poor performance of biomass as a dewatering aid, brief tests were performed to understand why this occurred and to identify potential process improvements to improve dewatering effectiveness with biomass addition.

Chemical conditioning of sludges is an essential step in successful mechanical biosolids dewatering. Polymer flocculants are mixed with biosolids at very low solids concentrations, usually within a pump, that transports the liquid to a gravity filter. The flocculant creates an attraction between particles in colloidal suspension which group together in "flocks" and this facilitates dewatering. In all the preceding test series, except those that included biomass and coal, the biosolids samples were undisturbed conditioned cake, collected directly from the discharge of a belt filter press. This material had a relatively high solids content of 27 percent. As shown above, all tests performed on undisturbed filter cake produced high levels of dewatering. Also, all mixed biomass cases produced much lower levels of dewatering. Therefore, additions of biomass, that required stirring or mixing, are not useful as a dewatering aid. Furthermore, any dewatering equipment that will stir or shear the sludge, such as a screw press, should be avoided. The best type of press is a machine that avoids shearing and stirring the material. This would be similar to a plate and frame type press, somewhat like the small press used in these dewatering tests. Lastly, the negative impact of sludge mixing on secondary dewatering effectiveness suggests that heating or cooling sludge might be problematic. To limit the size and expense of any heating or cooling device, the sludge must be turned over and heat transfer surfaces exposed to fresh sludge at relatively small scales. This would require mixing or dividing sludge to the point where dewatering effectiveness might be compromised. Therefore, the dewatering gains shown by the small-scale undisturbed heated sludge cake test results noted above might be substantially reduced because of the sludge mixing that would be required by the heating or cooling process in the full-scale system Therefore, it is concluded that the best approach for secondary sludge dewatering would be to process undisturbed sludge cake at room temperature, in a low-shear press. 


\subsubsection{Biosolids Dewatering Press}

Several mechanical dewatering systems are available on the market that could be applied to dewater biosolids. These systems have special attributes that are either beneficial or not, relative to the secondary biosolids dewatering need at room temperature. As noted above, a screw press is problematic, since it will tend to mix or stir the biosolids. Also, the screw press will not be able to generate the needed pressure of $483 \mathrm{kN} / \mathrm{m}^{2}$ ( $70 \mathrm{psi}$ ), as defined by the smallscale tests, because of the lack of biosolids confinement. In the screw press, the screw flights push the material forward to create pressure, and with the gelatinous sludge, pressure buildup will only be modest, before back mixing occurs.

Belt presses are widely used to dewater biosolids to $20-27 \%$ solids. They can apply up to about $69 \mathrm{kN} / \mathrm{m}^{2}$ (10 psi) pressure between the last set of rolls. Beyond this level, the biosolids can not be contained between the belts. To facilitate confinement of biosolids, Andritz has built a high pressure belt press that uses a frame and pressurized bladders to surround the belt and confine the biosolids. Using this machine, belt dewatering performance is improved. Figure 12 illustrates a primary dewatering press and the Andritz high-pressure press together. While improving dewatering, the Andritz system is bigger, more expensive and requires more maintenance then the primary dewatering press. The additional capital and operating costs with the high-pressure press have constrained the application of this machine.

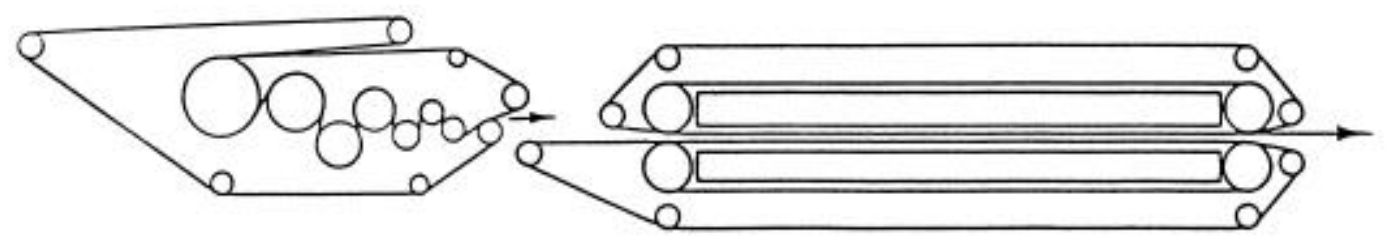

Figure 12 -- Biosolids Primary Belt Press Followed by High Pressure Secondary Belt Press

To reliably dewater biosolids at low cost, system design has to move past low-pressure belt technology to a high-pressure approach, as in the small-scale Altex tests. However, the approach must also go beyond a plate and frame device, which is a slow, batch-mode machine that is large, and requires substantial labor. To accomplish effective high-pressure dewatering at reduced maintenance and labor costs and potentially capital cost, Altex has identified a novel approach that processes the biosolids in the same way as is accomplished in the small-scale tests defined above. Given the high dewatering effectiveness achieved in the small-scale tests, the full-scale dewatering system should have good performance. This particular piece of equipment is considered proprietary, and will not be described in this nonproprietary document, but is incorporated into a separate Appendix A.

\subsection{TEST MATERIAL ACQUISITION}

Biomass, biosolids and coal fines materials were acquired in support of pellet production testing. After a review of logistics and costs, it was concluded that working with local raw materials was preferable to working with materials shipped from Detroit. This conclusion was based on an expected source variability and high shipping costs. For example, there was no single large source of sawdust for Detroit pellet production. Therefore, even if one Detroit sawdust supply was acquired for testing, this would not cover the expected range of materials 
anticipated to be utilized in Detroit. Furthermore, analysis of the sawdust composition is not the main driver of pellet quality. Sawdust size and moisture are important to pellet formation and quality. If these parameters are matched between the test materials and expected Detroit materials, then pellet quality could be simulated by the Altex tests. Given this situation, a local sawdust having a similar size distribution and moisture content to Detroit material appeared adequate for planned tests at Altex.

MSW light fractions, including those acquired in Detroit, will have some level of pathogens and pests. Testing of this material would typically require fumigation, to minimize personnel risk. Also, long distance shipping from Detroit would also require fumigation. To avoid this problem and expense, a MSW light fraction supply was simulated using locally available paper, cardboard and plastic wastes. This simulation should be reasonable, since contaminants represent only a small fraction of the material. Furthermore, to simulate MSW light fractions with paper, cardboard and plastic wastes, local supplies of these wastes are as good as using Detroit specific wastes. Therefore, the use of local materials to simulate MSW light fractions seemed reasonable.

Biosolids have a limited shelf life, and the material will continue to decay, even after dewatered and collected. The subsequent pelletization, drying and curing processes will halt this decay. However, shipping the raw material long distances, over substantial timescales, will change material characteristics. In particular, binding and odor characteristics will be altered. Given this problem, a local biosolids was used in the Altex tests to make pellets, rather than Detroit biosolids.

Of course, biosolids characteristics vary somewhat, depending on the contributions to the wastewater treatment plant. For example, a biosolids produced in an area where there is considerable food preparation and packaging will be different from biosolids in heavily industrialized or rural areas. However, prior tests on biosolids samples from five city locations indicated that the difference in binding characteristics between digested and undigested biosolids was a greater factor than the origin of the material. Nevertheless, it would be best to select a biosolids source that was produced in an area which is a mix of city, residential, and industrial activities, for a reasonable match to Detroit biosolids. Given this criteria, biosolids from Palo Alto, California were selected as the surrogate for Detroit biosolids. This material comes from a region where there is significant industry as well as substantial inputs from residences. The material is also similarly processed using belt filter presses and Multiple Hearth Incinerators (MHF), as is the practice in Detroit. Lastly, moisture content of Detroit and Palo Alto biosolids is similar. Given these characteristics, pellets made with Palo Alto or Detroit materials should be similar. Table 16 presents the properties of the Palo Alto, California biosolids. 
Table 16 -- Palo Alto, California Biosolids Analysis

\begin{tabular}{|c|c|c|c|c|c|}
\hline \multicolumn{2}{|c|}{ PROXIMATE ANALYSIS } & \multirow[b]{2}{*}{ Dry Basis } & \multicolumn{2}{|c|}{ ULTIMATE ANALYSIS } & \multirow[b]{2}{*}{ Dry Basis } \\
\hline & As Received & & & As Received & \\
\hline \% Moisture & 80.19 & $\mathbf{X x x x x}$ & \% Moisture & 80.19 & $\mathbf{X x x x x}$ \\
\hline$\%$ Ash & 6.87 & 34.67 & \% Carbon & 6.83 & 34.48 \\
\hline$\%$ Volatile & 11.92 & 60.19 & \% Hydrogen & 1.0 & 5.5 \\
\hline \multirow[t]{3}{*}{$\%$ Fixed Carbon } & 1.02 & 5.14 & $\%$ Nitrogen & 0.86 & 4.35 \\
\hline & $\mathbf{1 0 0 . 0 0}$ & $\mathbf{1 0 0 . 0 0}$ & \% Sulfur & 0.36 & $\mathbf{1 . 8 0}$ \\
\hline & & & \% Ash & 6.87 & 34.67 \\
\hline \multirow[t]{2}{*}{ Btu/lb } & 1287 & 6498 & \% Oxygen (diff) & 3.87 & $\mathbf{1 9 . 5 5}$ \\
\hline & & & & 100.00 & $\mathbf{1 0 0 . 0 0}$ \\
\hline \% Sulfur & 0.36 & 1.80 & & & \\
\hline MAF Btu & & 9946 & & & \\
\hline
\end{tabular}

Presently, Detroit Edison uses coal from Pennsylvania, blended with coal from the Powder River Basin. Coal fines that would be used to make pellets in Detroit are expected to be shipped from the same mine in Pennsylvania that currently provides the base coal supply. This is a typical bituminous coal that has a high heat content. Coal fines derived from the base coal will have a lower energy content, depending on the coal washing equipment and the ash separation effectiveness. Therefore, coal fines will have different properties and ash content than the base coal. Therefore, using actual coal fines from the region, rather than pulverizing the base coal, would be most appropriate. To simulate the coal fines to be used in Detroit, Pennsylvania bituminous coal fines, collected using a hyperbaric filter, were utilized. This provided a good simulation of the expected coal fines in Detroit. Table 17 presents the properties of the coal fines. The material is a Pittsburgh \#8 coal of $90 \%$ minus 28 -mesh-size, that has the appropriate characteristics to simulate the expected coal fines at Detroit. Two roughly 1-ton bulk bags of coal fines were acquired for the project, supplied by Consol.

Table 17 -- Coal Fines Properties

\begin{tabular}{|c|c|c|c|c|c|}
\hline \multicolumn{2}{|c|}{ PROXIMATE ANALYSIS } & \multicolumn{2}{c|}{ ULTIMATE ANALYSIS } & \\
\hline & As Received & Dry Basis & & As Received & Dry Basis \\
\hline \% Moisture & 5.80 & xxxx & \% Moisture & 5.80 & xxxx \\
\hline \% Ash & $\mathbf{6 . 8 7}$ & $\mathbf{7 . 2 9}$ & \% Carbon & 74.77 & 79.37 \\
\hline \% Volatile & $\mathbf{3 0 . 0 5}$ & $\mathbf{3 1 . 9 0}$ & \% Hydrogen & $\mathbf{4 . 5 1}$ & 4.79 \\
\hline \% Fixed Carbon & $\mathbf{5 7 . 2 8}$ & $\mathbf{6 0 . 8 1}$ & \% Nitrogen & 1.22 & 1.29 \\
\hline & 100.00 & 100.00 & \% Sulfur & 1.38 & 1.47 \\
\hline & & & \% Ash & 6.87 & 7.29 \\
\hline Btu/lb & 13124 & 13932 & \% Oxygen (diff) & $\mathbf{5 . 4 5}$ & $\mathbf{5 . 7 9}$ \\
\hline \% Sulfur & 1.38 & 1.47 & & 100.00 & 100.00 \\
\hline MAF Btu & & 15028 & & & \\
\hline
\end{tabular}

Wood waste was collected locally from the Carrera Millworks. In order to maintain the relationship between particle size, pellet size, and the small scale of the equipment, wood particles used in lab-scale production tests were screened to -25 mesh. For the pilot scale system, wood particles were screened to $-.32 \mathrm{~cm}(-1 / 8$ "). Full-scale systems could use even 
larger particle sizes. However, larger particle sizes will require larger pellets. Therefore, it is anticipated that $.32 \mathrm{~cm}(1 / 8$ ") particle size would be appropriate for full-scale equipment, as well as the pilot-scale test system.

Paper for AFP pellet production was acquired from Emerald Services, a local recycler. The materials were supplied in two separate bins, one of old corrugated cardboard containers (OCC), and one of nondurables such as newsprint, magazine print, and office paper. These were mixed in the needed proportions to simulate MSW light fractions.

The MSW light fractions, that are planned for use in the full-scale equipment, contain approximately 10 percent plastic, which is mostly plastic film. In MSW, plastic film consists almost entirely of high density polyethylene (HDPE). Therefore, use of this material in the pilotscale tests will simulate full-scale production. The HDPE plastic film, acquired as raw material for pilot-scale AFP pellet production, was blow molded $0.75 \mathrm{ml}$ liners. Before mixing the plastic film with other raw materials to create pellets, it was sent to the Multishear Corporation, Lafayette, LA, where it was processed in a Model 4X4X8 disk attrition mill. In this equipment, annular rows of blades rotate in proximity to annular rows of static blades. As the material flows from the center hub to the periphery, the blades shear the plastic to create a fine particle size. This processing reduced the plastic film to particles of approximately 8 mesh in size. This was a reasonable size for raw pellet material. It should be noted that the Multishear disk attrition mill is also effective at repulping paper products and wood, and similar equipment could have an important alternate role in the mixing steps of a full-scale system. However, a limit on its use is the requirement to positively feed or pump the raw material into the machine. Some mixtures may not be pumpable.

In summary, sawdust, paper, cardboard and plastic wastes were acquired to simulate Detroit wood and MSW light fraction wastes. Pennsylvania coal fines, characteristic of coal fines that would be shipped to Detroit, were also acquired. Lastly, undigested Palo Alto, California biosolids were collected as needed, during the tests.

\subsection{PELLET PRODUCTION TEST EQUIPMENT SETUP}

Much of the needed test equipment for pellet production and characterization was available at Altex, and had been successfully used to produce fuel pellets made from biosolids and coal fines. As noted in Section 4, this existing equipment was supplemented by a shredder and a secondary dewatering device.

\subsection{WASTE SHREDDER TEST EQUIPMENT}

For the pilot-scale tests, a small-scale biomass, sizing shredder was acquired. This 10-hp unit operates in the same manner as the hammermill equipment described in Section 4. Like a hammermill, the small-scale shredder is a high-speed impact machine, with revolving teeth, that breaks up materials within a chamber. An exit grate, in combination with rotating teeth, helps size the product. The feed rate can also be used as an operational parameter for sizing. Preliminary tests showed that the equipment appropriately reduced wood, paper, cardboard and film plastics, to a size compatible with pelletizing equipment. The shredder is incorporated into the AFP system, by coupling the shredder exit chute with the top of the mixer, in which biosolids, biomass, and any coal are mixed.

\subsection{BIOSOLIDS DEWATERING TEST EQUIPMENT S YSTEM}

Rather than simulate the entire ADDD machine in small scale, it was determined that only the process within one segment of the machine would be simulated. As such, the apparatus 
would operate in a batch mode, rather than continuously. Given the slow speed of the full-scale system, a batch operation would be reasonable and adequately simulate the full-scale system.

To economically duplicate the continuous operation of the ADDD was a relatively straight forward undertaking. A large hydraulic press served as a base to duplicate the pressing action of the ADDD concept. To scale-up this approach, and produce meaningful amounts of dewatered material for pellet production, a large hydraulic ram type press was acquired and modified. Modifications to the press included the installation of large top and bottom platens and a pair of trays. A grate inside the lower tray supports the upper tray. The lower tray is also a catch pan for displaced water. The press was also outfitted with a pneumatic control pump, for precise application of the time/pressure profile, that was developed in the lab-scale tests. To operate the unit, an operator manually loads the upper tray with a uniform volume of material. The tray is placed on top of the lower tray, the top platen is lowered down onto the confined material, and pressure is applied. Displaced water falls through the perforated sheet and is collected and drained from the lower tray.

Following modifications to the press, the unit was tested to verify performance. In the two initial tests, sludge solids content was increased from 26 percent to 32 and 33 percent, representing water reductions of 25 and 29 percent, respectively. These results were consistent with the small-scale tests and support the validity of the larger-scale test equipment.

\subsection{MIXERS}

The Altex prepug mixer was used exclusively throughout pilot-scale AFP pellet production. Bench-scale mixing was performed in a 19-liter (5-gallon) Hobart commercial unit.

\subsection{EXTRUDER S YSTEM}

The extruder system, illustrated in Figure 5, was configured in accordance with results of the lab-scale production test work. A shredder attachment was installed at the exit of the sealing die, and spacers were used to vary the working distance between the pelletizing die and final auger flight. The shredder attachment further assisted in reducing the size of biomass paper and cardboard materials, and the mixing of materials for optimal pellet consistency and strength.

\subsection{DRYER S YSTEM}

The Proctor-Schwartz Conveyor dryer is illustrated in Figure 6. Only the dryer sweep feeder was modified to accommodate the large pellet size.

\subsection{WEATHERIZER APPLICATION SYSTEM}

Weatherization tests indicated that the success of weatherization depended on obtaining a uniform coating of the weatherizing agent on the pellet. Given the porosity of biomass based pellets, if areas of the pellet were left uncoated, then water could infiltrate the pellet and spread internally. Therefore, it was important to apply a complete coating on the pellet. Furthermore, the weatherizing agent may be more expensive per ton than the pellet, based on fuel value, so it is also important to use the minimum amount of weatherization agent needed to produce a good pellet coating. Therefore, the coating applicator plays an important role in the AFP system.

To ensure uniform pellet coating, a motorized roller applicator was designed and fabricated. The applicator consists of a rotating horizontal drum and fixed back plate. Weatherizer is transferred to the pellets as they pass between the drum and back plate. The rotation of the drum also spins the pellets, evenly coating the entire surface, as well as the ends. The unit was tested, and installed in the pilot-scale production system, at discharge from the 
dryer. To assess the effectiveness of the applicator, tall oil soap was utilized as a potential weatherizing agent. This is a waste product from the pulp and paper industry that was shown to improve weatherability of biomass-based pellets in previous tests. Initial tests of the unit produced tall oil soap application rates of from 1-4 percent, depending upon the amount of weatherizer that was loaded on the roller.

\subsection{PELLET PRODUCTION PROPOSED TEST PLAN}

As noted in Section 5, sawdust and light fractions of Municipal Solid Waste (MSW) were selected as high potential biomass materials to be combined with biosolids and coal fines to produce AFP pellets. These biomass feedstocks were relatively dry. Therefore, drying cost burdens should be reduced with these materials.

However, with biomass materials that are low in moisture, extrusion at low biosolids content is challenging. This is because extrusion requires a certain mixture moisture level and plasticity to limit friction, power consumption, and heat buildup during the extrusion process. In preliminary tests with coal fines of $20 \%$ moisture content, biosolids/coal fines mixtures of $27 \%$ to $36 \%$ moisture content produced good extrudates at modest power, and with limited heat buildup. Bench tests indicated that higher biosolids contents than originally planned were needed to produce good wood and MSW light fraction pellets. Higher fractions of biosolids, that have $65 \%$ moisture content when fully dewatered, will increase mix moisture content substantially. Furthermore, given the $\$ 40.7 /$ tonne $(\$ 37 /$ ton) negative cost of wet biosolids, increasing the biosolids fraction in the mixture offsets biomass pellet production costs. This is beneficial. Six pellet raw material formulations were originally proposed for testing, that utilized biosolids fractions of from $10 \%$ to $25 \%$. Tests indicated that $55 \%$ biosolids to $45 \%$ wood waste, and $50 \%$ biosolids to $50 \%$ MSW light fractions were required to produce a quality pellet. Furthermore, as coal fines were added, a good quality pellet could still be produced, as long as the biosolids to biomass ratio remained the same. The recommended pellet dry mixture fractions are listed in Table 18 below, along with the mixture character. As indicated in the table, there were overlapping mixtures, with coal, that contain sawdust or MSW light fractions. Therefore, test results using these mixtures could be compared directly.

Table 18 -- Proposed Pellet Test Formulations

(Mass Percent on Dry Basis)

\begin{tabular}{|l|c|c|c|c|}
\hline \multicolumn{1}{|c|}{ Pellet Character } & $\begin{array}{c}\text { MSW Light } \\
\text { Fractions } \\
(\%)\end{array}$ & $\begin{array}{c}\text { Biosolids } \\
(\%)\end{array}$ & $\begin{array}{c}\text { Coal Fines } \\
(\%)\end{array}$ \\
\hline High biomass, no coal & 45 & 0 & 55 & 0 \\
\hline Mid biomass, low coal & 32 & 0 & 38 & 30 \\
\hline Low biomass, high coal & 22 & 0 & 28 & 50 \\
\hline High biomass, no coal & 0 & 50 & 50 & 0 \\
\hline Mid biomass, low coal & 0 & 35 & 35 & 30 \\
\hline Low biomass, high coal & 0 & 25 & 25 & 50 \\
\hline
\end{tabular}

Conditions under which the biomass mixtures were extruded and dried were varied during testing to define the best processing conditions. The starting conditions were based on successful tests with coal and biosolids under prior efforts. These conditions are listed in Table 
19. An important parameter was throughput. For the readily extrudable coal/biosolids mixture, a throughput of $4.5 \mathrm{~kg} / \mathrm{min}(10 \mathrm{lbs} / \mathrm{min})$ could be easily achieved, while still maintaining good pellet quality. With biomass mixtures, pellet throughput was reduced.

Table 19 -- Pelletization Baseline Test Conditions

\begin{tabular}{|c|c|}
\hline Extruder & $43 \mathrm{C}(110 \mathrm{~F})$ \\
Barrel temperature & $40.5 \mathrm{C}(105 \mathrm{~F})$ \\
Pellet temperature & $4.5 \mathrm{~kg} / \mathrm{min}(10 \mathrm{lbs} / \mathrm{min})$ \\
Throughput & \\
\cline { 1 - 2 } Conveyor Dryer & $16 \mathrm{~min}$ \\
Hot zone residence time & $8 \mathrm{~cm}(3-\mathrm{in})$ \\
Bed depth & $146 \mathrm{C}(295 \mathrm{~F})$ \\
Dry bulb temperature & $60 \mathrm{C}(140 \mathrm{~F})$ \\
Wet bulb temperature & $110 \mathrm{C}(230 \mathrm{~F})$ \\
Exhaust temperature & $1100 \mathrm{cfm}$ \\
Exhaust flowrate & $570 \mathrm{~kJ} / \mathrm{hr}(350 \mathrm{k} \mathrm{Btu} / \mathrm{hr})$ \\
Average heat load & $5 \%$ \\
Product moisture &
\end{tabular}

Also, given the abrasive fiber character and low plasticity of the biomass mixtures. It was necessary to cool the extruder barrel to control temperature. This cooling was accomplished with a simple water jacket with an adjustable flow rate. For the large pellet size of 1.9-cm to 3.8$\mathrm{cm}$ (.75-inch to 1.5-inch) dryer times increased to 20 minutes, rather than the 16 minutes for 1.3$\mathrm{cm}$ (.5-inch) biosolids and coal-fine pellets. This reduced dryer throughput, in line with the reduction in extruder throughput.

In summary, the tests showed that higher biosolids content was required to prepare high quality pellets from sawdust and MSW biomass. In contrast to coal fines/biosolids formulations, that required $10 \%$ to $25 \%$ biosolids fractions, biomass based pellets required nearly twice the biosolids content. Besides improving pellet quality, increased biosolids content improves process economics. Therefore, requiring more biosolids content is beneficial.

\subsection{PELLET PRODUCTION}

Bench-scale tests of key process steps were conducted to validate equipment selections and define operating parameters in preparation for pilot-scale continuous pellet production tests. These process steps included the biosolids dewatering, discussed previously, mixing, and extrusion. Initially, eight biomass formulations were tested to determine their suitability for processing in the AFP system and, thereby, refine the proposed test plan that was discussed in Section 7. These eight initial tests were followed by seven tests that focused on processes including plastics and paper as well as more mixtures that included coal fines. Lastly, five tests were carried out to produce formulations that would be more easily pulverized in coal-fired utility boiler equipment. These bench scale tests were then followed by pilot-scale pellet production tests. 


\subsection{Bench-Scale Pellet MiXtures 1 to 8}

\section{Mixing}

The mixing process is a key step in AFP production. Mixing impacts extrudability, green pellet strength and handleability, pellet surface quality, dry strength, density, weatherability, and grindability.

Owing to the high fiber content in biomass and differences in particle size, density and moisture, each of the raw materials included in the program exhibits its own unique mixing behavior. To evaluate the mixing of the various raw materials, eight formulations were tested. A listing of raw materials in this test series is given in Table 20.

Table 20 -- Pellet Raw Materials

\begin{tabular}{|l|l|c|}
\hline Raw Material & Particle Size/Description & Moisture Content \\
\hline Biosolids & Primary Dewatered Filter Cake & $73-74 \%$ \\
\hline Biosolids & Secondary Dewatered Filter Cake & $66-67 \%$ \\
\hline Wood & -25 mesh / Sawdust & $6 \%$ \\
\hline Paper & $\begin{array}{l}1.3-\mathrm{cm} \times 1-\mathrm{cm} \text { (1/2"x 1")/ Nondurable, reduced } \\
\text { mill }\end{array}$ & $7 \%$ \\
\hline $\begin{array}{l}\text { Old corrugated } \\
\text { containers }\end{array}$ & $\begin{array}{l}\text { 1.3-cm x 1-cm (1/2"x 1")/ Corrugated container, } \\
\text { reduced in mill }\end{array}$ & $4 \%$ \\
\hline Coal Fines & $90 \%-28$ mesh & $8 \%$ \\
\hline
\end{tabular}

Biosolids, dewatered by Altex, and as received from the wastewater treatment plant, were included in all test formulations as a binder. The wood used in the tests was a wood processing shop waste, collected from local secondary wood manufacturer. The paper was acquired from a local recycler. Nondurables and old corrugated containers (OCC) were delivered in separate bins. These paper materials were always added to the formulas in proportions consistent with their natural occurrence in a light fraction of municipal solid waste.

The criteria for mix quality was a thorough distribution of moisture in the well-mixed materials. In formulations that included a MSW light fraction, repulping of the nondurable paper and corrugated cardboard products proved beneficial to subsequent process steps. Also necessary for good pellet quality was a uniform dispersion of both wood and coal fines, and an adequate level of available mix moisture and plasticity for extrusion.

Table 21 shows a listing of the formulas used in this test series. Also listed in the table are ratings for extrudability, and dry pellet appearance from the tests. These qualities were also factors in evaluating the mixing process, and are discussed separately below.

Table 21 -- AFP Bench Scale Formulas 1-8

\begin{tabular}{|c|c|c|c|c|c|c|c|}
\hline Mix & $\begin{array}{c}\text { Wood \% } \\
\mathbf{- 2 5} \text { mesh }\end{array}$ & Paper & $\begin{array}{c}\text { Biosolids } \\
\text { (dry)\% }\end{array}$ & $\begin{array}{c}\text { Coal } \\
\text { Fines\% }\end{array}$ & $\begin{array}{c}\text { \%Mix } \\
\text { Moisture }\end{array}$ & Extrudability & $\begin{array}{c}\text { Dry Pellet } \\
\text { Appearance }\end{array}$ \\
\hline 1 & 76 & & 24 & & 42 & None & \\
\hline 2 & 67 & & 33 & & 45 & Poor & Poor \\
\hline 3 & 56 & & 44 & & 52 & Fair & Fair \\
\hline 4 & 32 & & 27 & 41 & 44 & Fair & Fair \\
\hline 5 & 32 & & 27 & 41 & 52 & Fair & Fair \\
\hline 6 & 40 & & 60 & & 60 & Good & Good \\
\hline 7 & 40 & & 60 & & 53 & Good & Good \\
\hline 8 & & 50 & 50 & & 57 & Good & Good \\
\hline
\end{tabular}


Mix \#1 was first prepared in a Hobart commercial mixer. Because of the disparity in material densities, the interaction with the wood was not sufficient to break down the cake using this type of mixer space. As a result, even through overall mix moisture content measured 42 percent, there was not enough moisture to form a cohesive mix. Mix \#1 was then "mulled" to improve biosolids dispersion and moisture distribution. The mulling action was achieved using a lab-scale extruder with an annular die. In a conventional clay extrusion system consisting of pug mill, sealing die, barrel and auger, materials from the pug are augured through an annular cavity where mix components are brought together under moderate amounts of pressure. Since an extruder extrusion is the AFP pelletizing method, this mulling of the mix is consistent with the system design. The consistency of Mix \#1, however, remained a damp powder, without any apparent plasticity. Mixes \#2 and \#3 were formulated with higher levels of biosolids, of 33 and 44 percent, respectively. Mix processing was the same as for Mix \#1. Plasticity and cohesiveness both improved with additional biosolids in the mix.

Mixes \#4 and \#5 contained coal fines additions. The coal was added last, to an already mixed combination of biosolids and wood. From a processing perspective, adding coal fines improved the performance in the mixer, by promoting the breakdown of the biosolids filter cake. Additional water was added to Mix \#5 to compensate for the corresponding reduction in overall mix moisture. The resultant consistencies were similar to that of Mix \#3. Apparently the coal fines additions had very little effect on the moisture distribution in these mixes.

Mix \#6 contained $40 \%$ wood and $60 \%$ biosolids. This formula mixed quickly and easily in the Hobart mixer without additional mulling. With the high moisture content in this formula, the mix transformed from a powder into a paste, and over time agglomerated into small balls in the mixer. Mix \#7 was identical to Mix \#6, however the biosolids were first dewatered in the ADDD simulator. This dropped the overall mix moisture from 60 percent to 53 percent. Extra time in the Hobart was necessary to thoroughly disperse the biosolids, however, additional mulling was not necessary. Mix \#7 did not ball up in the mixer.

Mix \#8 was the first attempt to include paper products in the formula. The formula chosen was high in biosolids content, based on the above experience with wood. Paper and corrugated cardboard presented a special mixing challenge because of their large particle size. Paper materials reduced in the mill are still $2.5 \mathrm{~cm}+1$ " in size, and to produce a smooth homogenous mix required a different mix strategy than the one used previously with wood.

The paper products in Mix \#8 consisted of 50 percent nondurables (newsprint, magazine print and office paper) and 50 percent Old Corrugated Containers (OCC). Initial mixing was carried out in the Hobart, and the result was a poor dispersion of biosolids and pieces of paper. Very little moisture was distributed and the mix was neither cohesive or plastic. Mix \#8 was then mulled, as the previous mixes, which improved moisture distribution, and began to break down the lighter grades of paper. Still the materials in the mix remained largely separated. A second mulling produced a much smoother mix, consisting of well mixed biosolids and repulped light paper, with small unmixed particles of the heavier corrugated material. To achieve a completely homogeneous mix a shredder attachment was installed on the end of the auger shaft. The shredder attachment is also a frequently used component in clay extrusion systems. The shredder is a radial set of knives that rotate with the pug shaft, shearing the material as it passes through the sealing die. A single pass through the shredder completed the processing of Mix \#8. The result was a smooth homogenous mix of repulped paper products and biosolids. 


\section{Extrusion}

Referring back to Table 21, the mixes in this test series were pelletized and rated for "extrudability" and dried pellet appearance. These ratings are somewhat subjective and so their meaning, will be defined. For a material to be extrudable it must flow through the die. Extrudability, as we are using it, goes beyond flow through the die to include the quality of the green pellet. A brief description of this rating system is given below.

\section{Extrudability:}

- Very Poor. Extrudate disintegrates upon exiting the die

- Poor. Extrudate is not uniformly shaped

- Fair. Extrudate has surface defects, cracks

- Good. Extrudate is well formed, surface is uniform, extrudates are able to survive handling in the green state.

Dry pellet appearance refers to the character of the dried product. Occasionally problems with poor pellet quality are not noticeable in the green state and surface cracks or segmentation may develop during the drying process.

\section{Dry Pellet Appearance:}

- Poor. Pellet disintegrated while drying

- Fair. Pellet is intact, but developed surface cracks or other defect

- Good. Pellet is well formed, surface is smooth

Pellet quality refers to characteristics that can be tested such as strength or density. The quality test results for pellets produced in this series are discussed below.

Again, the lab-scale extruder was used to perform the pelletizing tests, fitted with a .17 cm (7/16") (.4375) diameter die made of high-density and low-friction plastic. The attempt to extrude Mix \#1 was unsuccessful, as the mix would not flow through the die. This is usually attributable to low moisture in the mix.

Mix \#2 was the first extrudable formula. The compressed extrudate expanded dramatically as it emerged from the die to a diameter of $1.3 \mathrm{~cm}(75$ ") and large, deep cracks formed on the surface. The extrudate expansion or "springback" is a behavior consistent with dry fiber, indicating a need for more moisture in the mix. The surface cracking indicated friction between the materials in the mix, and the die. Material at the center of the pellets was moving through the die faster than material contacting the die at the pellet surface, again suggesting the need for more moisture in the mix. Green pellets could not be handled without disintegrating. The expansion and cracks continued to develop during the drying step.

Mix \#3 showed improvement. Springback at the die was reduced, as was the development of surface cracks. The pellet surface was rough but mostly unbroken. Green pellets could not survive much handling, and small surface cracks developed in the dried pellets.

Mixes \#4 and \#5 included coal fines in the formulas. In retrospect, coal fines addition at this stage was probably premature because it effectively lowered biosolids and overall moisture content. However, it was very useful to learn that up to 40 percent dry coal could be added to the formula without appreciably altering the extrudability of the mix. The appearance of the pellets produced from Mix \#4 resembled those from Mix \#3. Mix \#5 was identical to Mix \#4, but with 
additional water. Again, there were no improvements in extrudability or appearance, suggesting that the gelatinous biosolids may contribute more to extrudability than just moisture.

Mixes \#6 and \#7 contained 60\% biosolids. Mix \#6 extruded very smoothly in a single continuous string. The green pellet surface was smooth and free of cracks. Green handleability was good. Dried pellets actually shrank to slightly less than the diameter of the die. Mix \#7 was formulated with dewatered biosolids to determine the impact of reduced moisture biosolids. Again, extrusion was smooth, but stiffer than Mix \#6. Green pellet surfaces were smooth and crack free, and green pellet handleability was also good.

Mix \#8 was formulated from biosolids and paper. The repulping work performed during the mixing steps produced a smooth good quality extrudate. Initially there were small irregularities on the pellet surface. This was corrected by moving the auger back away from the die an additional $.64 \mathrm{~cm}$. This increased the space between the die and the last flight, which effectively increases the back pressure behind the die. Increasing back pressure at the die improved the appearance of the pellets. Overall, both the appearance and green strength of pellets produced from Mix \#8 were good.

\section{Pellet Quality}

Pellets produced from selected formulas were evaluated by tests of axial compression, drops from a height to concrete, measurements of dried pellet diameter (shrinkage), and pellet density. All of these pellets were dried to less than 5\% moisture. Results appear in Table 22.

Table 22 -- Pellet Quality Test Results

\begin{tabular}{|c|c|c|c|c|}
\hline $\begin{array}{c}\text { Mix } \\
\#\end{array}$ & $\begin{array}{c}\text { Pellet Diameter } \\
\text { Cm (in) }\end{array}$ & $\begin{array}{c}\text { Pellet Density } \\
\mathbf{K g} \mathbf{m}^{\mathbf{3}}\left(\mathbf{l b} / \mathbf{f t}^{\mathbf{3}}\right)\end{array}$ & $\begin{array}{c}\text { Drop to Concrete } \\
\mathbf{m}(\mathbf{f t})\end{array}$ & $\begin{array}{c}\text { Compression } \\
\text { Kg/kN (lbf / psi) }\end{array}$ \\
\hline 3 & $1.27(.50 ”)$ & $593.8(37.0)$ & +10 from $4.5(15 \mathrm{ft})$ & $12 / 1076(27 / 156)$ \\
\hline 4 & $1.19(.47 ”)$ & $656.5(40.9)$ & 9 from $1.5(5 \mathrm{ft})$ & $7 / 600(15 / 87)$ \\
\hline 5 & $1.24(.49 ”)$ & $666.2(41.5)$ & 10 from $4.5(15 \mathrm{ft})$ & $9 / 731(20 / 106)$ \\
\hline 6 & $1.04(.41 ”)$ & $616.4(38.4)$ & +10 from $4.5(15 \mathrm{ft})$ & $19 / 2192(42 / 318)$ \\
\hline 7 & $1.07(.42 ”)$ & $624.4(38.9)$ & +10 from $4.5(15 \mathrm{ft})$ & $23 / 2496(50 / 362)$ \\
\hline 8 & $1.07(.42 ”)$ & $714.3(44.5)$ & +10 from $4.5(15 \mathrm{ft})$ & $36 / 3468(80 / 503)$ \\
\hline
\end{tabular}

The highly fibrous nature of the biomass materials is best illustrated by the resilience displayed in the drop tests. A result of " +10 from $4.5 \mathrm{~m}(15 \mathrm{ft}) "$ means the pellet survived 11 drops from $4.5 \mathrm{~m}$ (15ft) to a concrete floor without damage. This strongly contrasts with previous results of pellet drop tests conducted on BioBinder pellets. BioBinder pellets, formulated from $85 \%$ coal fines and $15 \%$ biosolids binder, rarely survived one or two drops from $4.5 \mathrm{~m}$ (15ft). Interestingly, biomass pellets formulated with coal fines additions (Mix \#4, \#5) also produced lower scores in the drop test. In fact, pellets from Mix \#4 survived only 9 drops from just $1.5 \mathrm{~m}$ (5ft). This suggests that AFP pellets made from fibrous biomass will be very resilient to rough handling.

For the extrudable formulations, pellet quality, in terms of surviving multiple drops from $4.5 \mathrm{~m}$ (15ft) onto a concrete pad, was excellent. Pellets showed a high resistance to breakage, compared to lump coal or biosolids and coal fines pellets. This is most likely due to the fibrous nature of the raw material that creates a composite like structure that is very resistant to breakage. In addition, the formulations with $60 \%$ biosolids had crush strengths of over $2068 \mathrm{kN} / \mathrm{m}^{2}$ (300 psi). This exceeds the $827 \mathrm{kN} / \mathrm{m}^{2}$ (120 psi) highlighted as adequate pellet crush 
strength in the studies by Battelle[21]. These strong and resilient pellet formulations would be ideal for stoker use, where pellet configuration remains important up to and including combustion. For pulverized coal systems, the material is pulverized prior to combustion. Therefore, for these cases, pulverization characteristics are just as important as strength. Pellet pulverization characteristics were explored in later tests described below.

In summary, bench-scale preliminary pellet production tests showed that increased biosolids fractions were needed to create high-quality pellets during the planned extended pilotscale pellet production tests. Besides improving pellet quality, higher biosolids content also improves economics.

\subsection{Bench-Scale Pellet Mixtures 9 to 15}

These bench-scale tests focused on two areas of AFP development. First was the inclusion of MSW light fraction materials, including various grades of paper, and plastic films. As with paper, plastic also posed new challenges in the mixing and extrusion steps of pellet production relative to overall production. A second test focus was the addition of varied coalfines fractions to the AFP formulas. The purpose of these coal fines additions was to tailor the AFP pellet response to forces generated in a coal pulverizing mill. It was found by testing that biomass pellets can be very robust and resilient to crushing. While this characteristic is excellent for pellets to be used in stoker fired equipment, pellets may be too resilient for pulverized coalfired equipment. In these cases, pellets must be crushable along side coal in a pulverizer. If pellets resist being crushed, then pulverizer throughput will be reduced. This would then require pulverizer upgrades or a derating of the unit. This is not desirable. To avoid these problems and expenses, it was beneficial to tailor the pellet strength to the application of interest.

Prior to pellet production, "as received" sludge cake was mechanically dewatered to 3738 percent solids before mixing with the other raw materials. This is the same processing to be applied in a full-scale system. The formulas for pellets produced at bench scale in this series are listed in Table 23 below. Pellets were produced by a small lab scale extruder with a $1.3 \mathrm{~cm}(.5$ in) die.

Table 23 -- Bench-Scale AFP Pellet Formulas 9-15

\begin{tabular}{|c|c|c|c|c|c|c|}
\hline Mix \# & Biosolids\% & Paper\% & Plastic\% & Wood\% & Coal\% & Mix Moisture \% \\
\hline 9 & 35 & 35 & 0 & 0 & 30 & 43 \\
\hline 10 & 30 & 30 & 0 & 0 & 40 & 40 \\
\hline 11 & 40 & 36 & 4 & 0 & 20 & 51 \\
\hline 12 & 38 & 0 & 0 & 32 & 30 & 45 \\
\hline 13 & 33 & 0 & 0 & 27 & 40 & 36 \\
\hline 14 & 30 & 0 & 0 & 25 & 45 & 34 \\
\hline 15 & 27 & 0 & 0 & 23 & 50 & 32 \\
\hline
\end{tabular}

Mixes \#9, and \#10 were formulated from biosolids, paper, and coal fines. The paper fraction contained a mix of 50 percent old corrugated containers (OCC), and 50 percent nondurables, such as magazine print, newsprint, and office paper. These fractions are consistent with the proportions found in MSW, based on national averages. Preparation of this formula began by reducing the particle size of the paper in a hammer-type mill. This step was successful at reducing paper to particles of approximately $2.5 \mathrm{~cm}$ (1"). Next, the paper and biosolids were mixed together in the Hobart mixer. This distributed the biosolids evenly throughout the mix, 
but did not further reduce the paper particles. To effectively repulp the paper products, several sequential annular extrusions were carried out to mull the mix. This step is consistent with processing the material through the sealing die of a full-scale commercial extruder. Since the bench-scale extruder uses an annular die, no blockage or material accumulations could occur to interrupt operation.

Lastly, a shredder attachment, also routinely used in commercial extruders, was added to the equipment. The consistency of the material processed through the shredder was a repulped, nearly homogeneous mix. The subsequent pellet extrusion proceeded smoothly. Green state strength was good. However, incompletely repulped paper fragments emerged as surface irregularities on the pellets.

Mix \#11 was formulated from biosolids, paper and coal fines, plus a representative fraction of plastic film. Paper and plastic were run together through the hammer mill. The resultant size of the plastic film was large pieces about $5 \mathrm{~cm}$ x $15 \mathrm{~cm}(2$ "x 6"). The subsequent processing was similar to the two previous mixes. Throughout the subsequent process steps, the relatively large pieces of plastic did not break down to a workable particle size. Also, in the extruder, pieces of plastic accumulated behind the die and blocked die holes. It was decided that further testing with plastic film in the formula should be postponed, until better equipment for reducing the size of plastic film to particles was identified.

Mixes \#12, \#13, \#14 and \#15 were all formulations of biosolids and wood, with various amounts of added coal fines. Unlike the fibrous biomass materials, coal fines additions did not dramatically alter the behavior of the mix in the machinery. The processing of these mixes followed the procedures developed during prior tests. Production proceeded smoothly and without incident, validating those procedures.

\subsection{Bench-Scale Pellet MiXtures 16 to 20}

Pellet production in these bench tests focused on the development of AFP pellets formulated with coal fines together with MSW light fraction materials, including various grades of paper, and plastic films. Previously, these materials had been successfully processed into pellets, and because of their highly fibrous composition, the resultant pellets were nearly indestructible in crush tests. This characteristic resilience was even more pronounced with processed fibers from paper products, than had been the experience with unprocessed fiber from waste wood. Although this characteristic is ideal for stoker systems, excessively resilient pellets would increase grinding energy and costs for pulverized fuel boilers.

Very robust pellets are attractive for use in stoker type systems, where pellet size and the integrity during processing are important. However, for pulverized coal systems, pellets should not be more difficult to crush or grind than lump coal. Therefore, the robust pellets previously produced, are not well suited for pulverized applications. A means to adjust pellet strength by altering pellet composition was then pursued. Lab-scale production was directed at formulating a pellet from waste paper that would fracture and fragment in response to crushing forces, such as those anticipated in a ball-and-race-type coal pulverizer. This alteration in grindability was achieved by additions of special materials to the formula. The initial approach was to add coal fines to the MSW-light-fraction-based pellets. This strategy was successful with pellets made from waste wood. However, a second, more effective strategy for MSW-based pellets, was the addition of small plastic film particles. By adding small pieces of plastic, the structure of the pellet was sufficiently weakened to allow crushing and then grinding in the mill.

Prior to pellet production, "as received" sludge cake was mechanically dewatered to 3738 percent solids, before mixing with the other raw materials. In addition, a single batch of 
pellets was produced consisting totally of dewatered biosolids. The formulas for pellets produced at lab scale during this period are listed in Table 24 below.

Table 24 -- Bench Scale AFP Pellet Formulas 16-20

\begin{tabular}{|c|c|c|c|c|c|c|}
\hline Mix \# & $\begin{array}{c}\text { Biosolids } \\
\text { \% }\end{array}$ & Paper\% & Plastic\% & Wood\% & Coal\% & Mix Moisture\% \\
\hline 16 & 100 & 0 & 0 & 0 & 0 & 63 \\
\hline 17 & 25 & 25 & 0 & 0 & 50 & 43 \\
\hline 18 & 25 & 25 & 0 & 0 & 50 & 40 \\
\hline 19 & 20 & 20 & 0 & 0 & 60 & 52 \\
\hline 20 & 48 & 48 & 4 & 0 & 0 & 45 \\
\hline
\end{tabular}

Mix \#16 consisted of a sample of containing only dewatered biosolids. The high amount of moisture produced soft sticky pellets that barely could be handled. The interest in producing these pellets was primarily as a reference.

Mixes \#17, \#18 and \#19 were formulas of paper products, and coal fines. The paper products were a mix of 50 percent old corrugated containers (OCC), 30 percent nondurables, such as magazine print and office paper, and 20 percent newsprint. These proportions are consistent with national averages for the occurrence of these materials in a separated MSW light fraction. Preparation of these formulas was consistent with previously reported procedures. Mixes \#17 and \#18 contained 50 percent coal, and were distinguished only by the coal particle size. Mix \#17 contained -28-mesh particles, and Mix \#18 contained larger coal particles of -8 +12-mesh. Mix \#19 contained 60 percent added coal fines. All three formulas required water additions in order to extrude in the lab-scale machinery. Mix \#19 was still unextrudable through the $1.3-\mathrm{cm}(.5 ")$ die, and was pelletized with a $1.9-\mathrm{cm}(.75 ")$ annular die.

Mix \#20 contained no coal. Instead it was formulated from biosolids, paper products, and a 4 percent addition of plastic film. This fraction of plastic film is also consistent with national averages for this material in MSW. Previous attempts to incorporate plastic film into AFP pellets were unsuccessful, because the plastic could be reduced to a workable particle size. To produce sized plastic particles, the plastic film was first processed in a disk attrition mill, manufactured by the Multishear Corporation. This machine, and its operation, were described in Section 5.0. The resultant particles were approximately 8-mesh in size. Mixing and pelletizing proceeded without any of the previous difficulties.

The objective of these coal and plastic particle additions to the AFP formula was to alter the pellet response to crushing forces, and produce a pellet compatible with coal pulverizing equipment. The results of crush tests performed on these lab-scale pellet productions are described fully in Section 9.0.

\subsection{Pilot-Scale AFP Pellet Production}

Following bench-scale pellet production, pilot-scale production of large quantities of pellets was undertaken to prepare pellets for combustion testing at pilot scale. The following narratives describe the production experience, and a complete list of AFP pellet formulas produced at pilot-scale is presented in Table 25 . 
Table 25 -- AFP Pilot-Scale Productions

\begin{tabular}{|l|c|c|c|c|c|c|}
\hline $\begin{array}{c}\text { Sample } \\
\text { ID \# }\end{array}$ & $\begin{array}{c}\text { Biosolids } \\
\mathbf{\%}\end{array}$ & $\begin{array}{c}\text { Wood } \\
\mathbf{\%}\end{array}$ & $\begin{array}{c}\text { Paper } \\
\mathbf{\%}\end{array}$ & $\begin{array}{c}\text { Plastic } \\
\mathbf{\%}\end{array}$ & $\begin{array}{c}\text { Coal } \\
\mathbf{\%}\end{array}$ & $\begin{array}{c}\mathbf{k J} / \mathbf{k g} \\
(\mathbf{B t u} / \mathbf{l b m})\end{array}$ \\
\hline 12019901 & 55 & 45 & & & & $19476(8374)$ \\
\hline 12089901 & 38 & 32 & & & 30 & $23331(10031)$ \\
\hline 01140001 & 27 & 23 & & & 50 & $25902(11137)$ \\
\hline 01210001 & 50 & & 50 & & & $17668(7597)$ \\
\hline 02220001 & 24 & & 24 & 2 & 50 & $25537(10980)$ \\
\hline 02230001 & 40 & & 56 & 4 & & $18448(7932)$ \\
\hline 03010001 & 48 & & 48 & 4 & & $18744(8059)$ \\
\hline
\end{tabular}

Particular attention was focused on material behavior during this first production run of AFP pellets at pilot scale. Of special interest were any benefits that larger equipment would bring to the process.

Sample ID\# 12019901

Mix Formula: 55/45 Dewatered Biosolids/Wood Mix Moisture Content: 50\%

\section{MECHANICAL SECONDARY B IOSOLIDS DEWATERING}

Biosolids collected from the discharge of the belt filter press at the Palo Alto WWTP were tested twice for moisture content. Test results were $69.8 \%$ and $70.1 \%$. Secondary mechanical dewatering in the pilot-scale press reduced cake moisture content to $62 \%$, or a moisture reduction of 30 percent. These are unusually low moisture levels that are attributable to increased polymer addition at the wastewater treatment plant.

\section{Mixing and Feeding}

Mixing in the Fiedler prepug system improved the breakdown and dispersion of the biosolids over the bench scale experience. The resultant consistency of the mix was a wet powder. The dry wood was fairly effective at mitigating or masking the odor of the biosolids. There were no handling difficulties in either the mixer or the feeder.

Previous bench-scale work had demonstrated the benefit of mulling the mix to improve moisture distribution to the wood. The extent to which good moisture distribution is achieved determines the uniformity of the pellet surface, and minimizes the swelling or "springback" of the pellets as they emerge from the die. To accomplish the mulling step, the mix was put through a single pass of the extruder's sealing die, fitted with a sealing screen of 5/8" holes. A shredder attachment was also installed at the exit of the sealing die. Initially the mix resisted flowing through the sealing die. The pug drive current draw was high and very little material passed through the shredder. A majority of the mix simply back-fed to the pug. Only when the temperature of the mix reached $+93^{\circ} \mathrm{C}\left(+200^{\circ} \mathrm{F}\right.$ ) (the point where steam emerged from the material) did material flow begin through the sealing die. The consistency of the mix produced by this first pass through the sealing die appeared homogeneous and plastic. In retrospect, additional mulling of the mix may not have been necessary. However, for this first pilot-scale run, procedures developed at bench-scale were followed and the mix was returned to the feeder for an additional pass through the sealing die. 


\section{Extrusion}

Die: $5 \mathrm{~cm}$ (2") Carbon Steel

Pellet Diameter: $1.9 \mathrm{~cm}(3 / 4 ")$

The experience at start-up through the pelletizing die was very similar to the initial experience through the sealing die. Auger drive current was near overload until the operating temperature increased, at which time the power returned to a normal level and material flowed smoothly. Auger barrel temperatures climbed steadily to $57^{\circ} \mathrm{C}\left(135^{\circ} \mathrm{F}\right)$, but were easily kept under control by the auger barrel cooler.

\section{Drying}

Dry Bulb Temperature: $177^{\circ} \mathrm{C}\left(350^{\circ} \mathrm{F}\right)$

Feedrate: $1.8 \mathrm{~kg} / \mathrm{min}(4 \mathrm{lb} / \mathrm{min}$.)

Hot Zone Residence: 40 min.

Drying the AFP biomass pellets was accomplished in a single pass through the Procter Schwartz pilot-scale conveyor dryer. Because of high mix moisture content and the large diameter of the pellets, demand on the dryer was high. For this first test, the dryer temperature was conservatively set at $177^{\circ} \mathrm{C}\left(350^{\circ} \mathrm{F}\right)$, and belt speed was adjusted to produce a hot zone residence of about 40 minutes. Overall system throughput under these conditions was limited to $1.8 \mathrm{~kg}(4 \mathrm{lb} / \mathrm{min})$ and dryer performance was simply monitored to serve as a platform for future tests. Under these conditions, residual pellet moisture, sampled at the cooler discharge, was 17 percent.

Sample ID\# 12089901

Mix Formula: 38/32/30: Biosolids/Wood/Coal Fines

Mix Moisture: $46 \%$

Mixing and Feeding

Mixing in the Fiedler prepug mixer was again very good. To try and maximize moisture distribution to the wood, the biosolids and wood were mixed together first, and then the coal was added. The mix passed cleanly through the feeder without difficulty. In this test, the mixing was completed in a single pass through the extruder sealing die.

\section{Extrusion}

Die: $5 \mathrm{~cm}(2 ")$ Carbon Steel

Pellet Diameter: $1.9 \mathrm{~cm}(3 / 4 ")$

The extrusion experience was similar to the previous production run. Initially the mix resisted extrusion, the current drawn by the drives was high, and very little material flowed through the system. However, once the operating temperature rose, flow improved dramatically. Throughout the run, steam emanated from pellets as they emerged from the die. Barrel temperatures rose quickly, but were kept under control by cooling the auger barrel. During the run, barrel temperatures were maintained over a range of from $26^{\circ} \mathrm{C}$ to $47^{\circ} \mathrm{C}\left(80^{\circ} \mathrm{F}\right.$ to $\left.117^{\circ} \mathrm{F}\right)$. In general, cooler barrel temperatures improved the appearance of the pellets. Extruder throughput was intentionally limited to $1.6 \mathrm{~kg} / \mathrm{min}(3.5 \mathrm{lb} / \mathrm{min})$, to reduce the demand on the dryer.

Pellet green strength and handleability were good. Some fines were created during pellet cutting, conveying, and sweep feeding into the dryer. These fines tended to be large .32-cm $\left(1 / 8^{\prime \prime}\right)$ and probably related to the particle size of the wood. 


\section{Drying}

Dry Bulb Temperature: $204-232^{\circ} \mathrm{C}\left(400-450^{\circ} \mathrm{F}\right)$

Feedrate: $1.6 \mathrm{~kg} / \mathrm{min}(3.5 \mathrm{lb} / \mathrm{min})$.

Hot Zone Residence: 44 min.

One focus of this session was to maximize the operating conditions in the dryer in order to reduce the residual moisture level in the finished pellets. Belt speed was reduced to $7.6 \mathrm{~cm} / \mathrm{min}(3 \mathrm{in} / \mathrm{min})$, resulting in a hot zone residence time of 44 minutes. Dryer temperature was initially set at $232^{\circ} \mathrm{C}\left(400^{\circ} \mathrm{F}\right)$. The exhaust damper angle was increased from 30 to 45 degrees (from horizontal). The green pellet feedrate of $1.6 \mathrm{~kg} / \mathrm{min}(3.5 \mathrm{lb} / \mathrm{min})$ produced a bed depth of $2.5-\mathrm{cm}$ to $3.8-\mathrm{cm}$ (1-1.5").

Midway through the test, the dryer temperature was raised from $204^{\circ} \mathrm{C}$ to $232^{\circ} \mathrm{C}\left(400^{\circ} \mathrm{C}\right.$ $450^{\circ} \mathrm{F}$ ). By raising the temperature, drying time and throughput can be increased. Also, the throughput can be increased by increasing the hot gas flow and increasing the bed depth and reducing dryer belt speed. The challenge with increasing dryer gas temperature is the potential for igniting the fuel pellets. Besides assessing the increase in drying rate, it was also of interest to determine the temperature at which pellet ignition becomes a problem. Testing showed that increasing the dryer gas temperature to $232^{\circ} \mathrm{C}\left(450^{\circ} \mathrm{F}\right)$, could produce small fires on the dryer belt, so the dryer temperature was again set to $232^{\circ} \mathrm{C}\left(400^{\circ} \mathrm{F}\right)$. The potential for fire in the dryer is a function of pellet moisture content, temperature and hot gas oxygen content. It is not uncommon to initiate dryer fires while processing flammable materials. Commercial dryers have fire suppression systems that mitigate fires. In the test dryer, a water sprinkler system is installed to extinguish any fire. For the small pellet fire that occurred during this test, a simple manual dose of water put out the fire.

The dryer temperature was raised again, from $204^{\circ} \mathrm{C}$ to $218^{\circ} \mathrm{C}\left(400^{\circ} \mathrm{F}\right.$ to $\left.425^{\circ} \mathrm{F}\right)$. This quickly produced several "hot spots", or smoldering red hot pellets, but no open flames. The dryer temperature setting was again reduced to $232^{\circ} \mathrm{C}\left(400^{\circ} \mathrm{F}\right)$, and kept there throughout the rest of the run. The $232^{\circ} \mathrm{C}\left(400^{\circ} \mathrm{F}\right)$ gas temperature seems to be the maximum temperature at which this pellet formula can be safely dried. Residual pellet moisture under these dryer conditions was an acceptable 5 percent.

\section{Sample ID\# 01140001}

Mix Formula: Biosolids 27\% / Wood (-1/8") 23\% / Coal Fines 50\% Mix Moisture: $43 \%$

This production completed the series of AFP pellet formulations containing wood waste. Coal fines content was maximized to produce a pellet that would easily pulverize. Biosolids were utilized "as received" from the Palo Alto WWTP. No dewatering was performed due to the high coal content of this mix. Wood waste was collected from the Carrera millworks and particles were screened to $-.32 \mathrm{~cm}(-1 / 8$ "). The coal fines were Pittsburgh \#8, -28 mesh. Mixing was carried out in the Fiedler prepug. Wood and biosolids were premixed to promote moisture distribution to the wood. The final mixture ran exceptionally well through the machinery

\section{Extrusion.}

Die: $5 \mathrm{~cm}$ (2") Carbon Steel

Pellet Diameter: $1.9 \mathrm{~cm}(3 / 4 ")$ 
The extrusion was smooth and without incident. Extruder throughput was deliberately restricted to $1.8 \mathrm{~kg} / \mathrm{min}(4 \mathrm{lb} / \mathrm{min})$ (wet) to avoid exceeding the capacity of the dryer. Green pellet appearance was generally good with some occasional surface cracks. This condition improved when the extruder barrel temperatures rose and stabilized between $43^{\circ} \mathrm{C}$ to $48^{\circ} \mathrm{C}(110$ to $120^{\circ} \mathrm{F}$ ) mixture temperature. Green pellet strength and handleability were also both good.

\section{Drying.}

Dry Bulb Temperature: $232^{\circ} \mathrm{C}\left(400^{\circ} \mathrm{F}\right)$

Feedrate: $1.8 \mathrm{~kg} / \mathrm{min}(4 \mathrm{lb} / \mathrm{min})$.

Hot Zone Residence: $35 \mathrm{~min}$.

The dryer was operated at near maximum drying conditions. The dry bulb setting was $400^{\circ} \mathrm{F}$, and the hot zone residence time was 35 minutes. Bed depth was 3.8-cm (1-1/2"), or about two pellets deep. Under these operating conditions, the dryer needed to be continuously monitored for fires. Early in the run, a fire did occur, closely followed by two "hot spot" incidents. These were quickly controlled by a water spray. The rest of the drying session was trouble free. Residual moisture in the product ranged from 6 to 10 percent. Final moisture, tested on $1 / 17 / 00$, was 7 percent.

Sample ID\# 01210001

Mix Formula: 50/50 Biosolids/Paper

Mix Moisture: $46 \%$

This production was the first pilot-scale production in a series of AFP formulations containing paper products and plastic. Lab-scale procedures for preparing an extrudable mix from these raw materials were now tested at pilot-scale.

Before combining the raw materials, paper products were reduced to particles of approximately $2.5-\mathrm{cm}(1 ")$ in the hammer type mill. Initial mixing was performed in the Fiedler prepug. At startup, the mixer immediately seized, due to the highly abrasive nature of the dry paper. Thereafter, paper particles were added gradually to the biosolids. The resultant material consistency was the same as had been produced at lab-scale. The biosolids were well dispersed throughout the paper particles. Paper particle size remained unchanged.

The consistency of the mix, as discharged from the prepug, was not well suited to the Altex apron feeder. This feeder has a rectangular outlet gate and the height of the gate is varied to control flow rate. Because of the large paper particle size, material tended to accumulate and block the outlet. Raising the gate on the feeder helped minimize this tendency and the feeder was able to continue operating. A pug mill or screw conveyor would be a better equipment selection at this point in the mixing process. As the consistency of the mix changed with subsequent passes through the sealing die, so did the performance of the feeder.

In order to create a homogeneous mix of reasonable plasticity for extrusion, the paper particles needed further reduction. To accomplish this, the mixture was "mulled" by passing it through the sealing die of the extruder without pelletizing. This die is fed by the pug screw and precedes the main auger and die. Because of the large paper particle size, no attachments (i.e. sealing screen, shredder) were installed that might have become blocked and restrict material flow through the sealing die. Mulling the mix redistributed moisture from the biosolids to the paper, which then begins to break down producing a paste like consistency in the mix. The mix 
was also warmed as machine operating temperature increased. This promoted moisture redistribution, softened the mix, and greatly improving flow characteristics.

The first pass through the sealing die was difficult. Initially at cold startup the mix just filled and plugged the sealing die. When operating temperature rose, flow began very slowly through the sealing die. However, as incoming fresh material brought the operating temperature down again, the flow again stopped. One effective technique that minimized this problem was reducing the RPM of the pug shaft. This slowed the flow of fresh material into the sealing die, and helped to maintain operating temperature. During the second pass through the sealing die just prior to pelletization material flow was much more consistent.

\section{Extrusion:}

Die: $5 \mathrm{~cm}$ (2") Carbon Steel

Pellet Diameter: $1.9 \mathrm{~cm}(3 / 4 ")$

The extrusion proceeded smoothly from start up. Both the pug and auger drive power needs were high, reflecting the high-fiber content of the mix. Pellet appearance was fair at the die but, within seconds of leaving the die, pellets swelled and became lumpy and uneven. Extruder barrel temperatures were allowed to rise to $60^{\circ} \mathrm{C}\left(140^{\circ} \mathrm{F}\right)$, but pellet surface quality did not improve. The barrel temperature was then cooled to $35^{\circ} \mathrm{C}\left(95^{\circ} \mathrm{F}\right)$, which noticeably improved pellet appearance. Still there were lots of surface nonuniformities, thought to be the result of lumps of unpulped paper in the mix.

\section{Drying: \\ Dry Bulb Temperature: $232^{\circ} \mathrm{C}\left(400^{\circ} \mathrm{F}\right)$ \\ Feedrate: $1.8 \mathrm{~kg} / \mathrm{min}(4 \mathrm{lb} / \mathrm{min})$. \\ Hot Zone Residence: $35 \mathrm{~min}$.}

This production run was the first experience at pilot scale with a paper-based pellet. Dryer performance data was recorded to serve as a reference for future tests. Residual pellet moisture content under the operating conditions was 10 percent. When dried, the nonuniformities that developed on pellet surfaces shortly after extrusion became even more pronounced. There were no indications during testing that more aggressive drying would cause ignition problems in the dryer.

Sample ID\# 02220001

Mix Formula: Biosolids 24\% / Paper 24\% / Plastic 2\% / Coal Fines 50\% Mix Moisture: $55 \%$

This production was the first at pilot scale to include plastic film particles in the formula. Plastic film was acquired as $0.75-\mathrm{ml}$ trash can liners blow molded from HDPE. Before mixing, the particle size of the plastic film was reduced to approximately 8 mesh in a Multishear disk attrition mill. Again, before mixing, the particle size of the paper products was reduced to approximately $2.5 \mathrm{~cm}$ (1") in a hammer-type mill. Biosolids, from the Palo Alto WWTP, was dewatered mechanically in the pilot scale press. Coal fines were Pittsburgh \#8, -28 mesh. The coal fines used in this test contained 20 percent moisture, which effectively raised overall mix moisture by 10 percent. Under real world conditions, variations in moisture from one or more of the raw materials will have to be tolerated by the process. The impact of additional mix moisture was evident throughout the system. 
Initial mixing was carried out in the Fiedler prepug. Paper and biosolids were premixed to promote moisture distribution to the paper. Paper and plastic were added gradually to the biosolids to avoid strain on the mixer.

The mixture was then mulled to repulp the paper products with a pass through the extruder sealing die. Finally coal fines were added to the mixture in a second pass through the Fiedler prepug.

\section{Extrusion.}

Die: $5 \mathrm{~cm}$ (2") Carbon Steel

Pellet Diameter: $1.9-\mathrm{cm}(3 / 4 ")$

The extrusion was uninterrupted and smooth. Unlike the previous production without coal fines in the formula, the pellets produced in this run were smooth and uniform. The high moisture content of the mix limited the operating temperature of the extruder, which stabilized at only $29^{\circ} \mathrm{C}\left(85^{\circ} \mathrm{F}\right)$. Likewise, auger and pug drive power needs were very low. The green pellets were somewhat soft, and fines were created at the pellet cutter, and on conveyances to the dryer. Still, pellets were manageable.

More uniformly sized plastic particles would have improved the pellet production. During production, partial blockages developed in several of the die holes, which then produced incompletely formed pellets. These were accumulations of longer plastic particles that were settling out from the mix. Less mix moisture would have minimized this settling problem. Also, long plastic particles tended to keep pellets from separating cleanly on the first pass of the pellet cutter blade. Instead, some pellets would hang suspended by uncut plastic particles, until they were knocked down by subsequent passes of the cutter blades. This caused unnecessary damage to the pellet ends, and degraded overall green pellet quality. Modification to the cutter blades might reduce this tendency, and again, less mix moisture would have improved cutter performance.

\section{Drying.}

Dry Bulb Temperature: $191-232^{\circ} \mathrm{C}\left(375-400^{\circ} \mathrm{F}\right)$

Feedrate: $1.8 \mathrm{~kg} / \mathrm{min}(4 \mathrm{lb} / \mathrm{min})$.

Hot Zone Residence: 35 min.

Initial dryer operation was at $232^{\circ} \mathrm{C}\left(400^{\circ} \mathrm{F}\right)$, with a hot zone residence time of 35 minutes. Bed depth was $2.5-\mathrm{cm}$ to $3.8-\mathrm{cm}$ (1-1/2"), or about two pellets deep. Under these operating conditions, the dryer needed to be continuously monitored for fires. Midway through the run, incidents of "hot spots" in the dryer began to regularly occur. The high percentage of fines and incomplete pellets were the likely cause of the problem. Dryer operating temperature was reduced to $191^{\circ} \mathrm{C}\left(375^{\circ} \mathrm{F}\right)$, and the rest of the drying session was trouble free. In spite of the high moisture content in the green pellets, residual moisture in the product ranged from only 3 percent at $232^{\circ} \mathrm{C}\left(400^{\circ} \mathrm{F}\right)$, to 7 percent at $191^{\circ} \mathrm{C}\left(375^{\circ} \mathrm{F}\right)$.

Sample ID\# 02230001

Mix Formula: Biosolids 40\% / Paper 56\% / Plastic 4\% Mix Moisture: 55\% 
In this pilot-scale run, the AFP formula was modified to accommodate the additional moisture in the mix that would occur in the absence of secondary biosolids dewatering. Moisture in the biosolids as received from the Palo Alto WWTP measured 72 percent. Paper products and plastic in the mix were added in proportions consistent with their natural occurrence in a separated MSW light fraction. Before mixing, paper particle size was reduced to approximately $2.5 \mathrm{~cm}$ (1") in the hammer-type mill. Plastic film was reduced to particles of approximately 8 mesh in a Multishear disk attrition mill.

Initial mixing was carried out in the Fiedler prepug. Paper and plastic were added gradually to the biosolids to avoid strain on the mixer. The mixture was discharged to the Altex apron feeder and then mulled to repulp the paper products, with a single pass through the extruder sealing die. In spite of the high moisture content, material behavior through the sealing die was similar to our previous experience with paper based formulas. Only after operating temperature rose would the mix begin to flow.

\section{Extrusion.}

Die: $5 \mathrm{~cm}$ (2") Carbon Steel

Pellet Diameter: $1.9 \mathrm{~cm}(3 / 4$ ")

The extrusion was smooth and uneventful. Initially, extruder throughput was deliberately limited to $1.6 \mathrm{~kg} / \mathrm{min}(3.5 \mathrm{lb} / \mathrm{min}$.) (wet), to avoid exceeding the capacity of the dryer. Late in the session, throughput was increased to $2.3 \mathrm{~kg} / \mathrm{min}(5 \mathrm{lb} / \mathrm{min}$.).

Biosolids were not dewatered before mixing, and so in spite of an adjustment (increased paper fraction) to the formula, overall mix moisture was still high. As the mix flowed through the die, moisture filtered out from the mix, and water droplets fell from the pellets as they emerged. The high mix moisture also contributed to the settling out of longer plastic particles, which accumulated and partially blocked the entrances to some of the holes in the die. Partially blocked die holes produced incomplete, irregularly shaped pellets.

Again, longer plastic particles tended to keep pellets from separating cleanly on the first pass of the cutter blade, and some pellets would hang suspended by uncut plastic, until they were knocked down by subsequent passes of the cutter.

The resultant appearance of the green pellets was only fair. As they emerged from the die, pellet surfaces were slightly irregular. However, within seconds, swelling or "springback" produced large surface bumps and cracks. These irregularities grew much larger in the dryer. Green strength and handleability were also only fair. Excess moisture wetted the conveyor belts to the dryer.

\section{DRYING}

Dry Bulb Temperature: $191-216^{\circ} \mathrm{C}\left(375-420^{\circ} \mathrm{F}\right)$

Feedrate: $1.6-2.3 \mathrm{~kg} / \mathrm{min}(3.5-5 \mathrm{lb} / \mathrm{min})$.

Hot Zone Residence: $30-35$ min.

Initially, the dryer was operated conservatively at $191^{\circ} \mathrm{C}\left(375^{\circ} \mathrm{F}\right)$, with a hot zone residence time of 35 minutes. Bed depth was $2.5-\mathrm{cm}$ to $3.8-\mathrm{cm}(1-1 / 2$ "), or about two pellets deep. Under these operating conditions residual moisture in the pellets was 15 percent, due largely to the high moisture content of the mix. To reduce drying time, dryer temperatures were gradually increased throughout the session, to $216^{\circ} \mathrm{C}\left(420^{\circ} \mathrm{F}\right)$. Residual pellet moisture was reduced to 3 percent. At this point, throughput was increased to $2.3 \mathrm{~kg} / \mathrm{min}(5 \mathrm{lb} / \mathrm{min}$.), and the hot zone residence time was reduced to 30 minutes. The resultant residual moisture content was 
10 percent. There was no evidence that even more aggressive drying would run the risk of a fire in the dryer. This is consistent with our previous experience. AFP pellets without coal in the formula can be safely dried at a higher temperature than pellets formulated with a coal fines addition.

Plastic particles were visible protruding from the ends of freshly cut pellets as they entered the dryer. These particles were not noticeable on dried pellets and so apparently were melted in the dryer. This was also true for plastic particles exposed on pellet surfaces. At $191^{\circ} \mathrm{C}$ $\left(375^{\circ} \mathrm{F}\right)$, pellets ran cleanly through the dryer. But as temperature was increased, pellets began sticking to the belt and to each other. This was determined to be due to the melting plastic particles.

The condition became more pronounced at higher temperatures and left deposits of plastic on the dryer belt. These deposits will accumulate and increase problems with poor release and discharge if pellets that contain plastic particles are dried at temperatures above $191^{\circ} \mathrm{C}\left(375^{\circ} \mathrm{F}\right)$.

Sample ID\# 03010001

Mix Formula: Biosolids 48\% / Paper 48\% / Plastic 4\%

Mix Moisture: $43 \%$

This production run was similar to the previous run, except biosolids were mechanically dewatered before mixing with the other raw materials. This allowed for more biosolids in the formula and also reduced overall mix moisture. As before, the particle size of the paper products was reduced to approximately $2.5 \mathrm{~cm}$ (1") and plastic film was reduced by Multishear to particles of approximately -8 mesh.

Initial mixing was carried out in the Fiedler prepug. Paper and plastic were added gradually to the biosolids to avoid strain on the mixer. Friction from the abrasive paper products was evident as steam emanated from the material in the mixer. The mixture was discharged to the Altex apron feeder and then mulled to repulp the paper products with a single pass through the extruder sealing die.

\section{EXTRUSION}

Die: 5-cm (2") Carbon Steel

Pellet Diameter: $1.9-\mathrm{cm}(3 / 4 ")$

Initially at start-up, no material would flow through the pelletizing die. As temperature rose in the auger barrel water began to drip from the die, but there was still no material flow. Incoming material completely filled the auger barrel up to the feed spirals.

To encourage flow the die spacer was removed, effectively bringing the auger $1.3-\mathrm{cm}$ $(1 / 2$ ") closer to the die. On the restart, extrusion began immediately. As they emerged from the die, pellet surfaces were slightly uneven. Within seconds after leaving the die, small bumps and depressions began to develop on pellet surfaces. Throughout the production session, water continued to filtered out from the mix as it flowed through the pelletizing die.

Halfway through the session, fresh material plugged the sealing die which had to be manually cleared. The pug shaft RPM was reduced to slow the flow of cool fresh material through the sealing die and maintain the operating temperature.

Again, long plastic particles tended to keep pellets from separating cleanly on the first pass of the cutter blade. This caused unnecessary damage to pellets. The resultant appearance of the green pellets was only fair. 
In summary, this paper-based AFP formula displayed some challenging behaviors in the extruder. The reduction in mix moisture, achieved through secondary dewatering of the biosolids, produced a stiffer mix which ran cleanly through the machine without leaving behind accumulations of plastic particles at the die and sealing screen. However, the dramatic temperature related changes to the plasticity of the material and the behavior of the moisture in the mix suggest that this AFP formula might benefit from the addition of an extrusion aid to counter the abrasive nature of the paper fiber. The aid could be another waste product, such as trap grease. The continued separation of moisture is interesting and the basis for this water release will be explored in future efforts.

\section{DRYING.}

Dry Bulb Temperature: $177-232^{\circ} \mathrm{C}\left(350-400^{\circ} \mathrm{F}\right)$

Feedrate: $1.6-2.3 \mathrm{~kg} / \mathrm{min}(3.5-5 \mathrm{lb} / \mathrm{min})$.

Hot Zone Residence: $20-35 \mathrm{~min}$.

Previously, paper-based AFP pellets (without coal additions) had been safely dried at $232^{\circ} \mathrm{C}\left(400^{\circ} \mathrm{F}\right)$, with a hot zone residence time of 35 minutes, and these were the initial operating conditions in this test. However, a hot spot quickly developed near the discharge of the dryer and so operating temperature was reduced to $191^{\circ} \mathrm{C}\left(375^{\circ} \mathrm{F}\right)$. Hot spots continued to develop, occasionally only midway through the hot zone. The operating temperature was reduced again to $171^{\circ} \mathrm{C}\left(350^{\circ} \mathrm{F}\right)$, but hot spots continued to occur. Finally, the speed of the dryer belt was increased, reducing hot zone residence time to 20 minutes. Water used to control hot spots rewetted most of the final product and residual moisture test results were mixed.

It is likely that residues on the dryer belt, possibly plastic, were the cause of the ignition problems. Previously, productions of paper-based AFP pellets with similar moisture content have been safely dried at $232^{\circ} \mathrm{C}\left(400^{\circ} \mathrm{F}\right)$, and the preceding run at higher mix moisture (55 percent), was safely dried at temperatures of up to $216^{\circ} \mathrm{C}\left(420^{\circ} \mathrm{F}\right)$. The difficulties experienced in the dryer during this run further support the conclusion that pellets formulated with plastic should only be dried at lower temperatures.

\subsection{Pilot-Scale Pellet Production Summary}

\section{Mixing.}

Waste wood particles, biosolids, and coal fines combined easily and an extrudable mix was produced with a single pass through the prepug and pugmill/extruder. However, in order to produce a homogeneous mix with sufficient plasticity from a paper based formula, large paper particles needed to be essentially repulped. The degree to which this repulping was achieved directly determined the flow characteristics of the material in the extruder. While the sealing die of the extruder proved itself adaptable to repulping paper products, multiple passes were required suggesting that it is probably not the optimal equipment choice. On more than one occasion, material stopped flowing through the sealing die and it was necessary to dismantle the machine and manually remove the compacted material. The consistency of the compacted material is at once very sticky and abrasive and it could only be removed with a hammer and punch.

One example of machinery designed more specifically for this type of application is the Multishear disk attrition mill, used in this project to reduce plastic film to particles. The machine grinds, shreds, macerates, and disperses, all in a single step. In the device are two opposing horizontal disks, each with multiple rows of teeth. One disk is fixed and the other disk rotates. Material is pumped in between the disks through the center of the fixed disk and is then driven 
outward by centrifugal force to a discharge on the perimeter. According to the manufacturer, the material is subjected to millions of shears per minute, by the stationary and rotating teeth on the disks. Equipment such as this could mechanically pulp waste wood and paper products, reduce plastic film to particles, and disperse biosolids. The result would be a mixture of the AFP raw materials transformed into an extrusion ready consistency.

\section{Extrusion.}

Heat dramatically changed and benefited the flow characteristics of both wood-based and paper-based AFP pellet formulas. This behavior was more pronounced with the processed paper fibers than with wood. Heat was generated by the abrasive fibrous materials at every process step and the optimal system will conserve that heat as it benefits all subsequent process steps.

A second notable effect of heat on the paper-based formulas was that a considerable amount of water separated out from the mix as it flowed under pressure through the pelletizing die. Water that separated out inside the auger barrel was problematic, creating a "wet behind dry" condition that could stop the extrusion. Water that separated out as the mix moved through the die dripped from the pellets as they emerged. This might be turned to an advantage if a significant moisture reduction is achieved and the water is directed away from the product. Clearly at that moment, the mixture was well conditioned for further moisture removal. Woodbased AFP formulas did not exhibit any similar behavior.

\section{Drying.}

The experience drying biomass pellets at pilot scale, clearly defined dryer operational guidelines for future refinements of the AFP process. First, there is a distinction between the drying of pellets formulated from 100 percent biomass materials and the drying of pellets formulated from biomass with coal fines added to the formula. AFP pellets of 100 percent biomass are more difficult to dry, but can be dried safely at temperatures of $+232^{\circ} \mathrm{C}\left(+400^{\circ} \mathrm{F}\right)$, depending on moisture content. AFP biomass pellets containing added coal fines are more easily dried, but at temperatures above $191^{\circ} \mathrm{C}\left(375^{\circ} \mathrm{F}\right)$, they are likely to develop hot spots in the dryer. It should be noted that the presence and control of hot spots in the drying of combustible materials is not uncommon and modern dryers are equipped with detection and control devices to manage this condition.

Second is the issue of plastics in the pellets. At temperatures above $191^{\circ} \mathrm{C}\left(375^{\circ} \mathrm{F}\right)$, plastic particles in the pellets softened and caused adjacent pellets to stick together in the dryer. Even more problematic, melting plastic particles caused pellets to stick to the dryer conveyor belt, which interfered with release and discharge from the dryer. Furthermore, accumulated plastic residues on the belt are suspected of contributing to problems with ignition in the dryer during subsequent productions of pellets that did not contain plastic.

\subsection{PELLET WEATHERIZATION}

Economical weatherizing of the AFP fuel for transport or storage is challenging. Many agents are available that would perform well. However, the cost of these agents is prohibitive. Consider a commercial sealant that sells in bulk for $\$ 660 /$ tonne $(\$ 600 /$ ton) and that requires an application rate of 5 percent. It would then cost $\$ 33 /$ tonne (\$30/ton) to weatherize the pellet product. Consider also that on a Btu basis, the value of the fuel is only $\$ 16.5 /$ tonne ( $\$ 15 /$ ton). Clearly materials that are themselves wastes or byproducts have to be utilized as the weatherizer, and application rates have to kept to a minimum. These were the two areas of focus in our 
weatherizer developments. Besides cost issues, the biomass pellet is a special challenge to weatherize because the high fiber raw materials have a great affinity for water.

There are two paths for protecting the biomass pellet from moisture. The entire pellet can be formulated with an insoluble binder, which covers the biomass and prevents water infiltration, or the surface of the pellet can be sealed. In light of the application rates that would be required for complete internal water proofing, sealing the pellet surface seems to be the better path.

To evaluate the performance of a weatherizing agent, pellets were submerged in water for periods of 12 to 24 hours. This is an extreme, but very simple and effective test. Even an effective and high cost commercial sealant cannot completely protect pellets in this test, unless it has been very carefully applied.

From preliminary tests, it was learned that materials such as oils, greases and waxes cannot pass a submersion test, no matter how heavy the application. Low-cost new waterproofing materials needed to be identified and tested. One such material investigated was tall oil soap, a byproduct of the Kraft pulping process. It is produced in large quantities by the paper industry and is in good supply in the Great Lakes region. It is not a true waste material, and is sold for $\$ 55-61 /$ tonne $(\$ 50-55 /$ ton). Most tall oil soap is refined to produce tall oil, a commodity worth $\$ 110$ to $\$ 121$ a tonne ( $\$ 100$ to $\$ 110$ a ton), and exported worldwide. Tests of pellets coated with tall oil soap have shown that it has potential as a weatherizer. However, in its virgin state it is semi-soluble, and its effectiveness falls off with time. Therefore, some further processing of this material is needed to optimize its characteristics. Nevertheless, initial tests showed some promise.

Results of a 12-hour submersion test on compressed paper, biomass pellets and biomass pellets with an application of tall oil soap are graphically represented in Figure 13.

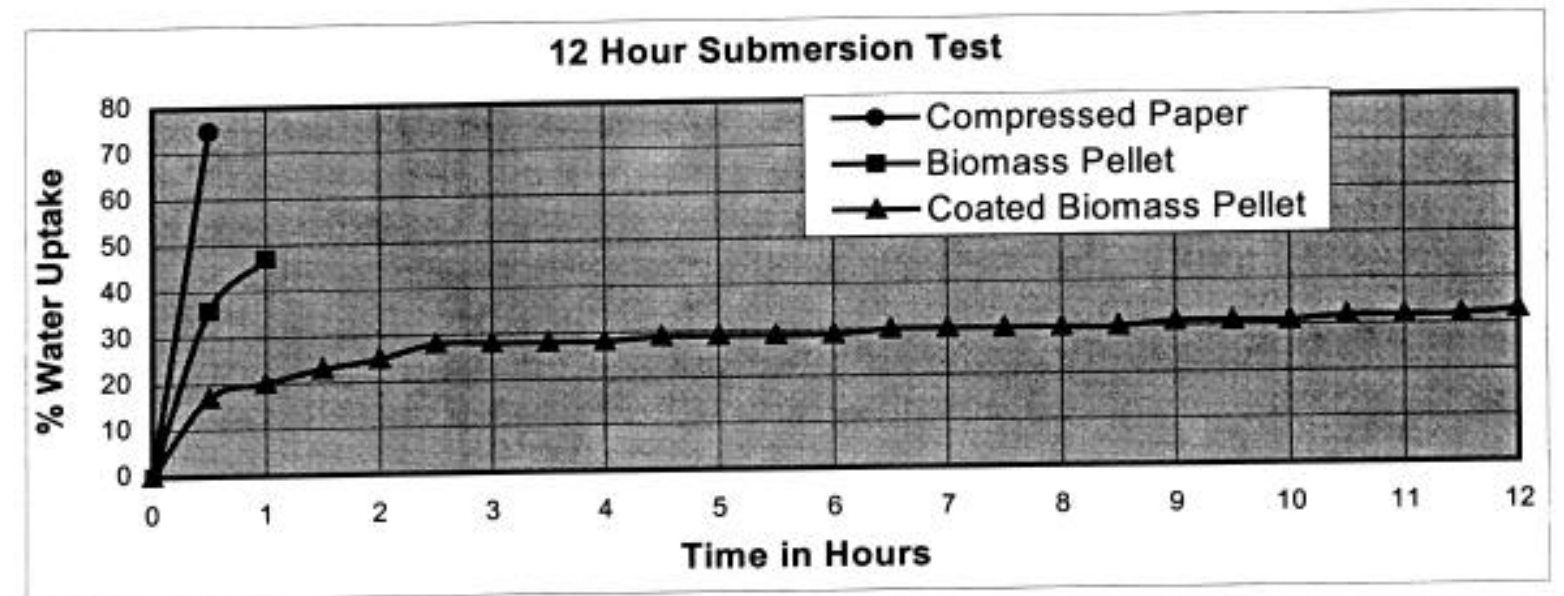

Figure 13 -- Weatherizer: Tall Oil Soap. 12-Hour Submersion Test

As can be seen from the graph, without protection, the compacted paper pellet quickly adsorbed three times its own weight in water and reached a moisture content of 75 percent. It also swelled and disintegrated. The uncoated AFP biomass pellet adsorbed nearly its weight in water within one hour, reaching a moisture content of 50 percent. However, the AFP biomass pellet remained intact. The weatherized pellet adsorbed water equal to one quarter of its dry weight in the first hour and reached a final moisture content of nearly 30 percent at the end of three hours. The superior water repellency of the coated pellets is apparent from these test results. 
In the above tests, the application rate for tall oil soap was about 4 percent. The material cost for this weatherizer, assuming a cost of $\$ 61 /$ tonne $(\$ 55 /$ ton)for the material, would equal $\$ 2.42 /$ tonne ( $\$ 2.20 /$ ton) of product. While the cost is reasonable, it still represents 14 percent of the value of the product as a fuel. It would be a great benefit to develop a less costly and even more effective agent. Work toward that goal continued.

Reducing pellet water uptake will help maintain energy content in all weather conditions. Also, if moisture content is reduced below 10 percent, then pellet decay processes will be reduced. Another approach to reducing pellet decay is to create a "bioshield" around the internally sterilized pellet, where microorganisms cannot survive. It is recognized that lime addition can alter pellet $\mathrm{pH}$ and thereby prevent microorganism colonization, even with some moisture present. To assess the potential for creating a high-pH barrier around pellets, a few green biomass pellets were rolled in lime and then dried. The objective was to develop a finely applied layer of lime on the pellet surface that would act as a microorganism barrier. These applications were all successful at creating a thin crust of lime that would not rub off. Pellets with well-formed surfaces developed the most complete and evenly formed coatings. Also, formulas with higher moisture content developed coatings that appeared heavier. These brief tests suggest that a high-pH barrier can be formed on pellets.

Coating pellets with lime adds only a small weight percent of lime to the pellet. While mixing lime with the pellet was shown to improve the weatherability of pellets, this approach increases the ash content and reduces the energy density of pellets. For stoker fired cases, where pellets are stored outdoors for long periods of time, the higher lime concentration is justified. However, for the anticipated limited storage time associated with cofiring in large power boilers, a minimal lime addition is best. Therefore, the mixed lime case was not emphasized during this test program, and weatherization agents that had fuel value were emphasized.

Waste plastic film, the same material that had been so problematic in the lab-scale production test, was also evaluated for its potential as an effective and economical AFP pellet weatherizer. Plastic film makes up about 5 percent of MSW composition and accounts for nearly 10 percent of the separated light fraction. Pellets, produced from the remaining 90 percent of an MSW light fraction could be easily weatherized with this amount of material. Plastic's high fuel value low-ash content and insolubility in water are also particularly attractive properties.

About 90 percent of all waste plastic films are made from one type of plastic, high density polyethylene (HDPE). This greatly reduces the problems associated with processing mixed resins. To apply the material as a pellet coating, it was first melted in an inert atmosphere to prevent oxidation. Pellet samples were then simply dipped in the melt. The application tended to be heavy because of the viscosity of the melt. A hot melt spray system would be more practical for the application.

AFP pellets, coated with remelted waste plastic, were completely submerged in water to test the performance of the material as a weatherizer. Results of the test are graphically illustrated below in Figure 14. 


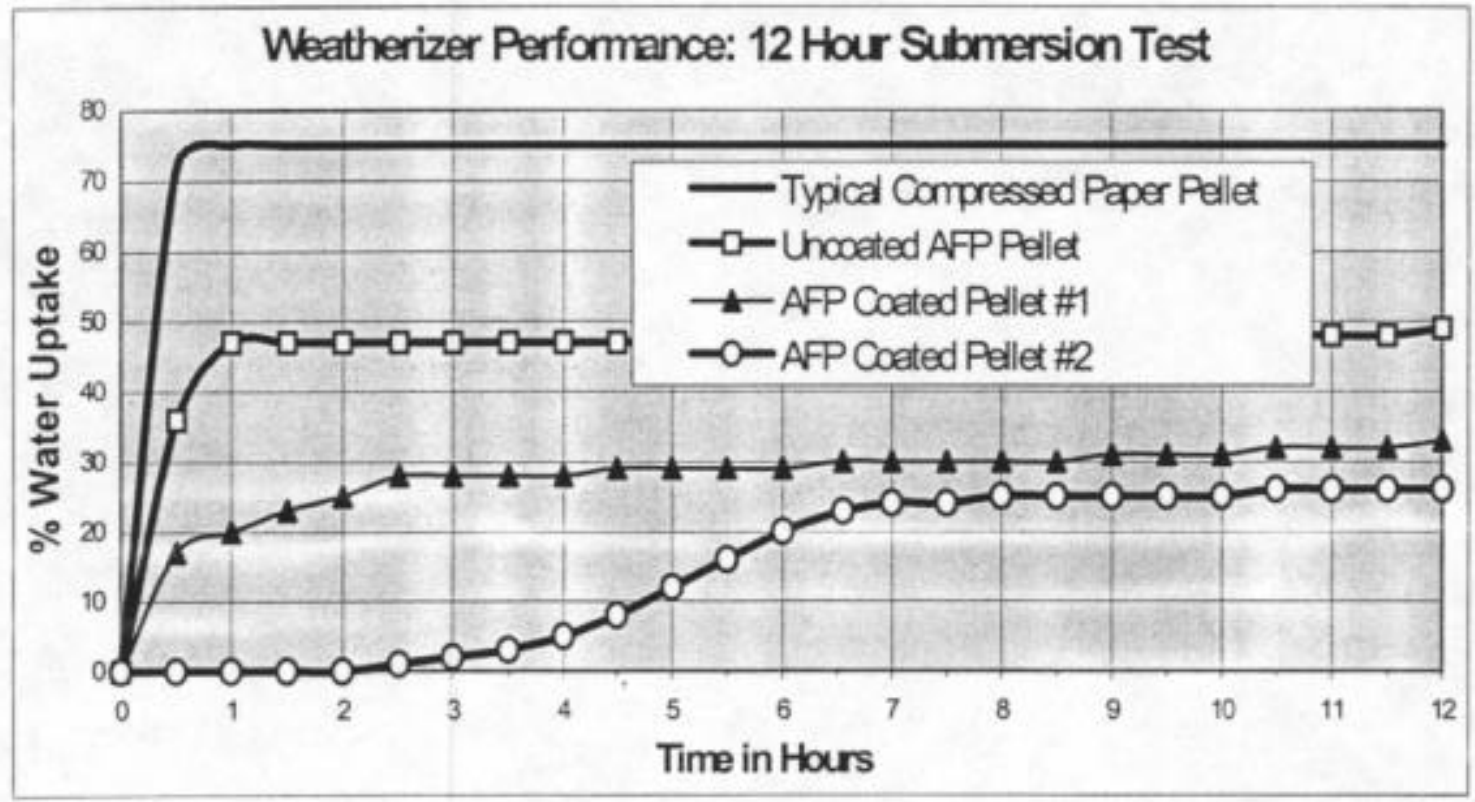

Figure 14 -- Weatherizer Submersion Test Results

The top line in the graph represents the water uptake of a conventional compacted waste paper pellet when submerged in water. As can be seen, without protection, the compacted paper pellet quickly absorbed three times its own weight in water. It also swelled and disintegrated. An uncoated AFP pellet absorbed its weight in water within one hour. The AFP coated pellet \#1 was treated with an application of tall oil soap as described earlier. Water uptake within the first hour was limited to only 20 percent and rose overall to only 32 percent during the twelve hour period. The AFP coated pellet \#2 was dipped in the melt of waste plastic. During the first two hours of the test, pellet \#2 was completely protected from any measurable water uptake. After 4 hours of submersion, water uptake had only reached 6 percent. However, within six hours, swelling in the pellet caused cracks in the protective plastic coating, which allowed more water to infiltrate the pellet and total uptake reached 20 percent. Although the waste plastic coating did not provide complete protection beyond the first two hours, it still outperformed all other weatherizers tested.

As a reference, it was decided to test the performance of commercial weatherproofers and sealants to determine the degree of protection that might be achieved with an "ideal" weatherproofing agent.

The first sealant tested was a commercial wood protection product manufactured by Armorall. The sealant was generously applied, allowed to dry, and then a second coat was added to ensure the pellet surfaces were completely sealed. The second sealant tested was Aqualene a commercial latex product, manufactured as a coating for durable paper products such as food packaging. It was also applied twice to maximize the protection it could provide the pellets. In both cases, the application rates were exaggerated in order to maximize the effectiveness of the sealant. Coated pellets were then completely submerged in water and their moisture uptake, measured as an increase in weight, was tested at 2-hour intervals for 24 hours. Results of the tests are graphically displayed in Figures 15 and 16 below.

As can been seen in the graphs, these two applied sealants performed very differently in the submersions tests. The Armorall product provided almost no protection for either type of 
AFP pellet. Within four hours, water uptake amounted to an overall increase in pellet weight of over 70 percent. The Aqualene product provided a much higher degree of protection, and weight increases due to water uptake were limited to 20 percent in wood pellets and to less than 10 percent in paper pellets, following the first 8 hours of submersion. Based on Altex experience, the performance of the Aqualene was quite good. However, it still falls short of complete pellet protection. Considering the high quality of this sealant, and the high application rate in this test, complete moisture protection for biomass fuel pellets through the application of a surface coating, whether a waste material or an expensive commercial sealer, is very difficult to achieve.

Referring back to the results in Figure 14, a waste plastic coating (Pellet \#2) was applied to AFP paper pellets, which completely kept out moisture after two hours of submersion, and limited water uptake to 25 percent after 8 hours. The commercial sealant Aqualene limited water uptake in the same type of pellet to 25 percent after 16 hours of submersion. It may therefore be concluded that the waste plastic coating is half as effective as the high-cost commercial sealant

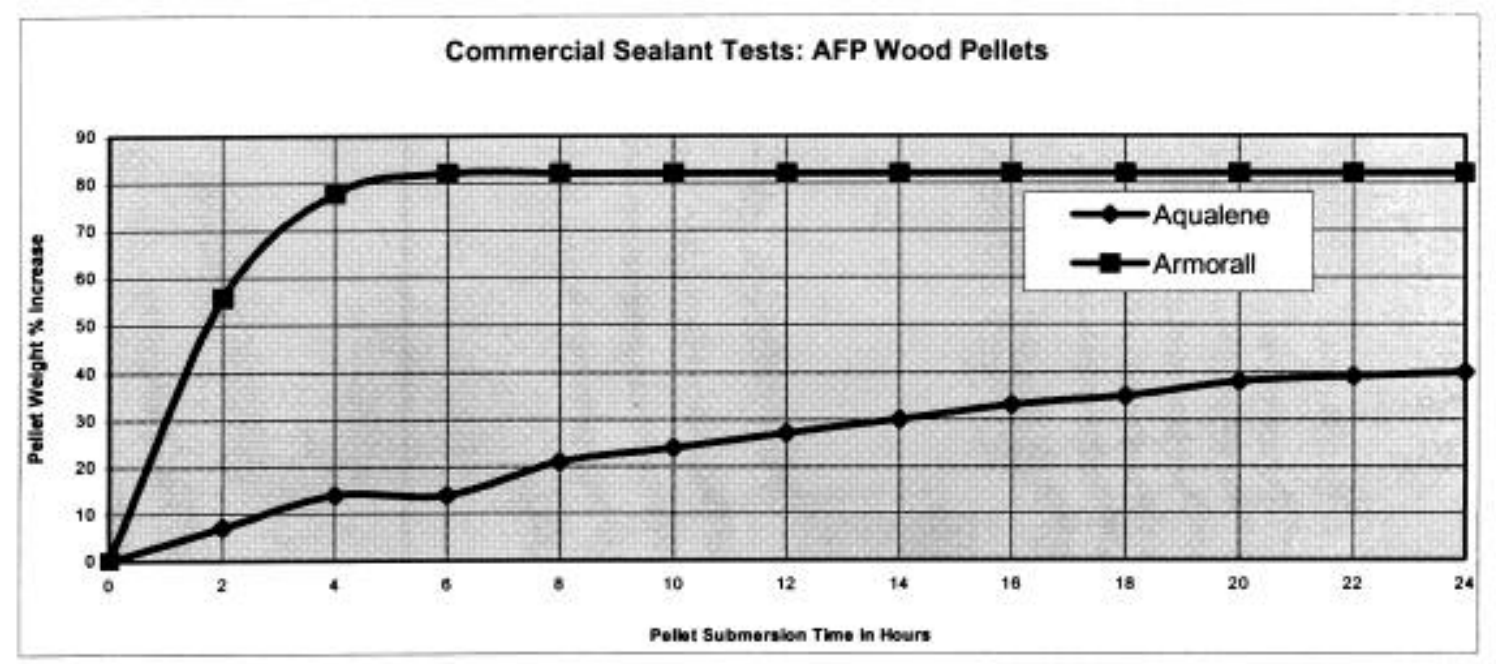

Figure 15 -- Commercial Sealant Tests of AFP Wood Pellets 


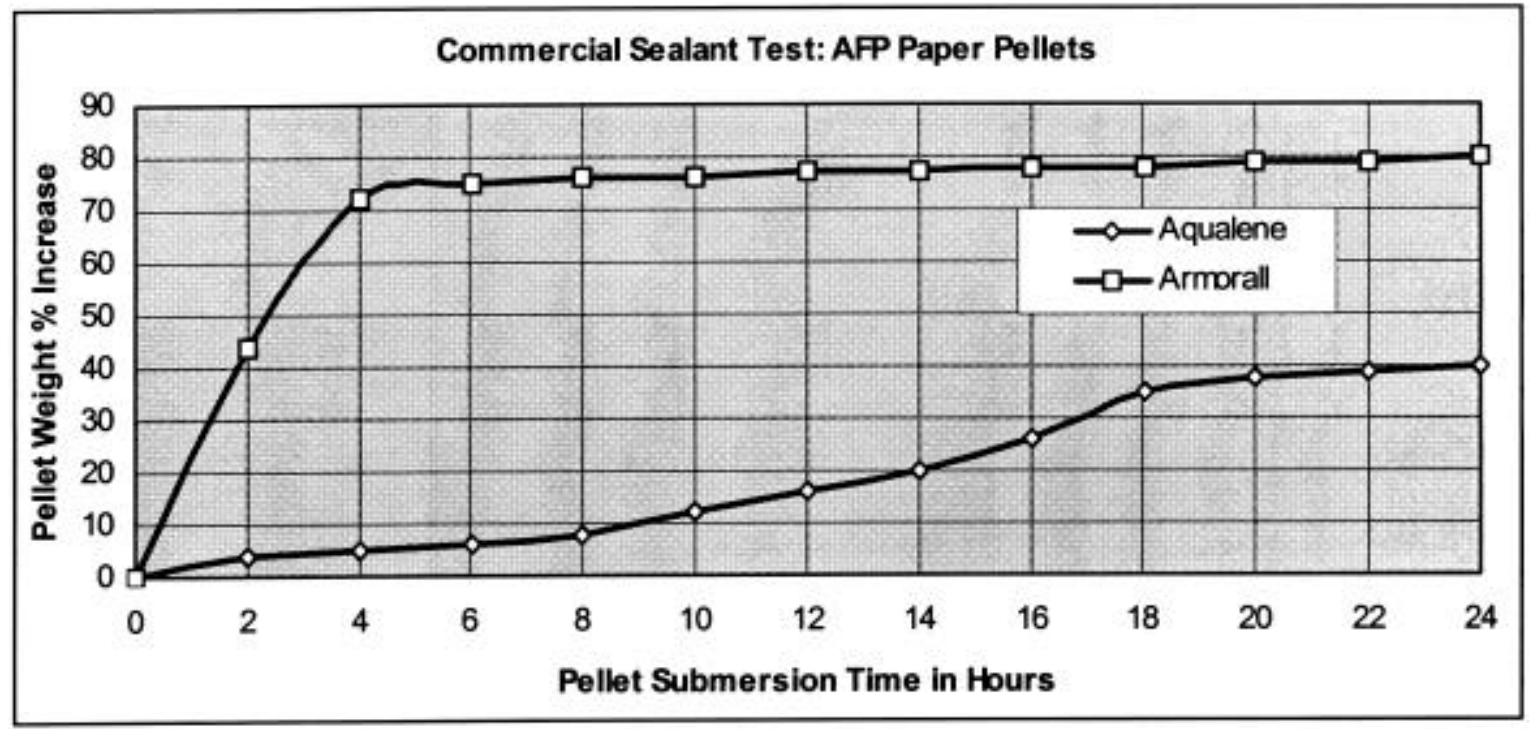

Figure 16 -- Commercial Sealant Tests of AFP Paper Pellets

Submersion is a severe test and under real world conditions very few pellets would actually be subjected to this condition, even in the wettest weather. The performance of the waste plastic coating is considered quite good, relative to the expensive commercial sealants that were tested.

\subsection{PELLET CHARACTERIZATION TESTS}

Pellet characterization covered tests associated with the storage, handling and transport of pellets. In addition, the grinding characteristics of pellet formulations was determined to assess how pellets would behave in existing pulverized fuel processing and handling equipment. Characterization tests covered pellets produced in bench scale, as well as pilot-scale equipment.

\subsection{Bench-Scale Production Pellet Quality Mixes 9 -- 15}

Pellets produced from selected formulas that included paper, plastics and coal fines in the lab tests were evaluated for quality by measurements of dry pellet diameter (shrinkage), density, axial compression, and durability when dropped from a height to a concrete pad. Results appear below in Table 26. The pellet formulations are given in Table 23.

Table 26 -- Lab-Scale Production Pellet Quality

\begin{tabular}{|c|c|c|c|c|}
\hline Mix \# & $\begin{array}{c}\text { Pellet Diameter } \\
\text { Cm (in) }\end{array}$ & $\begin{array}{l}\text { Pellet Density } \\
\mathrm{Kg} / \mathrm{m}^{\mathbf{3}}\left(\mathrm{lb} / \mathrm{ft}^{\mathbf{3}}\right)\end{array}$ & $\begin{array}{c}\text { Drop to Concrete } \\
\text { m(ft) }\end{array}$ & $\begin{array}{c}\text { Compression } \\
\text { Kg/kN (lbf / psi) }\end{array}$ \\
\hline 9 & $1.24(.49 ”)$ & $783.3(48.8)$ & 9 from $4.5(15 \mathrm{ft})$ & $27 / 2144(60 / 311)$ \\
\hline 10 & $1.42(.56 ”)$ & $582.7(36.3)$ & +10 from $4.5(15 \mathrm{ft})$ & $27 / 2144(60 / 243)$ \\
\hline 12 & $1.22(.48 ”)$ & $672.6(41.9)$ & +10 from $4.5(15 \mathrm{ft})$ & $23 / 1903(50 / 276)$ \\
\hline 13 & $1.27(.50 ")$ & $691.8(43.1)$ & +10 from $4.5(15 \mathrm{ft})$ & $14 / 1055(30 / 153)$ \\
\hline 14 & $1.32(.52 ”)$ & $736.8(45.9)$ & 8 from $4.5(15 \mathrm{ft})$ & $16 / 1138(35 / 165)$ \\
\hline 15 & $1.32(.52 ”)$ & $788.1(49.1)$ & 5 from $4.5(15 \mathrm{ft})$ & $17 / 1207(37 / 175)$ \\
\hline
\end{tabular}


As shown in Table 26, dried pellet diameter variations from the 1.3-cm (.5-in) die diameter are within $11 \%$, indicating that pellet shrinkage or swelling is minor. Given that large amounts of shrinkage or swelling upon drying can degrade the pellet structure, this limited variation in diameter suggests that pellet strength is good. Pellet density is mostly in the range of 642 to $803 \mathrm{~kg} / \mathrm{m}^{3}$ (40 to $50 \mathrm{lbs} / \mathrm{ft}^{3}$ ). The density of coal is $1364 \mathrm{~kg} / \mathrm{m}^{3}\left(85 \mathrm{lbs} / \mathrm{ft}^{3}\right.$ ) or less. Therefore, the density of the pellet material is approximately $50 \%$ that of coal. This is far superior to the unprocessed density of dried biomass, which can be $321 \mathrm{~kg} / \mathrm{m}^{3}\left(201 \mathrm{bs} / \mathrm{ft}^{3}\right)$. As shown in Table 26, three of the formulations exceeded 10 drops to a concrete pad from $4.5-\mathrm{m}$ (15-ft) without damage. Mix \#15 is the only formulation that doesn't survive at least eight drops before breaking. In this case, the coal fines concentration was $50 \%$, which was the maximum fraction tested. Given the large amount of coal fines, the fiber content of this mixture was less than the others tested and resistance to breakage was thereby reduced. While resistance to breakage is important for fuel pellets utilized in stokers, an extremely strong pellet may require excessive grinding energy for a pulverized coal application. This will be discussed further in the following section.

Another indicator of the importance of fiber content was the axial compression strength test results in Table 26. Paper based pellet formulations have substantially higher crush strength than sawdust based pellets. The force required to crush paper-based pellets is nearly twice that force required to crush sawdust-based pellets. This substantial difference is believed to be a result of the extended fibers from the paper that, when combined with the biosolids, creates a strong composite type material that is resistant to crushing. Unlike coal, fibrous pellets deform under pressure, whereas coal fractures. This pellet crush resistance and strength is ideal for stoker applications, where coal decrepitation and excessive fines create operational problems. However, in utility boiler applications, if pellets are too strong, then pulverization equipment and energy costs will be higher than desired.

To examine pellet grindability, a new test was added to the pellet quality test series which simulated initial crushing conditions in a coal pulverizing mill. The purpose of the test was to evaluate the initial crush response of AFP pellets in typical coal pulverization equipment. These initial crushing tests at Altex were then followed by pulverization tests at Hazen Research Inc., where the pellets were ground to a utility size specification. It is important to understand how compatible pellets would be with pulverization equipment typically used at PC powerplants.

It was expected that highly fibrous biomass materials would not grind well in equipment designed for pulverizing minerals. Coal is a relatively brittle material that fractures when crushed. With fiber-based pellets, while the material deforms under pressure, it does not easily fracture. The reason for this is the flexibility and resilience of the fibers. As noted earlier, this resilience is advantageous for stoker applications. However, for PC boilers, where pellets are pulverized before firing, the high pellet strength and resiliency is of less importance and grindability is of more importance. For these PC cases, reducing pellet resiliency and improving grindability would be beneficial. In order to reduce pellet resiliency, AFP pellets were produced from formulas containing various amounts of coal fines. It was speculated that, the addition of coal fines to the matrix would segregate bonded fiber bundles, and produce a response to crushing that more closely resembled lump coal.

The crush test was designed to evaluate the initial response of whole pellets to the action of a ball-and-race, or roller-and-race type mill. The test was not intended to produce a fine grind, but to examine how AFP pellets fracture and separate into smaller fragments that would subsequently be further reduced by a pulverizer. 
The test fixture was simple. The pulverizer race was simulated by a length of $7.6 \mathrm{~cm}$ (3") steel "C" channel. The roller was a 7.6-cm (3-in) wide steel wheel, 46-cm(18-in) in diameter that fit into the " $\mathrm{C}$ " channel. Pellets were laid down inside the channel, and crushed by rolling over them with the steel wheel. Each test was terminated after ten passes of the wheel. The pellet fragments were carefully collected, stage screened, and weighed. Results were reported as the percentage of the total sample weight that passed each stage of the screening. To calibrate the fixture, a test was performed on a sample of like sized lump coal and an AFP pellet produced without any coal fines addition. The results of crush tests, performed on AFP pellets produced at lab scale, are graphically illustrated in Figure 17 below.

From the graph, the impact of coal fines additions on the crush response of AFP pellets formulated with wood is clear. The bottom curve in the graph shows the particle size distribution of a crushed AFP pellet produced without any coal fines addition. The curve at the top of the graph shows the resultant particle size distribution of a crushed sample of lump coal. Comparing these two results, it can be seen that, under the same grinding action, the coal is reduced to a much finer size than the pellets. For the pellets, $20 \%$ of the crushed material was greater than 8-mesh, whereas $20 \%$ of the crushed coal was less than 25-mesh, for the same grinding action. Therefore, pellets are more resistant to crushing than coal. However, as fine coal was added to the pellet mix, the pellet crush response improved. With a coal fines addition of 50 percent, the crush response of the AFP was almost identical to that of the sample of lump coal. These results indicated that, depending on the application, the crush response of AFP could be adjusted, through the addition of coal fines.

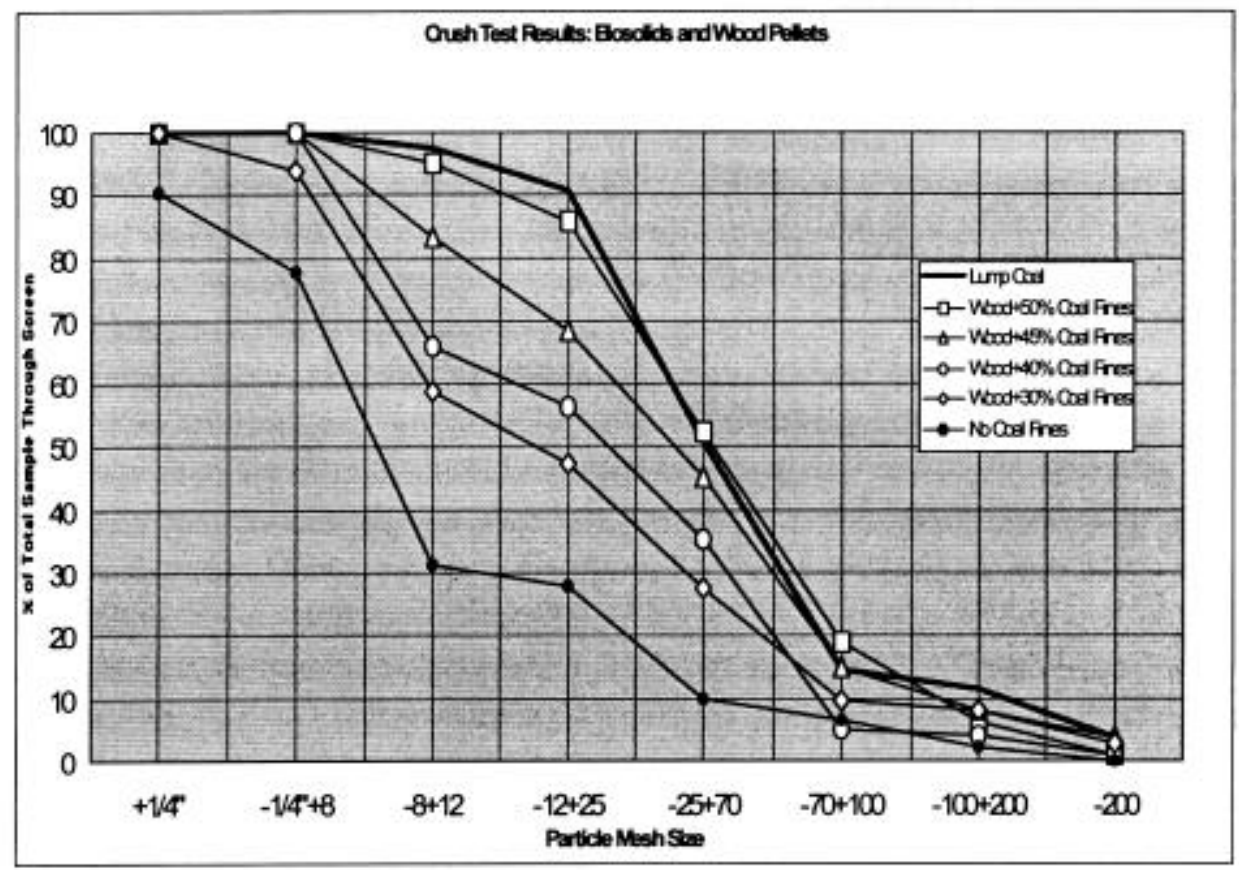

Figure 17 -- Lab-Scale Production Crush Test Results

\subsection{Bench-Scale Production Pellet Quality Mix 16-20}

Pellets produced at lab scale that were formulated to increase grindability were evaluated for quality by measurements of dry pellet diameter (shrinkage/swelling), dry pellet density, strength under axial compression, durability when dropped from a height to a concrete pad, and 
loss due to abrasion. Results appear below in Table 27. The pellet formulations were listed previously in Table 24.

Table 27 -- Lab Scale Production Pellet Quality

\begin{tabular}{|c|c|c|c|c|c|}
\hline$\underset{\#}{\operatorname{Mix}}$ & $\begin{array}{c}\text { Dry Pellet } \\
\text { Diameter } \\
\text { Cm (in) }\end{array}$ & $\begin{array}{c}\text { Dry Pellet } \\
\text { Density } \\
\mathrm{Kg} / \mathrm{m}^{3}\left(\mathrm{lb} / \mathrm{ft}^{3}\right)\end{array}$ & $\begin{array}{c}\text { Drop to Concrete } \\
\text { m(ft) }\end{array}$ & $\begin{array}{c}\text { Compression } \\
\text { Kg/kN (lbf / psi) }\end{array}$ & $\begin{array}{c}\text { Abrasion } \\
\text { Loss \% }\end{array}$ \\
\hline 16 & $.94(.37)$ & $610.0(38)$ & +10 from $4.5(15 \mathrm{ft})$ & $11 / 1600(25 / 232)$ & $<1$ \\
\hline 17 & $1.3(.51)$ & $802.6(50)$ & 9 from $4.5(15 \mathrm{ft})$ & $20 / 1517(45 / 220)$ & 2.6 \\
\hline 18 & $1.2(.49)$ & $915.0(57)$ & 10 from $4.5(15 \mathrm{ft})$ & $70 / 5667(155 / 822)$ & 2.3 \\
\hline 19 & $2(.78 *)$ & $658.1(41)$ & +10 from $4.5(15 \mathrm{ft})$ & $36 / 1151(80 / 167)$ & 4.9 \\
\hline 20 & $1.1(.47)$ & $771.0(48)$ & +10 from $4.5(15 \mathrm{ft})$ & $39 / 3378(85 / 490)$ & 3.0 \\
\hline
\end{tabular}

*1.9cm(.75") Die.

As shown in Table 27, with the exception of Mix\#16, consisting of 100 percent biosolids, dried pellet diameters variations remained close to the original diameter of the die, indicating only minor pellet shrinkage or swelling. Pellet densities ranged from 610 to $915 \mathrm{Kg} / \mathrm{m}^{3}$ (38 to 57 $\mathrm{lbs} / \mathrm{ft}^{3}$ ). The low density of Mix \#16 resulted from the high moisture content of the biosolids. The low density of Mix \#19 reflected the lack of plasticity and poor forming characteristic of an AFP formula with a 60 percent added coal fines fraction. The high density of Mix\#18 reflects its formulation with large dense coal particles. All the pellet samples reflect the general relationship between pellet density and strength. The primary focus of these lab-scale productions was to evaluate performance in the crush test, the results of which are discussed below.

Prior test results had shown how coal fines additions to the wood-based AFP biomass formula effectively altered the crush response of the pellets. In this lab scale test series, additions to the paper-based AFP formula were also tested. Tests used the roller-and-race crush apparatus described previously. The same procedures applied in the earlier crush test series were applied to these tests.

The curve at the top of the graph in Figure 18 represents the response of a sample of lump coal in the crush test. The remaining curves represent the crush response of the varied paper- based pellet formulas produced at pilot scale. What is apparent from these curves is that coal fines additions to paper-based pellet formulas provided very little improvement to their performance in the crush test. This is in sharp contrast to the pellets produced from wood based formulas, whose crush response could be tailored by coal fines additions, to match the response of lump coal. Only when plastic particles were added to the paper-based formula was the crush response of these pellets substantially altered. Because the plastic does not bond with the paper-fibers, particles of plastic create weak spots in the matrix where fracture can occur under pressure. 


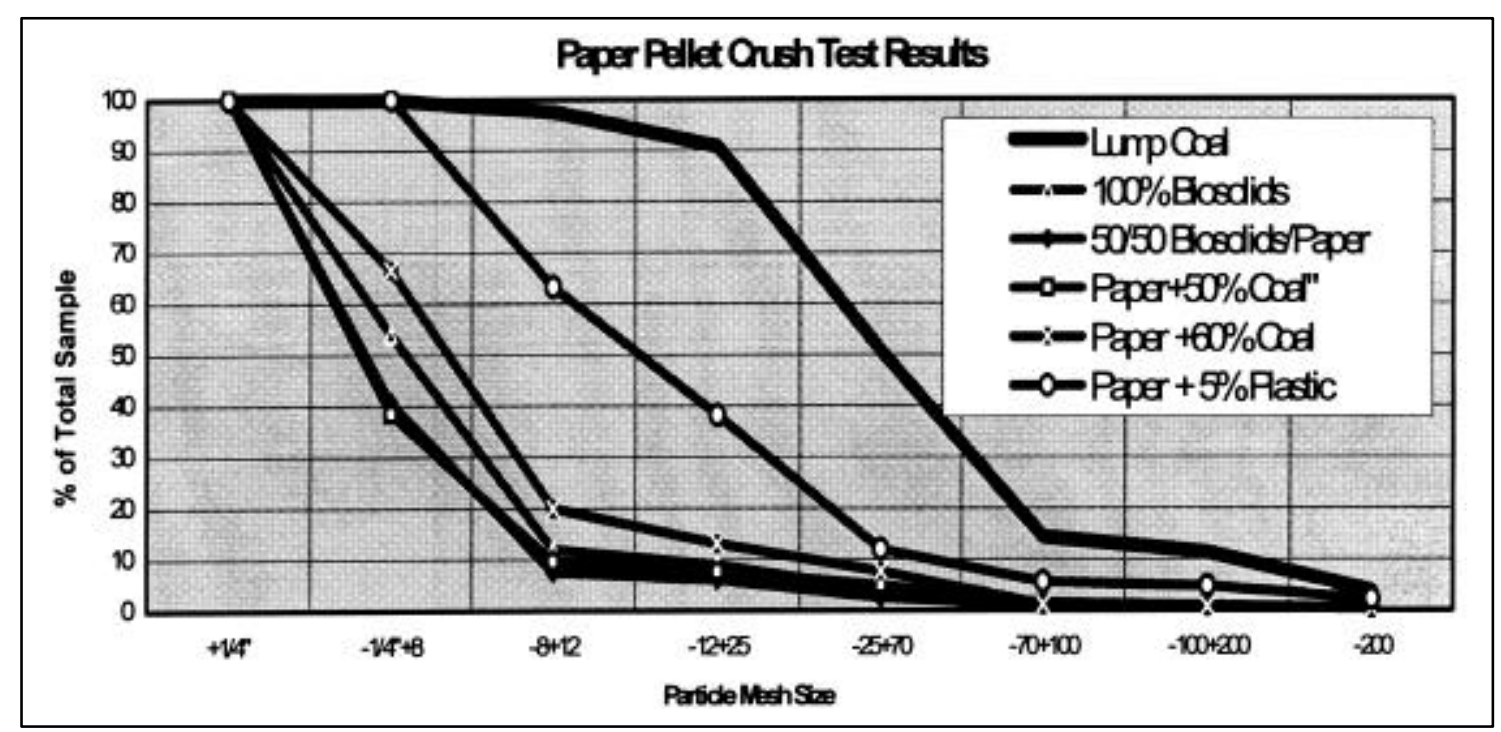

Figure 18 -- Lab-Scale Production Crush Test Results

\subsection{Pilot-Scale Production Pellet Quality}

Pellets produced at pilot-scale were subjected to the same suite of tests as those produced at lab scale. Test results for each sample were then compared with results of similar pellets to assess the impacts of changes in the AFP formulas. A complete listing of pilot-scale productions and pellet formulas is shown in Table 25 .

Table 28 compares test results for pellets produced at pilot-scale from formulas of biosolids and wood, both with and without coal fines addition. As noted earlier, the 12019901 formula consisted of $55 \%$ biosolids and $45 \%$ wood sawdust and the 12089901 formula consisted of $38 \%$ biosolids, $32 \%$ wood and $30 \%$ coal fines. According to compression, drop and abrasion test results included in Table 28, the pellet formula without coal had superior strength and durability, relative to the pellet with coal fines. This suggested that the AFP pellet with coal fines would perform better in the crush response test. This was found to be the case.

Table 28 -- Pilot-Scale Production Pellet Quality

\begin{tabular}{|c|c|c|c|c|c|}
\hline $\begin{array}{c}\text { Sample } \\
\text { ID\# }\end{array}$ & $\begin{array}{c}\text { Dry Diameter } \\
\mathbf{C m}(\mathbf{i n})\end{array}$ & $\begin{array}{c}\text { Dry } \\
\text { Density } \\
\mathbf{K g} / \mathbf{m}^{\mathbf{3}}\left(\mathbf{l b} / \mathbf{f t}^{\mathbf{3}}\right)\end{array}$ & $\begin{array}{c}\text { Compression } \\
\mathbf{K g} / \mathbf{m}^{\mathbf{3}}(\mathbf{p s i})\end{array}$ & $\begin{array}{c}\text { Drop to } \\
\text { Concrete } \\
\mathbf{~}(\mathbf{f t})\end{array}$ & $\begin{array}{c}\text { Abrasion } \\
\text { Loss \% }\end{array}$ \\
\hline 12019901 & $2.1(.825)$ & $610(38)$ & $1489(216)$ & 7 from $4.5(15 \mathrm{ft})$ & $1.5 \%$ \\
\hline 12089901 & $2.1(.815)$ & $562(35)$ & $1055(153)$ & 3 from $4.5(15 \mathrm{ft})$ & $4.0 \%$ \\
\hline
\end{tabular}

Pellets produced at pilot scale were crush tested. Results of those tests are given in Figure 19. 


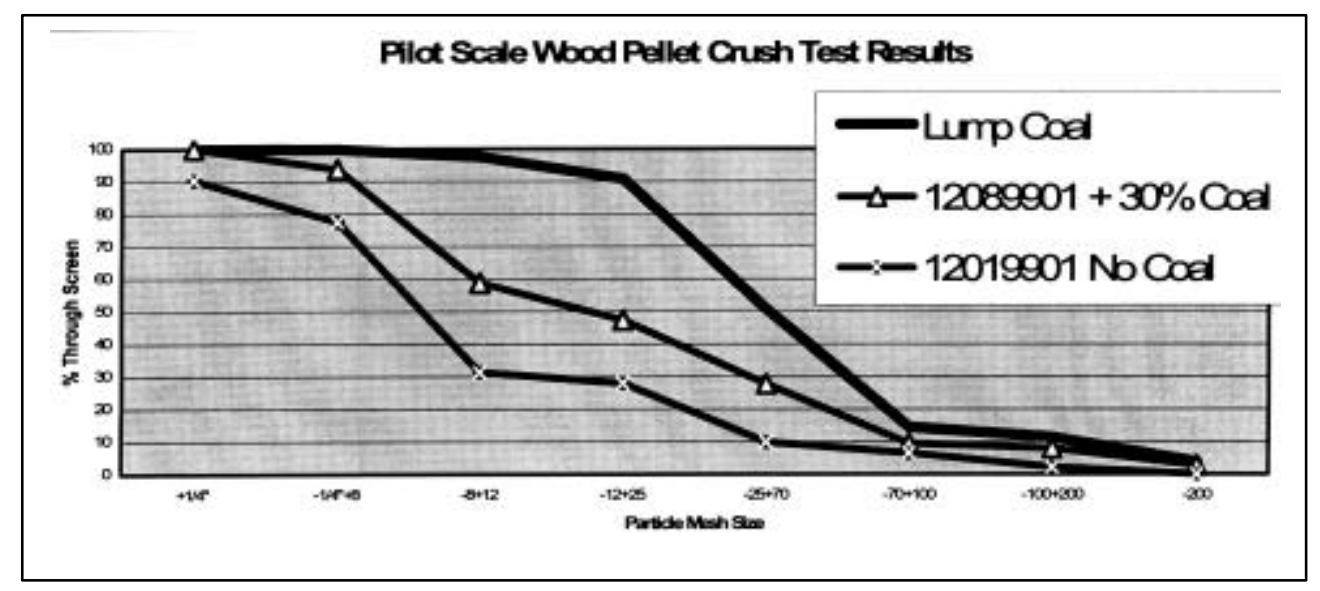

Figure 19 -- Pilot-Scale Production Crush Test Results

The top curve in the graph represents the response of lump coal in the test fixture. The bottom curve represents an AFP pellet without coal fines addition. As can be seen in the graph, coal fines addition to the AFP formula improved the crush response of pellets produced at pilotscale. These results were consistent with the lab-scale results, and again showed how coal fines could be used to adjust AFP grindability.

Sample ID\# 01140001. Table 29 compares test results of pellets produced at pilot-scale from biosolids and wood (12019901), to this production of biosolids and wood with an addition of 50 percent coal fines in the formula.

Table 29 -- 01140001 Pellet Quality Test Results

\begin{tabular}{|l|c|c|c|c|c|}
\hline $\begin{array}{l}\text { Sample } \\
\text { ID\# }\end{array}$ & $\begin{array}{c}\text { Dry } \\
\text { Diameter } \\
\mathbf{C m}(\mathbf{i n})\end{array}$ & $\begin{array}{c}\text { Dry } \\
\text { Density } \\
\mathbf{K g} / \mathbf{m}^{\mathbf{3}}\left(\mathbf{l b} / \mathbf{f t}^{\mathbf{3}}\right)\end{array}$ & $\begin{array}{c}\text { Compression } \\
\mathbf{K g} / \mathbf{m}^{\mathbf{3}}(\mathbf{p s i})\end{array}$ & $\begin{array}{c}\text { Drop to } \\
\text { Concrete } \\
\mathbf{m}(\mathbf{f t})\end{array}$ & $\begin{array}{c}\text { Abrasion } \\
\text { Loss \% }\end{array}$ \\
\hline 12019901 & $2.1(.825)$ & $610(38)$ & $1489(216)$ & 7 from $4.5(15 \mathrm{ft})$ & $1.5 \%$ \\
\hline 01140001 & $2.1(.818)$ & $658(41)$ & $1282(186)$ & 6 from $4.5(15 \mathrm{ft})$ & $3.2 \%$ \\
\hline
\end{tabular}

Test results show that the coal fines addition to this wood based AFP pellet formula produced a denser, better compacted pellet that was also more responsive to fracture under compression. This translated into better performance in the crush tests, as shown in Figure 20. The purpose of the crush test was to evaluate the way AFP pellets would respond in a coal pulverizing mill. The top curve in the graph represents the performance of a lump coal sample in the crush test fixture. The bottom curve is the performance of a pellet formulated from biosolids and wood. The curve in between shows the performance of AFP pellets produced from the same biosolids and wood formula, with an addition of 50 percent coal fines. As shown, the crush response more closely resembles that of the lump coal. Also, addition of coal increased abrasion losses to over $3 \%$. 
Sample ID\# 01210001.

Table 30 compares the quality test results of pellets produced at pilot scale, previously from biosolids and wood, and from this production of biosolids and paper.

Table 30 -- 01210001 Pellet Quality Test Results

\begin{tabular}{|l|c|c|c|c|c|}
\hline $\begin{array}{l}\text { Sample } \\
\text { ID\# }\end{array}$ & $\begin{array}{c}\text { Dry } \\
\text { Diameter } \\
\mathbf{C m}(\mathbf{i n})\end{array}$ & $\begin{array}{c}\text { Dry } \\
\text { Density } \\
\mathbf{K g} / \mathbf{m}^{3}\left(\mathbf{l b} / \mathbf{f t}^{\mathbf{3}}\right)\end{array}$ & $\begin{array}{c}\text { Compression } \\
\mathbf{K g} / \mathbf{m}^{3}(\mathbf{p s i})\end{array}$ & $\begin{array}{c}\text { Drop to } \\
\text { Concrete } \\
\mathbf{m}(\mathbf{f t})\end{array}$ & $\begin{array}{c}\text { Abrasion } \\
\text { Loss\% }\end{array}$ \\
\hline 12019901 & $2.1(.825)$ & $610(38)$ & $1489(216)$ & 7 from $4.5(15)$ & $1.5 \%$ \\
\hline 01210001 & $2.1(.835)$ & $578(36)$ & $2516(365)$ & +10 from $4.5(15)$ & $1.3 \%$ \\
\hline
\end{tabular}

The test results demonstrate some of the fundamental differences between these two very different AFP raw materials. When compared to wood, the waste paper pellets are less dense and compacted, while under compression testing and in drop tests they are much more resilient and resistant to breakage.

Some of the high strength of pellets formulated from waste paper products may reflect the presence of china clays, tackifiers, adhesives, and other materials added to the paper during processing. The additive content in certain paper grades, like magazine print, may be as high as 30 percent. It is likely that these additives act as additional binders, making the paper pellets more difficult to crush than pellets made from unprocessed wood. This was the first pilot scale production of AFP paper based pellets, and the formula did not contain coal fines. For this reason the pellets were not expected to do well in the crush test. Results of the test are given in Figure 21. Also appearing in the graph, for comparison, are curves representing the crush response of a pellet formulated from wood and a sample of lump coal.

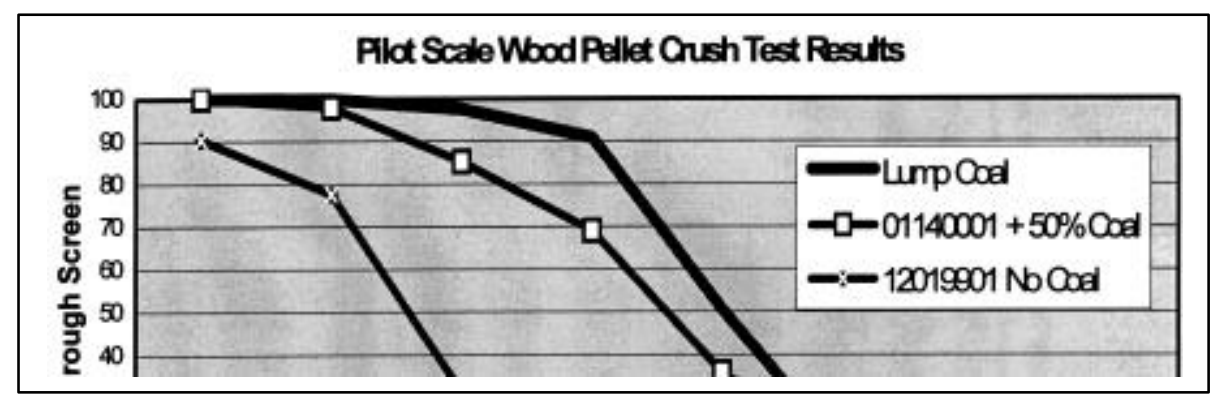

Figure 20 -- Pilot Scale AFP Wood Pellet Crush Test Results 


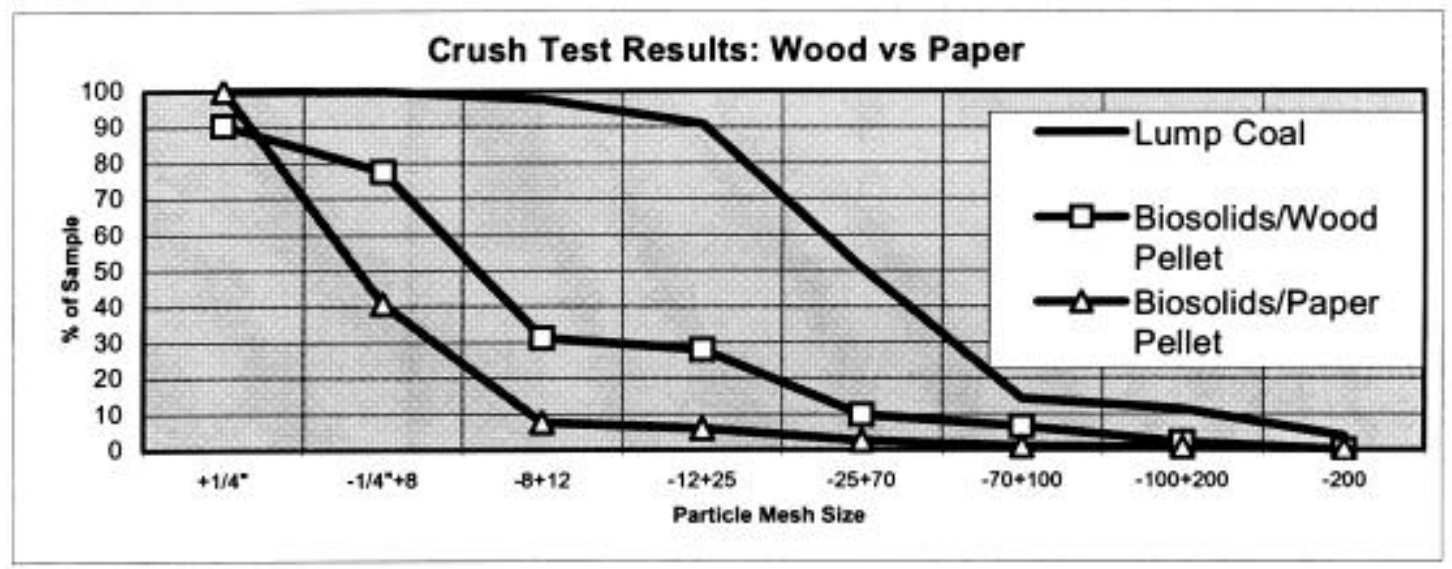

Figure 21 -- Crush Test Results of Wood Pellets and Paper Pellets.

As shown, neither of the fibrous pellets responded well to crushing compared to the coal sample, however the response of the wood pellet was measurably better than the response of the paper based pellet. Results indicate that pulverizing pellets formulated with paper products will be more difficult than pellets formulated from wood.

Sample ID\# 02220001.

Table 31 compares the test results of pellets produced at pilot scale from biosolids and paper (01210001), to this production of biosolids, paper, and plastic, with an addition of 50 percent coal fines in the formula.

Table 31 -- 02220001 Pellet Quality Test Results

\begin{tabular}{|l|c|c|c|c|c|}
\hline $\begin{array}{l}\text { Sample } \\
\text { ID\# }\end{array}$ & $\begin{array}{c}\text { Dry } \\
\text { Diameter } \\
\mathbf{C m}(\mathbf{i n})\end{array}$ & $\begin{array}{c}\text { Dry } \\
\text { Density } \\
\mathbf{K g} / \mathbf{m}^{\mathbf{3}}\left(\mathbf{l b} / \mathbf{f t}^{\mathbf{3}}\right)\end{array}$ & $\begin{array}{c}\text { Compression } \\
\mathbf{K g} / \mathbf{m}^{\mathbf{3}}(\mathbf{p s i})\end{array}$ & $\begin{array}{c}\text { Drop to } \\
\text { Concrete } \\
\mathbf{m}(\mathbf{f t})\end{array}$ & $\begin{array}{c}\text { Abrasion } \\
\text { Loss \% }\end{array}$ \\
\hline 01210001 & $2.1(.825)$ & $578(36)$ & $2516(365)$ & +10 from $4.5(15)$ & $1.3 \%$ \\
\hline 02220001 & $2.1(.815)$ & $658(41)$ & $1717(249)$ & 7 from $4.5(15)$ & $1.9 \%$ \\
\hline
\end{tabular}

Again, the coal fines addition to the AFP formula produced a denser, more compact pellet and the plastic particle addition made the pellets easier to fracture and fragment, as is demonstrated by results of the axial compression and drop tests. This performance was also validated in the crush test results. Lab-scale productions had shown that a small addition of plastic film particles to AFP paper-based pellets was even more effective at improving pellet crush response than large additions of coal fines. 


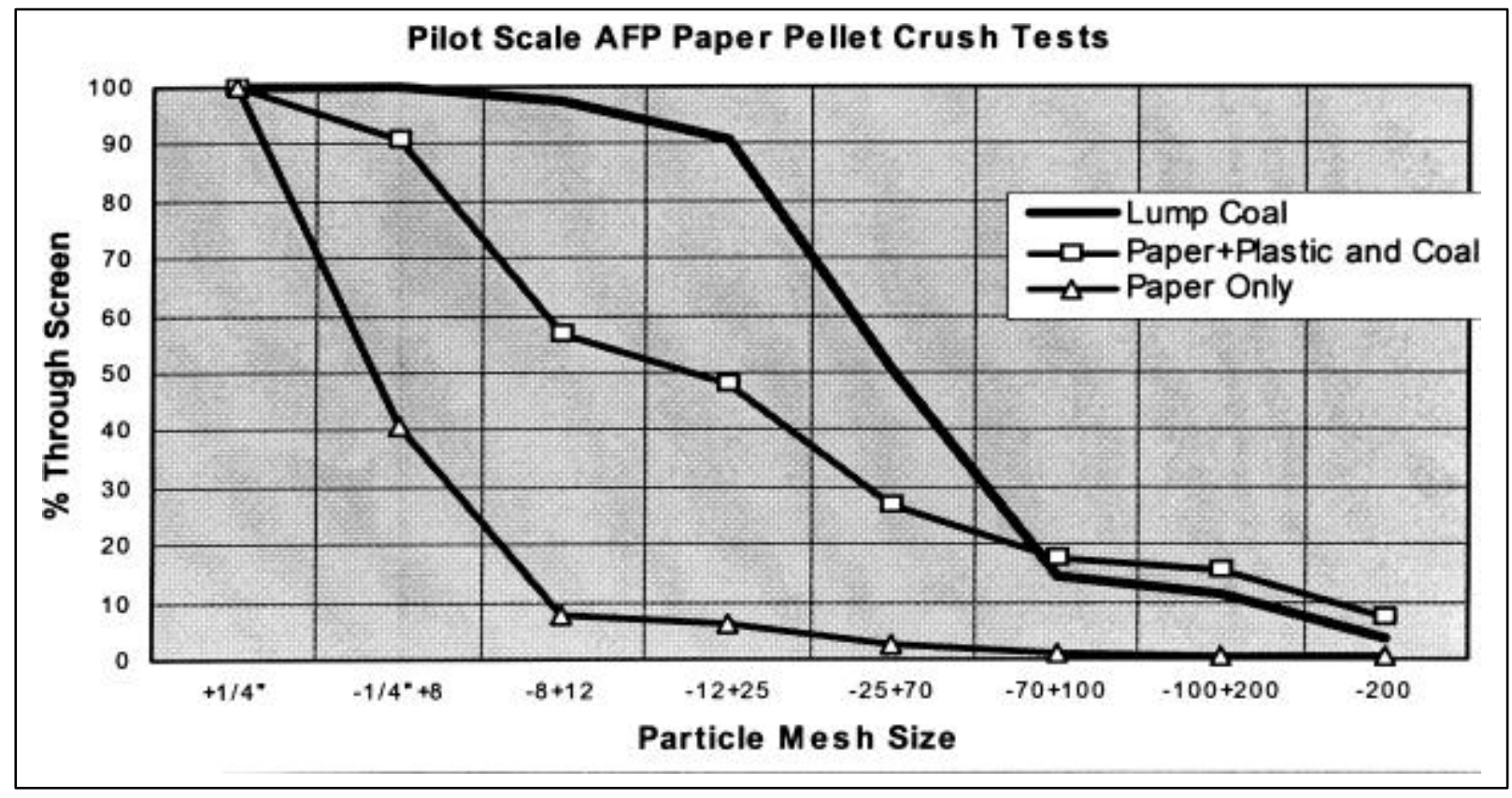

Figure 22 -- Pilot-Scale AFP Paper Pellet Crush Test Results

Curves on the graph in Figure 22 give the crush response of paper-based AFP pellets, paper pellets with coal fines and plastic additions (02220001), and a sample of lump coal. The results show a significant improvement in crush response with the additions of plastic $(2 \%)$ and coal (50\%). Test results have already shown that coal fines additions by themselves do little to change the crush response of paper based pellets. The improvement in the crush response of pellets in this production must then be attributed to the addition of plastic film particles.

\section{Sample ID\# 02230001.}

The formula for this production consisted of biosolids, paper, and plastic, but without any coal fines addition. Pellet quality testing revealed a consequence of drying AFP pellets, formulated with plastic film particles, at temperatures high enough to melt the plastic. The impact was most apparent from results of the compression and crush tests.

Test results are shown in Table 32.

Table 32 -- 02230001 Pellet Quality Test Results

\begin{tabular}{|l|c|c|c|c|c|}
\hline $\begin{array}{l}\text { Sample } \\
\text { ID\# }\end{array}$ & $\begin{array}{c}\text { Dry } \\
\text { Diameter } \\
\mathbf{C m}(\mathbf{i n})\end{array}$ & $\begin{array}{c}\text { Dry } \\
\text { Density } \\
\mathbf{K g} / \mathbf{m}^{\mathbf{3}}\left(\mathbf{l b} / \mathbf{f t}^{\mathbf{3}}\right)\end{array}$ & $\begin{array}{c}\text { Compression } \\
\mathbf{K g} / \mathbf{m}^{\mathbf{3}}(\mathbf{p s i})\end{array}$ & $\begin{array}{c}\text { Drop to } \\
\text { Concrete } \\
\mathbf{m}(\mathbf{f t})\end{array}$ & $\begin{array}{c}\text { Abrasion } \\
\text { Loss \% }\end{array}$ \\
\hline $02230001 \mathrm{a}$ & $2.1(.835)$ & $546(34)$ & $53779(7800)$ & +10 from $4.5(15)$ & $<1 \%$ \\
\hline $02230001 \mathrm{~b}$ & $2(.800)$ & $562(35)$ & $1862(270)$ & 8 from $4.5(15)$ & $1.4 \%$ \\
\hline
\end{tabular}

During production, samples were regularly pulled from the line ahead of the conveyor dryer for moisture checks and other tests. These samples were subsequently dried in a conventional oven at $121^{\circ} \mathrm{C}\left(250^{\circ} \mathrm{F}\right)$. In Table 32, these pellets dried at lower temperature are identified as $02230001 \mathrm{~b}$. Pellets that were dried in the conveyor dryer, at temperatures to $215^{\circ} \mathrm{C}$ 
$\left(420^{\circ} \mathrm{F}\right)$ are identified as 02230001a. Under axial compression the production pellets (02230001a) simply deformed. Under a force of $5516 \mathrm{Kg} / \mathrm{m}^{3}$ (800 psi), pellet height (length) was reduced to one half of the original, but still the pellets did not fracture. In comparison, pellets that were dried separately in an oven, at $121^{\circ} \mathrm{C}\left(250^{\circ} \mathrm{F}\right)(02230001 \mathrm{~b})$ fractured at 1862 $\mathrm{Kg} / \mathrm{m}^{3}$ (270 psi) in an identical test. Therefore, pellet strength depended heavily on drying temperature.

Plastic film particles were included in AFP pellet formulas to promote the fracture and fragmentation of waste paper pellets in a coal pulverizer. Lab-scale tests had demonstrated the effectiveness of the approach, which is believed to interfere with the bonding of the matrix within the pellets. Because plastic does not bond with the paper fibers, weak points in the matrix are created where fracturing can occur. However, at elevated temperatures, plastic softens and melts, as it did in the dryer during this production test. It is likely that a physical bond may form between the plastic and surrounding fibers if the plastic is melted and then cools. This effectively does away with the benefit of plastic particle addition to the formula. To preserve the benefit, drying temperatures cannot approach the softening temperature of the plastic.

High temperature drying cancels the grindability benefit of plastic particle addition to the pellets, a consequence that was also evident in the crush tests.

Pellet samples pulled from a production run ahead of the conveyor dryer and dried separately in a conventional oven at $107^{\circ} \mathrm{C}\left(225^{\circ} \mathrm{F}\right)$ are identified on the graph in Figure 23, as $02230001 \mathrm{~b}$. Pellets identified as $02230001 \mathrm{a}$ were dried at temperatures of 191 to $216^{\circ} \mathrm{C}\left(375^{\circ} \mathrm{F}\right.$ to $420^{\circ} \mathrm{F}$ ) in the pilot-scale conveyor dryer. The top curve in the graph represents the performance of a sample of lump coal in the crush test. The bottom curve is the performance of pellets from this production run (02230001a) dried at high temperature. The middle curve shows the performance of pellets formed during the same production run, but oven dried at $107^{\circ} \mathrm{C}$ $\left(225^{\circ} \mathrm{F}\right)(02230001 \mathrm{~b})$. As shown. pellets dried a $107^{\circ} \mathrm{C}\left(225^{\circ} \mathrm{F}\right)$ outperformed the pellets dried at 191 to $216^{\circ} \mathrm{C}\left(375^{\circ} \mathrm{F}\right.$ to $\left.420^{\circ} \mathrm{F}\right)$.

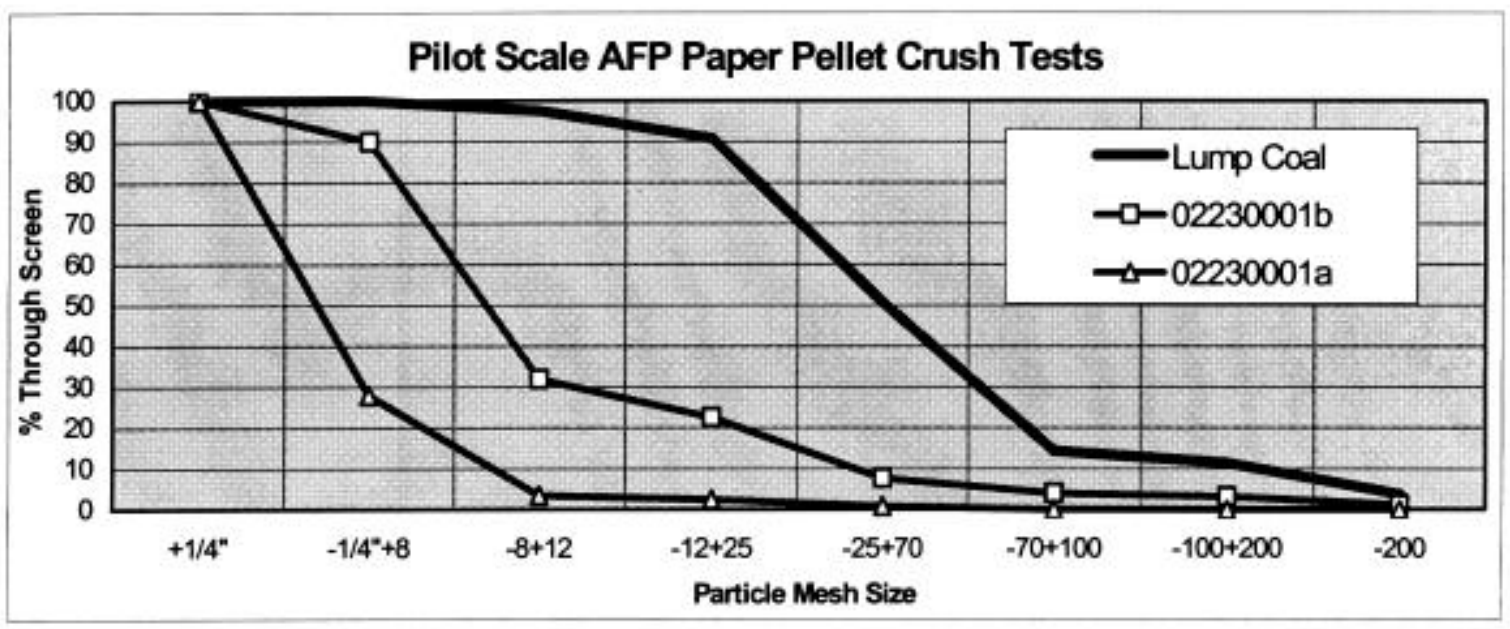

Figure 23 -- Pilot-Scale AFP Paper and Plastic Pellet Crush Test Result 


\section{Sample ID\# 03010001.}

The formula of biosolids, paper and plastic for pellets in this production closely resembled the formula of the preceding run (02230001). What distinguished this production was higher biosolids content and lower mix moisture made possible by secondary biosolids dewatering prior to mixing. Once again, pellets dried in the conveyor dryer at 177 to $204^{\circ} \mathrm{C}(350$ to $\left.400^{\circ} \mathrm{F}\right)(03010001 \mathrm{a})$ were tested against pellets that were dried separately in an oven at $107^{\circ} \mathrm{C}$ $\left(225^{\circ} \mathrm{F}\right)(03010001 \mathrm{~b})$. Test results were compared with results of previous tests on a paper-based pellet with plastic particle addition (02230001a) and paper-based pellets produced without any plastic (01210001). Test results are listed below in Table 33.

Table 33 -- 03010001 Pellet Quality Test Results

\begin{tabular}{|l|c|c|c|c|c|}
\hline Sample ID\# & $\begin{array}{c}\text { Dry } \\
\text { Diameter } \\
\mathbf{C m}(\mathbf{i n})\end{array}$ & $\begin{array}{c}\text { Dry } \\
\text { Density } \\
\mathbf{K g} / \mathbf{m}^{\mathbf{3}}\left(\mathbf{( b / f \mathbf { f t } ^ { \mathbf { 3 } } )}\right.\end{array}$ & $\begin{array}{c}\text { Compressing } \\
\mathbf{K g} / \mathbf{m}^{3}(\mathbf{p s i})\end{array}$ & $\begin{array}{c}\text { Drop to } \\
\text { Concrete } \\
\mathbf{m}(\mathbf{f t})\end{array}$ & $\begin{array}{c}\text { Abrasion } \\
\text { Loss \% }\end{array}$ \\
\hline $03010001 \mathrm{a}$ & $2(.795)$ & $658(41)$ & $1489(7800)$ & 6 from $4.5(15)$ & $1 \%$ \\
\hline $03010001 \mathrm{~b}$ & $1.9(.780)$ & $706(44)$ & $1055(566)$ & 3 from $4.5(15)$ & $1 \%$ \\
\hline $02230001 \mathrm{a}$ & $2.1(.835)$ & $546(34)$ & $1489(7800)$ & $\begin{array}{c}+10 \text { from } \\
4.5(15)\end{array}$ & $<1 \%$ \\
\hline 01210001 & $2.1(.835)$ & $578(36)$ & $1055(365)$ & $\begin{array}{c}+10 \text { from } \\
4.5(15)\end{array}$ & $1.3 \%$ \\
\hline
\end{tabular}

Density measurements showed that by reducing mix moisture, a denser pellet is produced. Again, under axial compression pellets dried at high temperature in the conveyor dryer would not fracture and will be difficult to reduce to smaller particles by crushing.

The drop test results demonstrate a relationship between density and the ability of paper based pellets to survive the test. Lower density pellets are better able to adsorb the energy of impact, while higher density pellets tend to fracture.

A summary of the pellet quality test results for pilot-scale productions is given below in Table 34. Pilot-scale production pellet formulas were given previously in Table 25.

Table 34 -- AFP Pilot-Scale Pellet Quality Summary

\begin{tabular}{|l|c|c|c|c|c|}
\hline $\begin{array}{l}\text { Sample } \\
\text { ID\# }\end{array}$ & $\begin{array}{c}\text { Dry } \\
\text { Diameter } \\
\mathbf{C m}(\mathbf{i n})\end{array}$ & $\begin{array}{c}\text { Dry } \\
\text { Density } \\
\mathbf{K g} / \mathbf{m}^{3}\left(\mathbf{l b} / \mathbf{f t}^{\mathbf{3}}\right)\end{array}$ & $\begin{array}{c}\text { Compression } \\
\mathbf{K g} / \mathbf{m}^{\mathbf{3}}(\mathbf{p s i})\end{array}$ & $\begin{array}{c}\mathbf{4 . 5} \mathbf{~ m} \text { Drop to } \\
\mathbf{C o n c r e t e} \\
\mathbf{m}(\mathbf{f t})\end{array}$ & $\begin{array}{c}\text { Abrasion } \\
\text { Loss \% }\end{array}$ \\
\hline 12019901 & $2.1(.84)$ & $610(38)$ & $1489(216)$ & 7 & 1.6 \\
\hline 12089901 & $2.1(.83)$ & $562(35)$ & $1055(153)$ & 3 & 3.4 \\
\hline 01140001 & $2(.81)$ & $658(41)$ & $1282(186)$ & 6 & 3.2 \\
\hline 01210001 & $2.1(.83)$ & $578(36)$ & $2517(365)$ & +10 & 1.3 \\
\hline 02220001 & $2.1(.83)$ & $658(41)$ & $1717(249)$ & 7 & 1.9 \\
\hline 02230001 & $2.1(.83)$ & $546(34)$ & $53779(7800)$ & +10 & $<1$ \\
\hline 03010001 & $2(.79)$ & $658(41)$ & $53779(7800)$ & 6 & 1 \\
\hline
\end{tabular}


The above tests indicated the resilience of pellets under axial compression, drop and abrasion tests. Also, tests showed how pellets would respond to crushing forces, as created in the initial stages of a typical coal pulverizer. Complete pulverization behavior is described below.

\subsection{Pellet Pulverization Tests}

AFP pellets intended for utility PC boilers can be specially formulated for compatibility with ball-and-race type coal pulverizers. By incorporating coal fines, or plastic in the case of MSW-based pellets, initial crushing/grinding properties can be improved. This was shown in tests that used the Altex roller-and-race test apparatus. This equipment simulated the initial grinding in a ball-and-race mill. However, additional tests were needed in equipment that simulates the final grinding steps in a ball-and-race mill. In order to assess the impact of AFP pellet formulations on pulverization efficiency, tests were carried out by Hazen Research Inc. These pulverization tests results were compared to those for a standard coal. In addition, pulverized material produced from tests at Hazen was then used as feed for the PC combustor tests carried out at Altex. The specific pellet formulations are given in Table 35. As shown in the table, biomass formulations that were expected to have good grindability based on Altex test (0114001 and 02220001) were selected for co grinding to assess the prospects of cofiring with coal. In addition, lump coal, pellets of biosolids/wood (12019901), and pellets of biosolids/paper (01210001) were tested. Coal was the reference. The Utah bituminous coal properties and initial size distribution used in the tests are given in Tables 36 and 37. Pellets without coal fines or plastic were expected to be difficult to grind and tests confirmed this expectation.

Table 35 -- AFP Pulverization Tests

\begin{tabular}{|c|l|c|c|c|}
\hline Test \# & Sample Description & $\begin{array}{c}\text { Pellet } \\
\text { Fraction }\end{array}$ & $\begin{array}{c}\text { Coal Fraction } \\
\text { Cassing 200 }\end{array}$ & $\frac{\text { Mesh }}{84 \%}$ \\
\hline 1 & Bituminous Coal & $0 \%$ & $100 \%$ & $81 \%$ \\
\hline 2 & AFP 01140001 & $100 \%$ & $0 \%$ & $83 \%$ \\
\hline 3 & AFP 01140001 & $10 \%$ & $90 \%$ & $90 \%$ \\
\hline 4 & AFP 01140001 & $20 \%$ & $80 \%$ & $89 \%$ \\
\hline 5 & AFP 02220001 & $20 \%$ & $80 \%$ & $81 \%$ \\
\hline 6 & AFP 12019901 & $100 \%$ & $0 \%$ & $81 \%$ \\
\hline 7 & AFP 01210001 & $100 \%$ & $0 \%$ & \\
\hline
\end{tabular}

The plan called for AFP pellets and lump coal to be co-pulverized together, then classified using a semi-autogeneous grinding (SAG) mill system. The SAG circuit consisted of a feeder, an 46-cm(18-inch)diameter ball mill, an $20 \mathrm{~cm}$ (8-inch) vertical classifier, a $23 \mathrm{~cm}(9-i n c h)$ cyclone, and a cartridge-type dust collector as illustrated in Figure 24. This system is normally used for determining the grinding properties of ores and industrial minerals. Initial calibration tests of the SAG system with $1.9 \mathrm{~cm}(3 / 4-i n)$ top-size coal demonstrated that the system could not effectively pulverize the coal to a desired specification of $80 \%$ passing $\left(\mathrm{P}_{80}\right) 200$ mesh. Alternatively, the materials were batch pulverized in $122-\mathrm{cm}$ by $122-\mathrm{cm}$ (4-by-4-ft) ceramiclined ball mill $61-\mathrm{cm}$ by $61-\mathrm{cm}(2-\mathrm{by}-2-\mathrm{ft})$ ball mill and then classified using the SAG circuit without a ball charge. Pulverized coal was used to establish the operating conditions for classification. 
Table 36 -- Utah Bituminous Coal Properties

\begin{tabular}{|l|c|}
\hline \multicolumn{1}{|c|}{ Property } & Value \\
\hline Moisture, \% & 9.53 \\
\hline Ash, \% & 7.46 \\
\hline Volatile, \% & 39.52 \\
\hline Fixed Carbon, \% & 43.49 \\
\hline Carbon, \% & 66.02 \\
\hline Hydrogen, \% & 4.29 \\
\hline Nitrogen, \% & 1.38 \\
\hline Sulfur, \% & 0.59 \\
\hline Oxygen, \% & 10.73 \\
\hline Btu/lb & 11,830 \\
\hline Nominal Size, cm (Inch) & $1.91(0.75)$ \\
\hline
\end{tabular}

454 kilograms (1000 lbs.) of 1.9-cm (3/4-in), top-size bituminous coal were pulverized to a $\mathrm{P}_{80}$ of 200-mesh using a $122 \mathrm{~cm}$ by $122 \mathrm{~cm}$ (4-by-4-ft) ceramic-lined ball mill. To achieve a $\mathrm{P}_{80}$ of 200-mesh, an hour of grind time was required for every $45 \mathrm{~kg}(100 \mathrm{lb})$ of coal (e.g. $136 \mathrm{~kg}$ required three hours of grind time). The coal was processed in three batches, two $136 \mathrm{~kg}(300 \mathrm{lb})$ batches and one $181 \mathrm{~kg}(400 \mathrm{lb})$ batch. The three-hour grind time for a $136 \mathrm{~kg}(300 \mathrm{lb})$ batch was used as a basis for batch grinding AFP 01140001 (27\%, 23\%, and 50\% of biosolids wood and coal) and $02220001(24 \%, 24 \%, 2 \%$, and $50 \%$ of biosolids of paper, plastic and coal) test samples

Table 37 -- Size Distribution of As-Received Coal

\begin{tabular}{|l|c|c|}
\hline \multicolumn{1}{|c|}{ Sieve No. } & Microns & \% Passing \\
\hline $1.9 \mathrm{~cm}(.75 \mathrm{in})$ & 19,050 & 96.8 \\
\hline $1.3 \mathrm{~cm}(.5 \mathrm{in})$ & 12,700 & 87.2 \\
\hline $.64 \mathrm{~cm}(.25 \mathrm{in})$ & 6,350 & 67.9 \\
\hline $6 \mathrm{Mesh}$ & 3,360 & 52.9 \\
\hline $10 \mathrm{Mesh}$ & 1,680 & 42.8 \\
\hline $20 \mathrm{Mesh}$ & 841 & 26.9 \\
\hline $35 \mathrm{Mesh}$ & 420 & 18.5 \\
\hline $65 \mathrm{Mesh}$ & 210 & 9.2 \\
\hline $100 \mathrm{Mesh}$ & 149 & 6.0 \\
\hline $200 \mathrm{Mesh}$ & 74 & 2.7 \\
\hline
\end{tabular}




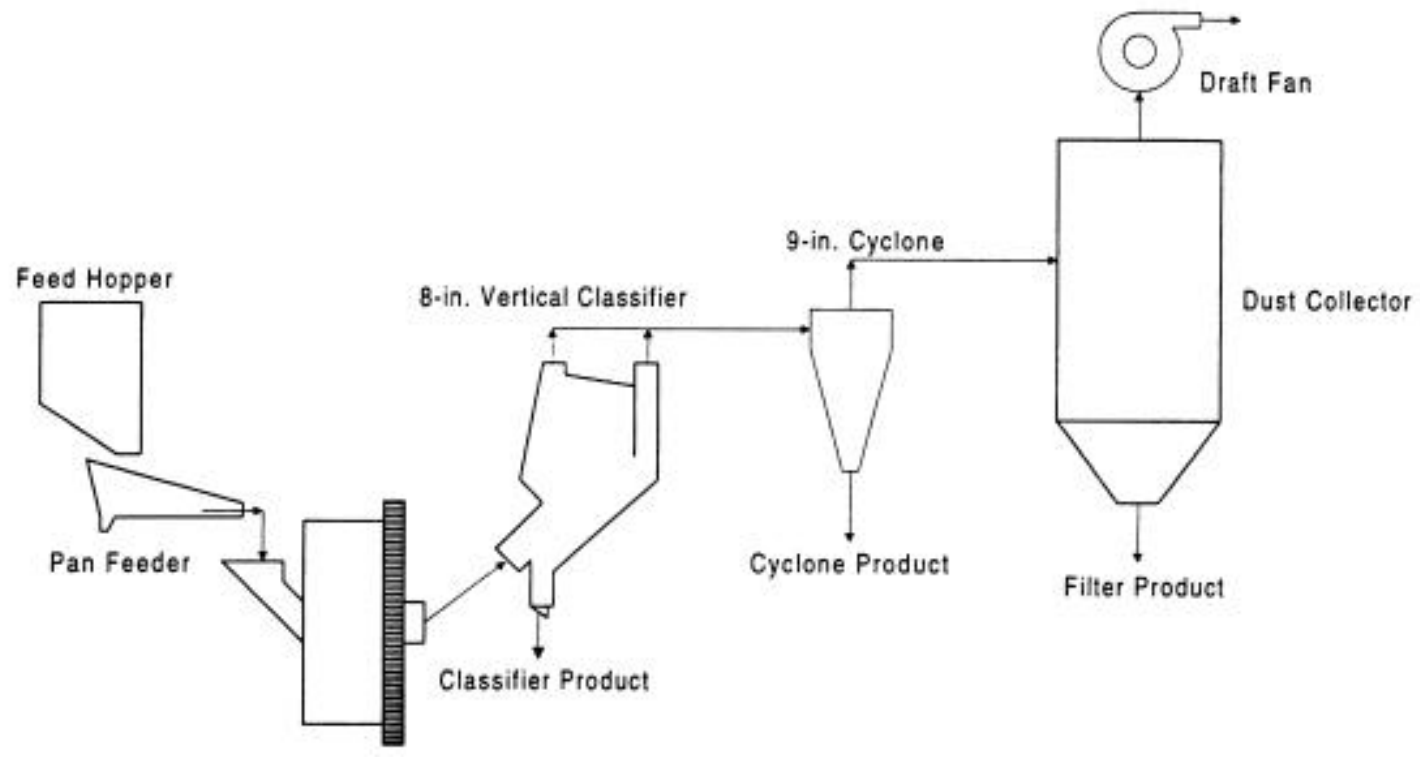

Figure 24 -- SAG Mill System

Three tests were completed on Sample AFP 01140001 and a single test on AFP 02220001. Each sample was batch pulverized for three hours in the $122-\mathrm{cm}$ by $122-\mathrm{cm}$ (4-by-4$\mathrm{ft})$ ball mill and then classified using the SAG system. Classification of the 100\% AFP 01140001 sample (test No. 3) was halted after processing about 45kg (100lb), because material was building up and plugging the cyclone underflow discharge. Table 38 summarizes the test results for these two pellet types.

Table 38 -- Summary of AFP 01140001 and AFP 02220001 Tests

\begin{tabular}{|c|c|c|c|c|c|}
\hline Pellet Type & $\begin{array}{c}\text { Feed } \\
\text { Rate, } \\
\mathbf{k g} / \mathbf{h r} \\
(\mathbf{l b} / \mathbf{h r})\end{array}$ & $\begin{array}{c}\text { Classifier } \\
\text { Product, } \\
\mathbf{k g}(\mathbf{l b})\end{array}$ & $\begin{array}{c}\text { Cyclone } \\
\text { Product, } \\
\mathbf{k g}(\mathbf{l b})\end{array}$ & $\begin{array}{c}\text { Filter } \\
\text { Product, } \\
\mathbf{k g}(\mathbf{l b})\end{array}$ & $\begin{array}{c}\text { Overall \% } \\
\text { Passing 200 } \\
\text { Mesh }\end{array}$ \\
\hline $10 \% 0114001$ & $31.3(69)$ & $.36(0.8)$ & $125.0(275.6)$ & $6.0(13.2)$ & 83.0 \\
\hline $20 \% 01140001$ & $31.7(70)$ & $.1(0.2)$ & $119.9(264.3)$ & $16.9(37.2)$ & 89.7 \\
\hline $100 \% 01140001$ & $7.7(17)$ & $.23(0.5)$ & $8.48(18.7)$ & $25.0(55.1)$ & 81.3 \\
\hline $20 \% 02220001$ & $44.9(99)$ & $.1(0.2)$ & $109.5(241.5)$ & $32.3(71.1)$ & 89.5 \\
\hline
\end{tabular}

The majority of the classified product reported to the cyclone underflow, as shown in Table 38. The classifier products averaged $83 \%$ passing $200 \mathrm{mesh}$, the cyclone products averaged $84 \%$ and the dust collector filter products averaged $95 \%$.

Pellet samples 01140001, co-ground with coal, had a pulverization time or throughput similar to that for coal. This was expected, based on Altex preliminary tests, and suggests that this material could be co-pulverized and co-fired with coal. Without coal in the mill, sample 01140001 throughput was greatly reduced and a fiber buildup problem occurred in the cyclone. Therefore, this material would be more difficult to grind by itself and different grinding equipment would be required. 
Consistent with sample 01140001 with coal, the pulverization of sample 02220001 with coal was similar to coal. Therefore, co grinding and cofiring of this material with coal should be possible. Particle Size Distributions (PSD) for selected materials are given in Tables 39 and 40.

Table 39 -- PSD for 10\% AFP 01140001 Tests

\begin{tabular}{|c|c|c|}
\hline Sieve No. & Microns & Overall, \% Pass \\
\hline 48 & 297 & 99.8 \\
\hline 65 & 210 & 99.3 \\
\hline 100 & 149 & 98.1 \\
\hline 200 & 74 & 83.0 \\
\hline
\end{tabular}

Table 40 -- PSD for 20\% AFP 02220001 Tests

\begin{tabular}{|c|c|c|}
\hline Sieve No. & Microns & Overall, \% Pass \\
\hline 45 & 297 & 99.1 \\
\hline 65 & 210 & 98.6 \\
\hline 100 & 149 & 97.7 \\
\hline 200 & 74 & 89.5 \\
\hline
\end{tabular}

Given this test experience, as well as the Altex crush test experience, it was anticipated that samples 12019901 (555\% biosolids/45\% wood) and 01210001 (50\% biosolids $/ 50 \%$ paper), that have no coal content, would be difficult to grind by themselves. This was found to be the case.

Samples AFP 12019901 and 01210001 were pulverized to a $\mathrm{P}_{80}$ of 200 mesh in a $61 \mathrm{~cm}$ by $61 \mathrm{~cm}$ (2-by-2-ft)ceramic-lined ball mill. 45 kilograms (100 lbs) of AFP 12019901 were processed in three batches, with an average grind time of 8 hours and 45 minutes. This is a very substantial grind time. Given the long grind time, an attempt was made to reduce total time needed by stage grinding to a coarse size before final grinding. Two of the batches were stage ground in a $18-\mathrm{cm}$ by $15-\mathrm{cm}$ (seven by six-inch) hammer mill that was fitted the 8-mesh screen. AFP 01210001 was also stage ground in the hammer mill. However, no reduction in ball mill grind time was achieved by stage grinding in the hammer mill. 27 kilograms (Sixty pounds) of AFP 01210001 hammer milled product took 10.5 hours of ball mill grinding to achieve the $\mathrm{P}_{80}$ specification. This is a long grinding time versus coal.

Particle size distribution (PSD) of the study samples was determined by wet and dry screen particle size analysis using the Tyler sieve series. Precise determination of PSD for the pulverized AFP materials was difficult because the fine particles tended to blind the smaller aperture sieves. Additionally, the fibrous nature of the pellets showed a tendency to retain fine particles along with the coarse particles. The pulverized pellets also exhibited strong electrostatic properties, which may have contributed to the fine particles being retained with the coarse. Size analysis samples were wet screened at 200 mesh, followed by dry screening of the plus 200-mesh fraction. Dry screening of the plus fraction yielded an additional 2 to $5 \%$ of minus 200-mesh particles.

Results showed that the classified products from the $20 \%$ pellet plus $80 \%$ coal blends had the highest percentages of particles passing 200 mesh. However, a small amount of coarse, but light, particles are produced that may cause plugging problems in pulverized coal burners, unless removed by classification. Furthermore, the fibrous and electrostatic characteristics of the pellets contribute to difficulties in fine grinding and determining accurate PSD. 
From these tests, it can be concluded that pellet mixtures, including those with wood or paper, that have coal can be co-ground with coal in existing equipment. However, pellet mixtures including those with wood or paper, without coal are not easily ground by themselves. A pellet mixture with wood and coal could be ground in a reasonable time without co-grinding with coal. However, some fine fibrous material deposited on and plugged the cyclone underflow discharge. These results suggest that grinding biomass pellets by themselves in existing coal pulverization equipment will be a significant challenge. In this case, special grinding equipment will be needed. This goes beyond the typical need to increase mill capacity based on the reduced energy density of the biomass pellets versus coal. Given the need for special equipment of individual biomass pellet grinding, the biomass pellets should be utilized in a value added NOx control approach. Alternatively, the biomass pellets can be co-ground and co-fired with coal at a low concentration, (e.g. 10\%) where grinding and feeding challenges are reduced. Lastly, it should be noted that the toughness of biomass pellets and their resistance to grinding are very desirable characteristics for stoker fired systems. Therefore, this is an ideal application for the biomass pellet.

\subsection{COMBUSTION TESTS}

The AFP pellets are ideal for combustion in stoker fired units that currently burn coal. Both $100 \%$ pellet firing as well as cofiring with coal can be considered in stokers. Besides stoker firing, it would be important to burn AFP pellets in pulverized-coal-fired boilers. This type of equipment comprises the bulk of all coal firing and is a major source of electric power production. Given the importance of both firing methods, AFP combustion tests were carried out in both stoker and pulverized-fuel pilot-scale test systems at Altex. The test equipment used and test results are described below.

\subsection{FIXED-B ED COMBUSTION TESTS}

The robust biomass based fuel pellets are an ideal fuel for stoker fired boilers. Using various die sizes and pellet cutters, pellets of specific sizes can be produced. This is advantageous in fixed-bed or stoker-type combustion. Also, besides having consistent shape, pellets are very robust and can withstand the handling needed during stoker operation. Importantly, the biomass pellets have high volatiles content and are porous, particularly after volatilization. This leads to good ignition characteristics and burnout. For example, prior tests of biosolids and coal pellets showed that the pellets had up to 30 percent higher burn rate and less carbon in ash than coal. A similar benefit was anticipated for AFP pellets of biosolids, biomass and coal.

Fixed-bed or stoker firing of coal occurs on a grate where combustion air is introduced from below through the grate. Spreader stokers, which are fairly large, distribute fresh fuel on top of a thin burning bed. The bed is carried by a moving grate and the ash is dumped off the end of the grate. Overfeed traveling grate stokers introduce the fuel as a thick bed (e.g. $12.7 \mathrm{~cm})$ at one end of the grate. Fuel is ignited at the top of the bed and the combustion front proceeds into the bed until all of the fuel is consumed. The remaining ash is dumped off the end of the traveling grate. Given the larger scale and more modern spreader stoker approach, the fixed-bed test system was designed to simulate the spreader stoker process.

\section{Test Combustor}

Figure 25 presents an illustration of the fixed-bed test combustor. It consists of a $20 \mathrm{~cm}$ (8") internal diameter rotating wire-grate bed contained in a refractory-lined cylinder. The 
maximum combustion firing rate is approximately 422,022 kJ/hr (400,000 Btu/hr). Sufficient residence time is available above the bed to ensure mixing and burn-up of any remaining fuel components. Exhaust gases are sampled in the downstream chamber and gas temperatures are measured below and just above the bed, and downstream. During operation, pellets are fed into the combustor above the grate using the screw feeder shown in Figure 25. These pellets drop to the bed. Rotation of the mesh grate uniformly distributes pellets, as in a spreader stoker. The hot burning material ignites the newly introduced pellets. With time, the pellets will burn to an ash, and drop through the wire mesh grate.

To start up the system, natural gas was supplied through a ring injector placed below the grate. Gas was also used to heat up the system prior to feeding pellets. Once pellets were ignited, gas was reduced and then turned off. Emissions and temperatures were then monitored and read into a computerized data acquisition systems for storage and later analysis.

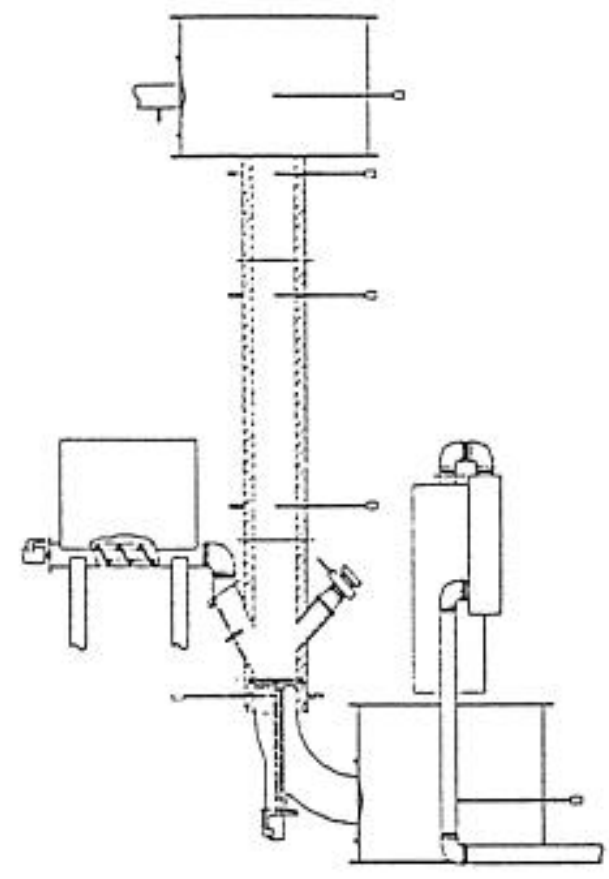

Figure 25 -- Fixed-Bed Test Combustor Schematic

Emissions from the bed were monitored by standard emissions monitors, as listed in Table 41, and included $\mathrm{NO}, \mathrm{NO}_{2}, \mathrm{CO}, \mathrm{CO}_{2}$, and unburned hydrocarbons. The gases are transported to the monitors by a heat traced line and pass through filters and a gas conditioner, prior to entering the meters. 
Table 41 -- Continuous Emissions Monitors

\begin{tabular}{|c|c|c|c|c|}
\hline $\begin{array}{l}\text { Measurement } \\
\text { Parameter }\end{array}$ & $\begin{array}{l}\text { Analyzer } \\
\text { Manufacturer }\end{array}$ & $\begin{array}{l}\text { Measurement } \\
\text { Principle }\end{array}$ & $\begin{array}{l}\text { Ranges } \\
\text { (parts } \\
\text { million) }\end{array}$ & Accuracy \\
\hline $\mathrm{NO}, \mathrm{NOx}$ & $\begin{array}{l}\text { Thermo } \\
\text { Environmental }\end{array}$ & Chemiluminescence's & $0-10000 \mathrm{ppm}$ & $\begin{array}{l}+/-1 \% \\
\text { Full-Scale }\end{array}$ \\
\hline $\mathrm{CO}$ & $\begin{array}{l}\text { Thermo } \\
\text { Environmental }\end{array}$ & Gas Filter Correlation & $1000 \mathrm{ppm}$ & $\begin{array}{l}+/-1 \% \\
\text { Full-Scale }\end{array}$ \\
\hline $\mathrm{O}_{2}$ & $\begin{array}{l}\text { Beckman } \\
\text { Instruments }\end{array}$ & Electrochemical Cell & $0-20 \%$ & $\begin{array}{l}+/-1 \% \\
\text { Full-Scale }\end{array}$ \\
\hline $\mathrm{CO}_{2}$ & $\begin{array}{l}\text { Beckman } \\
\text { Instruments }\end{array}$ & Nondispersive & $0-20 \%$ & $\begin{array}{l}+/-1 \% \\
\text { Full-Scale }\end{array}$ \\
\hline THC & $\begin{array}{l}\text { Beckman } \\
\text { Instruments }\end{array}$ & Nondispersive Infrared & $0-1000 \mathrm{ppm}$ & $\begin{array}{l}+/-1 \% \\
\text { Full-Scale }\end{array}$ \\
\hline
\end{tabular}

\section{Coal Reference Tests}

Prior to tests with biomass-based pellets, the test combustor was operated on coal and the results compared to those from conventional stoker combustion. The coal was a typical Utah bituminous lump coal that has the properties as given in Table 36

After heatup on gas, coal was fed to the bed and once ignited and burning, the gas was turned off. Observation of the bed showed that the coal was burning vigorously with flames jetting from the bed and extending beyond the viewport. Therefore, flames were greater than 15$\mathrm{cm}$ (6 in) in length. As in all fixed-bed systems, some nonuniformity in bed combustion was observed, particularly around the periphery of the combustor. However, gross nonuniformities were not observed.

Figure 26 presents the $\mathrm{CO}$ emissions in Parts Per Million (ppm) volume from the bed as a function of excess oxygen and load. As is typical for fixed-bed firing, excess oxygen in the range of $3 \%$ results in high $\mathrm{CO}$.

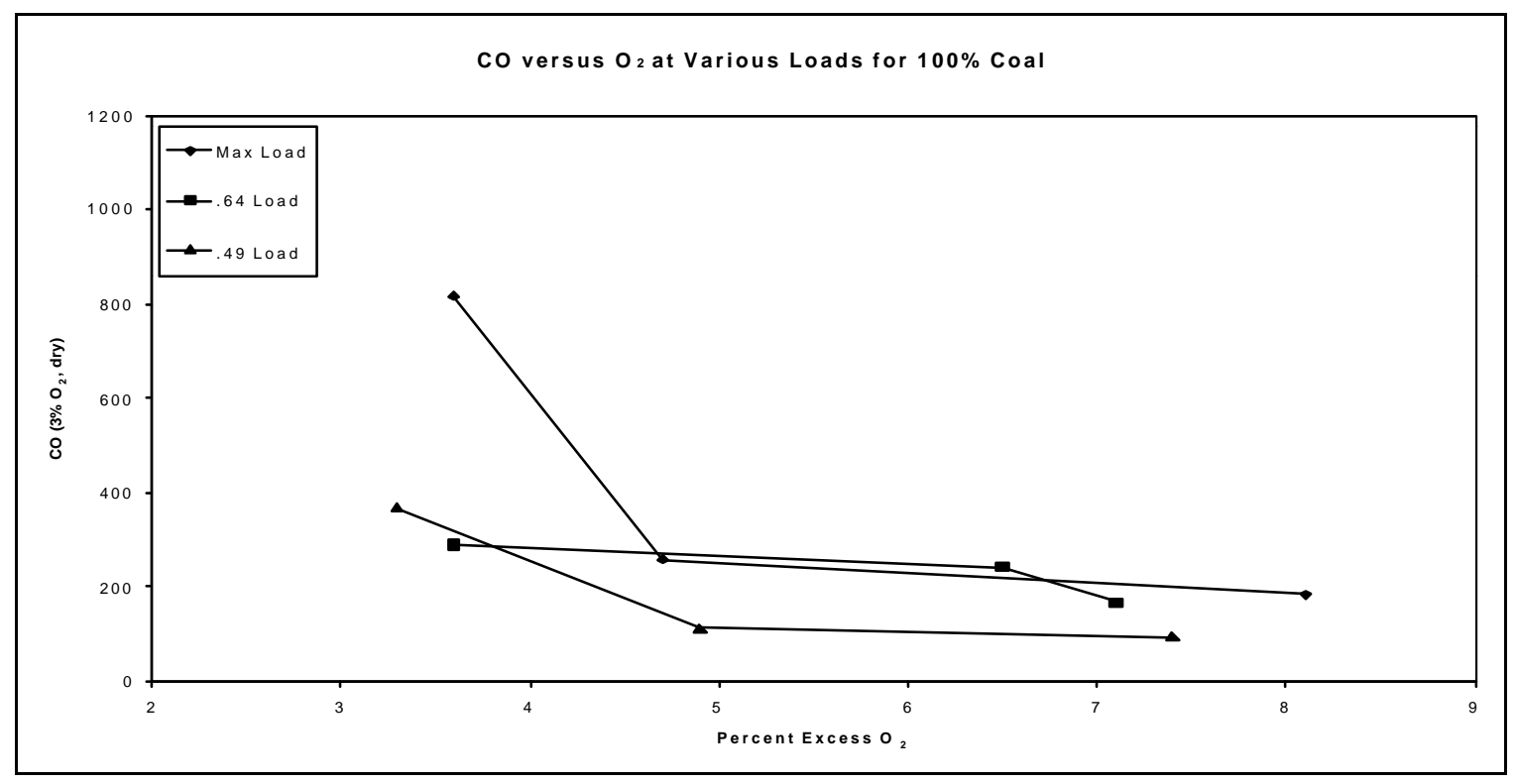

Figure 26 -- Fixed Bed Utah Coal CO Emissions Versus Excess Oxygen 
This is primarily due to bed nonuniformities, where air flow is limited and CO production is high. These nonuniformities eventually were reduced by mixing of products of combustion above the bed. However, if the gas temperature of products drops below $816^{\circ} \mathrm{C}\left(1500^{\circ} \mathrm{F}\right)$ the $\mathrm{CO}$ burnout reactions freeze, resulting in high $\mathrm{CO}$ concentrations exiting the combustor.

Apparently, this is what happened at low excess oxygen. At higher excess oxygen levels, there was sufficient oxygen at all locations of the bed to improve $\mathrm{CO}$ burnup both within and immediately above the bed. This was the case for excess oxygen levels above $5 \%$ as shown in Figure 26. Interestingly, the lowest CO level was found at approximately half load. At half load, temperatures are lower, but residence times are more than twice those at maximum load. These results suggest that the upper zone of the combustor was too cool for total $\mathrm{CO}$ burnout at either full or half load. The half load CO results were best because this gave the highest gas residence time before the cool zone was encountered. While the upper zone of the test combustor was cooler than desired, the variation of $\mathrm{CO}$ with excess air and the general level corresponds with full-scale stoker experience. Therefore, test results for NOx levels should also correspond to full-scale results.

NOx emissions from stokers are a function of bed firing rate and percent excess oxygen. Figure 27 presents the variation of coal combustion NOx in ppm with excess oxygen and load. It should be noted that all CO and NOx emissions reported in subsequent figures will be given in pm on a volume basis.

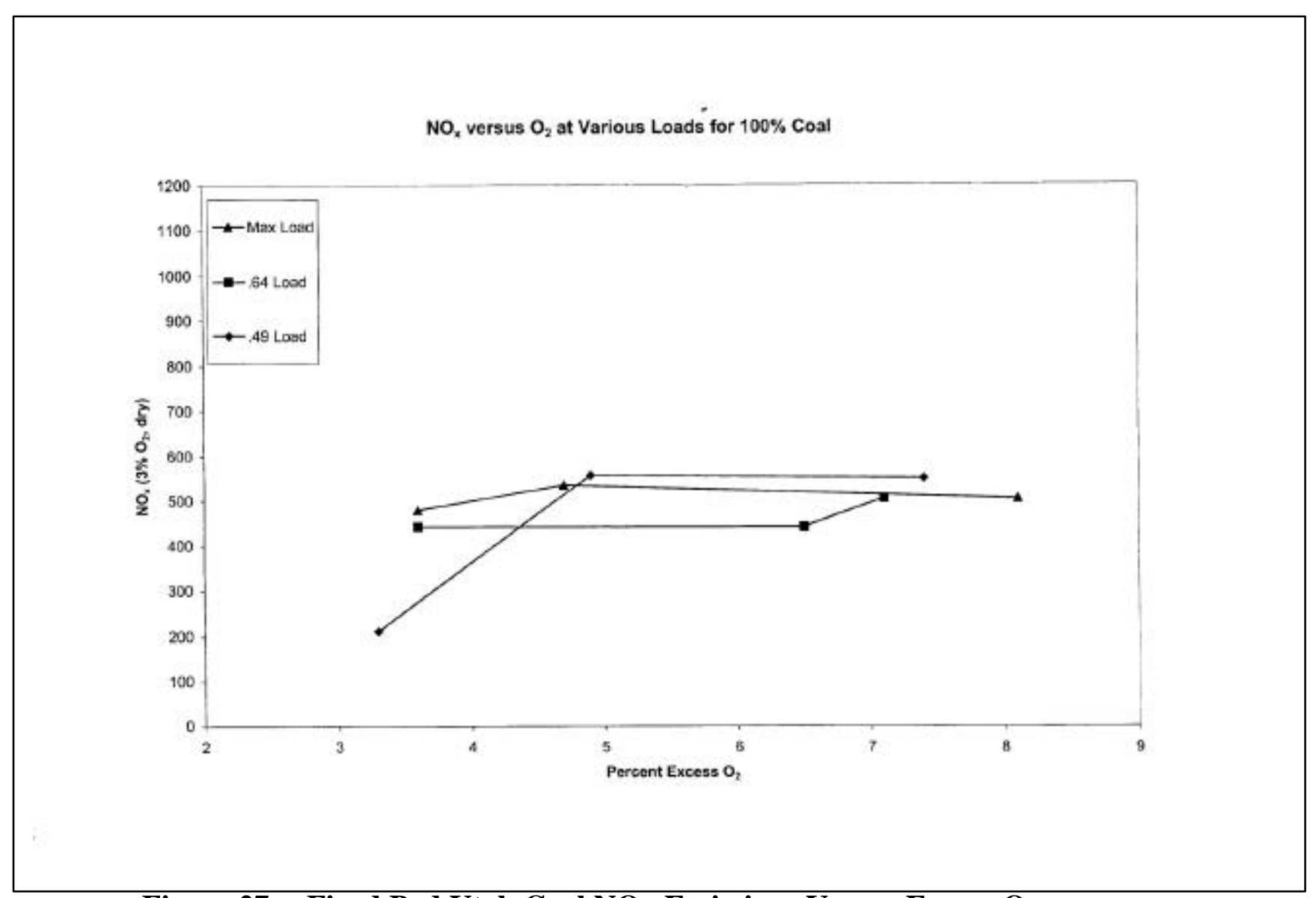

Figure 27 -- Fixed Bed Utah Coal NOx Emissions Versus Excess Oxygen 
In contrast to the $\mathrm{CO}$ emissions, NOx is suppressed at low excess oxygen. This is a result of reduced oxygen levels, where thermal NOx as well as the conversion of fuel bound nitrogen to NOx, are suppressed. At higher excess oxygen, NOx increased to a level between 450 and 600 parts per million (ppm), depending on load. These are substantial NOx emissions that exceed those produced by full-scale stoker systems, as shown in Figure 28, where the test combustor NOx emissions are compared to those obtained for full-scale stokers [17]. Therefore, the analysis of NOx emissions from the test combustor are conservative, relative to actual full-scale performance.

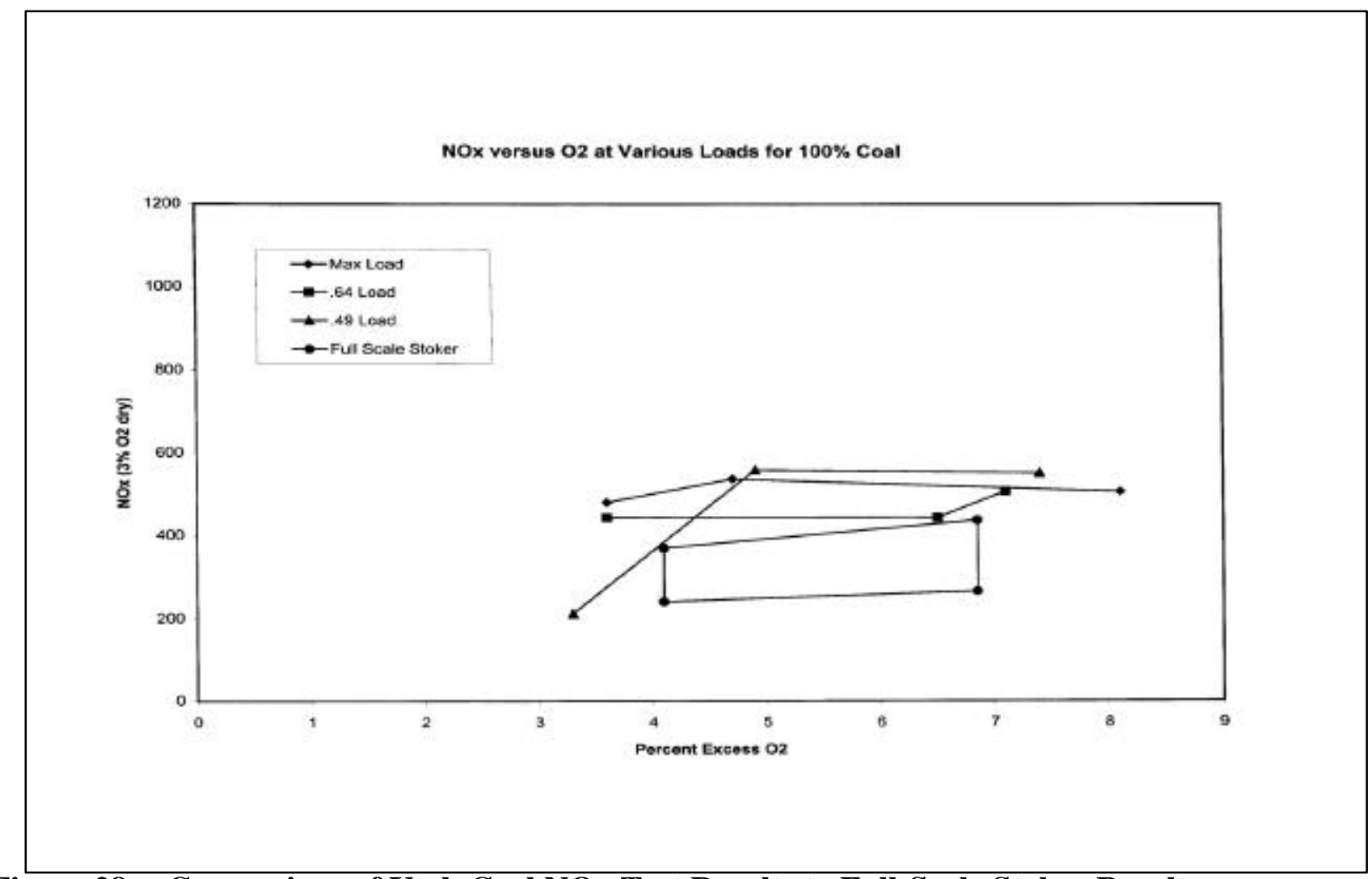

Figure 28 -- Comparison of Utah Coal NOx Test Results to Full-Scale Stoker Results

\section{Biomass-Based Pellet Stoker Combustion Tests}

The six biomass-based pellet mixtures burned in the test combustor are listed in Table 42 . These pellet mixtures were produced by the pilot-scale equipment and cover the case of biosolids and wood waste. Also, cases with biosolids and paper and biosolids paper and plastic were tested.

The paper fraction consisted of 50\% cardboard, 30\% magazine paper and $20 \%$ newspaper, consistent with expected fractions in MSW. The case with just paper represents a MSW light fractions mixture where plastic is separated from the waste, along with other components such as glass and metal. In addition to biosolids and wood waste or MSW light fractions, pellets were also tested that contained coal fines. These represented cases where coal was added to AFP pellets to give them more coal like characteristics.

As shown in Table 42(following page), high biosolids in the pellets resulted in high nitrogen content, that can drive high NOx emissions. In addition, pellet mixtures with high coal 
content tended to have higher sulfur content and $\mathrm{SO}_{2}$ emissions. Lastly, mixtures with high paper content will tend to have high ash content due to the high mineral content of coated paper found in MSW light fraction. While the above are general conclusions, the specific nitrogen, sulfur and ash contents depend on the fractions of biosolids, paper, plastic, wood and coal in the mix.

All of the test pellet mixtures listed in Table 42 were burned in the test combustor at maximum and reduced firing rates at various excess oxygen levels. Maximum firing rate was determined during testing by increasing the air and fuel flow rate until $\mathrm{CO}$ emissions exceeded $300 \mathrm{ppm}$ at the $5 \%$ excess oxygen level. Table 43 presents the maximum firing rates for the six pellet types tested. As shown, all of the pellet mixtures exceeded $1 \mathrm{MM} \mathrm{kJ} / \mathrm{hr}(1 \mathrm{MM} \mathrm{Btu} / \mathrm{hr})$, which is considerably greater than the typical 422,022 to $633,033(400,000$ to $600,00 \mathrm{Btu} / \mathrm{hr})$ firing rate with coal. It is speculated that the considerably higher volatile content of biosolids and biomass, relative to coal, helped to initiate and speed combustion. Also, with reduced fixed carbon, and higher solids porosity, the AFP pellets are expected to burn up faster than coal.

Table 42 -- Fixed-Bed Combustion Test AFP Pellet Compositions

\begin{tabular}{|c|c|c|c|}
\hline \multicolumn{2}{|c|}{ 55\% Biosolids, 45\% Wood } & \multicolumn{2}{|c|}{$\frac{50 \% \text { Coal, 24\% Biosolids, 24\% Paper }}{\text { and } 2 \% \text { Plastic }}$} \\
\hline \% Carbon & 47.69 & $\%$ Carbon & 61.50 \\
\hline \% Hydrogen & 6.11 & \% Hydrogen & 6.55 \\
\hline$\%$ Nitrogen & 2.28 & $\%$ Nitrogen & 1.60 \\
\hline$\%$ Sulfur & 0.45 & $\%$ Sulfur & 0.95 \\
\hline$\%$ Oxygen(diff) & 31.79 & $\%$ Oxygen(diff) & 18.20 \\
\hline Ash & 11.69 & Ash & 11.21 \\
\hline Total \% & 100 & Total \% & 100 \\
\hline \multicolumn{2}{|c|}{ 50\% Coal, $27 \%$ Biosolids and $23 \%$ Wood } & \multicolumn{2}{|c|}{ 50\% Biosolids and 50\% Paper } \\
\hline$\%$ Carbon & 63.57 & $\%$ Carbon & 44.08 \\
\hline$\%$ Hydrogen & 5.45 & $\%$ Hydrogen & 5.90 \\
\hline$\%$ Nitrogen & 1.77 & $\%$ Nitrogen & 1.99 \\
\hline$\%$ Sulfur & 0.96 & $\%$ Sulfur & 0.44 \\
\hline$\%$ Oxygen(diff) & 18.87 & $\%$ Oxygen(diff) & 31.89 \\
\hline Ash & 9.39 & Ash & 15.71 \\
\hline Total \% & 100 & Total \% & 100 \\
\hline \multicolumn{2}{|c|}{$55 \%$ Paper, $40 \%$ Biosolids, and $5 \%$ Plastic } & \multicolumn{2}{|c|}{$\underline{38 \%}$ Biosolids, $30 \%$ Coal, and $32 \%$ Wood } \\
\hline$\%$ Carbon & 43.56 & $\%$ Carbon & 57.23 \\
\hline$\%$ Hydrogen & 8.87 & $\%$ Hydrogen & 5.71 \\
\hline$\%$ Nitrogen & 1.61 & $\%$ Nitrogen & 1.96 \\
\hline$\%$ Sulfur & 0.36 & $\%$ Sulfur & 0.75 \\
\hline$\%$ Oxygen(diff) & 31.35 & $\%$ Oxygen(diff) & 24.07 \\
\hline Ash & 14.25 & Ash & 10.27 \\
\hline Total \% & 100 & Total \% & 100 \\
\hline
\end{tabular}


Table 43 -- Fixed-Bed Maximum Firing Intensity For Pellet Mixtures

\begin{tabular}{|c|c|c|c|c|c|}
\hline \multicolumn{5}{|c|}{ Pellet Composition } & $\begin{array}{c}\text { Maximum } \\
\text { Firing } \\
\text { Intensity }\end{array}$ \\
\hline $\begin{array}{c}\text { Biosolids } \\
\%\end{array}$ & $\begin{array}{c}\text { Wood } \\
\%\end{array}$ & $\begin{array}{c}\text { Paper } \\
\%\end{array}$ & $\begin{array}{c}\text { Plastics } \\
\text { \% }\end{array}$ & $\begin{array}{c}\text { Coal } \\
\text { \% }\end{array}$ & $\begin{array}{c}\text { MM kJ/hr } \mathbf{~ m}^{2} \\
\left(\mathbf{M M ~ B t u} / \mathbf{h r ~ f t}^{2}\right)\end{array}$ \\
\hline 55 & 45 & & & & $1.32(1.23)$ \\
\hline 50 & & 50 & & & $1.27(1.18)$ \\
\hline 24 & & 24 & 2 & 50 & $1.44(1.34)$ \\
\hline 27 & 23 & & & 50 & $1.49(1.39)$ \\
\hline 40 & & 55 & 5 & & $1.29(1.20)$ \\
\hline 38 & 32 & & & 30 & $1.56(1.45)$ \\
\hline
\end{tabular}

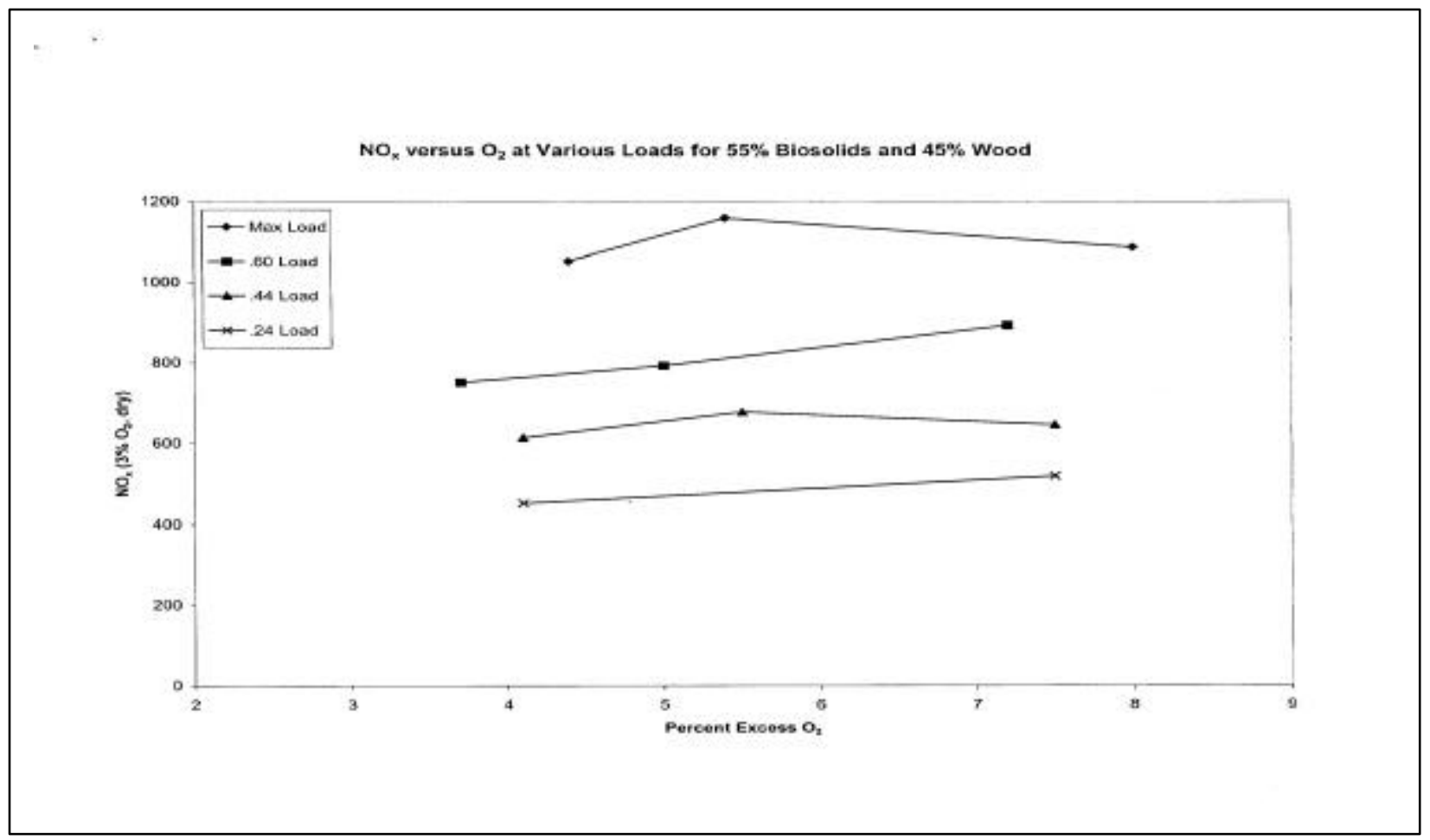

\section{Figure 29 -- Fixed-Bed NOx Emissions for 55\% Biosolids/45\% Wood AFP}

Figure 29 presents NOx results for the $55 \%$ biosolids and $45 \%$ wood AFP pellet. This pellet had the highest fuel bound nitrogen content and produced NOx emissions that peaked near $1200 \mathrm{pm}$ at $5.5 \%$ oxygen and maximum load. These are very high NOx emissions and are nearly twice the coal NOx results shown in Figure 27. As shown in Figure 29, reducing load and gas temperature, reduced NOx substantially. However, NOx emissions with this pellet formulation were very high.

This is primarily a result of the high nitrogen content of biosolids, which is approximately $3.84 \%$. Wood waste has a nitrogen content of only $0.37 \%$ and helps to offset the high nitrogen content of biosolids. While NOx emissions are high with this pellet mixture, the 
high volatility of the fuel and fuel bound nitrogen suggest that NOx control though air staging could be effective with this material. This will be shown in later test results.

Figure 30 presents $\mathrm{CO}$ emissions for the $55 \%$ Biosolids/45\% Wood AFP pellet mixture. As shown, the pellets were successfully burned even at $24 \%$ load. This is a turndown ratio of over four-to-one. Given that maximum firing rate was defined by $\mathrm{CO}$ exceeding $300 \mathrm{ppm}$, the CO levels at maximum firing rate are high. However, at $60 \%$ and $44 \%$ load, CO is below or in the range of $200 \mathrm{ppm}$. At the lowest load, $\mathrm{CO}$ is high at $4 \%$ oxygen. It is speculated that mixing and temperatures are low at this condition, leading to the freezing of $\mathrm{CO}$ and high exit levels of CO.

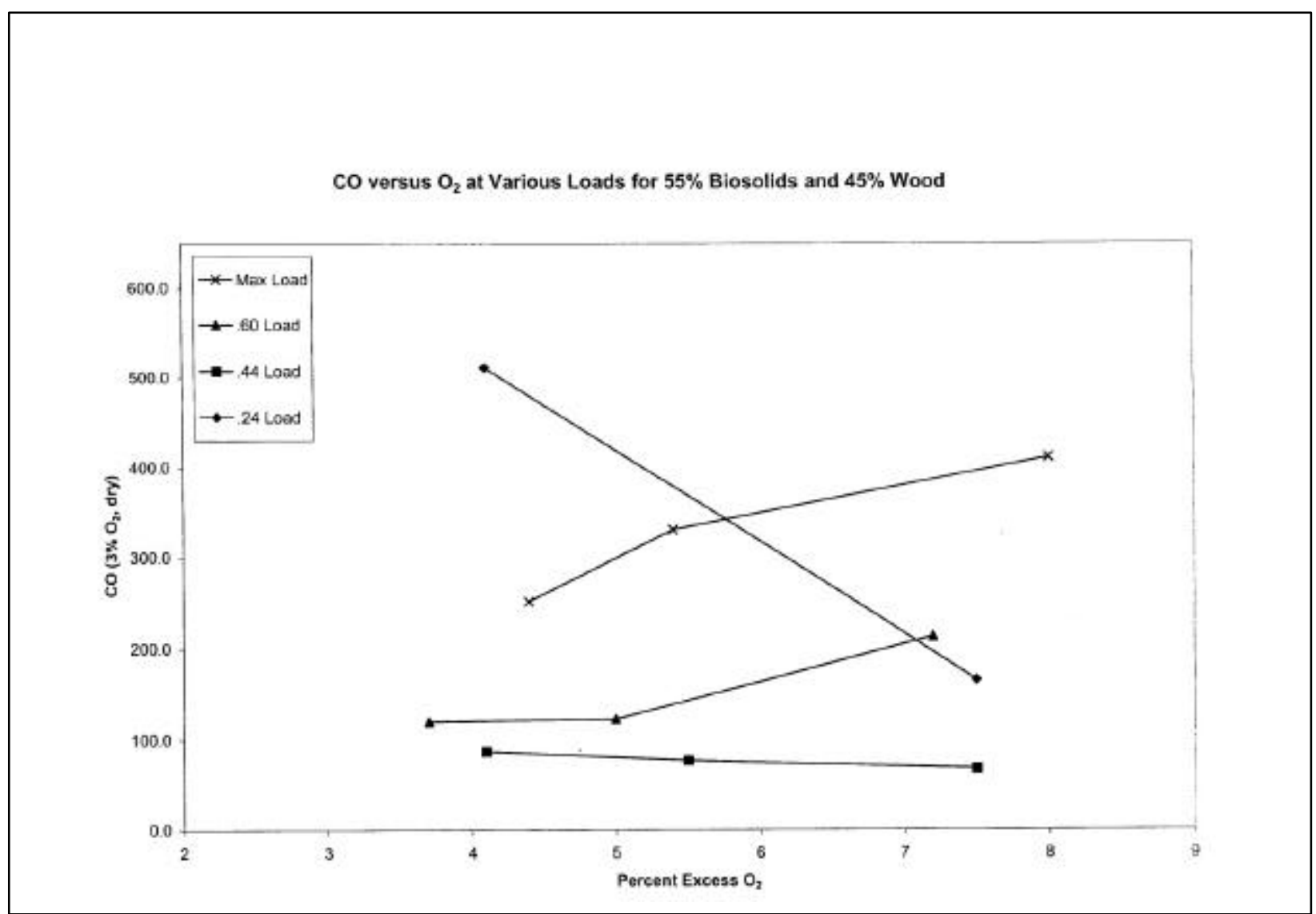

Figure 30 -- Fixed-Bed CO Emissions for 55\% Biosolids/45\% Wood AFP

Figure 31 presents the NOx emissions for a 50\% Biosolids/50\% Paper AFP pellet. As shown, NOx emissions are fairly constant over both percent oxygen and load variations. Importantly, NOx is significantly lower than the 55\% Biosolids/45\% wood pellet mixture discussed above. This is probably because the fuel nitrogen content of the $50 \%$ Biosolids $/ 50 \%$ Paper mixture pellet is lower, as can be noted in Table 42 . 


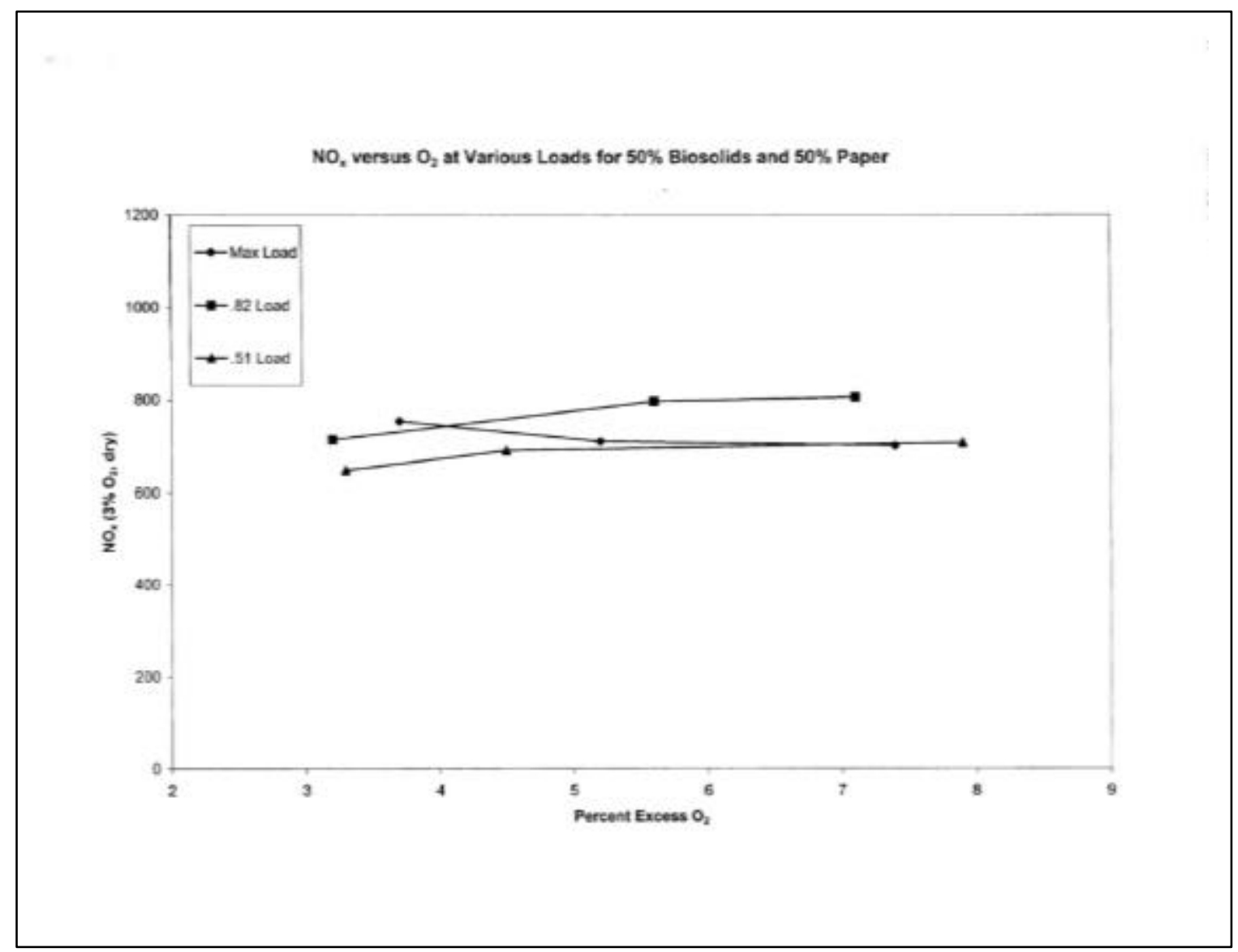

Figure 31 -- Fixed-Bed NOx Emissions for 50\% Biosolids/50\% Paper AFP

Figure 32 presents the $\mathrm{CO}$ emissions for this pellet mixture. As shown, $\mathrm{CO}$ emissions are all below $200 \mathrm{ppm}$, except for the lowest load at high excess oxygen. The high excess air levels at this conditions reduces gas temperatures to the point where $\mathrm{CO}$ burnout is delayed. 
Figure 33 presents NOx emissions for a 40\% Biosolids $/ 55 \%$ Paper/5\% Plastics AFP. As shown, NOx emissions are substantially higher than the 50\% Biosolids/50\% Paper mixture at high load. At lower load, results are more comparable. It is not clear why this pellet mix has higher NOx emissions than the case without plastic. Perhaps the small fraction of plastic makes the pellets breakup faster, thereby allowing a better contacting of fuel nitrogen and oxygen in the bed. This might help drive NOx versus the case without plastic.

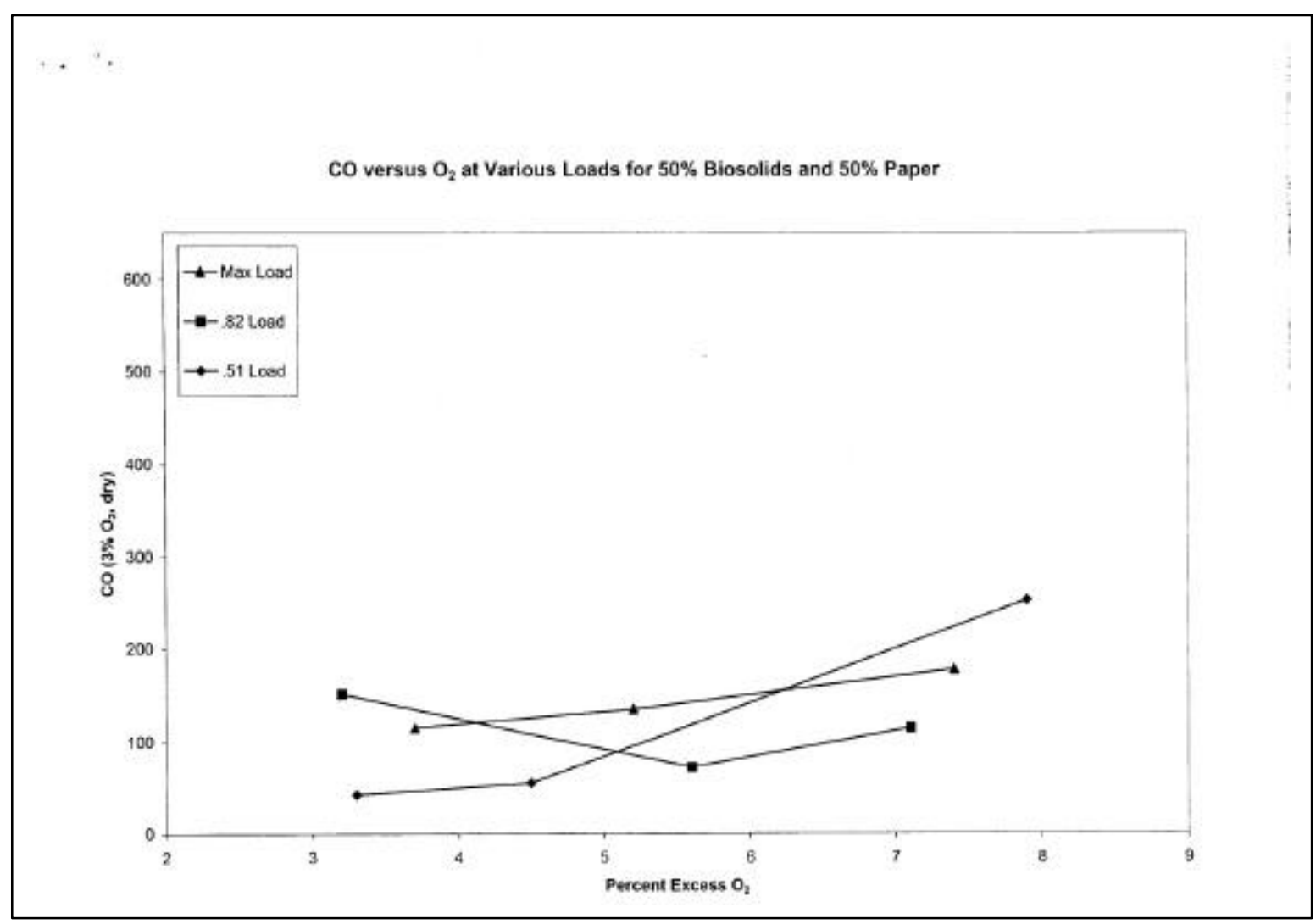

Figure 32 -- Fixed-Bed CO Emissions for 50\% Biosolids/50\% Paper AFP 


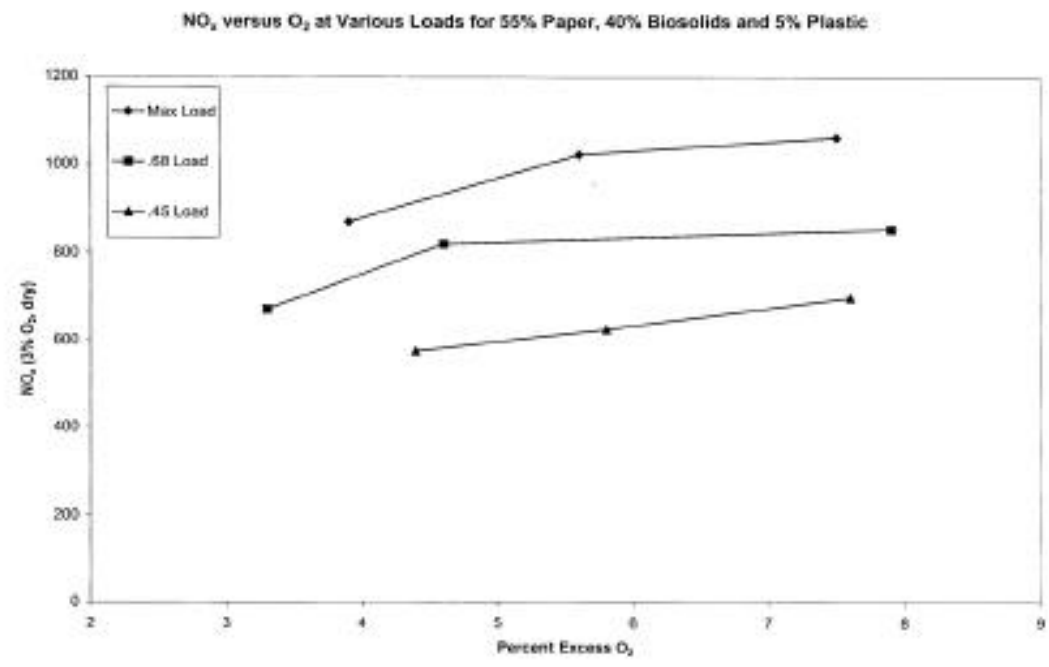

Figure 33 -- Fixed-Bed NOx Emissions for 40\% Biosolids/55\% Paper/5\% Plastic AFP

Figure 34 presents $\mathrm{CO}$ emissions for the $40 \%$ Biosolids/55\% Paper/5\% Plastic AFP. As shown, CO emissions are below 300 ppm, except for the high load and high excess air condition. At this point, residence time is short and temperatures reduced. This might tend to reduce $\mathrm{CO}$ burnout. The pellet mixture tests discussed above utilized pellets without any coal components. Adding coal is expected to give the pellet a more coal like characteristic.

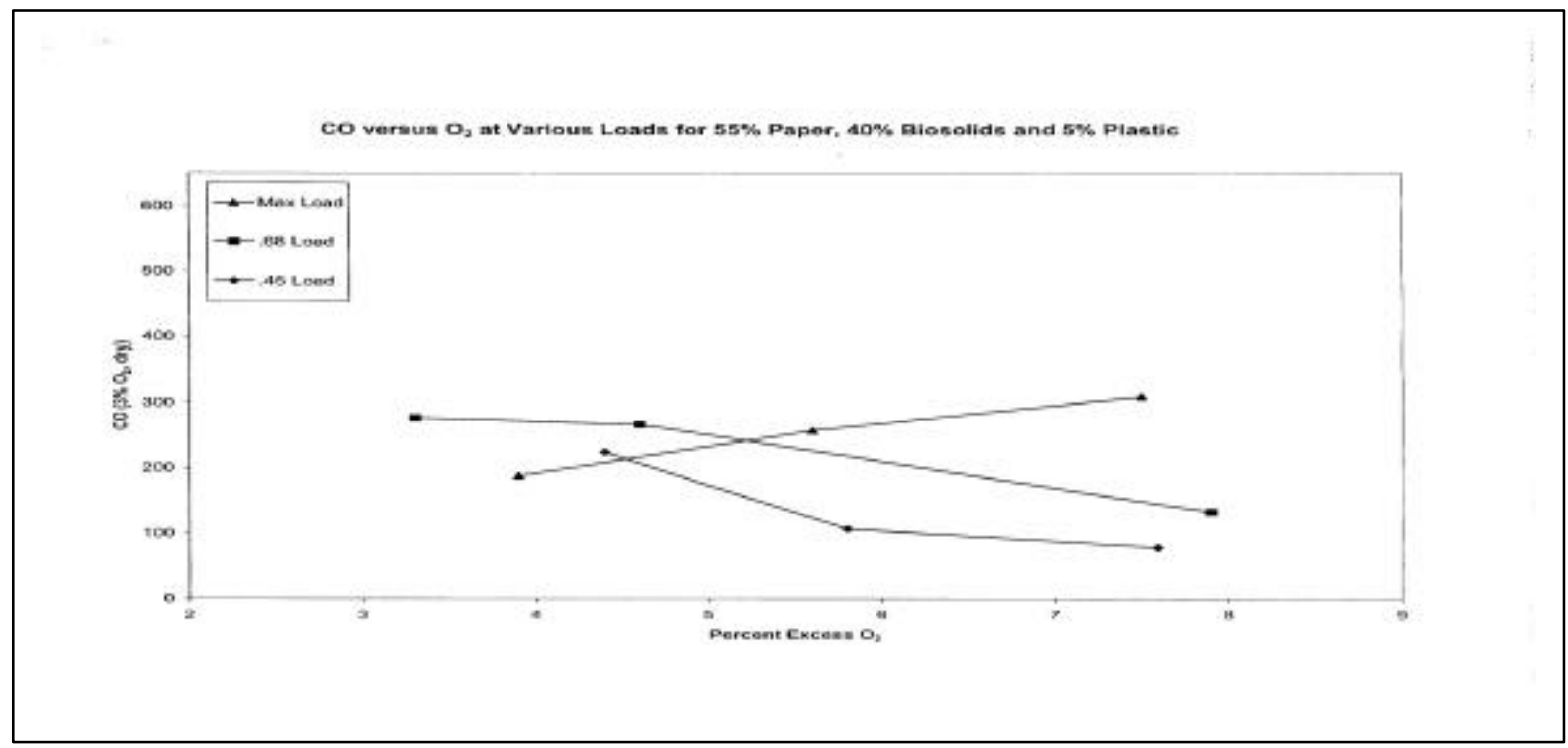

Figure 34 -- Fixed-Bed CO Emissions for 40\% Biosolids/55\% Paper/5\% Plastic AFP 
Figure 35 presents NOx emissions from a 38\% Biosolids/32\% Wood/30\% Coal AFP. As with just the biosolids and wood pellet, turndown with this mixture was good. Compared to the results in Figure 29, it appears that adding coal has reduced NOx emissions. This is expected, based on the coal only NOx results in Figure 27. However, NOx results are suppressed further than if the NOx contributions from biomass and coal fractions were simply added. This suggests some synergy between the coal and biomass materials in suppressing NOx. This is further shown in Figure 36.

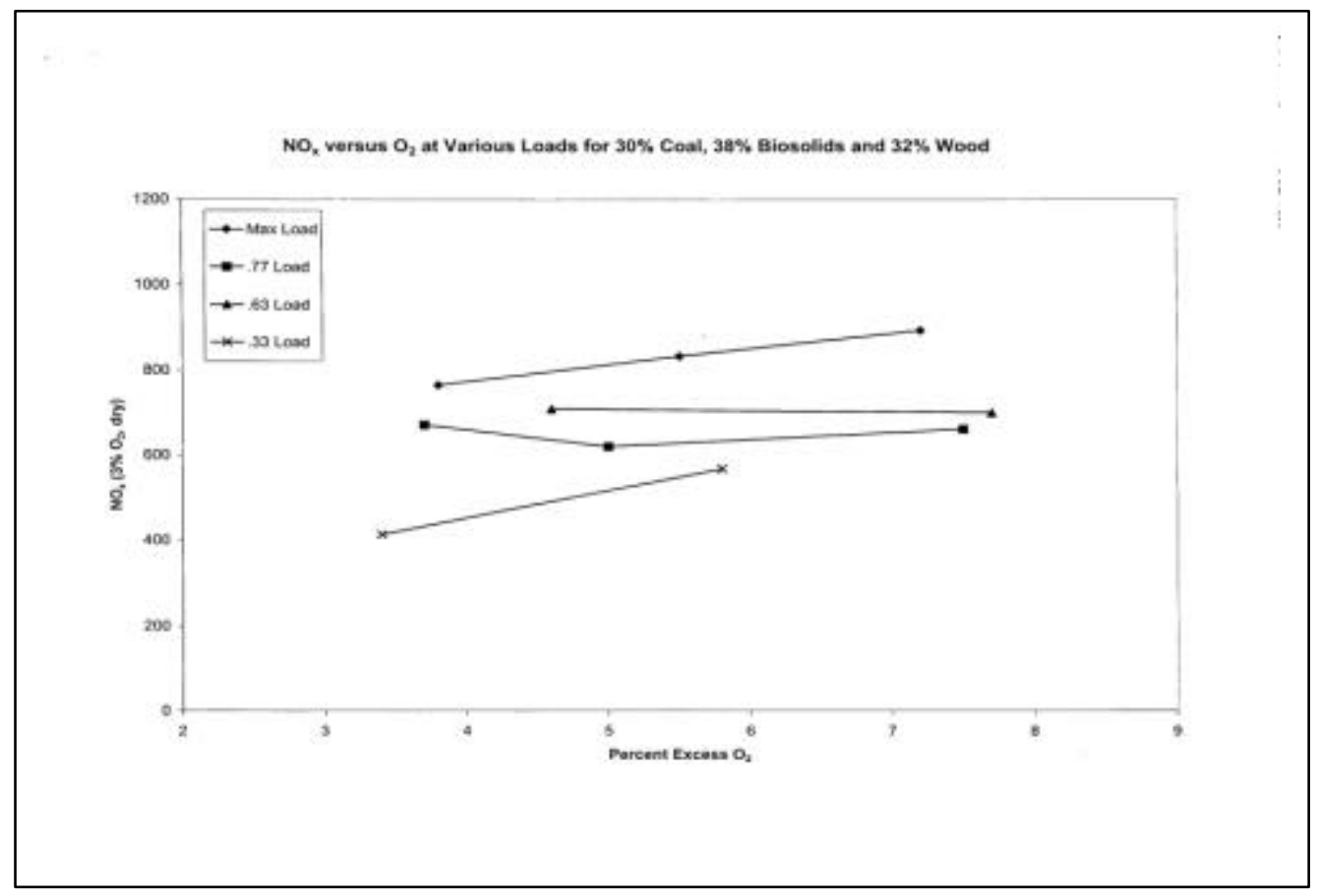

Figure 35 -- Fixed-Bed NOx Emissions for 38\% Bisolids/32\% Wood/30\% Coal AFP 


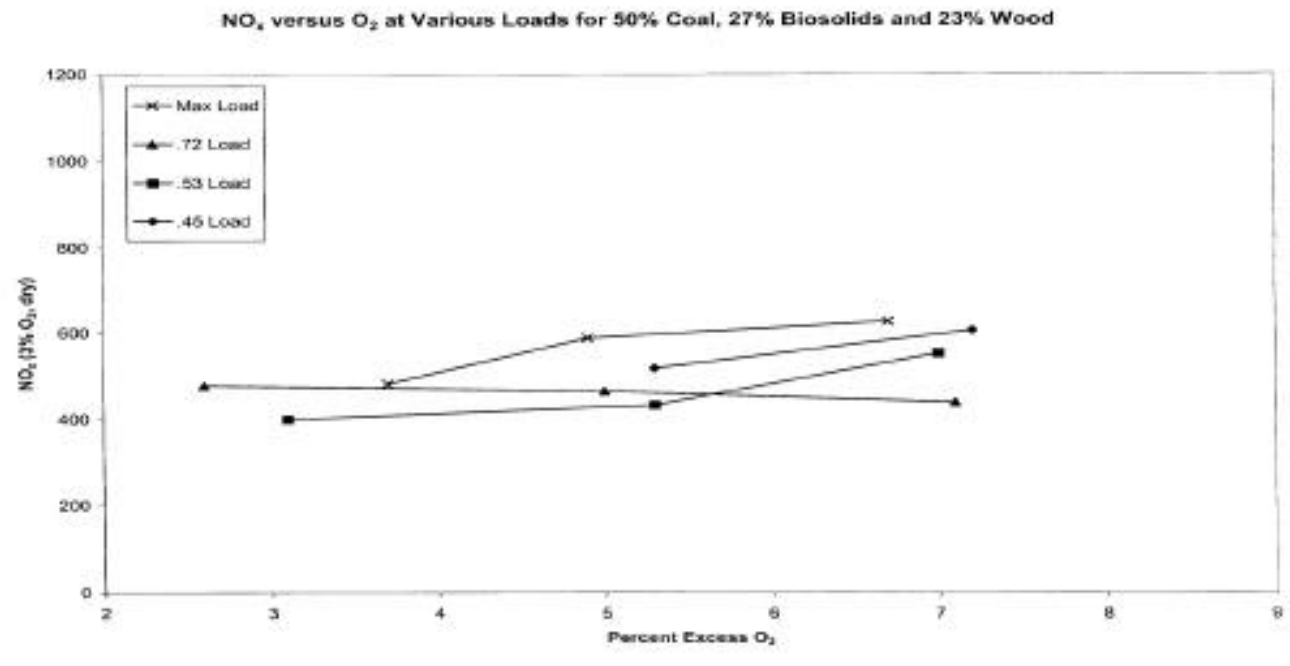

Figure 36 -- Fixed-Bed NOx Emissions for $27 \%$ Biosolids/23\% Wood/50\% Coal AFP

The AFP pellet mixture in this case has 50\% coal. Comparing the results in Figure 36 to those in Figure 35, it can be seen that NOx with $50 \%$ coal is further reduced, and is similar to the level for the coal only case shown in Figure 27. The reason for this NOx reduction beyond that expected based on individual components in the mix is not clear. It is possible that the presence of the greater fixed carbon with coal addition helps to reduce NOx by heterogeneous reaction. Whatever the reason, there appears to be a beneficial synergy between the high nitrogen biomass mix and coal.

Figures 37 and 38 present $\mathrm{CO}$ emissions for these two AFP pellet mixtures. For the $30 \%$ coal case, $\mathrm{CO}$ levels are relatively high and increase with excess oxygen. For the $50 \%$ coal case, $\mathrm{CO}$ is lower at high excess oxygen, but exceeds 500ppm at low excess oxygen. This is consistent with the coal results shown in Figure 26. As noted earlier, low excess oxygen levels should be avoided when burning coal in stokers. The reason for the substantial difference between the biomass only and biomass plus coal pellets could be a result of the difference in fixed carbon. With coal, fixed carbon is high (e.g. 61\%) and a more substantial part of the combustion is solid carbon burning in the bed. In the case of biomass, fixed carbon is very low (e.g. 5\% for biosolids) and most of the burning is by volatiles combustion above the bed. As excess air increases, the mixed gas temperature above the bed decreases, showing down the $\mathrm{CO}$ burnout reaction for the biomass volatiles. This process, combined with the reduced residence time a higher excess air, yields higher $\mathrm{CO}$ at higher excess air. In contrast, the higher excess air with coal increase oxygen solids contacting and overcomes bed flow nonuniformities and helps drive $\mathrm{CO}$ to $\mathrm{CO}_{2}$ conversion close to the bed. At lower excess air and nonuniform bed air flow, $\mathrm{CO}$ formed from carbon burning in proportions of the bed will not have enough available oxygen 
to convert to $\mathrm{CO}_{2}$, and this $\mathrm{CO}$ will escaped the system, giving the behavior exhibited in Figure 38 .

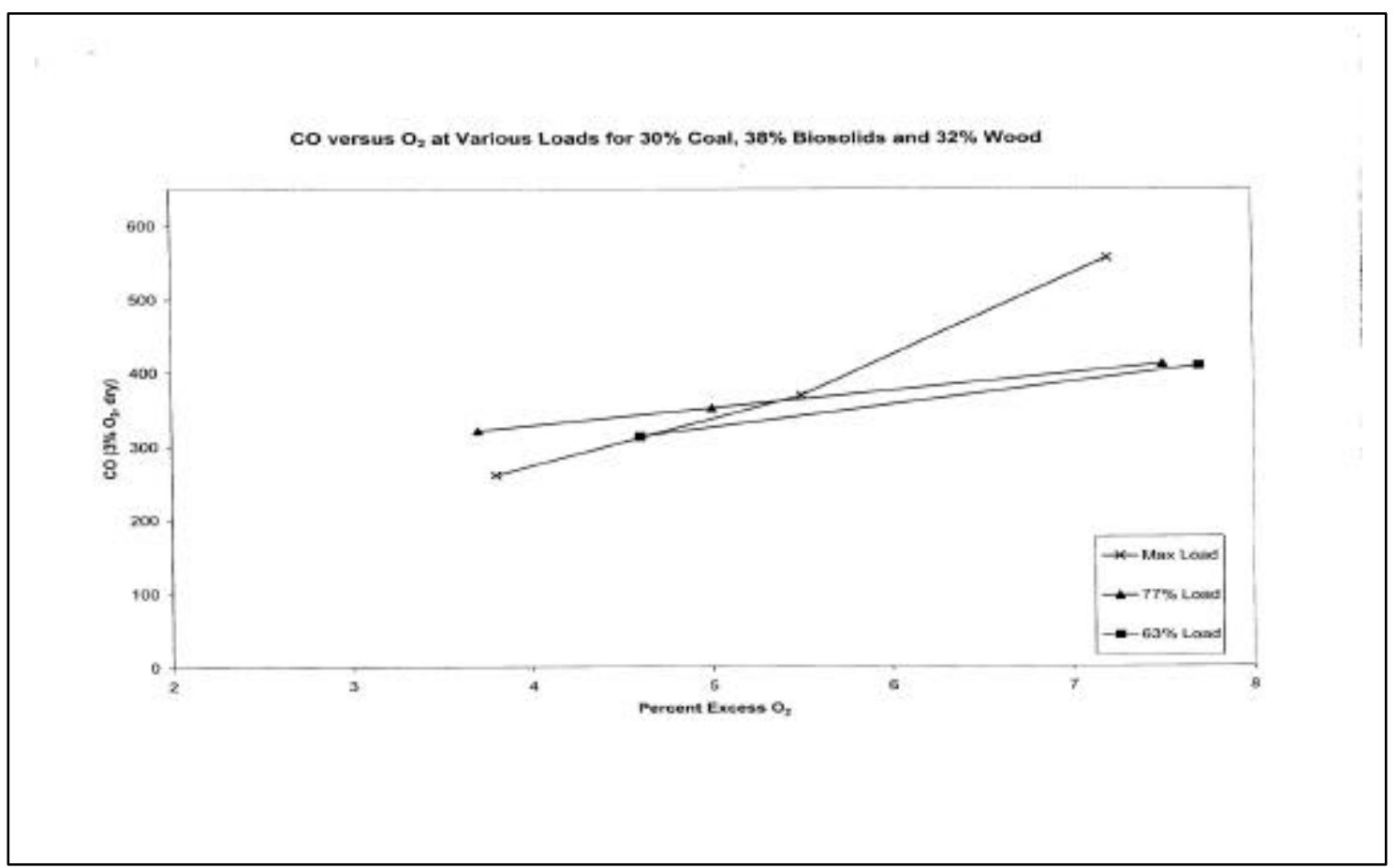

Figure 37 -- Fixed-Bed CO Emissions for 38\% Biosolids/ 32\% Wood/30\% Coal AFP

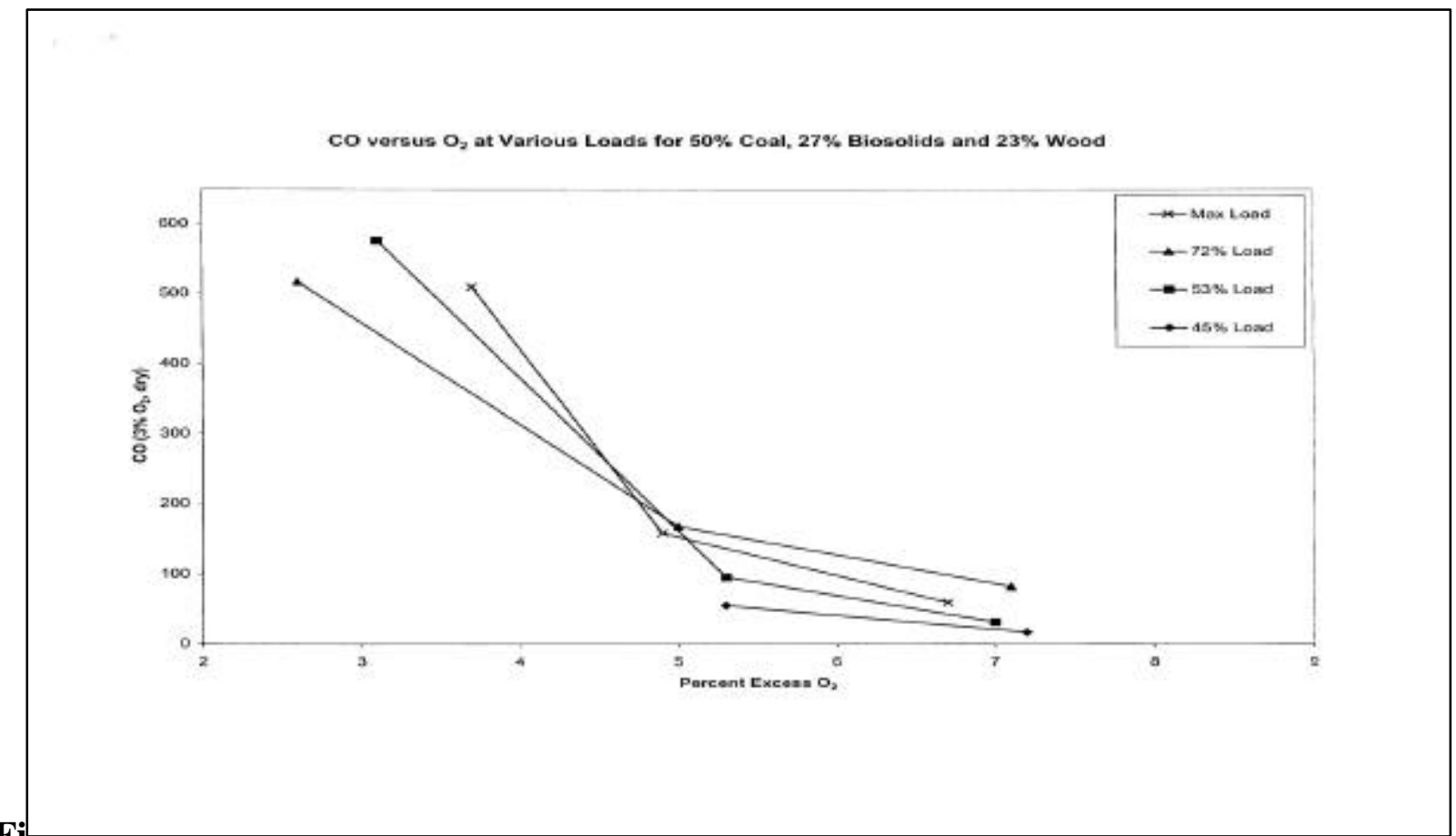

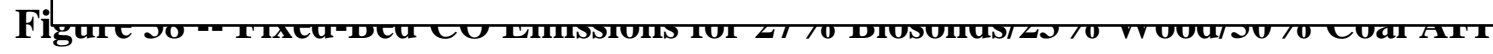

Figure 39 presents NOx emissions for a 24\% Biosolids/ 24\% Paper/2\% Plastic/50\% Coal AFP. As shown, the addition of 50\% coal has substantially reduced NOx emissions form all biomass pellet, as shown in Figure 33. In fact, similar to results for the wood-based pellet 
above, the addition of 50\% coal has reduced the biomass pellet NOx emissions to near those for coal only. Again, this suggests a synergistic effect between coal and the biomass in suppressing NOx emissions.

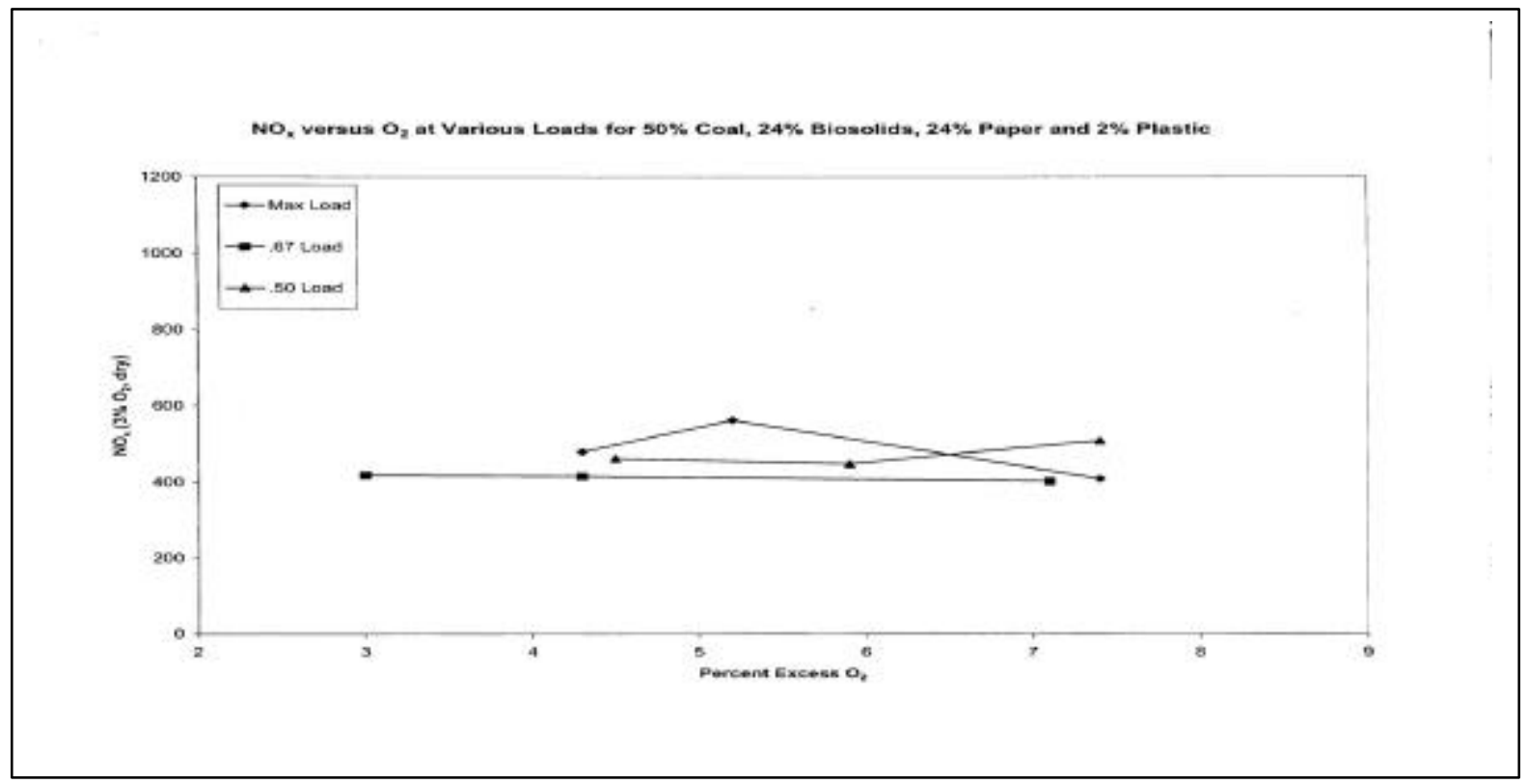

\section{Figure 39 -- Fixed-Bed NOx Emissions for 24\% Biosolids/24\% Paper/2\% Plastic/50\% Coal AFP}

Figure 40 presents the $\mathrm{CO}$ emissions for the $50 \%$ coal biomass pellet. As shown, $\mathrm{CO}$ emissions are higher than the biomass-only pellet and are particularly high at low excess oxygen, consistent with the coal behavior, as illustrated in Figure 26.

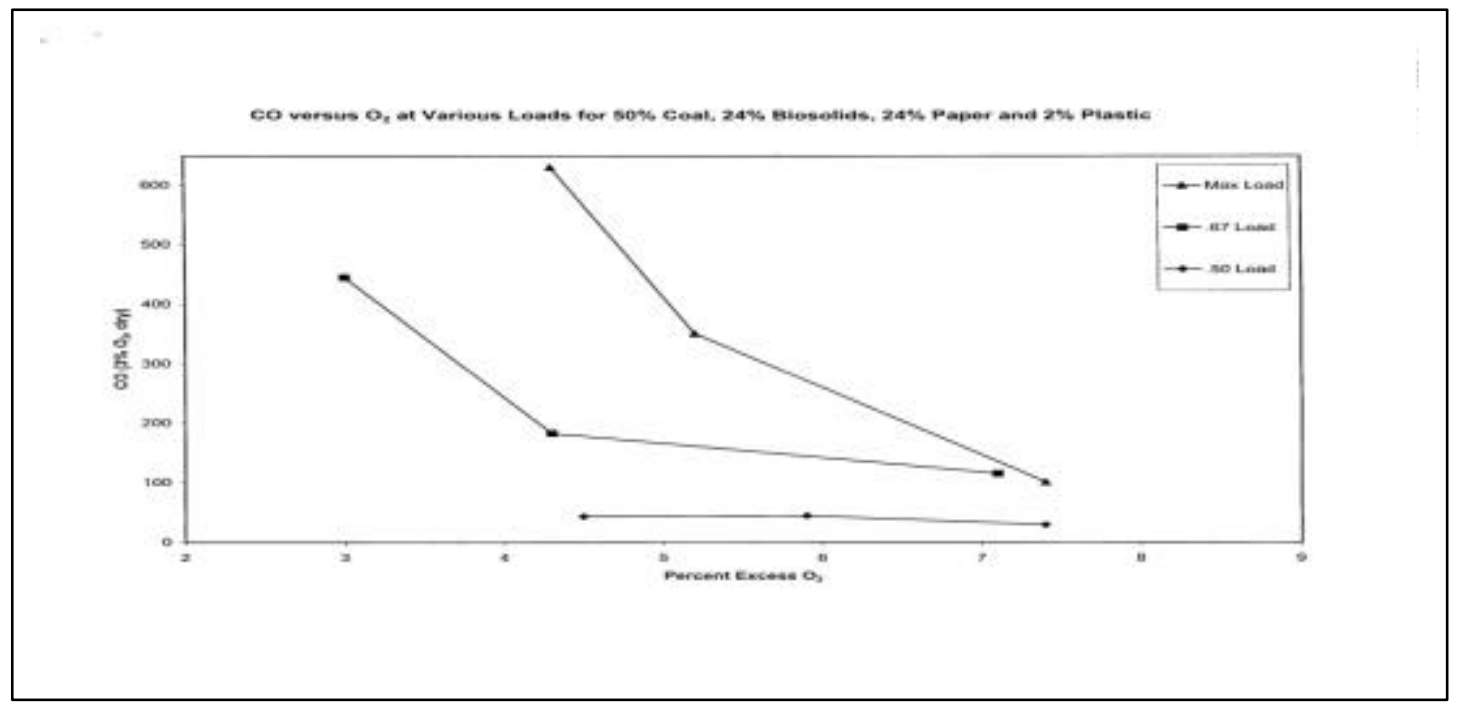

Figure 40 -- Fixed-Bed CO Emissions for 24\% Biosolids/24\% Paper/2\% Plastic/50\% Coal AFP 
In summary, these results show that the high nitrogen content biosolids can drive high NOx emissions relative to coal emissions. The low nitrogen content wood and paper/plastic wastes help to offset the high nitrogen content of biosolids. Nevertheless, these biomass based pellets will have high uncontrolled NOx emissions in stoker-fired boilers. Interestingly, the addition of coal to pellets reduces NOx emissions beyond what would be expected based on biomass versus coal fractions. In fact, at 50\% coal, NOx emissions of pellets are comparable to those for coal. This suggests that pellets with coal levels of 50\% would minimally increment NOx emissions at a stoker boiler previously fired on coal. This is an important consideration related to the need to re-permit a boiler when changing from coal to an AFP biomass-based fuel. From the fixed bed test results described above, it is clear that biomass-based pellets with biosolids only will have high NOx emissions. To maintain coal type emissions levels, some NOx control approaches would need to be implemented with these pellets. However, adding $50 \%$ coal to pellets reduces NOx back to a level similar to that for coal only. Test results showed that $\mathrm{CO}$ emissions form biomass only pellets were generally lower at low excess air. In contrast, pellets with $50 \%$ coal had higher $\mathrm{CO}$ at low excess air. This was consistent with lump coal firing in the same test facility. This suggests that a biomass only pellet might have an efficiency advantage (i.e. lower flue excess air) over coal. However, the specific advantage would have to be determined on an individual case basis.

\section{Staged-Air NOx Reduction}

It was also of interest to determine if NOx emissions for AFP all biomass pellets or biomass pellets with a smaller amount of coal could be controlled by conventional air staging. This is a relatively inexpensive NOx control technique where air flow to the bed is limited so that oxygen concentrations above the bed are reduced. By suppressing oxygen, NOx formed early in the bed reacts with fuel components and with $\mathrm{CO}$ and carbon higher up and is reduced back to molecular nitrogen. Air is then added above the bed to burn out any remaining fuel components. While staged-air NOx reductions depend on the initial stoichiometry, residence time and temperature under oxygen deficient conditions, NOx emission reductions are typically on the order of $30 \%$ in retrofitted boilers. To assess if air staging could reduce stoker NOx emissions with biomass-based AFP pellets, a brief test was run with the $38 \%$ Biosolids $/ 32 \%$ Wood $/ 30 \%$ Coal AFP. For these tests, stage air was introduced radially through two opposed 0.75 in. diameter pipes two feet above the bed, or at a staged zone residence time of $0.36 \mathrm{sec}$ at stoichiometry of 0.8 . The stage air was varied to achieve different staged zone stoichiometries. Of course, as the amount of stage air is varied, the stage residence time will vary. Total air flow was varied to cover excess oxygen levels from $3.5 \%$ to $6.5 \%$.

Figure 41 presents NOx emissions for the air-staged pellet tests. As shown, stage stoichiometries $\left(\mathrm{SR}_{1}\right)$ varied from 0.80 to 0.46 . From the figure, it can be seen that staging reduced $\mathrm{NOx}$ as $\mathrm{SR}_{1}$ decreased to .8. However, at $\mathrm{SR}_{1}$ of 0.46 , NOx increased. Comparing the baseline NOx without staging to the lowest staged NOx level, it can be concluded that biomass based AFP pellet NOx emissions can be reduced by approximately $50 \%$.

This is a substantial and beneficial reduction. However, as shown in Figure 42, CO emissions can be higher with staging, due to the delayed burnout air addition. While some $\mathrm{CO}$ increase was expected with air staging, the higher $\mathrm{CO}$ levels noted in Figure 42 may be an exaggerated effect. As noted earlier, the relatively small stoker test system had a cool burnout zone relative to a full-scale stoker system. Therefore, air staging, that pushes the burnout zone downstream into the cool zone, could raise $\mathrm{CO}$ levels beyond what is expected in a higher 
temperature full-scale stoker. A temperature of $816^{\circ} \mathrm{C}\left(1500^{\circ} \mathrm{F}\right)$ was measured in the burnout zone after stage air injection. This is too low for burnout of $\mathrm{CO}$ within the available residence time. From the figure, it appears that excess oxygen levels below 5\% are preferred.

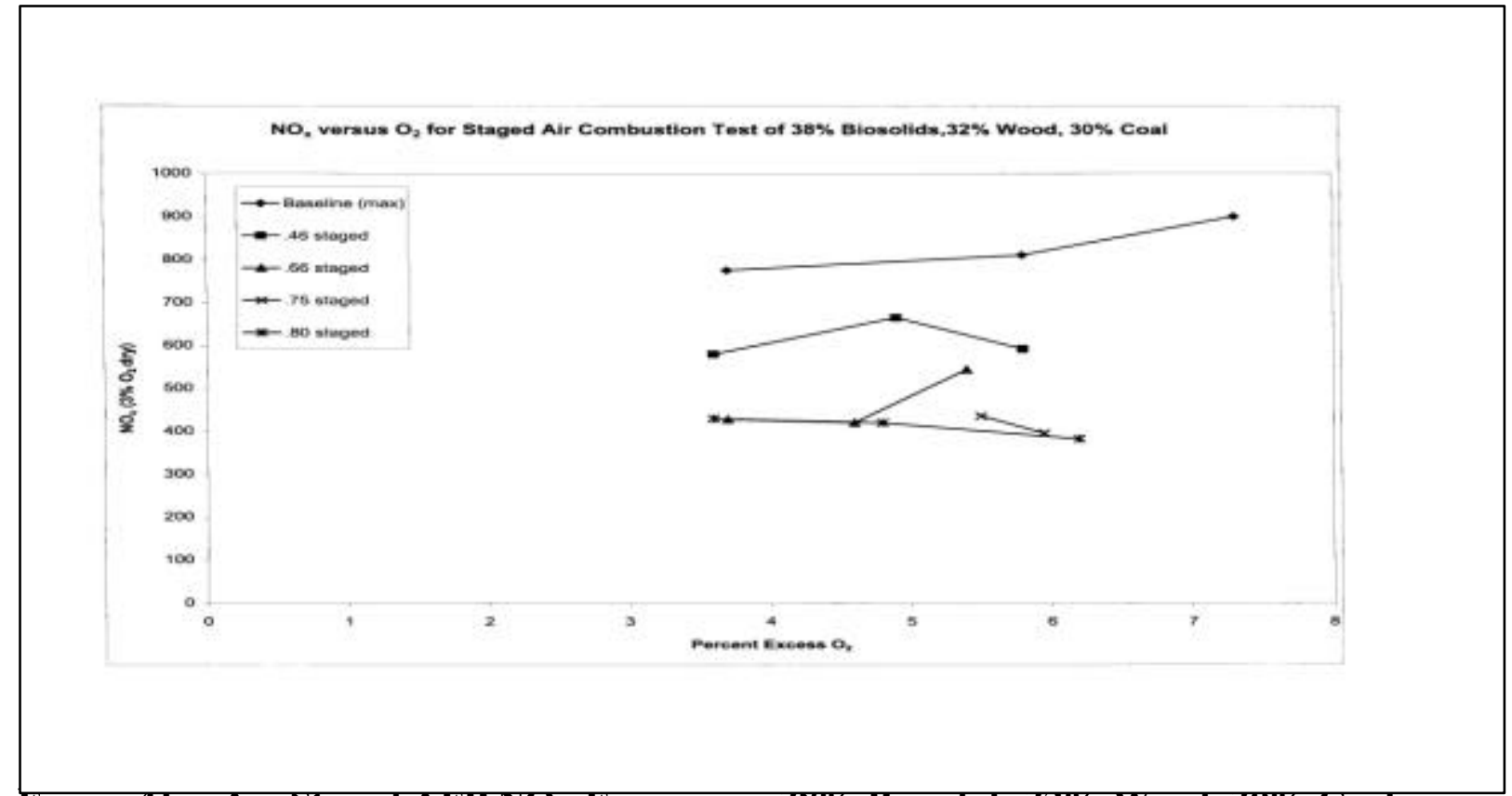

\section{Figure 41 -- AIr-Staged AFP NUx Emissions. $38 \%$ Blosolids,32\% Wood, 30\% Coal}

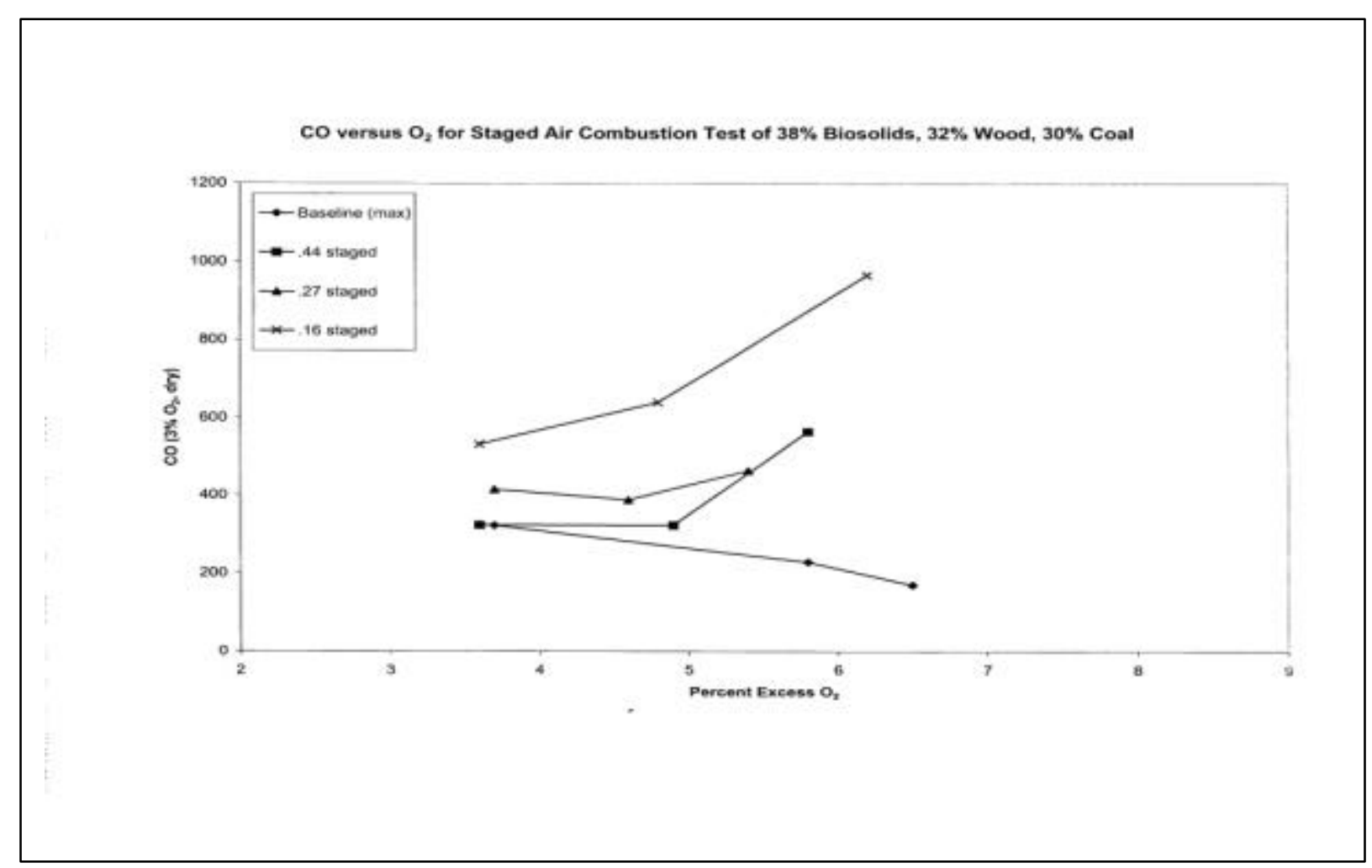

Figure 42 -- Air-Staged AFP CO Emissions 


\subsection{Pulverized Pellet/Coal Combustion Tests}

\section{Pulverized Pellet Test Equipment}

The pulverized-fuel test facility, illustrated in Figure 43, was originally designed for gas firing. Therefore, modifications to both the firebox and burner were required to fire pulverized AFP biomass based pellets and coal. In addition, special auxiliary injector configurations were needed to implement and test special biomass NOx control features. The emissions monitoring system was the same as that used in the fixed-bed combustion tests described in Section 11.1. The specific emissions monitors used are listed in Table 41. These monitors cover the emissions of interest.

To achieve the needed thermal conditions, to simulate full-scale boiler conditions, the combustor must be fired at a rate of $1.055 \mathrm{MM} \mathrm{kJ} / \mathrm{hr}(1 \mathrm{MM} \mathrm{Btu} / \mathrm{hr})$. This translates into approximately $41 \mathrm{~kg} / \mathrm{hr}(90 \mathrm{lbs} / \mathrm{hr}$ coal) and approximately $45 \mathrm{~kg} / \mathrm{hr}(100 \mathrm{lbs} / \mathrm{hr})$ of pulverized coal/AFP pellet co-fire fuel.

The existing burner was a gas-fueled high-swirl, lean-premixed design used to reduce NOx emissions. For stability, it used a large bluff-body that promoted high recirculation and stable ignition during gas firing. For coal/biomass burning, the burner needed to simulate both short flame front-wall and opposed-wall boilers and long flame tangentially fired boilers. These cover the dominant pulverized-coal-fired boiler types in use in the U.S.

To simulate front-wall and opposed-wall firing, a short and highly mixed flame must be produced. Figure 44 illustrates a typical swirl burner for front-wall or opposed-wall fired units. As shown, the burner has vane swirlers to induce swirl in the secondary air flow, which represents approximately $80 \%$ to $85 \%$ of the total flow. The pulverized coal is injected into the furnace through a central pipe that contains primary air. This fraction of air represents $20 \%$ to $15 \%$ of the total air flow. For boilers with relatively high depth, the coal and primary air injector is just a simple tube. This creates a moderate length flame, and moderate NOx emissions. For short depth boilers, and particularly short depth opposed-wall boilers, a spreader is used on the end of the fuel tube to disperse the coal into the air and create a short flame. While creating a short flame that will fit within the boiler, this highly mixed flame also produces high NOx emissions. 


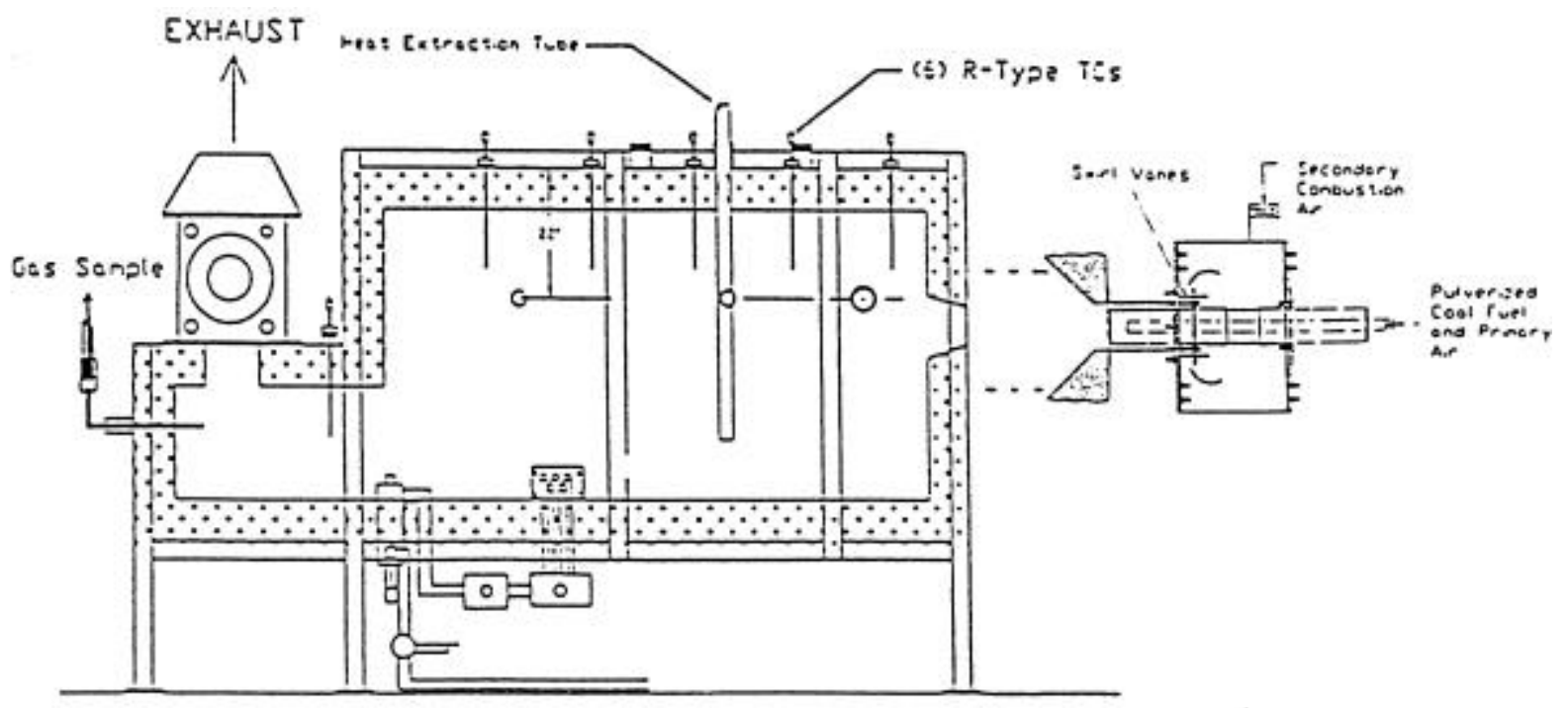

Figure 43 -- Pulverized Fuel Test Facility

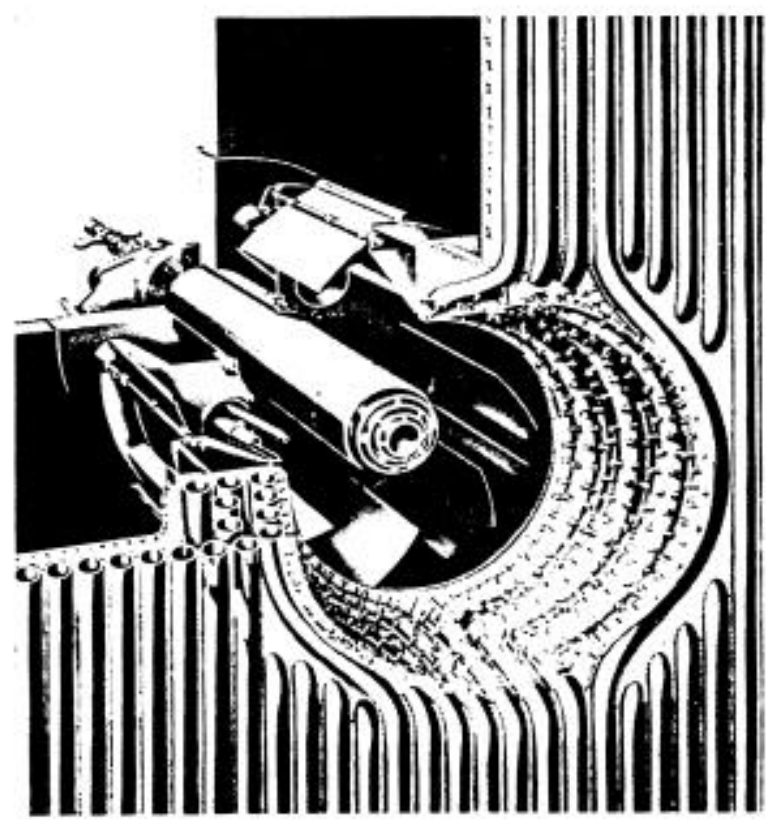

Figure 44 -- Typical Pulverized Coal Burner Configuration

Tangentially-fired boilers have very slow mixed flames. These units are designed to burn low grade fuels. Tangentially-fired boiler burners do not use any swirl, and have a simple straight fuel pipe, without any spreader. Primary and secondary air levels in tangentially-fired burners are similar to those for front-wall fired units. Due to the very slow mixing, flames are long and lazy. Because of the stretched out flames, temperatures are lower than swirl burner flames and NOx emissions are low

In conclusion, typical boiler types produce short, moderate and long flames that generate high, moderate and low-NOx, respectively. In addition, in most cases, low-NOx burners for 
these systems tend to further reduce mixing and stretch out flames. This moves the NOx emissions to moderate, low and very-low. NOx reductions in the range of $30 \%$ are possible with low NOx burners. In addition, for further reductions in NOx, stage air can be implemented. In this approach, only approximately $80 \%$ of the total air flow goes through burners. This limits oxygen availability in the initial flame zone and suppresses NOx. The remaining $20 \%$ of the air is then injected downstream of the burners to consume any remaining partially oxidized fuel components. Using stage air, NOx reductions in the range of $30 \%$ are possible.

For the biomass/coal combustion tests, it is of interest to simulate front-wall and opposed-wall firing in both conventional and low-NOx modes. These are the most challenging NOx emission cases. Simulating these cases is accomplished by modifications to the test facility burner and firebox. Figure 45 presents an illustration of the modified test burner. To achieve a configuration similar to the full-scale burner illustrated in Figure 44, the large bluff-body in the original burner was removed and replaced with a central fuel tube that contains about $15 \%$ primary air. Immediately surrounding the fuel tube is a secondary air jet that contains the remaining $85 \%$ secondary air. Baseline primary and secondary air velocities are set at $23 \mathrm{~m} / \mathrm{s}$ $(75 \mathrm{ft} / \mathrm{sec})$ and $30.5 \mathrm{~m} / \mathrm{s}(100 \mathrm{ft} / \mathrm{sec})$ respectively, to simulate full-scale burner momentum ratios.

To achieve the needed secondary air jet configuration, the original burner end piece was reduced in diameter by a metal insert. The existing adjustable swirl vanes channel the flow radially inward and then down the secondary annular jet, similar to what occurs in a full-scale swirl burner.

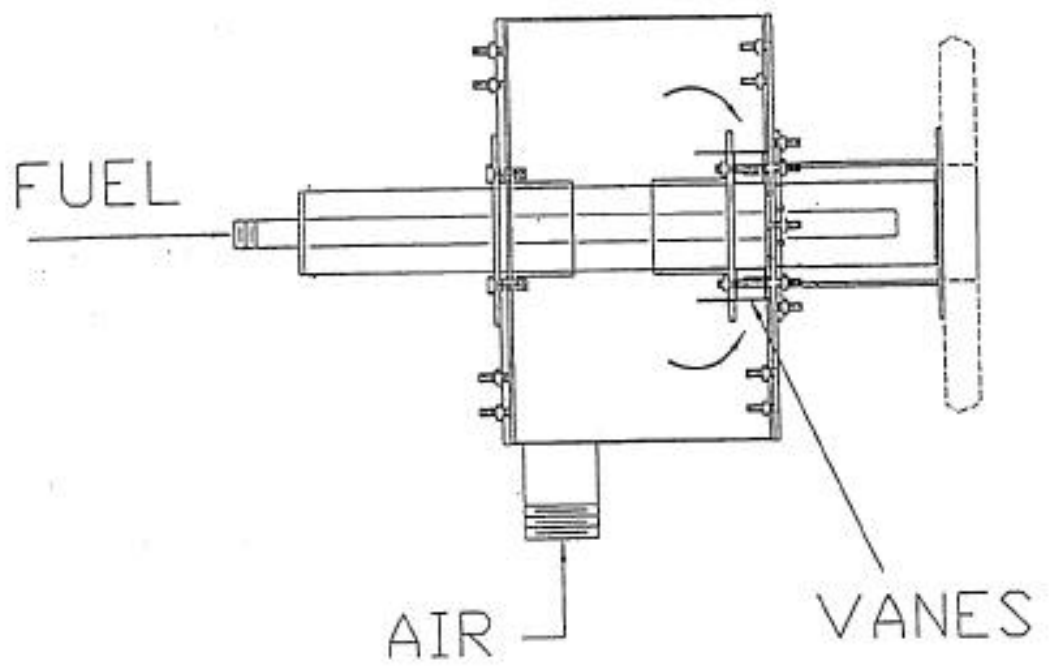

Figure 45 -- Pulverized Fuel Test Burner

As a means to alter swirl during operation, a second air supply that directed secondary air axially down the annular channel was incorporated into the burner. By varying the amount of air through the swirl vanes versus that through the axial injectors, swirl levels could be varied during operation. The base fuel tube design was just a simple tube. However, a conical spreader could be fixed to the end of the tube to disperse the coal into the secondary air and create a short flame. Through the use of variable swirl and variable fuel injection in the test burner, several types of coal-fired boilers could be simulated. Burner settings to simulate various firing modes are listed in Table 44: 
Table 44 -- Burner Firing Mode Options

\begin{tabular}{|l|l|}
\hline \multicolumn{1}{|c|}{ Firing Modes } & \multicolumn{1}{c|}{ Burner Configuration } \\
\hline Tangential Firing & Little to no swirl and simple fuel tube \\
\hline Low NOx Front or Opposed Wall Fired & Moderate swirl and simple fuel tube \\
\hline $\begin{array}{l}\text { Conventional Front or Opposed Wall Fired } \\
\text { Boiler }\end{array}$ & High swirl and simple fuel tube \\
\hline $\begin{array}{l}\text { Short boiler depth Front or Opposed Wall } \\
\text { Fired }\end{array}$ & High swirl and fuel spreader \\
\hline
\end{tabular}

By test burner adjustments, all of these cases could be simulated. In addition, firebox modifications allowed the simulation of special additional low NOx configurations. These are described below.

\section{AFP Staged Fuel Reburn NOx Reduction}

Reburning, or fuel staging, is another NOx control approach that has the potential to lower NOx emissions by 50\%. In this approach, fuel is injected above the burner zone, as well as through the burner. This second, or reburn zone, is operated with a deficiency of oxygen. Given the lower oxygen content and reduced temperature of this zone, previously formed NOx is reduced to molecular nitrogen and overall NOx emissions are thereby reduced. Air is then added above the reburning zone to burn out any remaining fuel components.

Natural gas is an ideal reburning fuel, because it ignites and burns rapidly and contains no bound nitrogen. Therefore, in small volume boilers, natural gas reburn fuel can quickly burn out prior to product gas quenching in the convective section. Also, without nitrogen in the fuel, NOx production in the burnout zone is minimized and NOx reduction in the reburning zone is maximized. Although coal reburning fuel is less expensive then natural gas, it is limited because it requires more boiler volume to completely burn out the fuel and nitrogen in the coal tends to offset reburn zone NOx reduction. Therefore, although less expensive, coal reburn fuel cannot be applied to all boilers and NOx reductions with coal are not as significant as those with gas. While coal has limitations as a reburning fuel, biomass-based fuel has less limitations. First, biomass typically has higher volatile content and lower fixed carbon content than coal, as illustrated by the typical properties listed below in Table 45 .

Table 45 -- Comparison of Coal and Biomass Properties

\begin{tabular}{|l|c|c|c|}
\hline & $\begin{array}{c}\text { Coal } \\
\text { dry }\end{array}$ & $\begin{array}{c}\text { Paper-Based } \\
\text { Biomass } \\
\text { dry }\end{array}$ & $\begin{array}{c}\text { Wood-Based } \\
\text { Biomass } \\
\text { dry }\end{array}$ \\
\hline Volatiles & $32 \%$ & $73 \%$ & $81 \%$ \\
\hline Fixed Carbon & $61 \%$ & $10 \%$ & $18 \%$ \\
\hline Btu/lbm & 13,900 & 6,800 & 8,350 \\
\hline
\end{tabular}

Therefore, biomass will volatilize more easily and completely than coal, and thereby act more like gas reburning fuel. This should permit the use of biomass reburning in more units. Furthermore, wood or paper biomass nitrogen contents are low, compared to coal. Therefore, the NOx reduction potential for biomass reburning fuel should be significantly better than that for coal. However, as noted earlier, biosolids contain high levels of nitrogen. Therefore, pellets of 
mixed biosolids and biomass can have a nitrogen content similar to that of coal. Nevertheless, given the substantial benefits of biomass, the separate injection of biomass reburning fuel was tested.

To simulate biomass fuel reburning NOx control, pulverized biomass was injected downstream of the burner. In a typical full-scale boiler, a row of reburning fuel injectors would be placed above the main burners to ensure an even dispersion and mixing of the fuel across the boiler. For the relatively small test unit, it was not practical to split the reburning fuel flow into several separate injectors. Therefore, a special single point injector that dispersed reburn fuel across the furnace cross-section was utilized.

Figure 46 presents an illustration of this injector design. As shown, the reburn fuel and approximately $5 \%$ of the total air flow was split into several streams that were dispersed across the furnace in a two-dimensional "fan" shape. The splitter plates were sufficiently long to turn the flow, including the pulverized biomass, in the needed directions. By splitting the single biomass flow and dispersing the material with splitter plates, multiple full-scale reburn fuel injection was simulated by a single point injector in the test system.

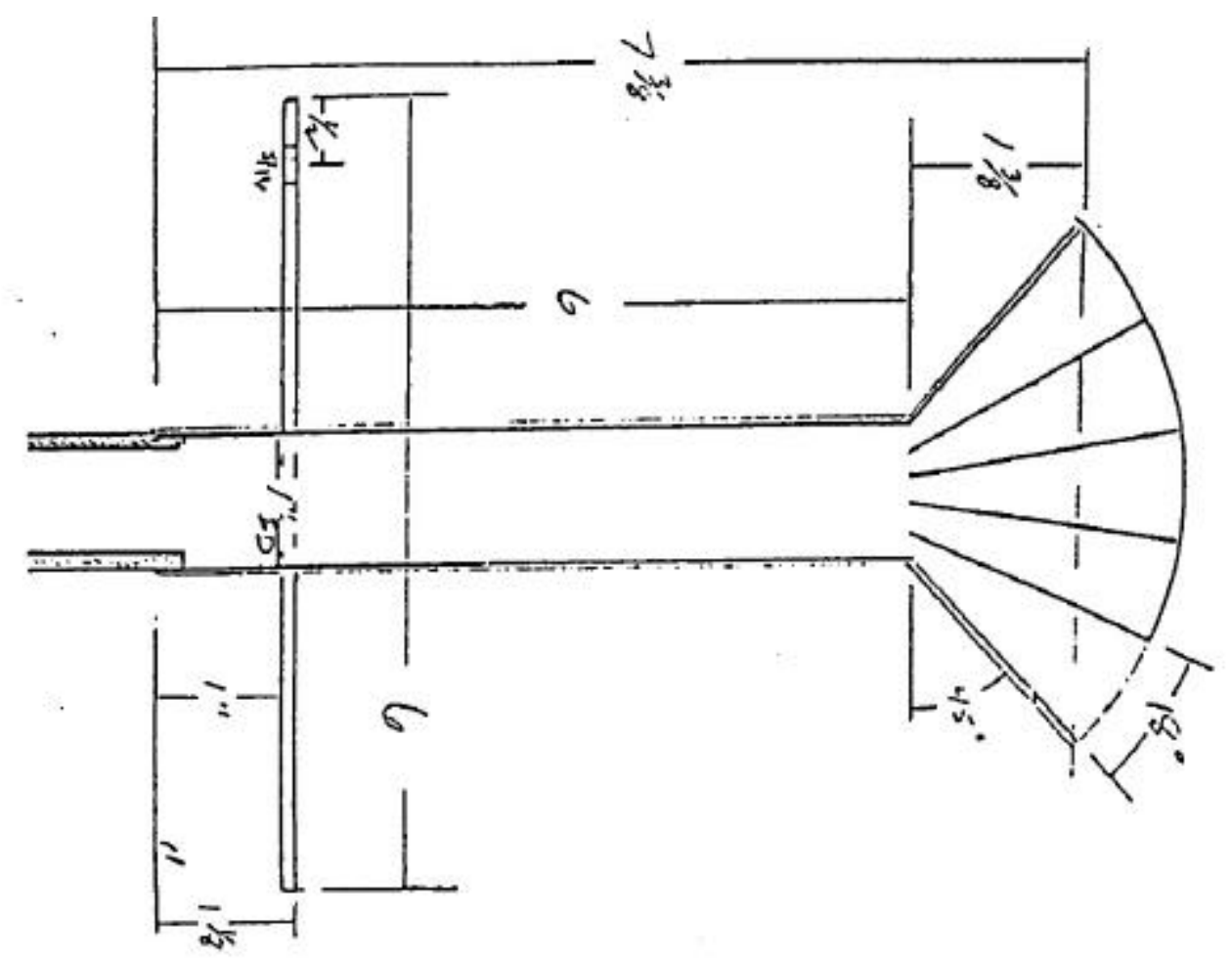

\section{Figure 46 -- Biomass Reburning Test Injector}

Burnout air injection in full-scale boilers is also achieved by multipoint injection. This approach is used to ensure good air and furnace gas mixing for complete and rapid burnout, before product gas quenching in the convective section. For burnout air injection, the test unit also incorporated multipoint air injection. The multipoint burnout air injector used in the test system consisted of five air injectors of $3.1 \mathrm{~cm}\left(1.19^{\prime \prime}\right)$ in diameter, spaced equally along the side 
of the firebox. To provide good air penetration and mixing, the injection velocity was $15 \mathrm{~m} / \mathrm{s}$ (50 $\mathrm{ft} / \mathrm{sec}$ ). Given the low cross flow velocity, burnout air penetration was good.

\section{AFP B IOMASS REBURNING TEST R ESULTS}

The focus of the pulverized fuel test was the use of biomass fuels as a reburn zone injectant that would reduce NOx from a typical coal-fired powerplant. By using the biomass as a NOx reducing agent, the value of the biomass to plant operations could be increased, relative to the use of the biomass as a straight energy substitute for coal. Furthermore, given the limitations of the pulverization of the biomass-based fuels and the low-energy density relative to coal, the percent cofiring for biomass as mixed with coal would be relatively low. Therefore, emissions during direct cofiring would be little impacted and test results would add little new knowledge. For the cofiring approach, the main issue would be how the biomass impacted fuel feed operations. This issue would be best addressed in tests on full-scale equipment. The pilot-scale fuel feed equipment utilized in this effort only has limited similarity to full-scale equipment. For example, in the full-scale equipment, lump fuel is fed to the pulverizer, that then grinds the fuel and air classifies the fuel prior to sending it directly to the burners. In the pilot-scale system, the fuel was ground off-site and then stored in drums, prior to screw feeding into the combustor using transport air.

Before the biomass reburn tests, the primary burner was reconfigured by installation of the conical spreader at the exit of the fuel injector tube. As noted earlier, the purpose of this diverter was to rapidly spread the coal out into the combustion air and produce a high NOx flame characteristic typical of highly mixed, short flame front-wall fired boiler systems. This type of system was expected to need a reburn system to control NOx, and was also expected to respond well to reburn NOx control.

Prior to the biomass reburning tests, a baseline test was run on pulverized coal. The coal used was consistent with that utilized in the pulverized pellet tests, as well as that used in the main burner during the subsequent reburn tests. Properties of the coal are given in Table 36. This is a typical Western bituminous coal.

Before initiating the coal firing, the unit was brought up to temperature using natural gas fuel at a firing rate of $1.055 \mathrm{~kJ} / \mathrm{hr}(1 \mathrm{MM} \mathrm{Btu} / \mathrm{hr})$. Once temperatures reached approximately $927^{\circ} \mathrm{C}\left(1700^{\circ} \mathrm{F}\right)$, the gas was turned down and the coal feed initiated. Ignition of the coal was observed, producing a very bright radiating flame relative to the nearly transparent natural gas flame. Fuel and air were then increased until the firing rate reached $1.055 \mathrm{~kJ} / \mathrm{hr}(1 \mathrm{MM} \mathrm{Btu} / \mathrm{hr})$ and $3 \%$ oxygen concentration in the exhaust. Since the feeder calibration was not precise, the load was set by setting the needed air flow and increasing the coal feed rate until the correct $\mathrm{O}_{2}$ concentration was achieved. It should be noted that the furnace operates under positive pressure and, therefore, in-leakage and its impact on firing rate determination is avoided.

Once the unit was operating on coal at the needed conditions, data was then recorded by the continuous emissions monitors listed in Table 41. Figure 47 presents a plot of the coal firing $\mathrm{NOx}$ emissions as a function of $\mathrm{O}_{2}$ in the exhaust gas. As shown, the NOx exceeds $1000 \mathrm{ppm}$ at $2 \% \mathrm{O}_{2}$, and increased modestly with $\mathrm{O}_{2}$. These are relatively high NOx emissions that are characteristic of the test systems burner that has a coal diverter integrated into the coal injector tube.

To determine how well the test system simulated a rapid mix high NOx boiler case, the NOx results, corrected to $3 \%$ oxygen and dry conditions, in Figure 47 were compared to those obtained in a full-scale boiler. As discussed previously, NOx emissions are a complex function

of fuel type and burner design. Therefore, NOx emissions can vary greatly. Given the fuel and 
burner type used in the pilot-scale facility, a comparison with test results for a highly mixed burner would be best. Field test results from reference 18 show that highly mixed burners can produce over $850 \mathrm{ppm}$ NOx. Therefore, the test combustor burner produced even higher NOx than field practice. Nevertheless, the general NOx level exhibited by the test unit indicated that reburn NOx reduction test results will be relevant to assessing reburn performance in full-scale systems. CO emissions for the base line coal tests are given in Figure 48.

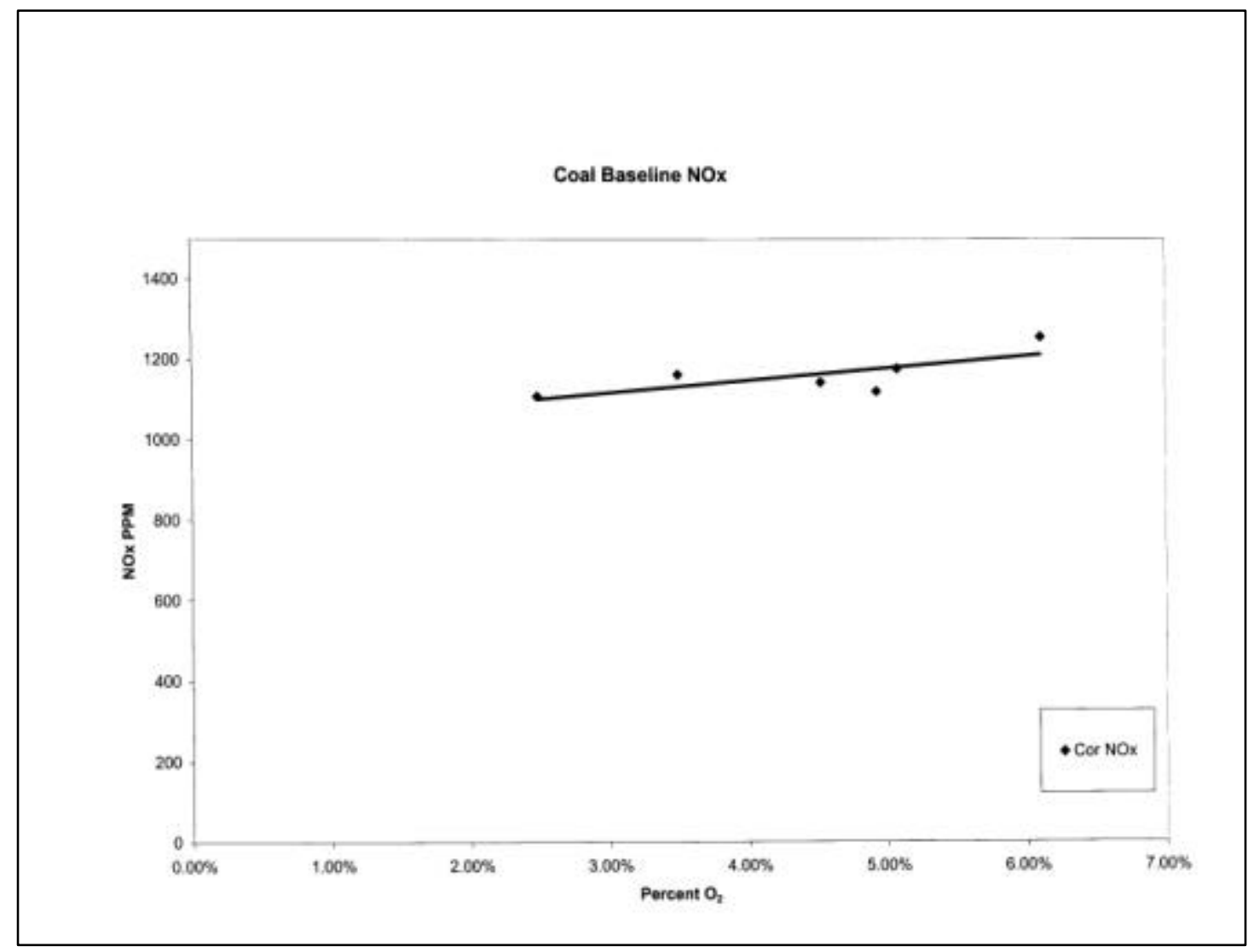

Figure 47 -- Pulverized Coal Test NOx Emissions 


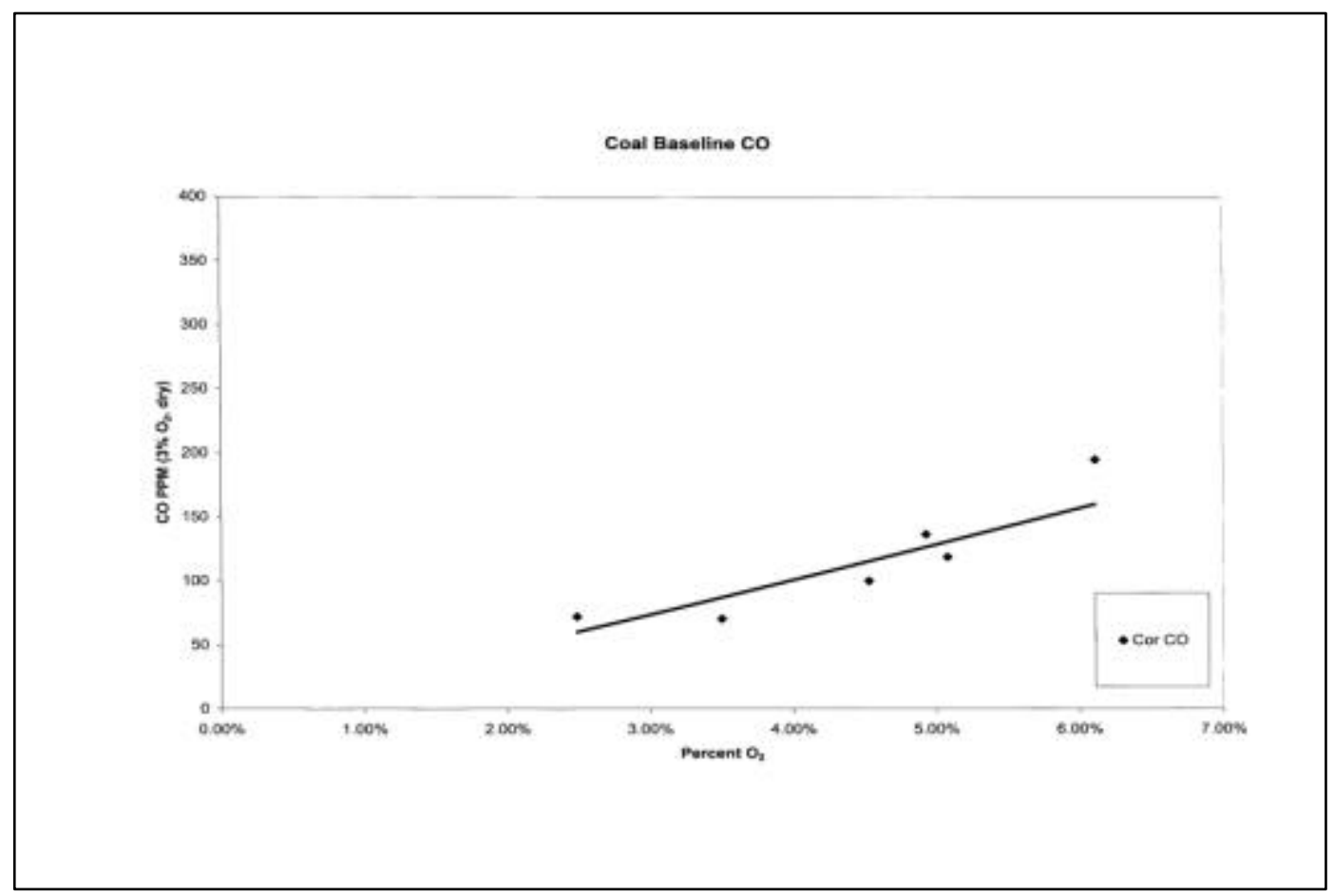

Figure 48 -- Pulverized Coal Test CO Emissions

As shown, $\mathrm{CO}$ was low at $2.5 \% \mathrm{O}_{2}$ and increased up to near $200 \mathrm{ppm}$ at $6 \% \mathrm{O}_{2}$. Although $\mathrm{O}_{2}$ is beneficial to $\mathrm{CO}$ burnout, as $\mathrm{O}_{2}$ increases, furnace temperature and residence time for burnout is reduced. Since $\mathrm{CO}$ burnout is very sensitive to temperature, it is probable that the $\mathrm{CO}$ increase with $\mathrm{O}_{2}$ is a result of lowered burnout temperature. While $\mathrm{CO}$ increased with temperature, the $\mathrm{CO}$ levels were all acceptable, relative to full-scale experience.

Given the acceptability of the baseline results, reburn tests were initiated. Based on prior reburn tests with conventional fuels, it was expected that NOx reduction would increase as reburn fuel fraction was increased. As this fraction is increased, the stoichiometry of the reburn zone is reduced. In the substoichiometric reburn zone, the NOx from the baseline coal flame would be reacted under a deficiency of $\mathrm{O}_{2}$ with fuel fragments, $\mathrm{CO}$ and soot from the reburn fuel combustion. This would help reduce NOx to molecular nitrogen. In addition, fuel nitrogen components from the reburn fuel would be converted to nitrogenous species (e.g. $\mathrm{NH}_{3}, \mathrm{NH}_{2}, \mathrm{NH}$, $\mathrm{HCN}$, and $\mathrm{CN}$ ) that would also react with NOx from the base coal flame. In these reactions, some of the NOx would also be reduced to molecular nitrogen. Therefore, these two processes acting together would reduce NOx. Following the reburning NOx reduction zone, air was added to bring the excess $\mathrm{O}_{2}$ back up to $4 \%$. This air is required to burnout any remaining fuel components. As the air is added, remaining nitrogenous species $\left(\mathrm{NH}_{3}, \mathrm{NH}_{2}, \mathrm{NH}, \mathrm{HCN}, \mathrm{CN}\right.$ etc.) could be oxidized to NOx. The total NOx reduction would then be a function of reburn zone reduction and burnout zone production processes. Figure 49 presents reburning NOx results, at $3 \%$ oxygen and dry gas, as a function of reburn percent for both pulverized wood/biosolids and pulverized paper/biosolids reburn fuels. Reburn percent is defined as the fraction of fuel injected in the reburn zone on an energy basis versus the total fuel energy. Both the coal and reburn fuels were ground to the needed $80 \%$ through 200 -mesh. As noted earlier, it is more difficult to grind the biomass fuel pellets. Nevertheless, with the proper equipment, the material can be reduced to the needed size. The properties of these mixtures as well as the base coal are given in Table 46. 
Table 46 -- Biomass-Based Reburn Fuel Properties

\begin{tabular}{|l|c|c|c|}
\hline & Coal & $\mathbf{5 5 \%}$ Bio/45\% Wood & $\mathbf{5 0 \%}$ Bio/50\% Paper \\
\hline Carbon \% & 66.02 & 47.69 & 44.08 \\
\hline Hydrogen \% & 4.29 & 6.11 & 5.90 \\
\hline Nitrogen \% & 1.38 & 2.28 & 1.99 \\
\hline Sulfur \% & 0.59 & 0.45 & 0.44 \\
\hline Oxygen \% & 10.73 & 31.79 & 31.89 \\
\hline Ash & 7.46 & 11.69 & 15.71 \\
\hline
\end{tabular}

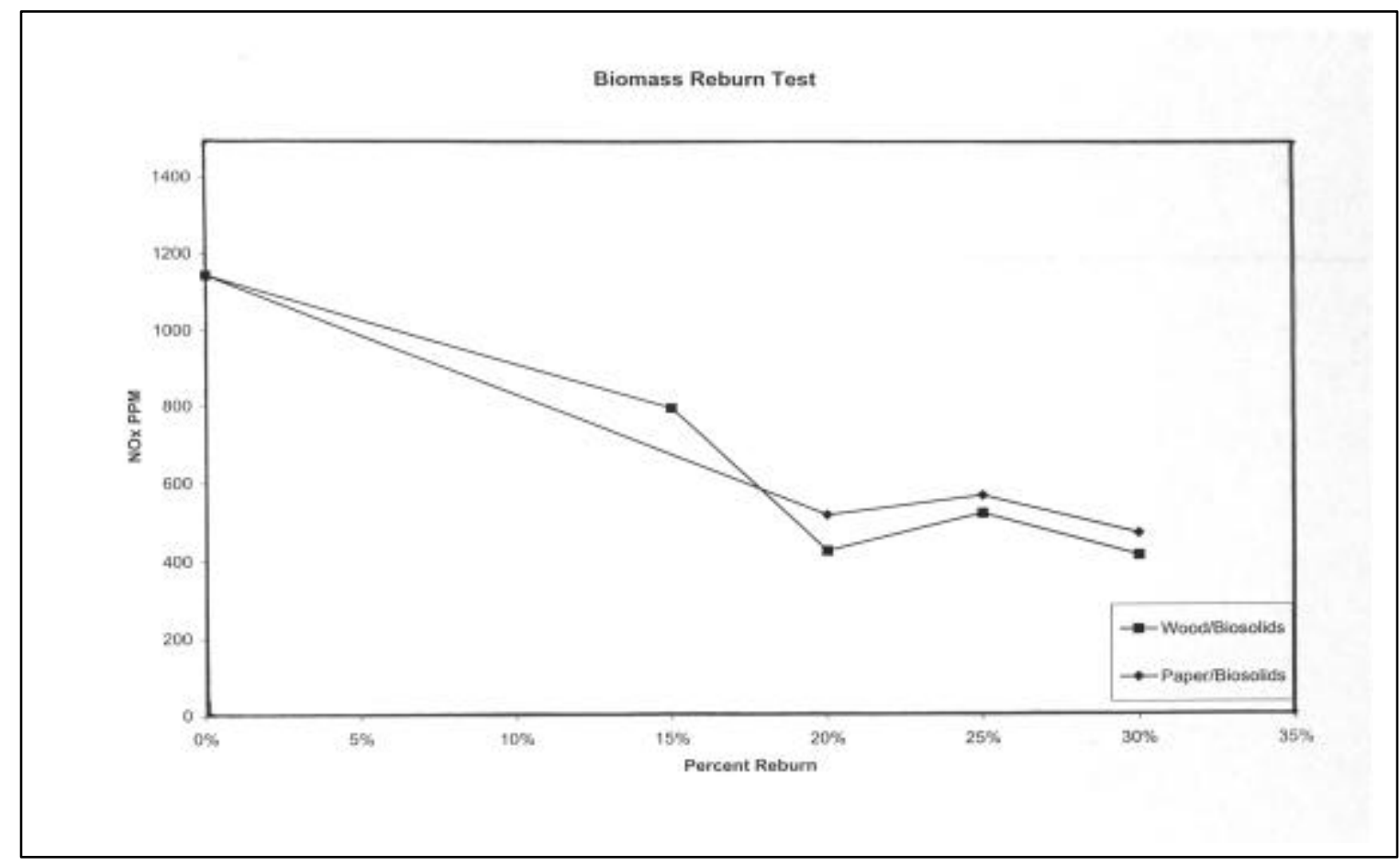

Figure 49 -- Biomass Reburn Test NOx Emission Results

As shown, nitrogen contents of both reburn fuel mixtures are higher than that of coal, as a result of the high biosolids content. This would tend to drive up NOx emissions when burned in a conventional burner designed for coal. However, under the oxygen deficient conditions in the reburn zone, NOx produced as a result of biomass burning should be minimized. Importantly, given the high volatiles content of the biomass, as evidenced by high hydrogen content and low carbon content, burnout of the biomass fuel should be rapid, once the burnout air is injected. This is expected to be an important advantage of biomass over the use of coal as a reburn fuel. Sulfur content of both biomass mixtures are lower than that of coal. This should help limit SOx emissions. Lastly, ash levels for the biomass are 50\% to $100 \%$ higher than the coal ash level. This will increase ash loadings on the tube banks. However, since the reburn fuel is a maximum of $30 \%$, the maximum increment in total ash will only be $18 \%$ to $34 \%$. Of course, an important issue is ash components and how the biomass components differ from the specific coal ash components. These impacts have to be addressed on a site specific basis. 
As shown in Figure 49, as the wood/biosolids reburn fuel was increased from $0 \%$ to $30 \%$, NOx was reduced by 63\%. This is a very substantial reduction in NOx. In addition, as the paper/biosolids reburn fuel was increased from $0 \%$ to $30 \%$, NOx was reduced by $58 \%$, roughly comparable to that achieved by wood/biosolids. Compared to reburn tests using coal fuels, biomass reburn appears to be as effective as coal at reducing NOx.

In general, coal reburn should yield a 50\% reduction in NOx [19], depending on the fuel type, amount of reburn, temperatures, stoichiometries and residence times. While extensive data on coal type is not available, the reburn test results in Figure 50 were obtained for Utah bituminous coal in a small test combustor [20].

As shown in Figure 50, from reference 20, NOx emissions with no reburn are approximately $1000 \mathrm{ppm}$ and at a maximum reburn of approximately $30 \%$ the NOx is $400 \mathrm{ppm}$. These coal reburning results are somewhat lower than the biomass case results, but the NOx reduction from baseline of $60 \%$ is consistent with the biomass test results. This consistency is remarkable, given the much higher nitrogen content of the biomass mixtures. As noted above, biomass, based on its high volatiles content, could create NOx problems in conventional burners, while acting as a good NOx reductant when used as a reburning fuel. Therefore, as supported by test results, biomass can be a good reburning fuel from a NOx control perspective. Furthermore, the high volatility and rapid burning of biomass will be advantageous to reburn fuel burnout, relative to the slow burnout expected for coal reburning fuel. With coal reburning, some unburned solids could exit the system. With biomass, burnout is faster and unburned fuel exiting the system is unlikely.

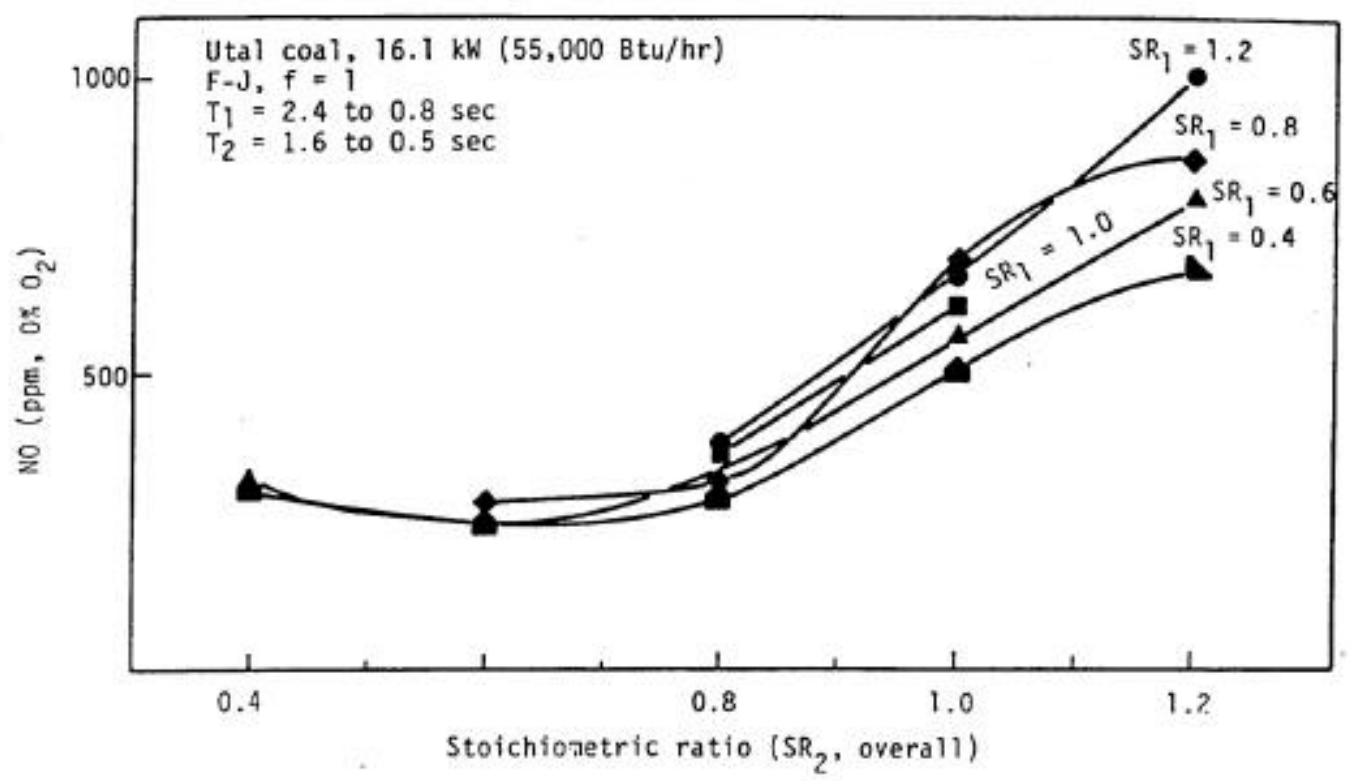

Figure 50 -- Utah Coal Reburn Test Results 
Besides showing good NOx reduction potential, biomass based reburning also showed an ability to reduce $\mathrm{CO}$ emissions. Figure 51 presents the $\mathrm{CO}$ emissions as a function of reburn fuel percent for the two biomass reburn fuels tested.

As shown, CO was about $100 \mathrm{ppm}$ initially, but decreased as percent reburn fuel increased. Therefore, by adding reburn, CO emissions were reduced by over $50 \%$. This could be a benefit in systems that burn low-quality coal and have high $\mathrm{CO}$ emissions, particularly when trying to reduce NOx through combustion modification. As noted above, the higher $\mathrm{CO}$ at high $\mathrm{O}_{2}$ under baseline conditions is probably a result of reduced temperature. With reburn, more fuel is burned above the main flame, which increases the gas temperature, thereby enhancing burnout once the final air is injected.

In conclusion, it appears that biomass reburning is an effective NOx control approach, reducing baseline coal NOx emissions from 58 to 63\%. The monetary value of this NOx reduction depends on the specific site, NOx control requirements and the cost of alternative NOx control methods.

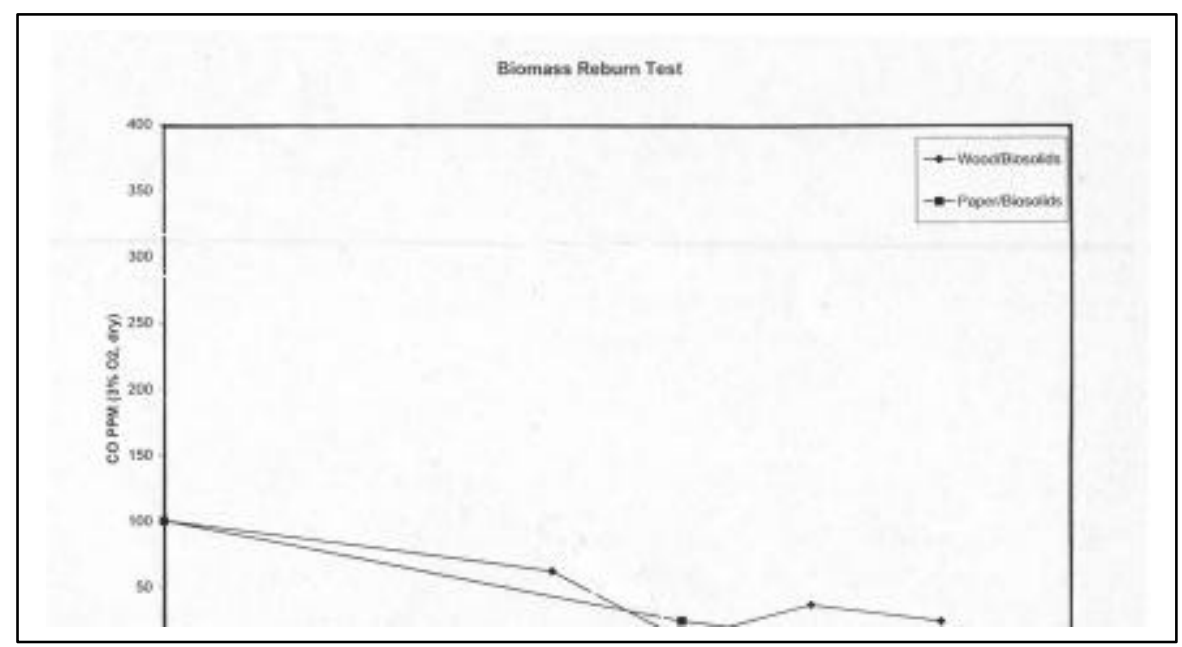

Figure 51 -- Biomass Reburn CO Emissions

\subsection{AFP ECONOMIC EVALUATION}

Test results, described above, defined the AFP handling, storage, transport and combustion characteristics. In particular, the emissions benefits of AFP the case where AFP pellets replaced coal and the unit was air staged. In addition, the NOx control benefits of using pulverized AFP pellets as a reburn fuel with pulverized coal burning were also determined.. To determine the economic benefits of AFP, a detailed economic analyses was carried out for a baseline 1000 TPD plant. Using equipment and operating costs, and assuming a fuel price based on coal values, the profitability and Internal Rate of Return (IRR) for AFP plants were determined. This analysis was carried out for the seven AFP biomass formulations produced during pilot-scale testing. These seven formulations are listed in Table 47. As noted earlier, these cases cover both wood and MSW light fraction based formulations. Also, some 
formulations contain coal fractions. As noted earlier, pellets formulated with coal fines are easy to grind and therefore compatible with pulverized coal fired systems.

Table 47 -- Economic Analysis AFP Formulations and IRR Results

\begin{tabular}{|l|c|c|c|c|c|c|c|}
\hline Mix ID No. & $\begin{array}{c}\text { Biosolids } \\
\%\end{array}$ & $\begin{array}{c}\text { Wood } \\
\%\end{array}$ & $\begin{array}{c}\text { Paper } \\
\%\end{array}$ & $\begin{array}{c}\text { Plastic } \\
\%\end{array}$ & $\begin{array}{c}\text { Coal } \\
\%\end{array}$ & $\begin{array}{c}\text { Capital } \\
\$ \text { MM }\end{array}$ & $\begin{array}{c}\text { IRR } \\
\%\end{array}$ \\
\hline 03010001 & 48 & 0 & 48 & 4 & 0 & 15.4 & 50.9 \\
\hline 02230001 & 40 & 0 & 55 & 5 & 0 & 11.7 & 59.0 \\
\hline 02220001 & 24 & 0 & 24 & 0 & 50 & 11.0 & 33.1 \\
\hline 01210001 & 50 & 0 & 50 & 0 & 0 & 14.5 & 54.2 \\
\hline 01140001 & 27 & 23 & 0 & 0 & 50 & 13.5 & 20.9 \\
\hline 1289901 & 38 & 32 & 0 & 0 & 30 & 15.9 & 27.5 \\
\hline 12019901 & 55 & 45 & 0 & 0 & 0 & 18.2 & 37.3 \\
\hline
\end{tabular}

Pellets without any coal are very robust and well suited to stoker type combustion systems. For each formulation, a baseline result was calculated that incorporated fixed input for biomass cost, biosolids disposal fee and dryer natural gas cost. In addition to these baseline economic results, the coal percent, biosolids percent, biomass cost, biosolids cost and natural gas costs were varied for the last formulation listed in Table 47. These results show the sensitivity of Internal Rate of Return (IRR) to important parameter variations.

\subsection{BASELINE FORMULATION ECONOMIC ANALYSIS RESULTS}

Each of the AFP formulations are processed at a rate of 1000 TPD product using similar equipment. This equipment consists of dewatering, extrusion, drying and all ancillary equipment, as listed in Table 48. This equipment is similar to that used in the successful pilotscale tests described earlier. Therefore, pellet quality produced by this full-scale equipment should be at least as good as that found from the pilot-scale tests. Costs and power needs of the full-scale equipment were primarily based on manufacture inputs. For the novel dewatering equipment, the cost was based on a similar type of machine used in other industrial applications.

While the equipment used for all AFP formulations was similar, it varied in scale as a result of the different input feed rates based on variations of initial moisture between the formulations. For example, the system extruder works best if initial moisture is maintained within a range. As the initial moisture of the mixtures vary, dry recycle from the pellet dryer is used to trim the initial moisture to the desired level. Given the greater initial throughput, for the same 1000 TPD output, the scale of extruders, dryers and all related ancillary equipment have to be increased. This impacts both capital and operating costs for the system.

The raw material costs for the first pellet formula, shown in Table 47, are presented in Table 49. As shown, the biosolids disposal fee is \$33/WTn (Wet Tonne) (\$30/WT). This is a very conservative figure, given that our surveys show that it costs some municipalities up to \$68/WTn (\$62/WT) to incinerate their biosolids. By using \$33/WTn (\$30/WT) as a fee to accept biosolids, municipalities have a large incentive to supply AFP plants with biosolids. It should be noted that small waste water treatment plants may pay lower fees, if the material can be land applied on nearby large tracts of land. This practice is not available to large treatment facilities in metropolitan areas, which are the main targets for AFP development. 
Table 48 -- AFP Plant Capital Costs and Power, Maintenance and Labor Needs

\begin{tabular}{|c|c|c|c|c|c|c|c|c|}
\hline Exvepment Desecription & ary & Costrit & Coetry! & moled & $\begin{array}{l}\text { Operauna } \\
\text { Faet }\end{array}$ & $\begin{array}{l}\text { Maine } \\
\text { Factor } \\
x \text { cont } \\
\end{array}$ & $\begin{array}{l}\text { Equip. } \\
\text { Maint } \\
\text { (partalabor) } \\
\text { syr }\end{array}$ & $\begin{array}{l}\text { Model o1 } \\
\text { Openaing } \\
\text { labor } \\
\text { manthrioers he }\end{array}$ \\
\hline 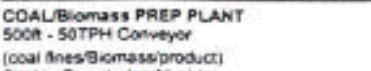 & 3 & $\$ 200.900$ & $\$ 000,050$ & $30 \mathrm{a}$ & 1.80 & 0020 & $\$ 12,000$ & 2 \\
\hline Sludge Dewaterng Nachine & 5 & 5125.000 & 5758,001 & soo & 100 & 0000 & 522.600 & \\
\hline $\begin{array}{l}\text { PELLETZATONON PLANT } \\
\text { Fines Storge Hoboer }\end{array}$ & 1 & $\$ 50000$ & $\$ 50.000$ & 50 & 905 & 0.000 & 5580 & t \\
\hline Feeder Surge Bn foad Mnes] & 1 & $\$ 20.500$ & 320,050 & or & 000 & 0010 & 5280 & \\
\hline $\begin{array}{l}\text { Live Gonom lestew - } 20 \mathrm{TPH} \\
\text { (coal Sness) }\end{array}$ & 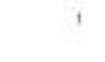 & 580,500 & $\$ 80,000$ & 75 & 100 & onso & 81.080 & \\
\hline 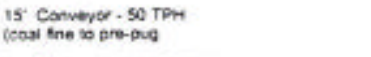 & 1 & 515.500 & $\$ 15,050$ & so & 100 & 0,030 & s+sa & \\
\hline Aux waver inpecton Spren & 1 & 55,000 & $\$ 5.000$ & 03 & ant & 0052 & 5250 & \\
\hline Sudje Oume Bn (studge at dabery viei & 1 & 530.900 & 530,050 & $Q d$ & 990 & 0010 & 5300 & 1 \\
\hline 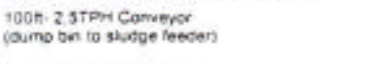 & 1 & 327000 & 527,000 & 30 & 225 & oost & $58 \div 0$ & \\
\hline Ftevder Surge 3 in isuogel & 1 & 520,600 & $\$ 20,000$ & 00 & 260 & 9010 & 5200 & \\
\hline $\begin{array}{l}\text { Eneder - } 125 \mathrm{TPM} \\
\text { (shodge) }\end{array}$ & 1 & 527,000 & $\$ 27,000$ & 30 & 100 & 0010 & $\$ 270$ & \\
\hline 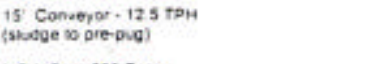 & 1 & $\$ 10,500$ & $\$ 10.900$ & 30 & 100 & $00 x 0$ & 5300 & \\
\hline NSW Bin - 500 Tens & 1 & 350.000 & $\mathbf{s 5 0 , 0 0 0}$ & 20 & 100 & 0030 & $\$ 1,500$ & \\
\hline $\begin{array}{l}\text { Foeder - 12 S tPm } \\
\text { To nammentral }\end{array}$ & t & 530600 & $\$ 70.000$ & so & +00 & gara & $\$ 100$ & \\
\hline $\begin{array}{l}15 \text { Comeeror } 125 \mathrm{TPH} \\
\text { NSW }\end{array}$ & 1 & $\$ 15000$ & $\$ 15,060$ & 20 & 100 & $\$ 030$ & $\$ 450$ & 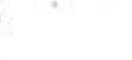 \\
\hline 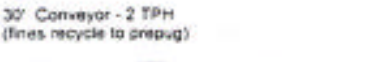 & 2 & $3: 2.000$ & 524,000 & 20 & 100 & 0050 & 5720 & \\
\hline 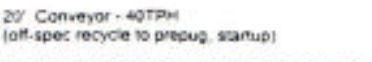 & 1 & 575000 & $\$ 15.000$ & 50 & oas & 0 ax & S4SO & \\
\hline 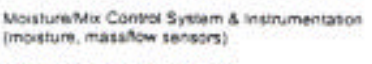 & 1 & 535000 & 525,000 & 10 & 100 & 9020 & 51,200 & \\
\hline Presug Sealer- Saeve sobo & 11 & 3130009 & $\$ 143,000$ & 3000 & 100 & 9060 & 50.500 & \\
\hline Estruder - Sleale 9820 $35 \mathrm{TPH}$ & 11 & 5230.900 & 5250,000 & 4000 & 100 & 0000 & $\$ 20.240$ & 11 \\
\hline Estruder Ciest & 4 & $53 \leq 00$ & $\$ 14,000$ & 90 & 000 & .000 & 512000 & \\
\hline Estruder Vacusm System & 1 & 315000 & $\$ 15.000$ & 320 & 100 & $a \infty 0$ & 5309 & \\
\hline Penat CutrevSize & 1 & 510,600 & $\mathbf{s i 0 , 0 0 0}$ & as & 100 & 0.050 & $\$ 600$ & \\
\hline 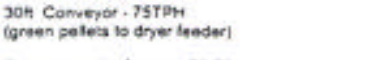 & 1 & $\$ 19,000$ & $\$ 18000$ & 30 & +00 & 0 ose & $5 \times 0$ & \\
\hline 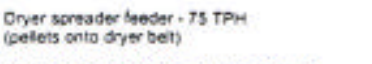 & 22 & $\$ 30000$ & $\$ 50,009$ & 70 & 100 & o osa & $\$ 2300$ & \\
\hline Comeror Drencooier - NCNC - $25 \mathrm{TPH}$ & 22 & $5+160,600$ & $\$ 2,420,000$ & 4700 & 100 & 9010 & $\$ 24.200$ & 11 \\
\hline Oryer Comral Packape-NDuC & 22 & 550000 & $5+10,000$ & 90 & 100 & 0.010 & 51,100 & \\
\hline Contact Serubbarcendensar & 22 & 385600 & $\$ 200,000$ & 40 & +00 & 0.030 & $\$ 6.270$ & \\
\hline ScreenertChssaner & 22 & 54000 & 599.000 & 100 & 100 & a.920 & 51.960 & \\
\hline \multicolumn{9}{|l|}{ POST PRODUCTIN PELLET COATING } \\
\hline Slorage Trikireased & $\circ$ & 550,000 & 30 & 300 & ots & 0020 & 80 & 。 \\
\hline Pump and Scray Spatem & $\bullet$ & 5125,000 & $\$ 0$ & 1000 & 100 & 0.050 & 30 & 。 \\
\hline Tumbieriasolcaton Onun & 0 & 525000 & so & 500 & 100 & व श्सए & 50 & $\bullet$ \\
\hline Tolal Purshased Eequipment Coat & $\begin{array}{l}\text { Tolal Fysiem } \\
\text { Toal Factore } \\
\text { Tocai annuai } \\
\text { Toai Operath } \\
\text { Sugentsing L }\end{array}$ & 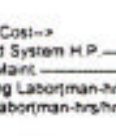 & 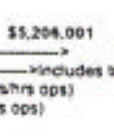 & $\begin{array}{l}2300.03 \\
\text { oransoersion }\end{array}$ & on eaviomene & & $\$ 171, \$ 10$ & : \\
\hline Plant Capacity: 1900 tho & $a y$ & $\operatorname{Cosin}_{\cos (1)}$ & $\begin{array}{l}\text { Tolas } \\
\text { Coat4\$1 }\end{array}$ & $\underbrace{\text { Electpor }}_{\text {ho }}$ & $\underset{\text { Fast }}{\text { Osarating }}$ & $\begin{array}{l}\text { Factor } \\
x \cos 1\end{array}$ & (parsilavon & $\begin{array}{l}\text { Laser } \\
\text { manthriograed }\end{array}$ \\
\hline \multicolumn{9}{|l|}{ Transporatommenating Equigment } \\
\hline $\begin{array}{l}\text { Truak (elecold) } \\
\text { Containers/Biosolid) }\end{array}$ & 2 & $\begin{aligned} 575.000 \\
50.000\end{aligned}$ & $\begin{array}{r}\$ 150,000 \\
\$ 32,000\end{array}$ & & & $\begin{array}{l}0.93 \\
0.93\end{array}$ & ${ }_{s, 500}$ & , \\
\hline Traiersigiosolidg & 2 & $\$ 30,000$ & $\$ 80,000$ & & & 0.93 & 51,000 & \\
\hline 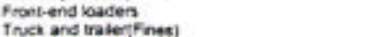 & 1 & $\begin{array}{l}5575,000 \\
1100000\end{array}$ & $\$ 575.000$ & & & 0.05 & 528750 & 1 \\
\hline $\begin{array}{l}\text { Truck ard tratertinasi } \\
\text { Scale }\end{array}$ & 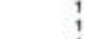 & $\begin{aligned} 3100,000 \\
580,000\end{aligned}$ & $\begin{array}{l}\$ 100.000 \\
\$ 800.000\end{array}$ & & & $\begin{array}{ll}0.05 \\
0.99\end{array}$ & $\begin{array}{l}55000 \\
51.000\end{array}$ & \\
\hline Stomen Pad & $i$ & $\$ 15,000$ & 515.000 & & & 000 & 1450 & \\
\hline Tolul ranspotaden sovipmeret & & & 002,000 & & & & & \\
\hline
\end{tabular}


Table 49 -- AFP Plant Raw Material Data and Costs

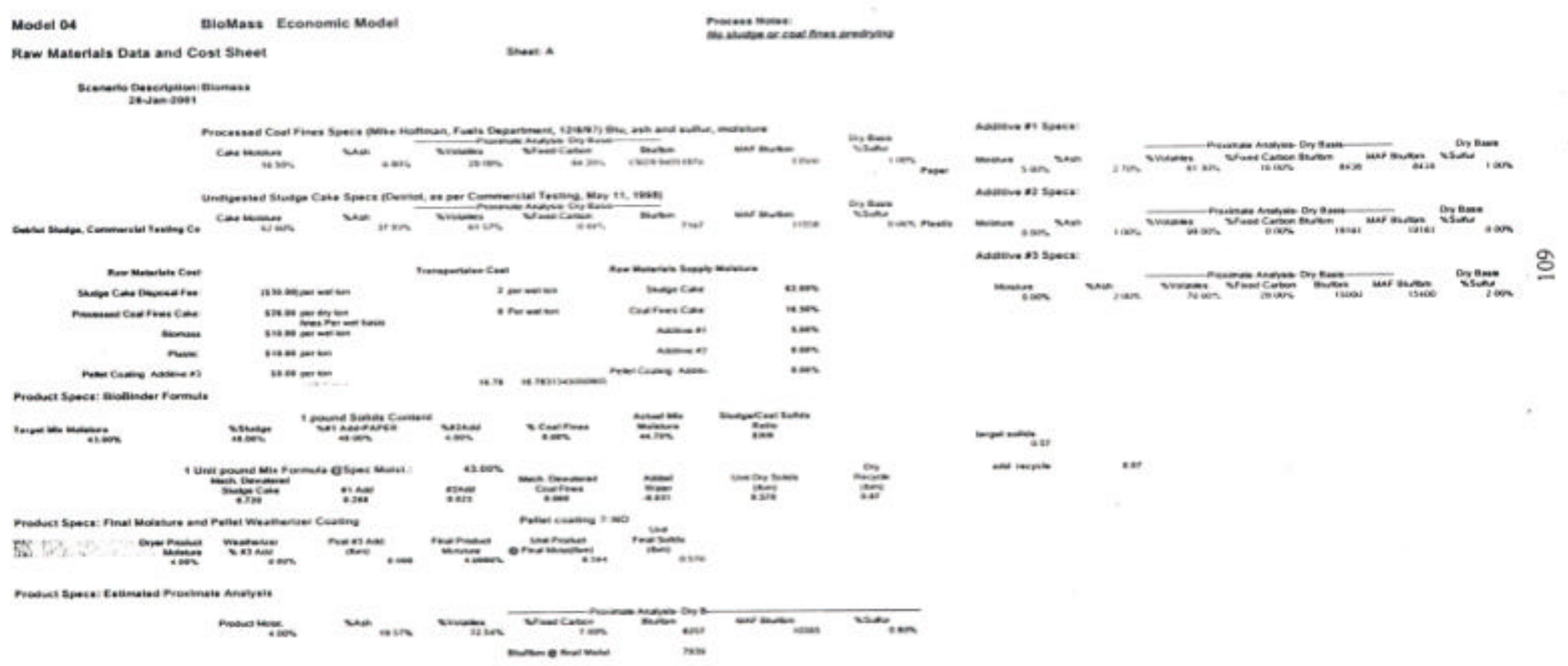


Biomass baseline costs are assumed to be \$11/WTn (\$10/WT). MSW light fractions of the first formulation are obtained by separating MSW. The cost to dispose of MSW is in the range of $\$ 55 / \mathrm{WTn}(\$ 50 / \mathrm{WT})$. Separating the light fractions adds cost. However, our assessments suggest that the MSW facility could still save money after separating the light fractions even if they didn't charge for the waste. Therefore, by using a \$11/WTn (\$10/WT) charge for the MSW light fractions, the economic results should be conservative. It should be noted that this $\$ 11 / \mathrm{WTn}(\$ 10 / \mathrm{WT})$ charge is also used for the wood waste that is incorporated in other formulations. Surveys of wood waste suppliers indicated that wood waste could cost from zero to greater than $\$ 11 / \mathrm{WTn}(\$ 10 / \mathrm{WT})$, depending on the quality of the waste and alternative uses. It is anticipated that low-quality wood waste will be used in AFP. The assumed \$11/WTn (\$10/WT) waste cost is then related to gathering and shipping costs to get the low quality material to the AFP plant. This is a reasonable baseline assumption. As mentioned above, a sensitivity analysis, where biomass and biosolids costs are varied, is presented below that shows the impact of variations in raw material costs on IRR.

While the first formulation in Table 47 contains no coal, Table 49 does contain the $\$ 29 / \mathrm{Tn}(\$ 26 / \mathrm{T})$ cost of coal fines that applies to other cases. This cost is based on a survey of coal fine prices in the Detroit area and is a relatively high price for a fuel that creates handling, transport and storage problems. However, coal users currently accept some fines as part of a coal shipment and factor the cost of fines into the overall shipment price. Our own estimates suggest that fines should cost at least $\$ 4.4 / \mathrm{Tn}(\$ 4 / \mathrm{T})$ wet less than the base coal, simply because of the higher moisture and associated drying costs. However, for the moment, the conservative $\$ 29 / \mathrm{Tn}(\$ 26 / \mathrm{T})$ wet coal cost is used for formulations that contain coal fines.

While not a part of the pellet, natural gas is assumed as the fuel for the pellet dryer. This is an expensive and high quality fuel that probably shouldn't be used to dry low-cost fuel pellets. Nevertheless, to be conservative, natural gas is utilized as the dryer fuel.

Table 48 presents the capital cost for the 1000 TPD plant, as well as supporting equipment, power, maintenance costs and operating labor. Using these raw material, capital, maintenance and labor costs, the profitability of AFP 1000 TPD plants can be determined. As part of the calculation, the capital equipment is assumed to be $30 \%$ supported by debt with an interest rate of 10 percent over a loan period of 10 years. The system is expected to operate over the full year at an average output of 1000 TPD. A tax rate of $40 \%$ is used to determine the IRR.

Table 50 presents the costs per ton product for the first formulation in Table 47. These results clearly show the valuable economic benefit of biosolids. In fact, because of the biosolids fee, the operating costs for this case are negative.

Relative to other costs, labor is a significant contributor to cost, as expected. Importantly, the dryer natural gas fuel cost is the next largest cost and even exceeds the impact of the capital charge. This demonstrates the economic benefit of using low-cost dewatering to reduce moisture, rather than thermal drying. Also, this suggests that the dryer should be fueled by low cost pellets rather than natural gas. This point will be amplified by the sensitivity analysis results presented below.

Using the described economic model, the IRR for the first formulation, as well as the remaining six formulations, was calculated and is presented in Table 47, along with this capital cost. As shown, the IRR varies substantially, from an extremely attractive $59 \%$ to a low of $20.9 \%$. It is anticipated that venture capitalists would be attracted by an IRR of $59 \%$. Even a $20.9 \%$ IRR exceeds a typical industry requirement of $15 \%$, or better. However, given the 
potential risk of a new technology, the $20.9 \%$ IRR is probably at the lowest acceptable level for high investment interest.

Table 50 -- AFP Plant Costs Per Ton Product for $48 \%$ biosolids/48\% Paper/4\% Plastic Formulation

\begin{tabular}{|l|c|}
\hline & $\$ / \mathrm{Tn}(\$ / \mathrm{T})$ \\
\hline Biosolids & $40.02(36.38)$ \\
\hline Paper & $5.34(4.85)$ \\
\hline Plastic & $.44(.40)$ \\
\hline Biosolids Transport & $2.67(2.43)$ \\
\hline Maintenance & $.52(.47)$ \\
\hline Labor: & $6.49(5.90)$ \\
Operation & $1.19(1.08)$ \\
\hline Supervisor & $1.77(1.61)$ \\
\hline Nlectric Power & $6.27(5.70)$ \\
\hline Natural Gas & $.01(.01)$ \\
\hline Water Total & $.42(.38)$ \\
\hline Deodorant Charge & $.46(.42)$ \\
\hline Taxes and Insurance & $.15(.14)$ \\
\hline Land Lease & $14.30(13.00)$ \\
\hline$\quad 9.63(4.21)$ \\
\hline$\quad 9.67(8.79)$ \\
\hline
\end{tabular}

These results show that all AFP formulation cases are economically attractive. The most attractive formulations are those without coal, that have the highest biosolids content. Given the very substantial positive impact of including biosolids, as shown in Table 50, it can be concluded that the higher biosolids content cases give the best economic return. Given the high cost of coal fines, which is similar to the cost of coal, adding coal to pellets reduces the IRR. The impact of biosolids and biomass costs, as well as coal fraction are highlighted below.

\subsection{AFP COST SENSITIVITY ANALYSIS R ESULTS}

For the sensitivity analysis, the last formulation in Table 47 was utilized as a base. This case uses $55 \%$ biosolids and $45 \%$ wood waste and yields an IRR that lies approximately midway between the highest and lowest IRRs calculated for formulations. Therefore, it represents a reasonable base to perform sensitivity calculations.

For the first sensitivity calculation, the baseline $55 \%$ biosolids fraction was reduced and the wood waste fraction increased. This calculation clearly shows the economic benefit of utilizing biosolids. As shown in Figure 52, as biosolids fraction increases and biomass fraction decreases, IRR increases from nearly $5 \%$ to the baseline $37 \%$. This shows that it is very beneficial to maximize biosolids content. However, biosolids availability will be limited by the local waste water treatment plant output. Also, pellet quality will be reduced at high biosolids fractions. Therefore, a realistic biosolids content range is $40 \%$ to $60 \%$.

In the second sensitivity calculation, coal displaced biomass, with the biosolids content held constant at 55\%. As shown in Figure 53, as biomass fraction is increased from zero to the 
$45 \%$ baseline level, IRR decreases from $53 \%$ to $37 \%$. This is a very substantial decrease in IRR. Given the high cost of coal versus biomass, it might initially be surprising that displacing biomass with coal increases IRR. However, it should be noted that the initial biomass moisture is assumed to be $50 \%$. This is a substantial moisture level that increases initial throughput and capital costs as well as dryer operating costs. This significantly impacts operating cost and indicates that wastes with lower moisture content are preferred, even if they are initially higher in cost.

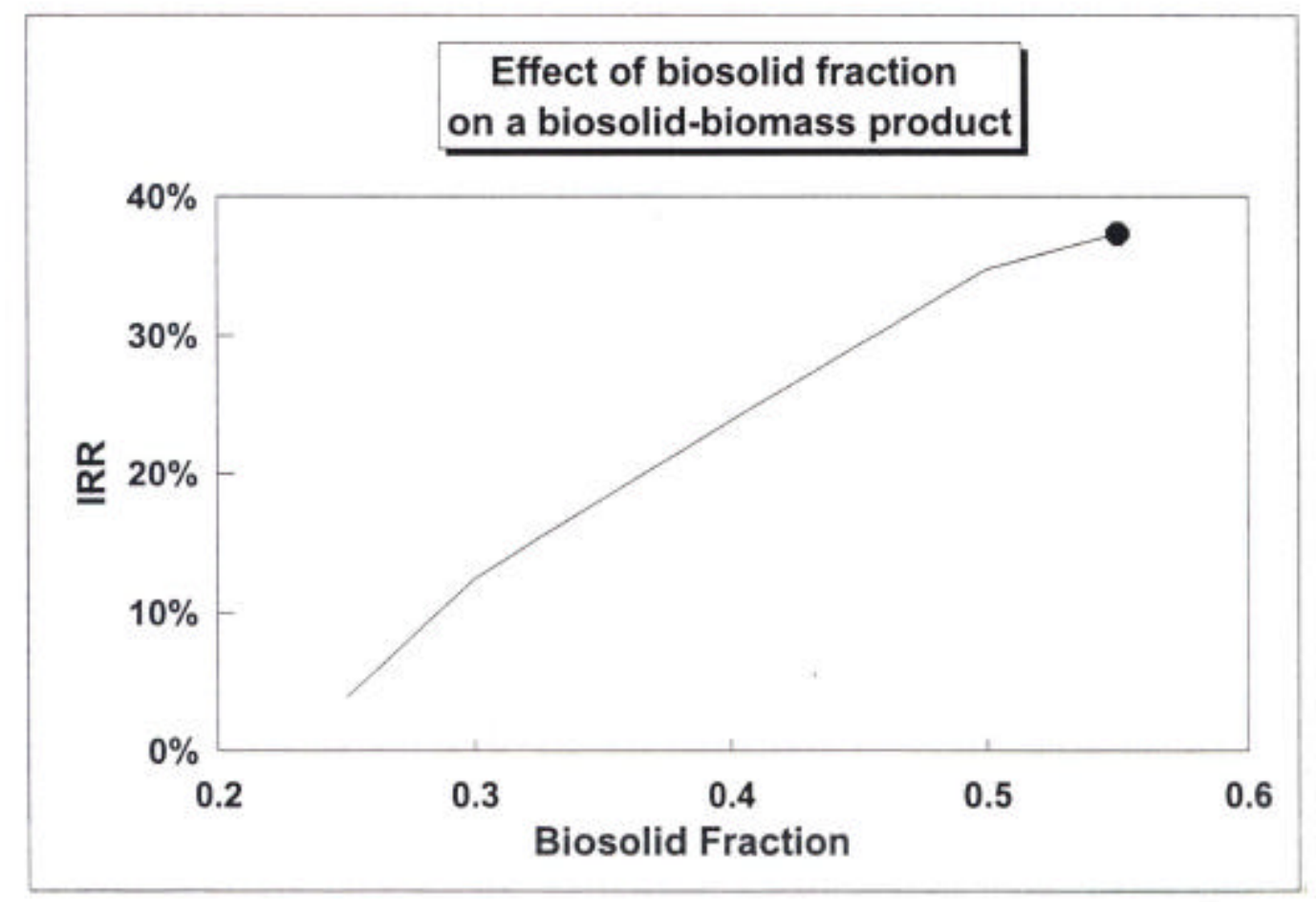

Figure 52 -- Impact of Biosolids Fraction on Internal Rate of Return

Related to biomass cost, the third sensitivity calculation determined the economic impact of biomass cost. As noted earlier, low grade biomass wastes can have zero cost. This would be the case with high moisture materials and those that would have few alternative uses. 


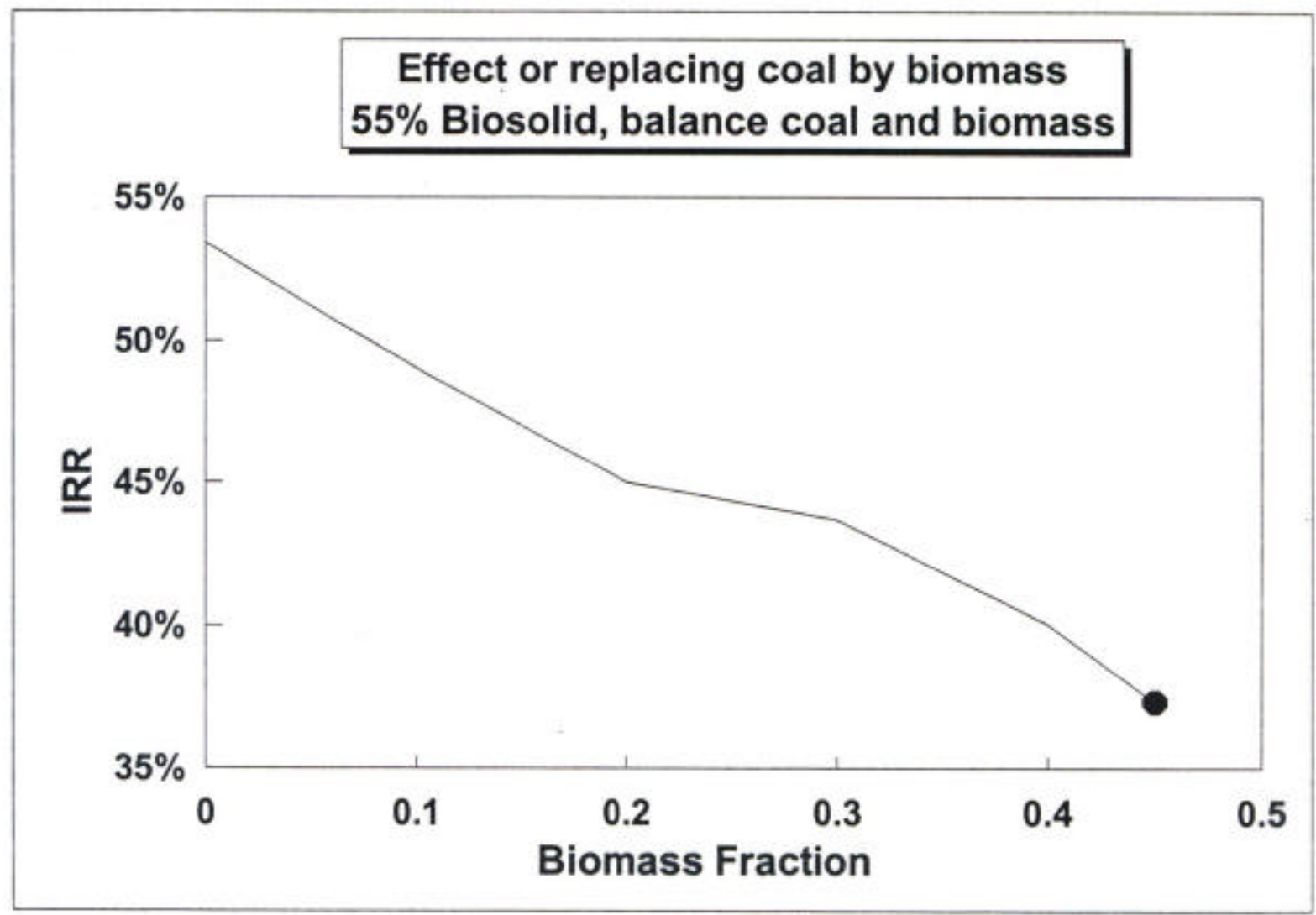

Figure 53 -- Impact of Biomass Fraction on Internal Rate of Return

At the other end of the spectrum, high quality wood waste that can be incorporated in valuable products could cost up to $\$ 33 / \mathrm{Tn}(\$ 30 / \mathrm{T})$ wet. Using this range of biomass cost, the impact on IRR was calculated. Figure 54 presents the results of the calculation. As shown, as biomass cost increases from \$0/WTn to \$33/WTn (\$30/WT), the IRR decreases from 50\% to $10 \%$. This shows the strong effect of biomass cost on IRR. Given the minimum $20 \%$ IRR to attract investors, for the $55 \%$ biosolids case, a biomass maximum cost would be approximately $\$ 27.5 / \mathrm{WTn}(\$ 25 / \mathrm{WT})$. It should be noted that this was for a biomass moisture of $50 \%$ that drives up drying costs. Impacts of drying fuel cost are given below.

For the fourth sensitivity calculations, the impact of natural gas drying fuel on IRR was determined. Natural gas, as well as petroleum, fuel costs have varied substantially. A few years ago, natural gas costs were relatively close to coal costs. Recently, due to market conditions, natural gas spot prices have greatly increased. While the current supply and demand are unbalanced, historical experience suggests that natural gas prices will decrease from the current very high levels. 


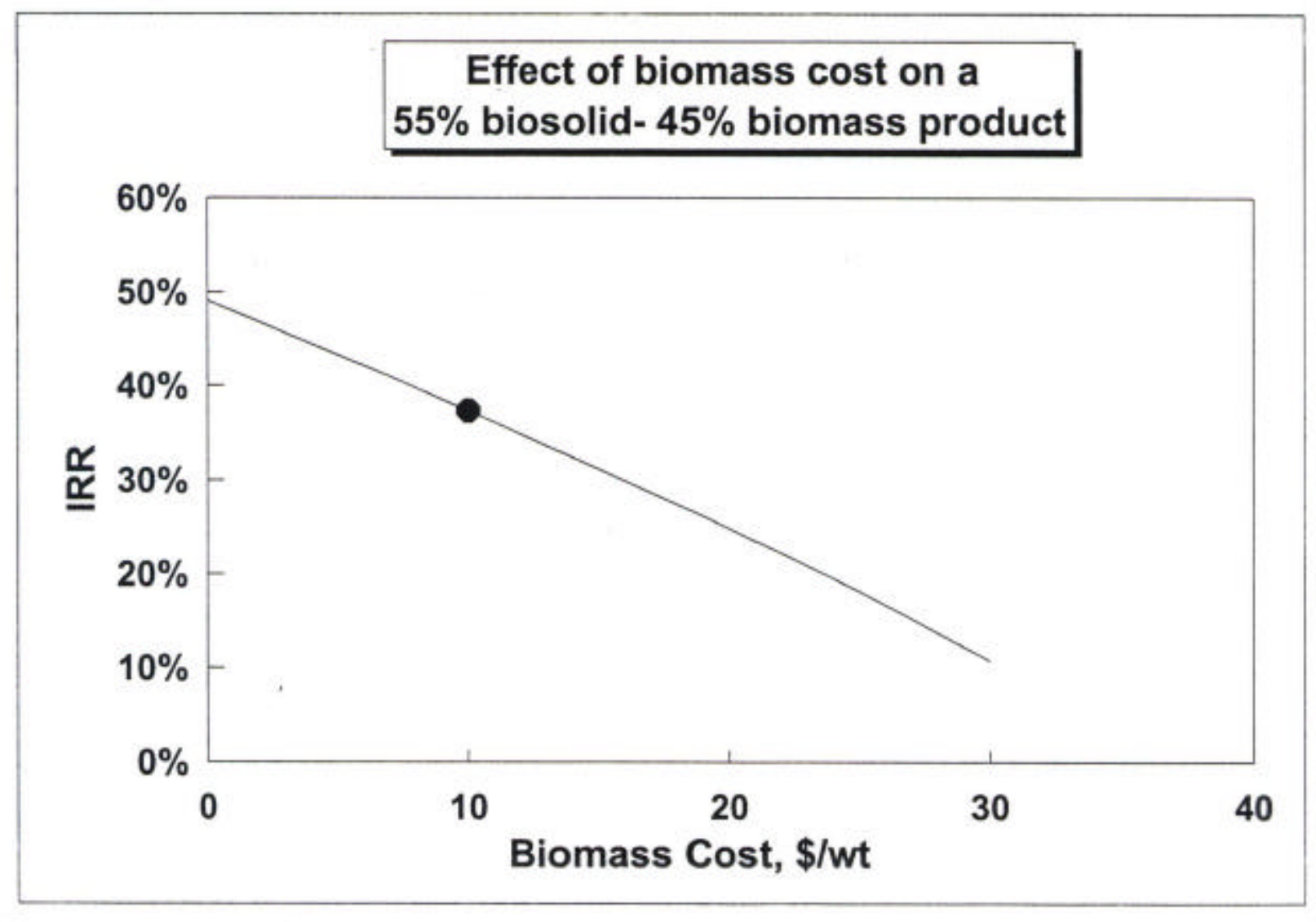

Figure 54 -- Impact of Biomass Cost on Internal Rate of Return

However, it is worthwhile to examine the impact of natural gas costs on IRR. Figure 55 shows how IRR decreases as natural gas costs increase from $\$ 1.42 / \mathrm{MM} \mathrm{kJ}$ to $\$ 7.58 / \mathrm{MM} \mathrm{kJ}$ (\$1.50/MM Btu to \$8.00/MM Btu). As shown, for \$1.42/MM kJ (\$1.50/MM Btu), similar to the price of coal, the IRR is a substantial $43 \%$. However, at $\$ 7.58 / \mathrm{MM} \mathrm{kJ}$ (\$8.00/MM Btu), the IRR is a low 5\%. This shows the significant impact of drying and natural gas cost on IRR. In fact, if the special AFP dewatering step is removed from the process, the baseline 37\% IRR for this case is reduced to $17.5 \%$. From this result, the importance of dewatering and the benefit of reduced initial moisture content is clear.

While natural gas prices have recently spiked upwards, the price of pellets in the calculations have been set at low levels characteristic of coal. Possibly pellet values will increase if natural gas and petroleum prices remain high. This will help offset any impact in natural gas cost. However, most importantly, for scenarios where natural gas costs are high, pellets should be used to fuel the dryer. Given that the dryer has a particulate control device, firing the dryer on pellets would be environmentally acceptable. 


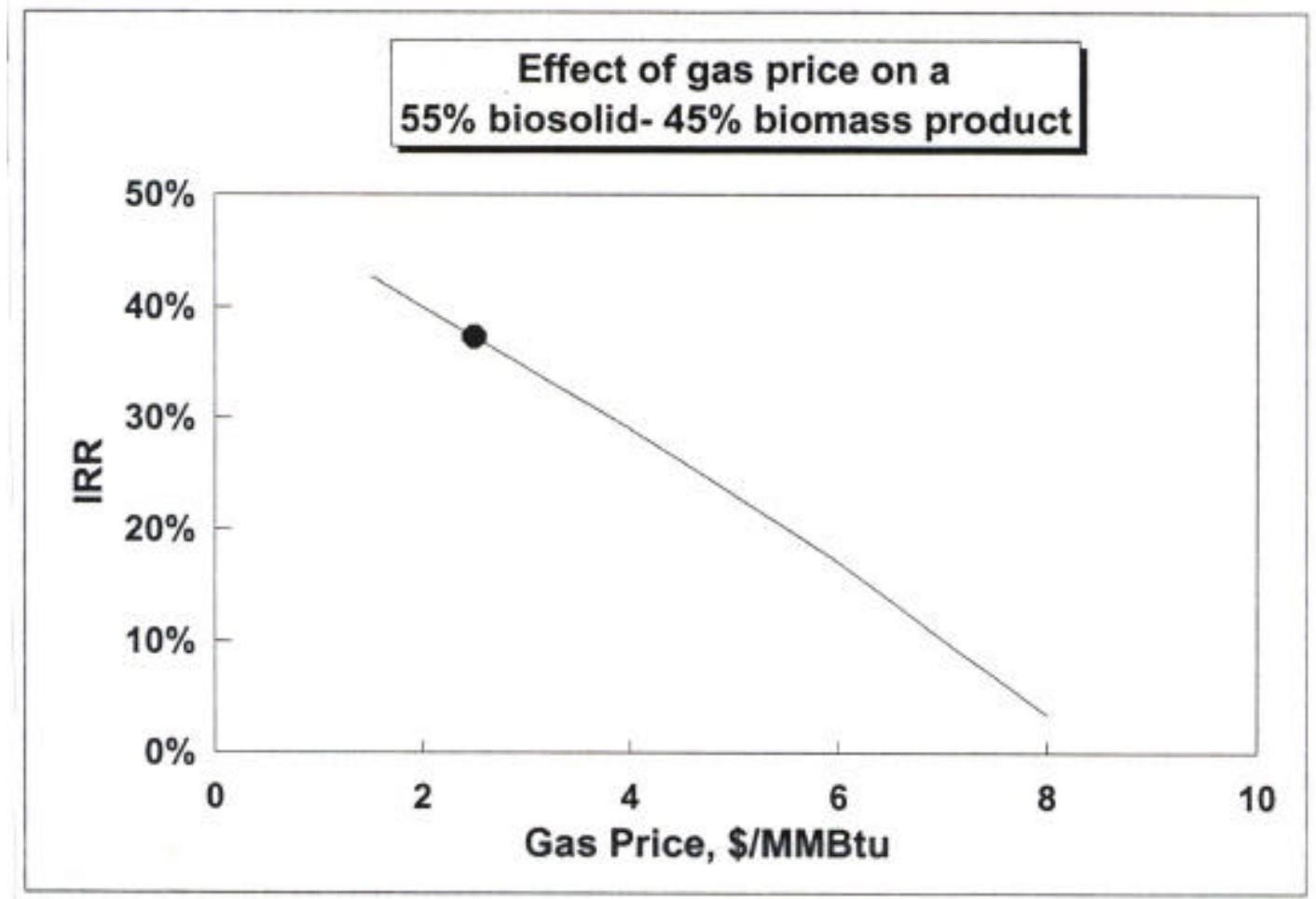

Figure 55 -- Impact of Natural Gas Fuel Cost on Internal Rate of Return

While a detailed economic analysis has not been carried for a coal fired dryer, given the low cost of pellets (sales price of $\$ 1.16 / \mathrm{MM} \mathrm{kJ}(\$ 1.22 / \mathrm{MM} \mathrm{Btu})$ ), it is anticipated that the additional costs would be equivalent to a fuel cost of $\$ 2.37 / \mathrm{MM} \mathrm{kJ}(\$ 2.50 / \mathrm{MM} \mathrm{Btu})$. As noted in Figure 55, this gives an attractive IRR of 37\%. Therefore, using pellets as the dryer fuel is a reasonable option for cases where natural gas fuel costs are high.

In the last calculation, the impact of the biosolids fee on IRR was determined. Figure 56 shows the decrease in IRR as the biosolids fee is reduced from $\$ 44 / \mathrm{Tn}(\$ 40 / \mathrm{Tn})$ wet to $\$ 11 / \mathrm{Tn}$ $(\$ 10 / \mathrm{T})$ wet. As shown, at $\$ 44 / \mathrm{WTn}(\$ 40 / \mathrm{WT}), \mathrm{IRR}$ is $90 \%$. Given that it costs waste water treatment plants $\$ 68 / \mathrm{T}(\$ 62 / \mathrm{T})$ wet to incinerate biosolids, a $\$ 44 / \mathrm{WTn}(\$ 40 / \mathrm{WT})$ fee is plausible. This shows the excellent returns that can be generated by high fees. Certainly the $\$ 22 / \mathrm{WTn}$ $(\$ 20 / \mathrm{WT})$ fee for the baseline is very possible and gives an attractive return. However, at $\$ 11 / \mathrm{WTn}(\$ 10 / \mathrm{WT})$, processing costs offset the benefit of the fee and IRR decreases to near zero. For good returns, fees should be greater than \$22/WTn (\$20/WT). 


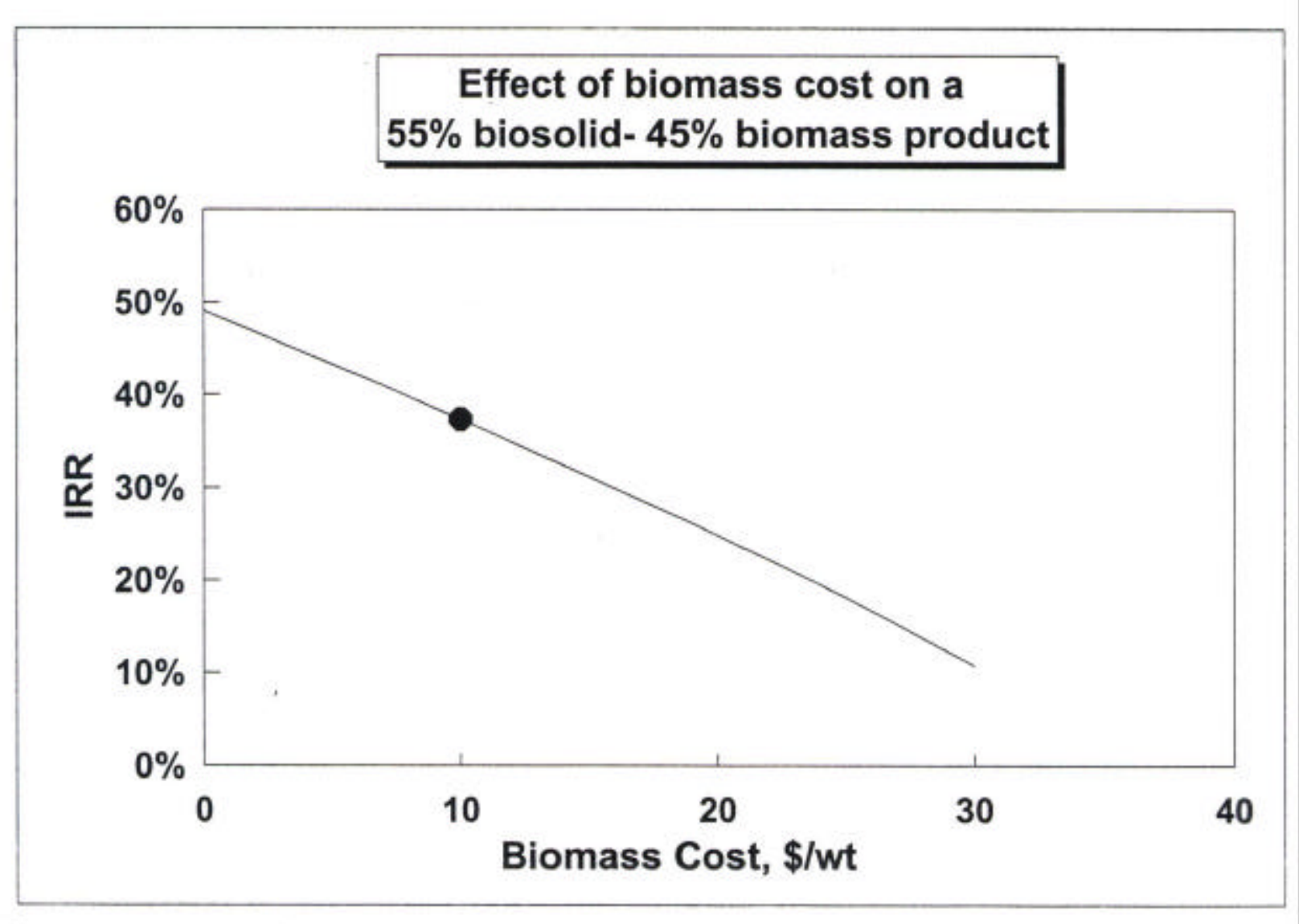

Figure 56 -- Impact of Biosolids Fee on Internal Rate of Return

\subsection{PROJECT SUMMARY CONCLUSIONS AND FUTURE PLANS}

The objective of producing power from biomass in a fuel form compatible with conventional coal fired utility equipment, and at a cost competitive with traditional fossil fuels, is challenging from any perspective. However, work under this project showed that the AFP path, when fully developed, has the potential to achieve those goals. Specific information supporting the technical and economic feasibility of AFP is summarized below.

After a survey of several sources, it was determined that sufficient biomass materials do exist in abundance, in a favorable form, and in close proximity to potential utility fuel consumers. From the survey it was also clear that all biomass materials are lower in energy content and density than fossil fuel. Many of the materials are also high in moisture, with the potential for decay. This decay can result in a loss of energy content and the production of VOCs and odors. Therefore, processing of biomass is required to preserve fuel value, increase energy density, improve storage and handling characteristics, and transportability. While the initial cost of some biomass resources may be very low, the required processing and transport costs, can drive up the delivered fuel cost to a level that is not competitive. As a specific example, even in a case where low cost barge transportation is an option, the delivered cost of a logging waste derived fuel to the Detroit, MI area is estimated to be $\$ 3.58 / \mathrm{MM} \mathrm{kJ}$ ( $\$ 3.78 / \mathrm{MM}$ Btu). In contrast, the delivered cost for coal to Detroit is only $\$ 1.07 / \mathrm{MM} \mathrm{kJ}$ (\$1.13/MM Btu). 
Therefore, this biomass resource cannot be competitive without a credit or subsidy. These unfavorable current cost scenarios are similar for agricultural crop wastes, with the added penalty of crop seasonality. From analysis and assessment it was concluded that only biomass wastes associated with products that have already carried the burden of collection and transport costs are economically viable.

In the AFP program, a material known as the "light fraction" of municipal solid waste (MSW) was utilized. This material is composed of durable and nondurable paper products, corrugated cardboard, and plastic film, and is available in large quantities in the Detroit area. Post-consumer biomass derived products constitute a viable biomass resource because they have borne the expense of collection and transport; two of the major cost obstacles to biomass energy utilization.

Expanding this approach, municipal biosolids were also selected as a viable urban biomass resource. Based on previous experience, Altex has found that biosolids can act as an effective binder of coal fines and add fuel value as well. In addition, biosolids carry a significant negative value, which can more than offset the costs of processing biomass into a useable fuel form. This eliminates a third significant barrier to biomass utilization, and transforms the AFP process into one that is competitive with coal prices and provides an attractive return to investors.

The third urban biomass resource selected for the AFP program was wood processing waste. This material is generated by secondary wood manufacturers such as Detroit area furniture makers, panel manufacturers, and millworking shops. The average yield from secondary wood manufacture is less than $50 \%$, so these supplies can be substantial. Of the three selected materials, wood processing waste has the highest value and is in the shortest supply.

In addition to the three biomass components selected for AFP, coal fines were also introduced into selected formulations. The reasons for the coal fines additions were used to give the fuel some coal like characteristics for stoker boilers, and to effectively alter the consistency of the AFP pellets so that they can be efficiently pulverized in utility boiler applications.

While urban biomass waste has favorable economic characteristics, it is recognized that theses wastes can be contaminated by other materials. In the case of biosolids, the dumping of industrial wastes into the sewer system can contaminate benign organic wastes in biosolids. Waste dumping programs have been initiated to reduce industrial dumping into municipal sewers and, as expected, biosolids metal concentrations have been substantially reduced. To ensure that biosolids are not contaminated, industrial waste dumping programs must be expanded and rigorously enforced. This will be generally beneficial, as well as specifically beneficial to the use of biosolids as fuel. In addition to biosolids, Altex identified, municipal solid waste, a second significant urban biomass energy resource that is susceptible to contamination. When "disposable" post-consumer biomass products are discarded, it is inevitably into a container with other wastes. This mixing of wastes combines materials of high value with materials of little or no value, and also creates the opportunity for contamination. If light fractions of MSW were separated by consumers, then the potential for contamination would be reduced. Also, the cost of separation would be eliminated. These are important benefits that would advance the use of MSW in using light fractions as a fuel. Both of the above examples point out an important issue associated with the use of waste biomass as a fuel. When biosolids and MSW were just sent to landfills contamination and environmental concerns were not considered. However, now that these wastes are considered resources for fuel and other higher value reuse, it is very important to institute and enforce industry and consumer programs to separate the valuable elements of 
wastes from contaminants. Once valuable elements and contaminants are mixed together, the cost of separation makes the original valuable material worthless. This is unacceptable in a civilization with finite limits on fossil energy, air quality, water quality and land. Large quantities of pellets were produced for pellet characterization and combustion testing. Twenty formulations were prepared in bench-scale equipment to identify the six formulations that were subsequently prepared in greater quantities using the pilot-scale equipment.

Bench-scale tests also demonstrated the potential for advanced dewatering techniques to reduce biosolids moisture content, and the concept of a secondary dewatering device was developed. At room temperature, the secondary dewatering test apparatus achieved moisture reduction increases of up to $31 \%$. This represents a significant amount of water, which increases the value of the biolsolids by reducing the costs of thermal drying. Further, with addition of heat even higher levels of moisture reduction were achieved. At $99^{\circ} \mathrm{C}\left(210^{\circ} \mathrm{F}\right)$, biosolids moisture reduction was increased by $39 \%$.

Beyond the novel secondary dewatering step, the originally proposed processing steps of mixing, screw extrusion and conveyor drying were implemented using Altex bench-scale and pilot- scale equipment. Bench and pilot scale tests showed that high quality AFP pellets could be produced. The AFP formulations produced at pilot-scale are listed in Table 25. These included mixtures of biosolids and wood, biosolids and MSW light fraction, and mixtures containing coal fines and plastic particle additions. In pellet production with MSW light fractions, formulas with and without plastics were produced. In preliminary tests it became apparent that plastic films, which constitute $10 \%$ of the MSW light fraction, could be separated during the mixing process. In one test series, separated plastic was used to advantage as a pellet weatherproofing material.

In every case, the AFP biomass pellets were very robust and would make an excellent fuel for stokers where size consistency and robustness is a benefit. However, it was found that AFP biomass pellets would also be difficult to pulverize in standard utility coal equipment. To improve grindability, coal fines were added to the biomass pellet formulas in the amounts listed in Table 25. This provided the means to effectively tailor the response of the pellets in a pulverizer.

AFP Pellets with coal fines additions required less energy to dry. When included, plastic film in pellets tended to soften in the dryer and leave residues on the dryer belt. Of all the materials, the plastic was the most challenging at every process step, but still was manageable.

Bench-scale pellet characterization tests results are summarized in Tables 26 and 27. From the tests it was found that AFP pellets have a density in the range of 642 to $803 \mathrm{kN} / \mathrm{m}^{3}$ (40 to $\left.50 \mathrm{lb} / \mathrm{ft}^{3}\right)$ or about half the density of coal. Also, depending on the formulation, pellets could be produced that resisted crushing forces of from $1034 \mathrm{kn} / \mathrm{m}^{2}$ up to $5667 \mathrm{kN} / \mathrm{m}^{2}$ (150psi up to $822 \mathrm{psi}$ ). These are very robust pellets that exceed the pellet strength criteria published in earlier work by Battelle [21]. In subsequent tests, pellets survived repeated drops from $4.5 \mathrm{~m}$ (15 feet) onto a concrete pad. Lastly, in abrasion tests, losses were generally limited to less than $3 \%$. From these results it can be concluded that bench-scale pellet quality was high.

The test results for AFP pellets produced at pilot-scale AFP are summarized in Table 34. In pilot-scale AFP production, pellets of approximately $1.9-\mathrm{cm}(3 / 4$ ") in diameter were produced. Again, pellet density was approximately half that of coal, and crush strength varied from 1034 $\mathrm{kn} / \mathrm{m}^{2}$ up to $5516 \mathrm{kN} / \mathrm{m}^{2}$ (150psi up to $800 \mathrm{psi}$ ), with some pellets resisting fracture beyond the limit of the test apparatus. While the pilot scale pellets survived fewer $4.5-\mathrm{m}$ (15-ft) drops to concrete than the bench-scale pellets, their performance still exceeds the anticipated need for good handling and transport. The losses in abrasion tests were all below $3.4 \%$. 
These pellet quality test results showed that AFP pellets are very robust; however, for pulverized fuel fired systems, the energy required to pulverize pellets would be excessive. To assess how AFP pellets would respond in a coal pulverizing mill, initial grinding tests were carried out at Altex and AFP pulverization tests were carried out at Hazen Research Inc. Altex initial grinding tests showed that inclusion of coal fines or plastic particles in AFP pellet formulas could alter the pellet response to crushing forces. Without these additions, the highly fibrous pellets were extremely resistant to crushing. Coal fines were added to AFP pellets formulated with wood. The higher the fraction of added coal fines, the easier it was to crush the pellets. At a coal fines fraction of 50\% test results showed almost no difference between the response of the pellets and the response of a like sized sample of lump coal. With waste paper based AFP formulations the addition of plastic particles, in fractions of up to 5\%, improved the crush response for these pellets as well. Interestingly, coal additions did not substantially improve the response of pellets formulated with paper. These Altex test results were supported by those from Hazen Research. AFP pellets of wood and coal fines, and AFP pellets of paper and plastic were more readily pulverized than pellets without coal and plastic, respectively. However, grinding time for these materials was long, suggesting that special grinding equipment would be required for these materials. In contrast to pellet only results, pellets co-ground with lump coal at $10 \%$ or $20 \%$ weight fraction had grinding characteristics similar to that of coal. This suggests that pellets could be co-ground with coal in existing pulverized fuel facilities. However, the lower energy density of pellets might limit peak load for pulverizer capacity limited systems.

To evaluate the combustion and emissions of AFP formulations, tests were carried out in instrumented facilities at Altex that simulated both full scale stoker, and pulverized fuel fired systems. Table 42 summarizes the maximum firing rate for the six AFP formulations tested in the stoker system. As shown, all AFP firing rates greatly exceed typical stoker firing intensities. This was attributed to the high volatile content, and the porous nature of AFP pellets relative to lump coal. Because of the high nitrogen content of the biosolids in the formulations, NOx emissions were high, exceeding $1000 \mathrm{ppm}$ in some cases. Both the high nitrogen content, and high volatility, were driving high NOx production under conventional combustion conditions. While NOx was high, $\mathrm{CO}$ was acceptable, at the correct excess oxygen level. While the baseline NOx emissions during stoker firing were high, air-staging tests showed that NOx could be reduced by $50 \%$. The very effective air-staging NOx reduction was likely related to the easily volatilized fuel bound nitrogen, that was reduced to molecular nitrogen in the fuel rich region. These results show that AFP pellets can be efficiently burned in stokers, and with the implementation of air staging, achieve NOx emissions lower than those for conventional coal firing.

Cofiring AFP with coal at low fractions (e.g. 10\% AFP) in a pulverized fuel facility is expected to change emissions by less than $10 \%$ simply due to dilution effects. It is of interest to assess how AFP pellets when co-fired with coal might influence fuel handling, processing and transport equipment performance. However, these are questions that would best be answered at full scale, rather than with the pilot scale equipment at Altex. For example, the pilot-scale equipment pulverizes the fuel separately, then stores and feeds the processed fuel to the single test facility burner. In full-scale boilers, the fuel is ground on-line and fed to multiple burners directly from the pulverizer. In addition to this fundamental difference, the test facility has a substantially higher surface area to volume ratio in all components that can influence deposition 
results. Therefore, for fuel handling, processing and transport issue assessments, tests in fullscale equipment are needed.

The major thrust of the pulverized fuel tests at Altex was to determine the pollution control benefits of AFP fuel when separately injected into a pulverized coal fired facility. To accomplish this, a reburn fuel injector and a downstream air injection system were integrated into the Altex pilot scale combustion test facility. Pulverized mixtures of biosolids/wood, and biosolids/paper, were then injected downstream of the coal burner. While more difficult to pulverize then coal, use of separate and special pulverizers for the reburn fuel will accomplish the needed pulverization. The specific AFP and coal properties are given in Table 45. Tests were run with reburn fuel fractions of from $15 \%$ to $30 \%$. Test results showed that biosolids/wood and biosolids/paper AFP could reduce baseline coal NOx emissions by up to $63 \%$ and $58 \%$, respectively. These are very substantial NOx reductions that add to the economic value of biomass fuel. Of course, to this NOx control value has to be added the value of greenhouse gas (i.e. fossil $\mathrm{CO}_{2}$ ) emissions reductions. Depending on the setting of carbon tax levels, this AFP economic and environmental benefit can be very large.

While the environmentally related economic benefit of AFP can be large in the future, the present economic benefits of the AFP process can also be substantial. Using raw material costs, equipment cost estimates from manufacturers, and utilities and labor costs, the economic return for an AFP plant operating at 1000TPD was calculated. After tax Internal Rates of Return (IRR) were found to vary from an extraordinary $59 \%$ to an acceptable $21 \%$, depending on the AFP formulation, as summarized in Table 46. For those formulations with high biosolids content, IRR was high. Sensitivity analyses then indicated the importance of various parameters. When biosolids were displaced by coal, IRR decreased. The cost of moisture reduction was also important to return, and underscored the benefit of dewatering. In fact, eliminating the dewatering step reduced IRR by nearly one half. In addition, the impact of natural gas dryer fuel cost on IRR was determined. As the natural gas fuel cost is increased from $\$ 1.42 / \mathrm{MM} \mathrm{kJ}$ (\$1.50/MM Btu) to $\$ 7.58 / \mathrm{MM} \mathrm{kJ}(\$ 8.00 / \mathrm{MM}$ Btu), IRR decreases from an attractive $45 \%$ to an inadequate $5 \%$. This suggests that low cost AFP should be used to fuel the dryer, rather than high cost natural gas. Another strong driver on AFP IRR is the cost of biomass. As biomass costs are increased from zero to \$33/WTn (\$30/WT), the IRR decreases from an attractive 50\% to an inadequate $10 \%$. Lastly, the impact of the biosolids tip fee on IRR was determined. With a biosolids tipping fee of $\$ 44 / \mathrm{WTn}(\$ 40 / \mathrm{WT})$, the return is an extraordinary $90 \%$. Given that it costs wastewater treatment plants up to $\$ 68 / \mathrm{WTn}(\$ 62 / \mathrm{WT})$ to incinerate biosolids, a $\$ 44 / \mathrm{WTn}$ (\$40/WT) tipping fee is not unreasonable. Only when the biosolids tipping fee drops to \$11/WTn (\$10/WT) does IRR approach zero. Therefore, with a conservative tipping fee of $\$ 22 / \mathrm{WTn}(\$ 20 / \mathrm{WT})$, or higher, AFP return is attractive.

Work under this project showed the viability of AFP production equipment to produce robust pellets with good combustion performance, that can produce acceptable emissions, when the system is configured to take advantage of the special NOx reduction characteristics of AFP fuel. Economic analyses showed the critical need of acquiring a large source of biosolids for incorporation into the AFP. At the initiation of the effort, Altex and DTE (Detroit Edison) were working together to secure a source of biosolids from the Detroit Water and Sewerage Department (DWSD). After several meetings with DWSD, they initiated work with a consultant to produce an RFP that would have allowed competitive bidding for acquisition of the needed quantities of biosolids for AFP production. Competing uses of biosolids were in land application approaches and in alternative incineration/process heat applications. Of the ten technologies 
reviewed, the AFP approach was considered to be one of the four best. However, before the RFP process could be completed, the City of Detroit signed an agreement with Minergy, a Wisconsin Electric Power Company subsidiary, to acquire DWSD biosolids. Minergy uses a high temperature incineration approach, and will build the new facility in Detroit. The agreement with Minergy disrupted the Altex/DTE biosolids acquisition plan, and unless the Minergy plan collapses due to permitting difficulties, or other reasons, the Altex/DTE planned AFP facility in Detroit is no longer possible. Given the success of the pilot scale tests and analyses, it is worthwhile to explore implementing the AFP process in other cities with large biosolids resources. A potential prospect is the city of Cincinnati, Ohio. Preliminary discussions have been held with the wastewater treatment plant operator and coal suppliers in the region. More discussions are planned to evaluate the AFP potential for this site, as well as others. These discussions will be planned over the coming months.

\section{REFERENCES}

1. Private communication with Ron Goldsmith, Cogeneration Facility Manager, Blue Diamond Almond Growers, Sacramento, California, September 30, 1995.

2. Private communication with Mike Borino, Operations Manager, Wadham Energy, Williams, CA, February 13, 1998.

3. Prinzing, D.E., Hunt, E.F., and Battista, J.J., "Co-Firing Biomass with Coal at Shawville", Proceedings of the Seventh Annual Bioenergy Conference, Sept 15-20, 1996, Nashville, Tennessee

4. Woodworth, R., Kelly, J., Namazian, M., and Miller, G., "Reconstitution of Beneficiated Coal Fines Using the BioBinder Process" DOE Grant No. DE-FG03-93ER81485, July 1994.Kreis, R.D., and L.R. Shuyler, "Beef Cattle Site Selection for Environmental Protections," Environmental Protection Technology Series, EPA-R2-72-129.

5. National Sewage Sludge Survey: Availability of Information and Data, and Anticipated Impacts on Proposed Regulations, U.S. EPA, Federal Register, Vol. 55, No. 218, November 9, 1990.

6. Private communication with Chuck White, U.S. EPA, Office of Science and Technology, Washington, D. C., September 14, 1992.

7. Private communication with Don Brown, Operations Manager for Newark/Fremont Sanitation District, Fremont California, January 6, 1993.

8. Kelly, J., Miller, G., and Namazian, M., "Reconstitution of Beneficiated Coal Fines Using the BioBinder Process," DOE Grant \#DE-FG03-93ER81485, Phase II Final Report, June 1997.

9. Van DeKamp, W., and Morgan, D., "The Co-Firing of Pulverized Bituminous Coals with Straw, Waste Paper and Municipal Sewage Sludge," Combustion Science and Technology, 1996, Vol. 121 pp 317-332.

10. Train, R.E., R. Cahn, and G.J. McDonald, "Environmental Quality," The First Annual Report of the Council on Environmental Quality, Washington, D.C. (1970).

11. Garver, W., and Ritter R., "Annual Waste Management, " Recycling and Disposal of Solid Waster", T. Yen Editor, Ann Arbor Science, Ann Arbor, Michigan, (1975)

12. Taiganides, E.P., and R.L. Stroshire, "Livestock Waste Management," ASAE Pub. Proc., 271, 95 (1971).

13. Manahan, S.E. Environmental Chemistry, pp80-81, pp119, pp197, p501 Ch 21, pp619-620. 
14. Van Wylen, G.J., "Thermodynamics", John Wiley and Sons, New York, 1963.

15. Vincent Corporation Newsletter, issue no 41, entitled "NREL" April 8, 1996.

16. Bisanda, E.T.N., and Ansell, M.P., "The Effect of Surface Treatment on the Properties of Sisal-Epoxy Composites," Cellulose Sources and Exploitation, Ch. 29 pp 235-240

17 Starely, G.P., Slaughter, D. M., Muunro, J.M., Pershing, D.W., "Formation and Control of

NO Emissions from Coal-Fired Spreder-Stoker Boilers," Nineteenth Symposium (International) on Combustion, pp 1311-1320, 1982.

18 Lisauskas, R. A. and Rawdon, A. H., "Status of NOx Controls for Riley Stoker Wall-Fired and Turbo-Fired Boilers." Proceedings of the 1982 Joint Symposium on Stationary Combustion NOx Control, Volume 1: Utility Boiler Application, Chapter 4-1. July 1983.

19 Takahashi, Y., Masayasu, S., Takeshi, K., and Others. "Development of "MACT" InFurnace NOx Removal Process for Steam Generators." Proceedings of the 1982 Joint Symposium on Stationary Combustion NOx Control, Volume 1: Utility Boiler Application, Chapter 15-1. July 1983.

20 Kelly, J. T., Pam, R. L., and Suttmann, S. T., "Fuel Staging for Pulverized Coal Furnace NOx Control." Preceedings of the 1982 Joint Symposim on Stationary Combustion NOx Control, Volume 1: Utility Boiler Application, Chapter 17-1. July 1983.

21 Conkle, H.N., et al., "Pelletizing/Reslurrying as a Means of Distributing and Firing Clean Coal", Battelle Final Report on DOE Contract No. DE-AC22-90PC90166 - September 29, 1992. 


\section{ACRONYMS AND ABBREVIATIONS}

\begin{tabular}{|c|c|}
\hline English Standard Units & SI Units \\
\hline Inch/es- in, in., inches, (") & Centimeter/s- cm \\
\hline Foot or Feet- ft, ft., (') & Meter/s- m \\
\hline Mile/s- mi, mi. & Kilometer/s- km \\
\hline Pound/s- lb, lb., lbs & Gram/s- g \\
\hline Pound $_{\text {mass }}-1 \mathrm{bm}$ & Kilogram/s- kg \\
\hline Pounds per square inch- psi & Kilo Newtons- kN \\
\hline Standard Ton $(2,000 \mathrm{lbs})-\mathrm{T}$ & Metric Tonne $(1,000 \mathrm{~kg})-\mathrm{Tn}, \mathrm{TN}$ \\
\hline Density- pound $\mathrm{mass} / \mathrm{feet}^{3}$ & Density- kilograms/meters ${ }^{3}$ \\
\hline Btu- British Thermal Unit & Kilo Joules- kJ \\
\hline
\end{tabular}

\begin{tabular}{|l|}
\hline \multicolumn{1}{|c|}{ Other Abbreviations } \\
AFP- Altex Fuel Pellet \\
IRR- Internal Rate of Return \\
MSW- Municipal Solid Waste \\
MM- million \\
ppm- parts per million volume basis \\
CO- Carbon Monoxide \\
$\mathrm{NO}_{\mathrm{x}}$ - Nitrogen Oxides
\end{tabular}

